UC-NRLF

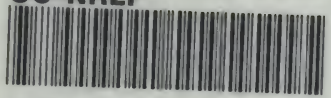

$\$ B 264449$ 


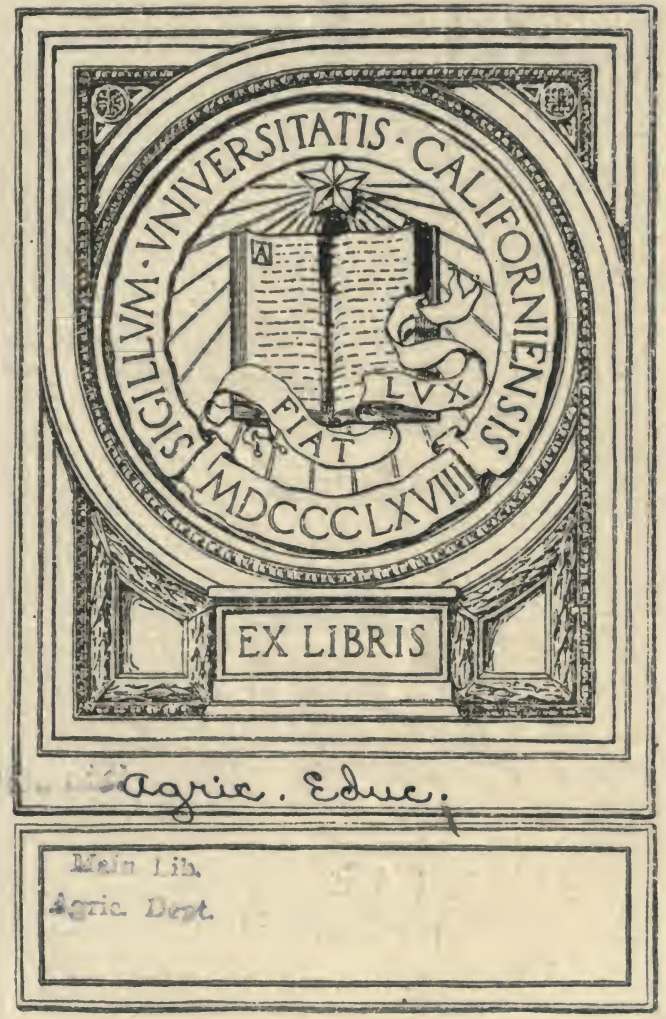



Digitized by the Internet Archive in 2007 with funding from Microsoft Corporation . 


\section{THE SCHOOL GARDEN BOOK}




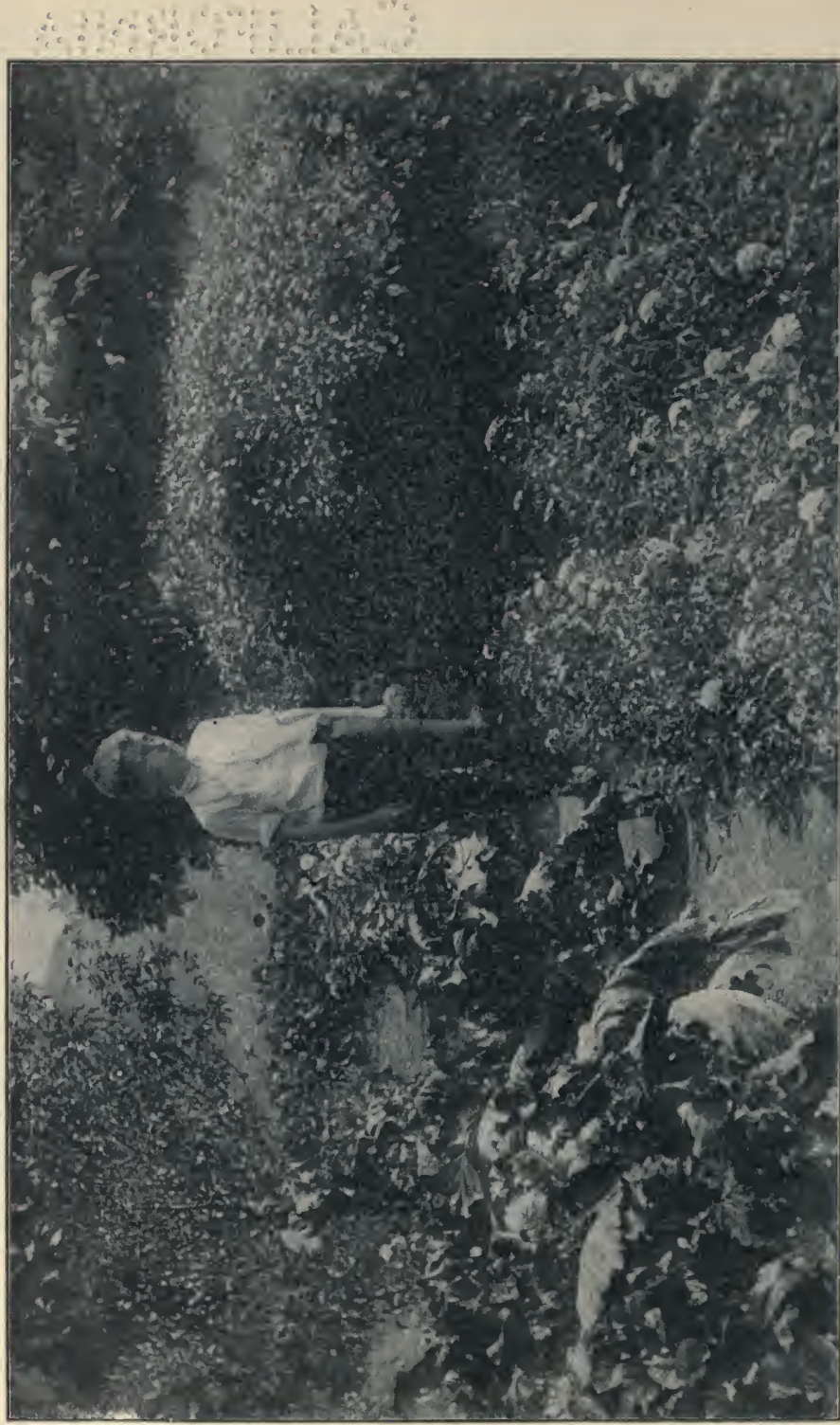




\section{THE}

\section{SCHOOL GARDEN BOOK}

BY

CLARENCE M. WEED

State Normal School, Lowell, Massachusetts

AND

PHILIP EMERSON

Cobbet Grammar School, Lynn, Massachusetts

\section{ILLUSTRATED}

\section{NEW YORK \\ CHARLES SCRIBNER'S SONS \\ I9I I}


Copyright, 1909, by

CHARLES SCRIBNER'S SONS
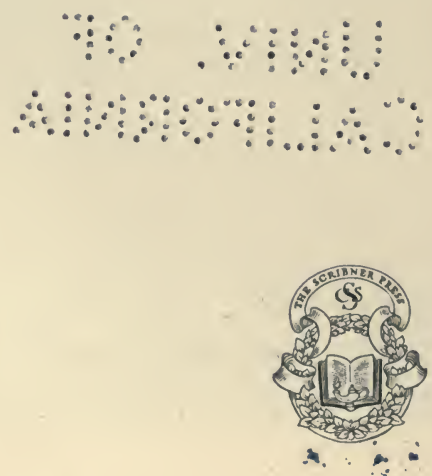


\section{CONTENTS}

INTRODUCTION • • • • • • • 3

PART I

\section{THE GARDEN MONTH BY MONTH}

CHAPTER

I. September . • . . . . . . . 29

Modern Dahlias. Growing Plants from Cuttings. A Glorious Autumn Flower. Planting Bulbs Out-doors. The September Calendar.

II. OCTOBER

Cosmos: A Beautiful Annual. Sweet Herbs. Getting the Garden Ready. California Poppies. Growing Hyacinths In-doors. The October Calendar.

III. November

The Chrysanthemum. Autumn Perennial Flowers. Planting Daffodils In-doors. Annual Flowers for Window-boxes. The November Calendar.

IV. December • • • • • • • •

Flowering Plants for Window Gardens. Growing Lilyof-the-Valley In-doors. The Selection of Seed. Growing Named Varieties. Roman Hyacinths. The December Calendar.

V. JANUARY ${ }_{\text {Attractive Foliage Plants. Clay Flower-jars. Seed }}^{\cdot}$ Testing. The Classification of Vegetables. The January Calendar.

VI. FEBRUARY

Daffodils. Starting Early Vegetables. Seed-Leaves or Cotyledons. The February Calendar. 
A Neighborhood Garden Club. Starting Early Flowers. Radishes. The March Calendar.

VIII. APRIL

Children's Home Gardens. The Spring Awakening. Planting Hardy Annuals. The April Calendar.

IX. MAY

Hardy Perennials. Climbing Vines. Window-boxes and Porch-boxes. Planting Tender Annuals. The May Calendar.

X. June

Iris Border Gardens. Beets, Turnips and Carrots. Poppies. Summer Flowering Bulbs. The June Calendar.

XI. July

Sweet Peas. Beans for Garden Culture. The Structure of the Flower. Nasturtiums. The July Calendar.

XII. August

Useful Flower-jars. Marigolds. Pot Herb Crops. Planning for Winter Flowers. Pansies. The August Calendar.

PART II

GARDEN EXERCISES FOR PUPILS

XiII. General Exercises • . • . . . 245

XIV. Spring Flowering Bulbs . . . . . 249

XV. Flowers from SeEd . . . . . . 266

XVI. Vegetables . • . . . . . . 289

BIBLIOGRAPHY . . . . . . . . . '315

INDEX $\quad . \quad \cdot \quad \cdot \quad \cdot \quad \cdot \quad \cdot \quad \cdot 317$ 


\section{LIST OF ILLUSTRATIONS}

A Prize Garden and Its Gardener . . . . . . . Frontispiece

PAGE

Garden of the South End Industrial School, Roxbury, Massachusetts 2

Window-box of Sheet Zinc

White Hyacinths in Paper Pot set in Jardinière . . . 5

Some Good Weeders . . . . . . . . . 8

China Aster Seedling .

A Young Gardener and His "Team" . . . . . . I5

Single Cactus Dahlia . . . . . . . . . . $\quad{ }^{27}$

Striped Single Dahlia: Fedora . . . . . . . . 28

A Show Dahlia . . . . . . . . . 30

Decorative Dahlia: Mrs. Winters . . . . . . 32

Rooted Cutting of Geranium . . . . . . $\quad$ • 36

Young Geranium Grown from a Cutting . . . . . : $3^{8}$

Young Geranium Plant in a Paper Flower-pot . . . . $: 3^{8}$

Begonia Stem Cutting . . . . . . . 39

Gloxinia Leaf Cutting . • • . • • • • 39

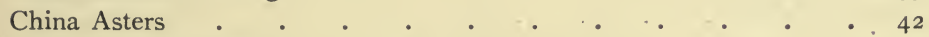

Dwarf Comet Asters . . . . . . . . . . 43

Comet Asters in Bamboo Holder. From. "The Flower Beautiful" . 44

Fifty Bulbs of Campernelle Jonquil . . • . • • • 46

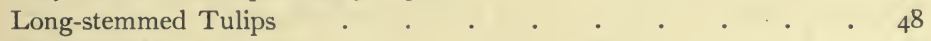

Bulbs of Madonna Lilies . . . . . . . . . 49

White Cosmos . $. \quad . \quad . \quad . \quad . \quad . \quad . \quad . \quad . \quad 53$

Pink Cosmos in Austrian Glass Vase . . . . . . $\quad . \quad 54$

Parsley Seedling . . . . . . . . . . . 59

Spearmint Cuttings Rooting in Sand . . . . . . . 60

Sage Seedling . . . . . . . . . . . 6I

A Young Gardener . . . . . . . . . . 62

California Poppies in a Slender Vase . . . . . 65

Hyacinth Growing in Water in a Tall Hyacinth Glass . . . 66

Three Hyacinth Bulbs Grown in Four-inch Paper Flower-pot . 67 
Chrysanthemum Flower

Chrysanthemums in a Japanese Cylinder Jar

New England Asters in a Japanese Flower-jar .

Twelve Bulbs of Chinese Lily Narcissus

Water Culture of Chinese Lilies

Water Culture of Paper-white Narcissus

Single Geranium

Single Geranium in a Japanese Jardinière . . . . . $\quad$. 88

The Baby Primrose

Cyclamen Blossoms

Lilies-of-the-Valley in Japanese Flower-jar

Plumose Asparagus

IOI

Silk Oak or Grevillea

102

Seedling Asparagus Sprengeri

Norfolk Island Pine in a Japanese Jardinière

105

Rex Begonia in a Japanese Flower-jar

106

The Umbrella Plant

Crocus in a Clay Flower-jar

Tomato Seedlings in a Window-box .

107

108

109

Trumpet Daffodil

I 12

I 2 I

Single Trumpet Daffodils in a Japanese Jardinière

122

A Double Daffodil

I 24

I 24

The Stella Narcissus

126

Trumpet Daffodils

Onion Seedling

Tomato Seedlings: The Rise and Fall of the Cotyledons

Crocus Blossoms

Poet's Narcissus. From "The Flower Beautiful" . . . . I36

A Home Garden: Cobbet School, Lynn, Massachusetts . . . 138

Wild Cucumber

Three Generations in the Home Garden . . . . . . 142

French Marigold . . . . . . . . . . 145

Nasturtium Seedling in Paper Flower-pot . . . . 146

Easter Lily

Tulips for the Home Garden

A Boy's Home Garden

A Good Home Garden 
Drummond Phlox

Blossoms of Coreopsis

Trumpet Daffodils

Peonies in a Japanese Flower-je:

Perennial Phlox

Trollius or Globe Flower

Plan for a Border Garden of China Asters

Oriental Iris

Siberian Iris

Plan for Iris Border Garden

German Iris

Japanese Iris

Bulbs of English Iris

Plan for Subirrigation

White Shirley Poppies. From "The Flower Beautiful"

A Jar of Tuberoses

Celia Thaxter's Garden

Hooded Sweet Peas

Typical Forms of Hooded Sweet Peas

Snapdragon Sweet Peas

Shirley Poppy

Snapdragon

Nasturtiums in a Rose Bowl

Madonna Lilies

Oriental Iris in a Japanese Flower-jar

Perennial Phlox in a Japanese Flower-jar

Nasturtiums in a Green Glass Flower-jar .

Cosmos in a Slender Vase

Japanese Iris in an Izumo Vase

African Marigolds in a Bamboo Wall-holder. From "The Flower Beautiful"

** The authors desire to express their thanks to Roger Newton Perry for the photograph of "A Young Gardener and His Team"; to the Committee on Children's Gardens of the Massachusetts Horticultural Society, for several of the other out-door views; to the Houghton-Mifflin Company for the privilege of using the four pictures and the short discussion of Poppies from "The Flower Beautiful": and to Misses Isabelle Cragin and Alice Manning for several of the drawings of flowers and young plants. 

THE SCHOOL GARDEN BOOK 


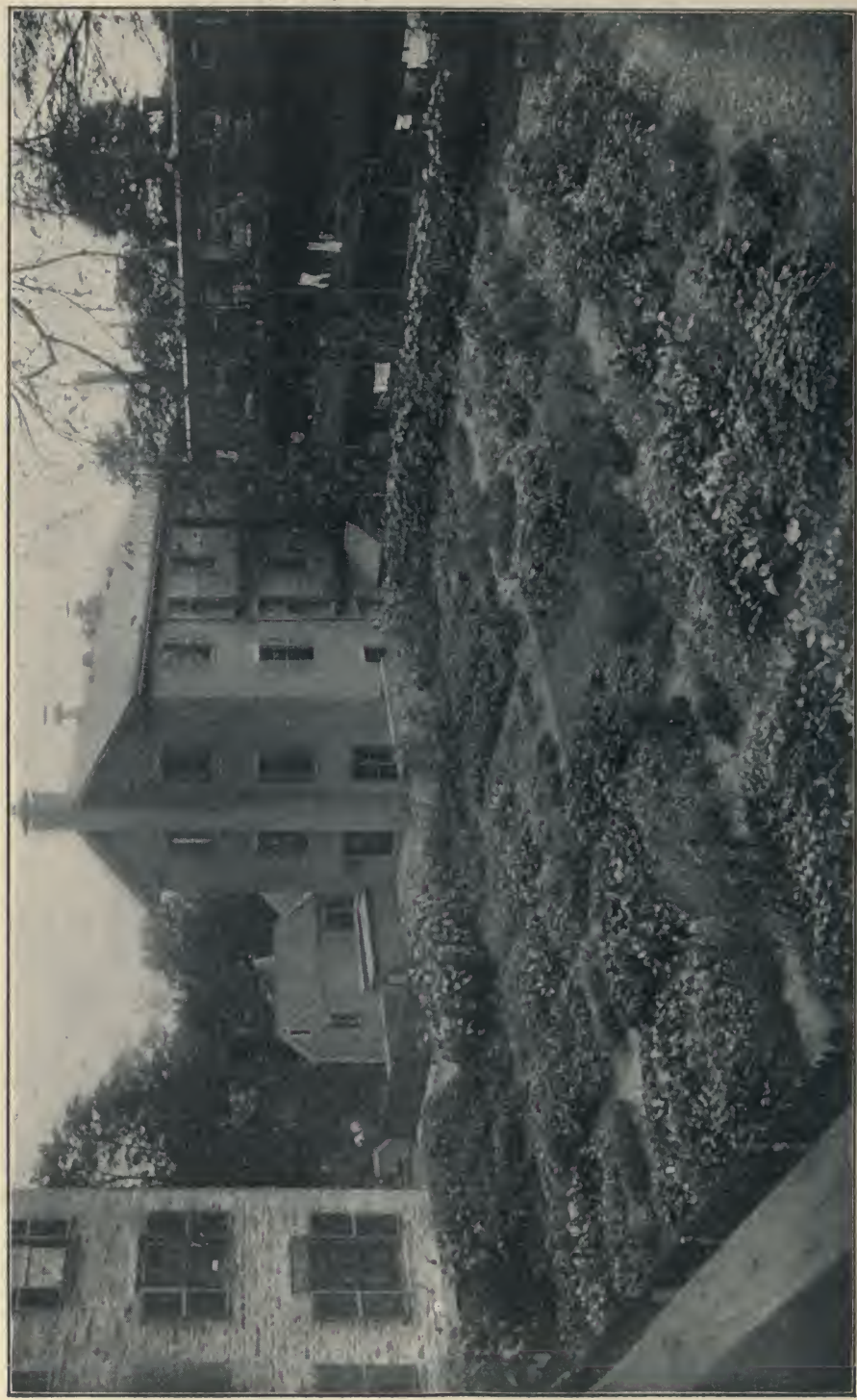

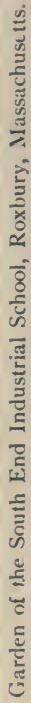




\section{THE SCHOOL GARDEN BOOK}

\section{INTRODUCTION}

From the point of view of this book the school garden is any garden in which a boy or girl of school age takes an active interest. It may be simply a tiny seedling growing in a little flower-pot in-doors or an extensive series of garden crops growing in a large garden out-doors. So far as crops are concerned, however, the scope of the book is limited to flowers and vegetables, no attempt being made to include the fruits, large or small, the ornamental trees and shrubs, or the agricultural crops.

The gardens to be considered from this point of view may be collective or individual, or both; they may be in-doors or out-doors, or both; they may be at the school or the home, or both. In all of these cases the plants to be grown are much the same and the methods involved in growing them are similar. Yet, a short preliminary discussion of special plans and methods to be used in connection with these various kinds of gardens may be worth while.

\section{In-door Gardens}

Few objects add so much to the attractiveness of a schoolroom, or a living-room in the home, as a good window-box filled with beautiful flowering plants. In the great majority of cases such a box will be much more successful as well as a 
$\therefore 4 \%$ THE SSHOL GARDEN BOOK

great deal more attractive than are the unsightly flower-pots which are so commonly used for growing plants in-doors.

Five things are required by a living plant-food, warmth, moisture, light, and air: granted these, a plant should live and thrive in almost any sort of situation. The proportions in which different plants require these five essentials vary decidedly, and in growing flowers in the house we must understand the conditions required by the particular plant

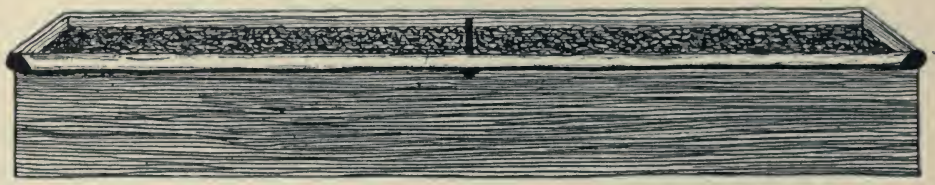

Window-box of Sheet Zinc.

we are dealing with. In general, the necessary conditions are most easily given by means of window-boxes, which may be placed near the window that an abundance of light and air may readily be obtained. And it is not at all necessary that this window-box should be a crude, unsightly affair: it should rather be a carefully made, attractive object, harmonizing with the interior of the room and adding to its general effect. It is worth while to go to some trouble and expense in order that the receptacle for such a little garden in-doors should be so attractive that it may always be used with satisfaction.

The most satisfactory window-boxes are made of sheet zinc, and are of a length and width to fit the window-sill or to rest upon brackets just beneath it, and of a height of four or five inches. Under the ordinary conditions of a furnace or steam heated home or school-room, plants will thrive in 
these water-tight boxes with absolutely no provision for drainage or the escape of surplus moisture from the bottom. Evaporation takes place so rapidly from the upper surface of the soil that, with any reasonable common sense in watering, there is no danger of the souring of the soil or of the checking of the growth of the plants. In watering it is only necessary to pour in enough water about twice a week to saturate the soil and then to leave it until the surface has become dry again.

These boxes should be re-enforced around the top with a strip of wire, and if they are very long another wire should run across from side to side in the middle. They can be made by any tin-smith, and when complete should cost about one dollar apiece. They should be painted on the outside, and at least part of the way down on

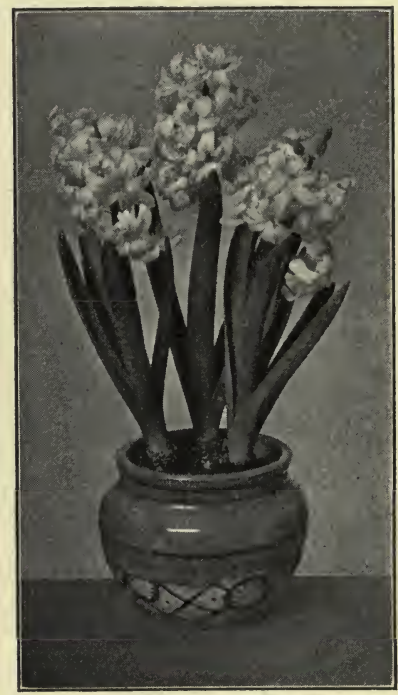

White Hyacinths in Paper Pot Set in Jardiniere. the inside with dark-green carriage paint. When thus ready for use they are to be filled with rich loamy garden soil, whereupon they may be utilized in growing almost any sort of plant that will thrive in-doors.

Instead of being made of zinc alone these boxes may be made of wood and lined with zinc. The wood may be finished to harmonize with the wood-work of the room. Very attractive boxes may be made of old cedar wood. 
Such boxes are particularly useful for starting seedlings, as well as for holding flower-pots in which bulbs or other plants are growing. They have the great advantage that they can be turned end for end at frequent intervals and thus cause the leaves and blossoms of the plants growing in them to take on a symmetrical appearance. There is also an advantage in the fact that in very cold weather such boxes can easily be removed from the window.

In general, such window-boxes will be in the nature of collective gardens, representing the interest of the whole school. As a rule the only individual gardens practicable in-doors will be those grown either in special small boxes or in flower-pots. Such individual gardens are practicable in the case of a number of plants which may be grown from seed, as well as in the case of the spring flowering bulbs and various plants which are grown from cuttings. The paper flower-pots, which may be obtained from any florist or seedsman, are in many respects more desirable than the ordinary pottery ones. They have special advantages in their cheapness, in the ease with which they may be stored away in little space, in the small amount of room they take up when placed side by side in a window-box or on a plant-shelf, and especially in the fact that evaporation does not take place from the sides of the pots as it does in the case of the ordinary flower-pots.

These paper pots are not easily broken, so they can be carried safely from the school to the home by little children, and they are so inexpensive that any school can afford to provide them for the use of the pupils. The smaller sizes cost but twenty-five cents per hundred. 


\section{Out-door Gardens}

Passing now to the out-door gardens, we come, of course, to a field in which the range of possibilities varies with the conditions of almost every school. It is true, however, that even under the most adverse conditions some kind of collective garden at least is possible. If it is nothing more than an outside window-box, it may easily become of important service in the work of the school. In collective gardens short rows or parts of longer rows may be planted by individual pupils in connection with a plan for a complete whole, in which the part done by each pupil shall serve as a unit. For any gardens but the very smallest this will probably be found a more satisfactory method than to have the collective garden planted without distinguishing the part done by each pupil.

The school which has an opportunity for each pupil to have an individual garden is fortunate indeed. The size as well as the crops to be grown will depend, of course, upon the conditions and the interest shown by the teacher and pupils. Such crops may be planned for the entire season or for only the early part of the season, and suggestions for the special crops to be grown under these varying conditions will be found in the later pages of this book.

The final end of the school garden is the home garden. In any community the success of the school garden movement after it has been in operation for a number of years will properly be measured by its results in bringing about a general love for flowers and plants, as shown by the gardens and home grounds of the pupils that have been in attendance. In the case of the home gardens the opportunities, of course, are infinitely varied, but here again it will almost 
always be possible for a pupil who so desires to have some sort of garden.

The tools necessary for school garden work are neither elaborate nor expensive. A spade, a hoe, a rake, and a trowel are perhaps the most essential parts of the garden outfit; and it is very desirable that they be supplemented by

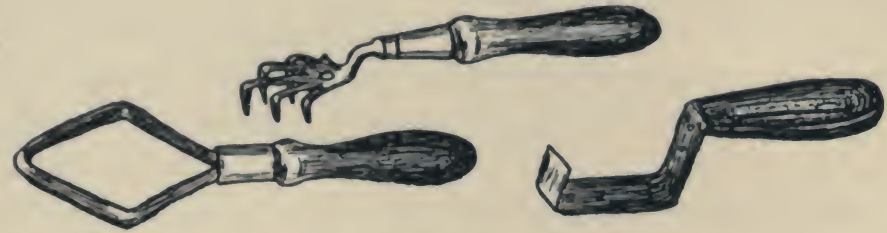

Some Good Weeders.

one or two good forms of weeders, a garden line, and a watering-can, the latter especially in those cases when watering from a hose is not practicable. When once supplied these tools will, of course, last indefinitely, and pupils should always leave them thoroughly clean and hung in the proper places.

If the only visible results of the school garden work are found in the crops grown, the garden has only served a part of its purpose. It should supply the material for a considerable proportion of the school work in drawing and English, and may very well help to vitalize the work in arithmetic and geography. At least one garden booklet should be made by every pupil who has anything to do with the garden, this booklet to contain the drawings and language records of the pupils. In the following pages this phase of the work has been constantly kept in mind, and some of the illustrations are transcripts from such garden records or suggestions for helping to make them. A pocket note-book for each pupil 
will be desirable, in order that the memoranda of dates may be made at the proper time.

\section{Plans and Problems}

School gardens should present in concrete form the best ideals for home gardens and grounds. It is desirable, therefore, that the design and planting plans for the surroundings of a new school, or for the betterment of an old school-yard, should be prepared by a landscape gardener employed for the purpose. Where this is not yet possible, a superintendent or principal should take special pains to study the conditions of a school-yard and its surrounding homes, then apply the principles of general landscape gardening as presented in the completed development of school grounds elsewhere. The work of carrying out these plans should be done by the pupils, in the course of a series of years, that they may properly profit thereby, and protect as their own these improvements.

In general, lawns bordered by shrubbery and hardy flowering plants, with vines clothing the walls of the school building, should characterize the school grounds next the street, a type of good home grounds. The out-door school gardens are best placed at the side of the school buildings, when a sunny exposure is possible there, separated from ample playgrounds in the rear with their bordering shade trees. For many schools and teachers, however, the practical problem must be that of accomplishing results with little encouragement at first and under difficult conditions. But there, too, a fine and fit ideal, wisely set forth in practicable plans according to which one may work, is essential to economy of effort and to full success. 
All difficulties may be overcome. Where school-yard space is very limited, it is likely that homes are likewise crowded in close tenements. Then outside winclow-boxes, porch and shed tops, should be utilized. Or the sunny borders of the playground may be planted, being protected by a low, stout rail from encroaching play. In return, the remaining play space may be multiplied by home-made apparatus. It is surprising how many children find amusement on a long fourinch plank tilt, or swarm up and down climbing ladders, poles, and ropes. So, if ground space is already limited, carry either gardens or play into the air.

A school garden need not be in the school-yard, although most parts of one are best placed there. Adjoining back yards and near-by vacant lots may be used. Wherever adjacent houses encroach on gardens, it will be found that much valuable soil now lies fallow. The former owners have departed, and present tenants either do not know the gardener's art or lack time and inclination to apply it. But they will often accord to a school the privilege of using a weedy back yard or neglected garden. Its management the first year determines the continuance of the privilege. If a back yard is small, it may still supply space for a propagating bed of perennials, or opportunity to experiment with various annual flowers and to raise seedlings for distribution to home gardens. A larger yard or a vacant lot may be divided into individual garden plots, so that every pupil of a class or grade may have independent practice under school supervision.

Many school-yards have been graded with gravel and ashes to form playgrounds, so that lack of good soil is an obstacle to making a garden. This condition frequently requires 
rather costly measures. Some soils may be enriched by liberal manuring, and for this purpose fertalizers may be obtained free of expense from near-by stables, even in a city. Some schools have made a start on a small scale with soil brought from the woods and from home gardens in little bags by the children. Thoroughgoing work, however, implies the purchase of soil in liberal quantity. While this should be provided by the school authorities, some communities are not yet ready to approve such public expenditure. Experience shows that in such cases it is possible to raise funds easily by a school entertainment or by a subscription taken among the parents. To use the money to the best advantage, one should watch for the opportunity to secure the soil from a contractor, when a cellar is being dug on a lot with good soil in the neighborhood of the school. It is wise to place the soil deeply, say twenty inches in depth, rather than in a shallow layer in order to secure a larger garden. Plants will live in shallow soil, but they thrive in thoroughly cultivated deep soil.

In some communities public sentiment may still class school gardening as a useless fad. This hostility may be changed. The hearty endorsement and co-operation of superintendent and school board is a first requisite. The aid of the press may be secured to praise the work elsewhere, to call for its introduction, to approve heartily the first efforts in the community, to call for its active development and for the substantial aid of the authorities. In connection with a parents' association, or an improvement club, a public meeting may be held to present values and methods, for school gardening only needs to be fairly presented to win ample support. 
At times hoodlums discourage school gardening by uprooting and overturning plants and flower-boxes in sheer vandalism. This has been overcome in many places by persistent effort until general pride in the results secured affects even the members of street gangs and insures their appreciation. Such a victory is well worth the patience, skill, and labor it costs, for it means that home grounds and gardens will be respected as never before, because of the finer public spirit developed and spread through the children to every neighborhood and home.

\section{School Garden Exhibits}

Competitive exhibitions of garden products are very helpful in extending and intensifying interest in horticulture. When one sees an array of beautiful flowers of many types and varieties, or tables set forth with displays of fair fruit and fine vegetables, he wishes he possessed a garden full of such products, and quite naturally resolves to grow another season the sorts that please him best. Moreover, every exhibitor, comparing his choicest products with those shown by others, is stimulated to renewed endeavors, that he may rank as high or higher at the next prize competition. Exhibitions of the products of school gardens and children's home gardens have repeatedly proved the means of convincing the public that gardening by children is worth while, for the best results from many districts and homes are thereby impressively massed, and many people may visit such displays easily.

An exhibition should be planned in advance if possible. The classes of exhibits in which entries are desired should be announced in the papers or by circulars. The announcement may invite general displays of flowers and also of 
vegetables, from school gardens and from children's gardens, or it may ask for exhibits of flowers and vegetables of a few sorts that the children are thus stimulated to grow with special care. In the latter case it is usual to limit the number of specimens allowed; for example, to a dozen vases of Comet Asters, one blossom in each, or to four heads of lettuce. This favors quality rather than quantity, and makes it easier to compare exhibits. A few simple rules as to entries and the award of prizes should be adopted and announced. As an aid in preparing these, send to the secretary of some horticultural or agricultural society of your section asking for their schedule of exhibits and prizes.

In the case of a children's garden exhibition, it is wise to make sure that many children will certainly exhibit products, for they

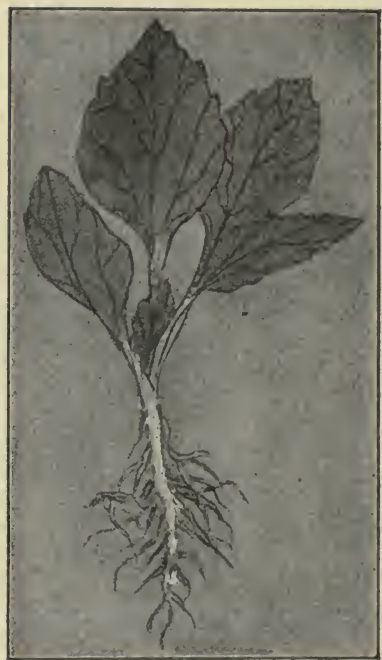

China Aster Seedling. often fear to do so in the belief that their products are not worthy. It is often advisable, also, to get the best amateur gardeners, the most successful farmers, local florists, and large estates of wealthy men who employ professional gardeners, to contribute displays, if the hall is large enough. Their fine exhibits need not discourage the children, nor belittle the children's achievements in the mind of the public. They will rather heighten the enthusiasm of both children and public for the fine art of horticulture. 
It is well to give space at a school garden exhibition for selected illustrations of the regular school work that is based upon the gardening. For example, a series of sketches of flowers and plants in line and color, illustrating the work of successive grades, may be hung from wires against the walls. The garden note-books of the children, and their booklets of sketches with pen, pencil, and brush describing chosen flowers, may be placed on a table. The public will be as much interested in this handiwork as in the flowers and vegetables. A display of photographs of gardens and of flowers forms an appropriate and attractive feature for an exhibition.

The general public will be especially interested if at announced hours of the afternoon and evening groups of chosen pupils may be seen at work. Some may draw or paint flowers. Others may show how plants should be propagated from slips, making cuttings, and setting them in sand, and also potting cuttings already rooted. These potted slips may then be sold for the benefit of the school garden-fund.

Perhaps an agricultural fair or horticultural display is to be held near your school. If so, be sure to enter products from your garden. Even if they win no prize, you will find it well worth your effort, for you will see more clearly what you must do to succeed another year. Study the list of classes of exhibits and the rules carefully. Plan your entries in advance. Prepare neat exhibition labels giving the names of all varieties you intend to show. Very early in the morning of the exhibition day cut the flowers you have chosen for display, and in case they are to be carried some distance, lay them loosely and carefully in a roomy box separated by tissue paper, where they will be kept free from wilting or injury. In the case of vegetables, say carrots, dig enough 
roots so that you may choose specimens to the required number that are of large and uniform size, and of regular form. Before learing home, clean in water carefully those selected. At the hall first enter your exhibit and learn where it should be placed. Secure bottles of water for the flowers, trays for the vegetables, and then carefully take your ex-

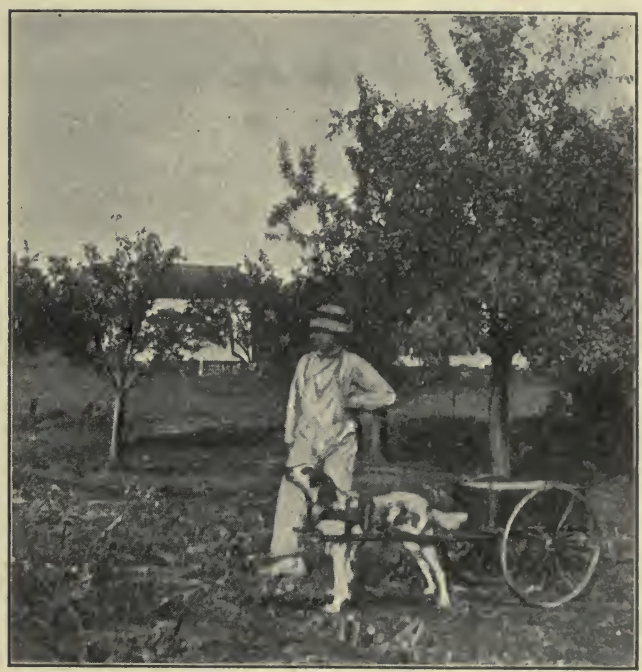

A Young Gardener and his "Team."

A Prize Winner in the Garden Coutest of the Massachusetts Horticultural Society.

hibits from their boxes and properly arrange them. Avoid crowding a display. Dispose its parts carefully to give the most pleasing effect. Plan it as you would a design at school, applying the same principles.

It is the custom to award prizes to the best exhibits. In the case of children's garden exhibits, it is probably best to have the judges rank them in classes, with an indefinite num- 
ber in each class. This stimulates the children to attain a certain standard rather than to distance a competitor. If this should call for many prizes, it need not entail great expense, for the best prizes for young gardeners are supplies for their gardens. Plants, bulbs, books, and the like for this purpose may be purchased very cheaply at wholesale, and will often be donated by interested dealers. Ribbon badges, a color for each rank, have value as prizes, also.

A horticultural exhibition by a school or town is well worth all the effort it may cost. Since it may be made profitably even on a very small scale, one may be successfully planned and conducted after school opens in September. Or a group of children may conduct one in their neighborhood. Get the children and home gardeners living near you interested. The editor of your paper will announce your Flower Show. Some parents will provide money for bulbs as prizes, or a small fee for admission may be charged for the same purpose. It can be held in some open barn or clean carriage-house, if no better hall or room seems available. Get a teacher, the nearest florist, and the parent most interested in flowers to act as judges. Try it.

\section{School Garden Management}

The method of conducting school garden work depends upon the standing and stage of development of this phase of education in a community. At first the work may have to be done at recess and after school by the pupils, at the initiative and under the direction of their teachers. This plan possesses the merit of being wholly voluntary, hence it enlists the interest and loyalty of the pupils to the full. It can no more succeed to the full as a permanent plan in gardening 
than with any other branch of instruction. Before long, however, gardening will be given recognition in the authorized division of time for most school systems. At first the work may seem strenuous, for a teacher's ingenuity must be exercised to properly supervise a portion of a class at work at their desk and a group busy in the garden.

Some teachers have accomplished wonders under such a plan, especially where a principal gives his active co-operation. Much good work may be accomplished by sending pupils out in small squads, threes or fours, to perform definite tasks. One pupil should be foreman in each squad. A written statement of work to be done, a contract, should be given him. This foreman should be a reliable boy or girl, possessing good judgment and a capacity for leadership. The teacher must see that he understands the contract and the detail of the task. When completed, the results will be examined by the teacher. This plan enables a teacher to keep classroom work continuously in hand, while allowing pupils most needing garden work to undertake it during the time of studies in which their standing is high or which are not vital to their advancement. Further, it trains boys and girls to act under the guidance of their fellows, and to give directions to their equals, in turn.

Wherever there is an enthusiastic teacher or earnest public there will be related interest and devotion on the part of children, and ways and means will be found to conduct the school garden. Some schools have organized garden clubs for home garden work in different neighborhoods and have federated them for co-operation and to maintain the school garden. Improvement societies in some towns and cities have hircd garden teachers to give instruction in the schools and to 
visit the home gardens throughout the summer. Teachers in many schools have made gardening a success through their own devoted efforts until the authorities took the work up and provided special instructors and facilities.

The most satisfactory results are, of course, secured where a specially trained instructor in gardening is employed to direct the work of class teachers, and who may personally instruct groups of pupils in the school gardens and visit home gardens. Some school systems provide a special teacher to every large school, or to two smaller schools, who is unassigned to a class. She is employed mainly to make the graded school system more elastic by aiding pupils who are slow to comprehend, or who have lost work through absence, to maintain or regain class standing, and by helping the ablest pupils to skip grades without loss of essentials. This appeals to all, the most conservative included, as worth the expense. Incidentally, such a teacher makes it possible to conduct field study by groups of pupils with an effectiveness seldom attained by regular class teachers. She is also available to take groups of pupils into the garden for systematic work in planting and culture. Under this plan it is wholly possible to secure a teacher in each school who shall be thoroughly competent to give garden instruction and thus ensure full success from the start.

\section{School Gardening for Profit}

While the true purpose of a school garden or a child's home garden is educational, it may often best attain this end when it becomes commercially successful, at least to the extent of becoming self-supporting. A school garden will naturally give many plants to its pupils as prizes to stimulate 
home gardening, and it may also easily earn money enough to meet all its expenditures by selling plants, flowers, and vegetables to the public.

Fresh vegetables of fine quality command high prices. The public are ready to pay fancy prices to schools or to children without question at the start, and they are willing to continue to do so if the quality of products warrants it. This puts a premium on raising the best of everything that is as effective a stimulus as a prize competition. While it is well worth while to compete at horticultural exhibitions, because pride in the school or home garden will be augmented by success in winning prizes, the finest success is measiured rather by the production of vegetables and plants that find a steady market.

There are various vegetables rarely seen in markets that may be raised profitably for neighborhood sale. For example, Swiss chard wilts on the shelves of a stall, but when freshly cut for dinner it is the finest summer pot-herb imaginable. Customers who commence its use continue. Families tired of red turnip radishes from the markets will relish crisp white icicle radishes or summer radishes from a boy's home garden. Those weary of stale and stringy pod beans from the stores will delight in tender beans picked in the neighborhood but an hour before dinner. A garden of herbs may be managed so as to enlist a permanent line of customers, who will send for their mint, tarragon, dill, sage, and the like as household need arises.

The best plan for profits, however, is the sale of plants for home gardens. The main costs of the hardy plants catalogued by large dealers, and of bedding plants supplied by local florists, are incident to advertising, soliciting orders, packing, 
and transportation. A school may sell plants at a third or a fourth of the usual retail prices and yet secure a good income, since the costs named above are not incurred and the labor cost is nothing, because it is incidental to garden instruction and training.

A cold frame is a great help in raising plants for sale, even in the case of vegetables, as it enables one to place lettuce and radishes on the market before their price declines. A cold frame requires no special skill: it is merely a glazed sash, or several sashes, resting on low plank sides so as to incline to the south, and serving both to trap the sun's heat and to protect plants from frost, wind, and beating rains. Under its cover annual flowering plants may be thickly planted in March. The hardy sorts may be pricked out in the open in April, leaving space to transplant tender kinds within the frames. In May and June these are ready for sale to the public, and for award as prizes to children whose home gardens show that the plants from school will receive careful culture at their hands. When the frames are cleaned of annuals, seeds of biennial and perennial flowering plants may be sown. By late August these may be transplanted. The fully hardy sorts may be set in the open garden. This gives frame space to separate half hardy kinds, such as pansies and daisies, wallflower and snapdragon. Those that are transplanted with difficulty, like oriental poppies, may be set in pots sunk in the soil of the frames. All of these will be ready for sale in early spring, and in time to give room for separating seedlings of annuals needing frame protection. This general plan has met success in schools of both western and eastern cities.

There is ready sale for pots of bulbs which have been well 
rooted and are ready to be brought to the warmth and light for flowering. Many people enjoy seeing them push up their leaves, bud and blossom, who have neither time, skill, nor patience to give the care necessary to start the bulbs. They will pay so liberally that the school need be at no expense for the bulbs and supplies it keeps for its own use. Here again the plan of raising plants for sale leads to the purchase and care of so many bulbs of a kind that every pupil may be given ample practice in their culture.

\section{Text-book, Class-room, and Garden}

Study, teaching, and training should be closely related in school gardening. The garden supplies materials and experience as a basis for class-room sketching, discussion, and composition. The experiments and discussion of the class-room make clear the principles of plant nature upon which successful culture is founded. Portions of this text form a manual of directions for field experiments in the garden as a laboratory. Other pages best follow the garden work and classroom consideration of the simpler features of special topics.

A good plan to use as an introduction to the study of dahlia types, for example, is the display of a collection of dahlia flowers before the class. Frequently the children can bring many varieties from their homes. Local gardeners will gladly contribute blooms of the varieties they keep for sale, and many commercial growers of dahlias will send a box of the blooms marked with their variety names, if a school will pay the express, since future orders will well repay the trouble. When secured, place each variety in a vase or bottle. Have the children arrange them in groups according to the character of the blossoms. Then give them the names for the 
standard types. Let the class choose those that are most graceful and pleasing as cut flowers. Have them note which types and varieties are most lasting. The aster, chrysanthemum, iris, and other leading families of flowers may wisely receive similar consideration.

This class study, with its training in observation and oral expression, will naturally be accompanied and followed by sketching the flowers and by writing brief descriptions of chosen types or comparisons between types. Thereafter the pupils will appreciate to the full the summary given in the text and be prepared to continue sketches and notes on the dahlia for a September flower booklet.

When considering the care of dahlia tubers, tell the pupil the origin of the plant, compare it with the potato, and lead them to infer the care probably necessary. Then raise ore plant from the soil, with its tubers and roots, and have the pupils observe the narrow necks of many tubers, the burls at the base of the stalk, the abundant sap, and other features necessary to judge the pains needed when digging and storing dahlia tubers. Thereafter the text serves as a summary of views formed independently upon a basis of observation and inference at school, and as a guide to further well-directed observation and work at home.

The same general procedure should be followed with other topics. The chapter on reproducing plants from cuttings may wisely be preceded by a class exercise wherein the teacher calls attention to the roots starting from the blunt lower end of an old geranium plant, once a slip itself, and leads the children to relate previous home experience with slips and plant propagation.

Most children have a general knowledge of some common 
vegetables and flowers. A preliminary lesson should review this practical information and use it as a means of judging the proper cultural methods. Then the class will turn to the book with interest and compare their conclusions with those based on longer experience. If some then prefer their own way, well and good; they will then give special care to the succeeding experiment to see how far they may be right. 

PART I

THE GARDEN MONTH BY MONTH 



\section{SEPTEMBER}

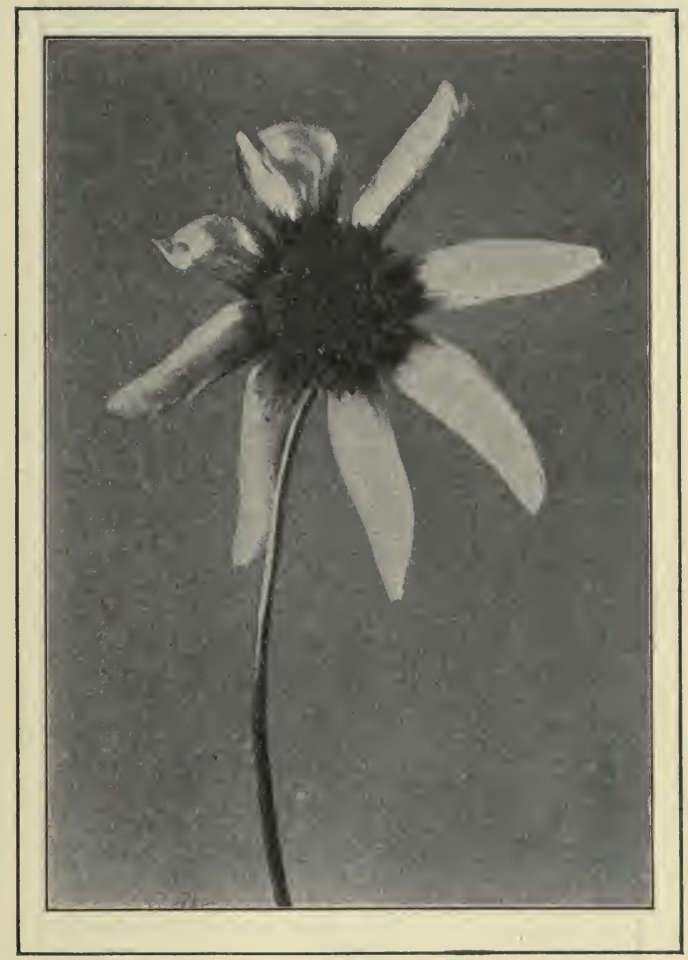

Single Cactus Dahlia.

A garden should be connected with every school, where children can at times gaze upon trees, flowers, and herbs, and be taught to enjoy them.-Comenius. 


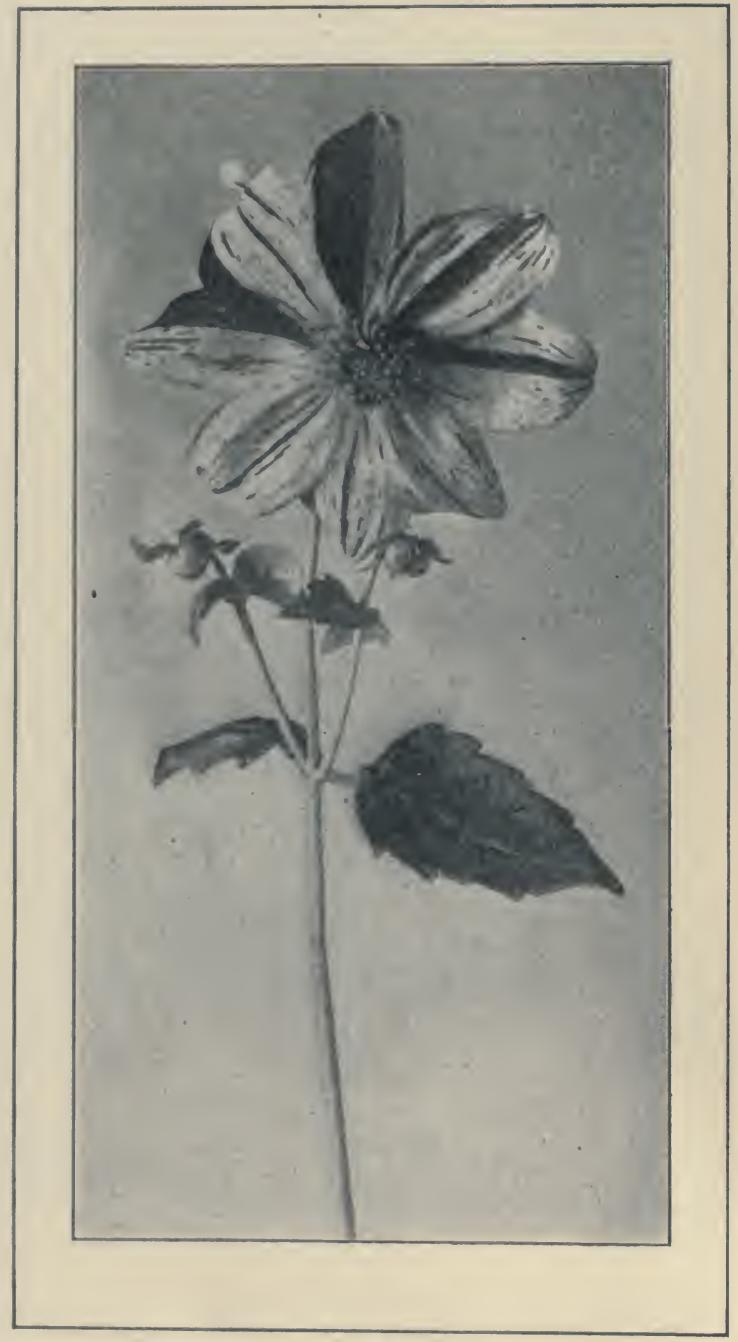

Striped Single Dahlia: Fedora. 


\section{I \\ SEPTEMBER}

\section{MODERN DAHLIAS}

The month of September is a season for the enjoyment of flowers full more than for their culture. Our appreciation of anything depends very largely upon our knowledge of it. Consequently, if we are to take the greatest delight in the September blossoms, we need to know them intimately. As we learn to distinguish the leading types and varieties by name we come to appreciate more fully the peculiar characteristics of form, color, or fragrance that gives to each the grace and interest we prize.

An excellent way to learn to know a flower is to reproduce it in some sort of drawing. Consequently, the pages for the garden booklet of this opening month of the school year may well be a record with pencil, brush, or pen of the leading classes of the prominent autumn flowers. As you become familiar with the choice treasures of the school garden, you will plan quite naturally to grow some yourself another year, and this is a good season to secure seeds, bulbs, or slips of the sorts that please you best.

One of the most remarkable of recent developments in the growing of plants is the renewed interest in the cultivation of the dahlia. A few years ago this flower was seldom found outside the old-fashioned gardens, where the large globular varieties, of the type called the Show Dahlia, were chiefly in 
evidence. To most people these artificial-looking blossoms had very little interest, and consequently were rarely planted. During the last few years, however, the general introduction of the Pompon, the Decorative, and especially the Cactus

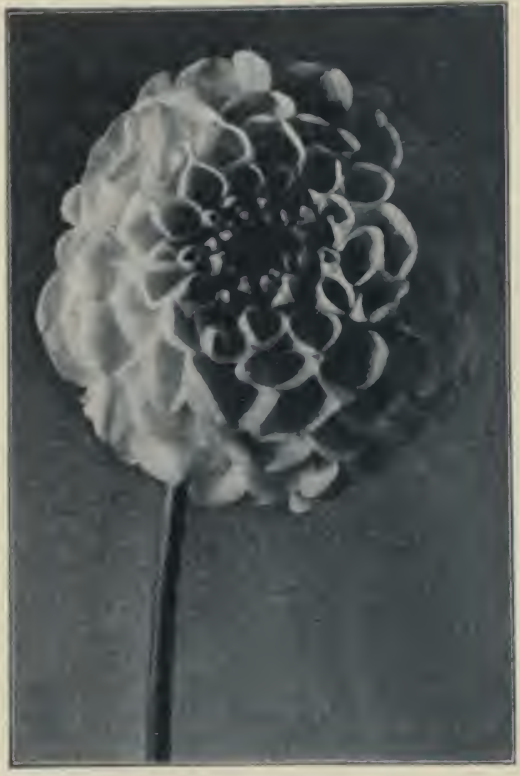

A Show Dahlia.

Dahlias, has served to increase very greatly the popularity of the flower, as well as largely to extend its range of usefulness.

Several well-marked types of dahlia are now available for any garden, and are displayed as a central attraction of every September exhibit. The Show Dahlia is still grown widely, for a large number of varieties in an extraordinary range of color have been introduced, while the qualities have been great ly improved through careful selection. You will notice them in very many border gardens, where they make a pleasing appearance along fences and walls or the sides of buildings. While too heavy and formal to possess the grace one desires for cut flowers, they are yet extremely beautiful in their coloring. The more striking varieties, those striped, spotted, or with light margins to the petals against a darker ground color, are sometimes separately classed as Fancy Dahlias, although 
this adjective is used in distinguishing similar colored varieties of the other types.

For almost a century the Pompon Dahlias have been grown, especially on account of their value in furnishing cut flowers, since they blossom profusely and throughout a long period. On this account they are often called Bouquet Dahlias, while by the Germans, with whom these flowers have been very popular, they have been commonly called Lilliputian Dahlias. They originated about I 808 with a German gardener, who is said to have first obtained the flower as a sport, or accidental variation, from the single-flowered dahlia. A large number of varieties are now offered, the flowers having a great range of coloring, while they cost less than new varieties of the other types. The plants are usually low in habit, and are used for bedding as well as for growing in the border in front of the taller classes of dahlias.

By far the most popular type of dahlia is the cactusflowered form. In this the petals have the edges rolled back lengthwise, and these long, narrow florets are oddly yet gracefully curved in marked contrast to the Show Dahlia. With the introduction of this wonderful blossom, an array of possibilities almost as great as has been seen in the development of the chrysanthemum was at once opened up. The precise origin of this type is somewhat mysterious. In I872, a gardener in Holland received from Mexico a box of dahlias, most of which had been ruined through long delay in transit. One of them, however, developed into a Cactus Dahlia, the first one known to European gardeners. From this single plant the numerous modern varieties have been developed, and by careful selection in the hands of many growers the blossoms have been constantly improved. There 
are hundreds of beautiful named varicties to-day, varying greatly in color, and very soon we may expect a flower which is extremely desirable for many purposes. At present most of the Cactus Dahlias do not last long as cut flowers; but this quality is being improved, and the flowers are so beautiful for interior decoration as well as for garden adornment that one can afford to renew a supply in the flower jars at frequent intervals.

The Decorative Dahlia is another recently developed and very desirable type. It has very large, loosely formed blossoms, with broad petals, of a type somewhat intermediate between the Show and Cactus Dahlias. While the Decorative Dahlias have not the bizarre beauty of form

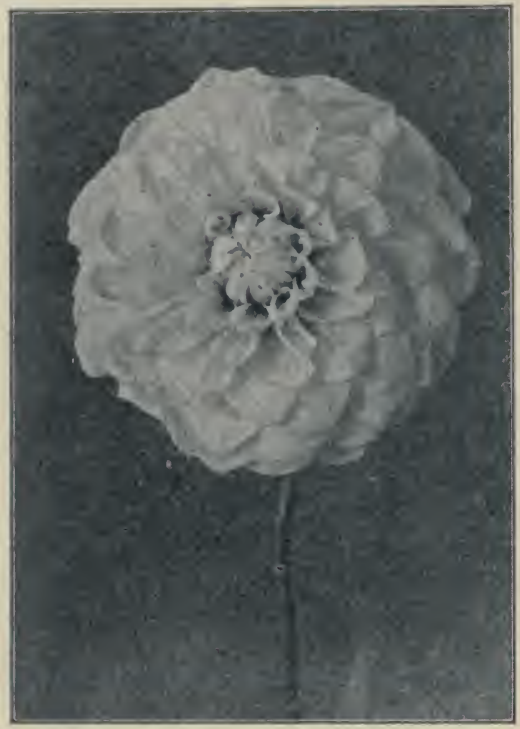

Decorative Dahlia: Mrs. Winters. shown by the cactus sorts, they are, nevertheless, attractive in a quiet way, and are useful for cutting as well as for the border garden. Although it has frequently been predicted that they would go out of cultivation in competition with the cactus forms, many new and beautiful varieties are introduced every year, and the catalogues continue to give long lists of sorts, an indication that they are holding their own in popular favor. 
The single dahlias are among the most striking blossoms produced in modern gardens. The flowers are of immense size, with the broad petals of the ray florets furnishing a ground for the most lavish display of color. The flowers are so large that they attract attention from a considerable distance, and consequently may be used along walls and fences which are too far away from the garden paths to be adorned by plants with smaller flowers. The sub-type of Century Dahlias is one of the most striking of recent introductions. The plants are tall and branch freely, while the flowers are correspondingly large, sometimes over seven inches in diameter.

For decorative grace that renders them of extraordinary value for use as cut flowers, none of the dahlias can compare with the single cactus forms. There is an element of beauty about these that reminds one of the orchids, and their long petals display some of the most delicate colors imaginable. Any one who aspires to a representative collection of dahlias should certainly plant some of this type, of which Lord Goff is one of the best varięties.

Some forms are intermediate between single and double types of dahlias. Very recently semi-double Peony Dahlias have been introduced from Holland, which are akin to the Decorative Dahlia in their large, loose petals and pleasing flower form. As is always the case with a flower which is leaping into popularity, some types are introduced which have merely the value of oddity, but in which the real beauty of the flower has been sacrificed. In the case of the dahlia this is illustrated in the French Collarette Dahlias, which have been largely advertised as a desirable novelty. No one with a discriminating sense of the beauty of 
flowers would care to plant these monstrosities a second season.

Give every leading dahlia type place in your note-book. Make sketches of typical dahlia blossoms, and if the flower details are too difficult for you to paint or draw, then carefully represent in color or line one typical floret. Illustrate in other ways your accounts of the form and coloring of the blossoms, the habits of the plants, and their uses. If you take photographs, mount some that show fine groups of dahlias, and place with them in your book plans that show how dahlias are used in the best gardens in your community. Pictures of the different types may be cut from old catalogues and used to illustrate some pages. Make a list of the best-named varieties under each type which you see at the September flower shows, as a guide to purchase the following spring.

Probably you have some dahlias in your school or home garden. They will soon need care. Since the plant originated in Mexico it is not hardy in a cold temperate climate, and, like the potato, the tubers must be cared for in some cellar through the winter. As soon as the first frosts have blighted the bloom and foliage of the dahlias, their stalks should be cut down to within a foot of the ground, and the mass of tubers should be lifted. Push a spading fork underneath the clump, from a distance to one side, then raise tubers and soil together. This should be done so carefully that no tubers will be cut or torn from the plant, for the buds are at the base of the stalk, and a piece of dahlia tuber, unlike a cutting of a potato, cannot produce a plant.

The tubers must be kept in some cellar such as is suitable for storing potatoes or root crops. It should not be too near 
the furnace where the tubers will dry up, neither where they will freeze, nor where abundant moisture will favor fungous growth and decay. Since the stalk holds an abundance of watery sap, the tubers should be placed on their side for a day or two to allow this to run off, thus avoiding decay of the base of the stalk with its buds. The earth floor of a cellar closet or bin is usually a safe place for storing. Some pack the clumps loosely into barrels. Every clump should be marked with the variety and type names on a wooden tag wired to the base of the stalk. If you have no dahlias of your own to care for thus, quite possibly some neighbor may have a surplus of some sorts and be glad to give you or your school clumps which he himself does not intend to take up and preserve.

\section{GROWING PLANTS FROM CUTTINGS}

An eminent horticulturist has said that one plant in a tin can may be of more help and inspiration to some mind than a whole lawn with beautiful flowers may be to another. One who has loved and cherished a garden of any kind will be able to appreciate the truth of this statement, and to realize the delight to be found in watching a plant as it grows. This delight is felt to its fullest extent when one has started the plant himself and has toward it the feeling one has for the things of his own growing.

Aside from the growing of plants from seed the simplest method of propagating many plants is by Cuttage. This is defined as "the practice or process of multiplying plants by the means of cuttings." And a cutting is defined as "a severed portion of a plant inserted in soil or water with the intention that it shall grow; a slip." 
It is easy to see that the requirements of a part of the plant thus cut off from any connection with the roots are different from those of the normal growing plant. The latter thrives in direct sunshine and in the open air, the water which passes freely from the leaves being replaced through the roots; but in the cutting no such replacing of water can take place unless the cut end is in water or some material

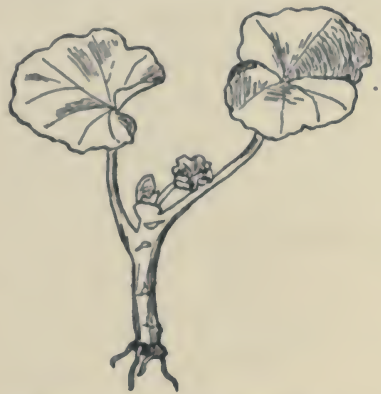

Rooted Cutting of Geranium. saturated with water. The cutting is a plant without a root, and its first business is to develop a root system. The cuttings of many plants will do this quickly and surely if we give them the right conditions.

The simplest way of inducing a cutting to send out roots is to place it in water. If you will put the end of a willow twig in a bottle of water for a few weeks you will see the roots come out in great numbers. The same process will take place, but perhaps more slowly, if you immerse a slip of a Rose Geranium or an end of a gloxinia leaf in water; and very good plants of these flowers may be started in this way.

A method that is not quite so simple, but is in general more satisfactory, is to start the cutting in moist sand or sandy soil. For this purpose a special little garden is desirable. A window-garden box or a shallow box of almost any sort may be filled with two or three inches of clean sand and used as a propagating box. This will probably be the most satisfactory method. When the cuttings are first planted, have a sheet of paper laid over the box to exclude direct sunshine, 
and if the room is warm and dry, arrange to confine the air in the box by a covering of glass.

The commonest cuttings of house plants are stem cuttings. One of the simplest illustrations of such cuttings is to be found in slips of the common geranium. A vigorous branch is cut off or broken off at a place where it will snap easilyfor roots start best from young, growing portions - and is then trimmed off just below a node or the place where a leaf comes out. Only two or three leaves should be left on the slip, that no more water may evaporate than the plant can supply without roots. The slip is now ready to plant, and should be inserted into the sand of the propagating box to a distance of about two inches.

In a few weeks a special hardened tissue called the callus will have formed over the cut end of the stem, and a little later roots will appear through or near the callus. As soon as these roots are started the new plant may be potted in a small pot, where more roots will continue to develop as the plant grows.

The geranium is an illustration of what is called a soft'wood cutting. One can also grow hard-wood cuttings in a very similar way. Early in spring cut from a thrifty young willow a piece of twig about six inches long and insert it in sand in the same way that the geranium was inserted. In two or three weeks roots will have started, and the cutting may be planted in a three-inch pot, and later planted outdoors where it can continue to grow. Hard-wood cuttings are sometimes induced to root by burying them in the soil or sand for several weeks, then bringing them to the surface that the buds may develop. The story of "Mary's Garden and How it Grew" gives an interesting account of reproducing the California Privet for a hedge in this way. 


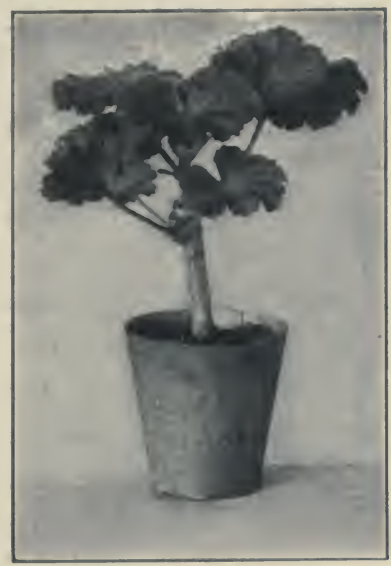

Young Geranlum Grown from a Cutting.

Some of the hardy perenniai flowering plants seem to make and root their own cuttings. In the case of many tall-growing perennials, such as the heleniums and boltonias, the old stalks and roots die after they bloom in the autumn, but a ring of underground side shoots from the parent stem start roots of their own, and in the spring make independent plants grouped in a clump. In consequence, these are among the easiest of all plants to propagate. Some weeds have the same habit, unfortunately. Worst of all is witch-grass, whose underground stems root at every joint and may send up a shoot from any joint. Cutting up such a pest merely multiplies it by cuttings. It should be carefully picked or raked from the soil and destroyed.

Another method of propagating through cuttings is found in those plants which are multiplied by means of sections of roots, as in the case of common horse-radish: these are called root cuttings. One can get through any florist or seedsman bunches of horseradish roots, which may be cut into sections three or four inches long and be carefully, planted

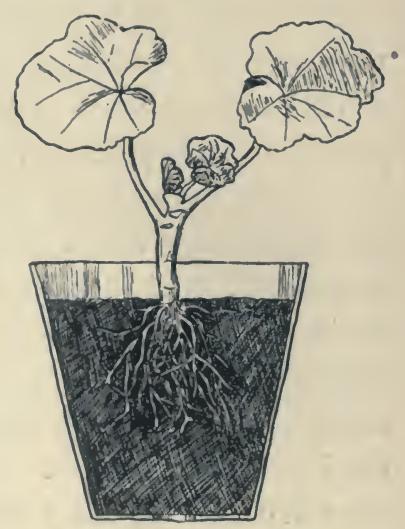

Young Geranium Plant in a Paper Flower Pot. 
either horizontally or with the lower end down.

Some hardy perennial flowering plants are also propagated by root cuttings. If you will cut a few of the thick roots of a clump of Perennial Phlox this fall, then next spring lift the clump for division, you will find that buds have developed on the cut ends of the

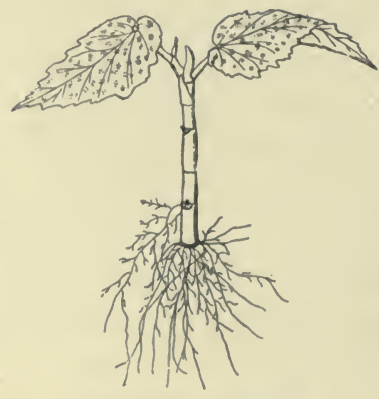

Stem Cutting, Begonia. severed roots. If carefully planted, these will give new plants of the same varieties.

A somewhat similar method of propagation by cuttings is . illustrated in the case of the common potato, which is a tuber, or thickened underground branch, whose eyes are buds. When planted, each potato is commonly cut into several pieces in order that many new plants may develop from a single tuber. Each one of the parts thus cut off is a tuber cutting.

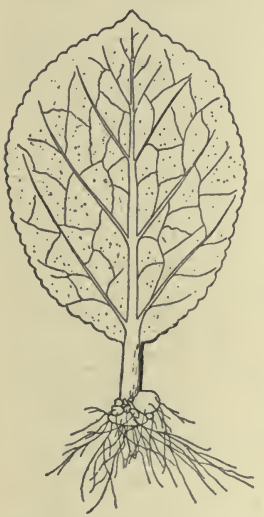

Gloxinia Leaf Cutting.

Even leaf cuttings may be made in the case of several kinds of house plants. This is one of the best ways of propagating certain sorts. A good example is the gloxinia, the leafstems of which root readily in water or in moist sand, while buds form on the leaf ribs. The thick leaves of many of the begonias also take root readily, and the leaves are commonly utilized for growing new plants.

Early in autumn it is possible for any one to start a fine garden in-doors with slight expense. Most of the tender plants 
that make banks of brilliant color in parks and home grounds are allowed to die when frosts come. The owners are glad to supply slips from them at the close of a season; so if you will secure the boxes, sand, and soil necessary for starting and growing them, you can obtain the plants themselves free. Try cuttings from various plants which you admire; experiment in rooting the slips in water, sand, and soil. Thorough knowledge and skill will come with experience.

\section{A GLORIOUS AUTUMN FLOWER}

On the twelfth day of February, I735, Peter Collinson, Botanist Royal to the British Empire by appointment of King George II, wrote to John Bartram, Botanist Royal to the American Wilderness by appointment of his own kingly soul: "In the little box that the insects came in are some seeds. The China Aster is the noblest and finest plant you ever saw, of that tribe. It was sent by the Jesuits from China to France; from thence to us: it is an annual. Sow it in rich mould immediately, and when it has half a dozen leaves transplant it in the borders. It makes a glorious autumn flower. There are white and purple in the seeds."

Thus it is probable, as it is fitting, that the first of these noble blossoms to expand their beauty in the New World grew in the famous garden on the Schuylkill River, where the life-long labor of John Bartram, the first great flower lover in America, wrought such excellent results. It is pleasant to fancy the tender care these seeds received and the interest with which the plants were watched as the white and purple blossoms opened to make, as the good Peter had written, "a glorious autumn flower." It is easy to imagine that the 
flowers were shown to many visitors, by whom the seed was eagerly sought for new plantings.

The asters which were first grown in Europe and America between I 730 and I 740 were very different from those which are now being cultivated. For one thing, they were all single varieties, resembling in general appearance the Ox-eye Daisy. Each flower had a large yellow centre composed of tubular florets, with from two to four rows of ray florets surrounding it. In the seeds sent by Collinson to Bartram white and purple varieties were included. A red variety is said to have been obtained by Philip Miller, of Chelsea, England, in I 73I, and a blue variety was also known about that time. Some twenty years later the same gardener received seeds of double varieties in red, white, and blue colors, and by the end of the eighteenth century flowers with blue and white stripes had appeared and the aster was well started on its way toward the marvellous development which has since taken place.

These asters are commonly called by two general namesChina Asters because they originated in China, and German Asters because the modern development of the plant was largely brought about by German florists. Professor Bailey thinks the first remarkable development was in the production of the quilled type of flower, in which the central florets were produced into quills. Varieties of this type were popular about the middle of the nineteenth century, and many of them are still grown, under the name of German Quilled Asters. These blossom in hemispherical masses and occur in a great variety of colors.

The most satisfactory classification of these asters is that suggested by Professor Bailey in the "Cyclopedia of Horticulture." The flowers are divided into two great groups, 
namely, the Flat-rayed and the Quilled, each of which is subdivided into two lesser groups. The Flat-rayed Asters include a large proportion of the more important varieties. In these all, or nearly all, of the florets are flat instead of tubu-

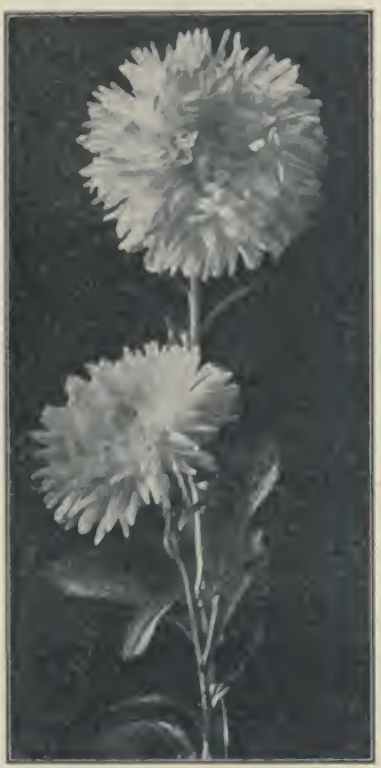

China Asters.

lar. In one group, these flat florets are curved upward and inward, as in the case of the Jewel or Ball-flowered Asters; in the other group the florets are curved downward and outward, as in the beautiful Comet Asters. In the case of the Quilled Asters one type has three outer rows of florets flat and reflexed, while the rest of the florets are tubular. These are the German Quilled Asters already mentioned. In the other group all the florets are tubular, as in the variety called the Victoria Needle Aster.

None of the modern asters surpass the Comet type in charm and distinctive beauty, the recurved petals of the large, soft, broadly rounded flowers suggesting the form of some of the more beautiful sorts of chrysanthemums. There is a great variety of coloring in these Comet flowers, the tones varying from pure white to blue and violet and red, and even pale yellow in the solid colors, with a great many intermediate striped sorts. As to size of plant these Comet Asters are divided into two types: the Giant Comets reach a height of two feet, with large 
flowers upon long stems, while the Dwarf Comets are but half as high. with the flowers on shorter stems. A rather new form of the China Comet is the single-flowered one, in which the ray petals are long and slender. New varieties of these Comet types are continually being added to the florists' lists.

Aster types are not so clearly defined and widely recognized by standard names as are the leading dahlia forms, so the names and descriptions of asters in the seed catalogues may puzzle you. For this reason your notebook sketches and descriptions of the best illustrations of each standard type grown in your community, accom-

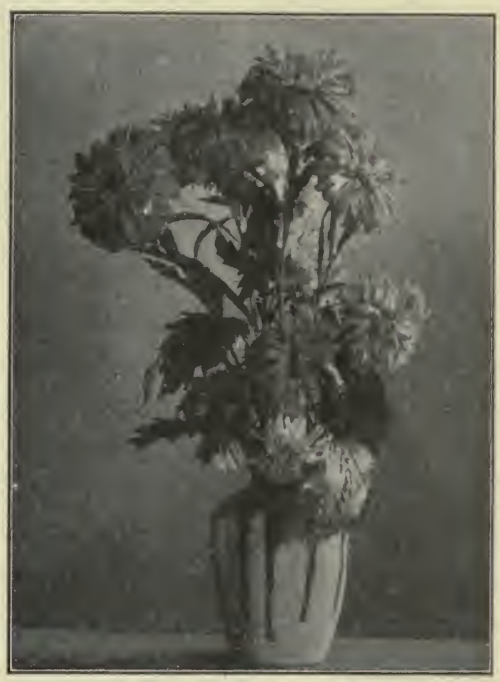

Dwarf Comet Asters. panied by records of the trade names of the seeds sown, will enable you to order just the sorts you prefer another spring.

While studying the aster, plan to preserve seeds of the best varieties of each type. The best seed is home grown, because freshest, and taken with such care in selection as is hardly possible commercially. When cutting flowers for the house, leave the earliest and best blossoms to mature. When the seeds are ripe, the flower heads should be cut and dried; then the seed should be separated, cleaned, and placed 


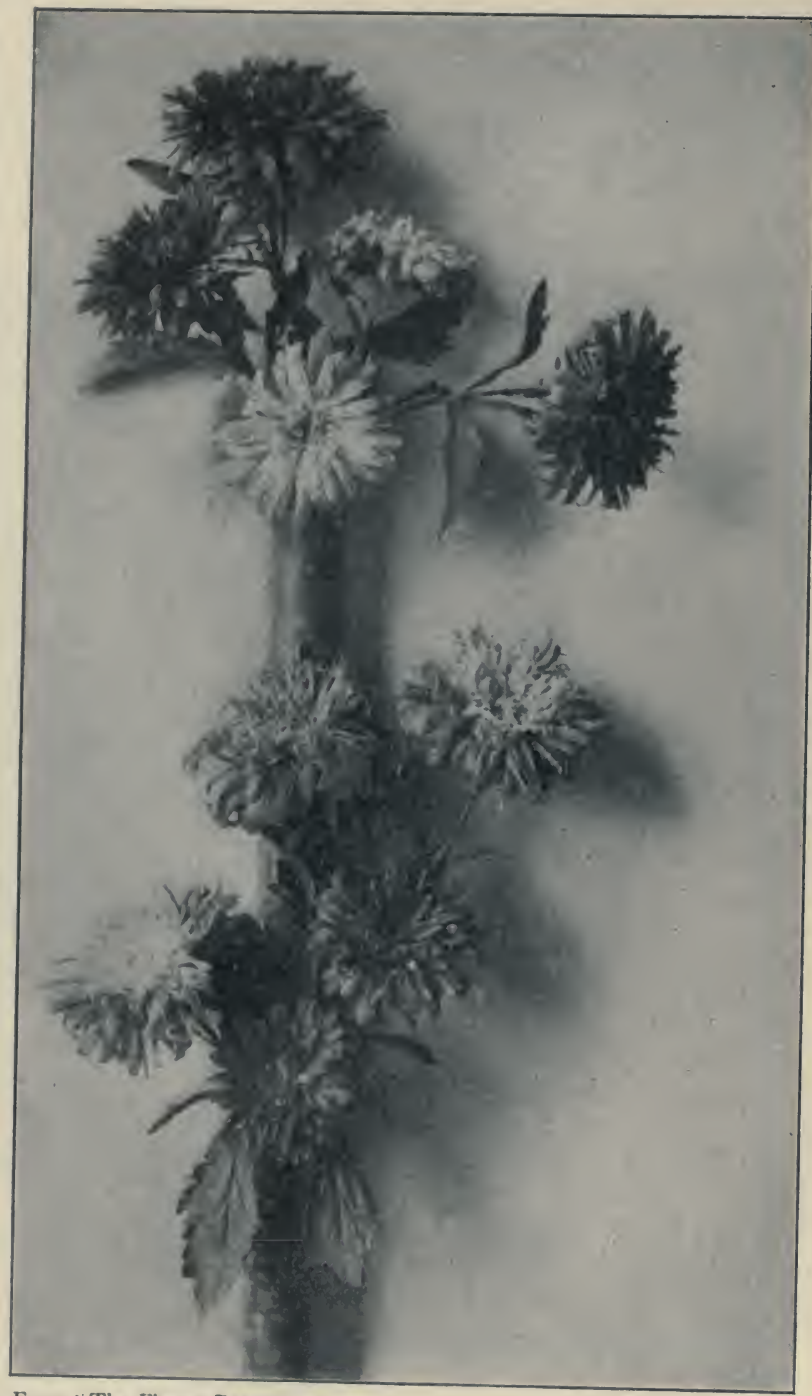

From "The Flower Beautiful."

Comet Asters in Bamboo Holder. 
in labelled envelopes. Every school garden should follow planis from seed to seed for their life history. Every home gardener will find great satisfaction in this work, too, for it is by careful selection that varieties are improved. Moreover, the best double flowers usually produce seeds sparingly, so that good seed is expensive. All the surplus seed of fine quality that one produces will be highly appreciated if distributed to one's flower-loving friends as gifts, or it may serve as a basis of exchange for other seeds or for bulbs and plants with one's neighbors. A school garden may very properly be utilized to supply seeds for the home gardens of its district. But all this work should be based upon a study of the finest types of flowers, that selection of seed may be intelligent.

\section{PLANTING BULBS OUT-DOORS}

The only way to be rewarded by a beautiful show of blossoms in early spring in the out-door garden is to plant in autumn the spring flowering bulbs. These are so inexpensive and so beautiful that it is not strange that they are becoming more and more popular every year. And the fact that when once established most sorts continue to develop a new supply of bulbs for future flowering renders them all the more desirable.

Fortunately, these spring flowering bulbs can be planted to advantage in a great variety of situations. Arranged in the form of beds they commonly make the most striking display to be seen in spring in parks and gardens. Scattered with less formality along the edges of the border garden or beneath the shrubbery, or dotted here and there on the lawn, they often make an even more pleasing show than in the 
formal garden. They will do well in almost any situation provided the soil is fairly rich and well drained, and the bulbs of each variety are planted at a uniform depth rather early in the season. For these plants are able to blossom so soon in spring because of the fact that they have gained much of their root growth the previous autumn. Consequently it is de-

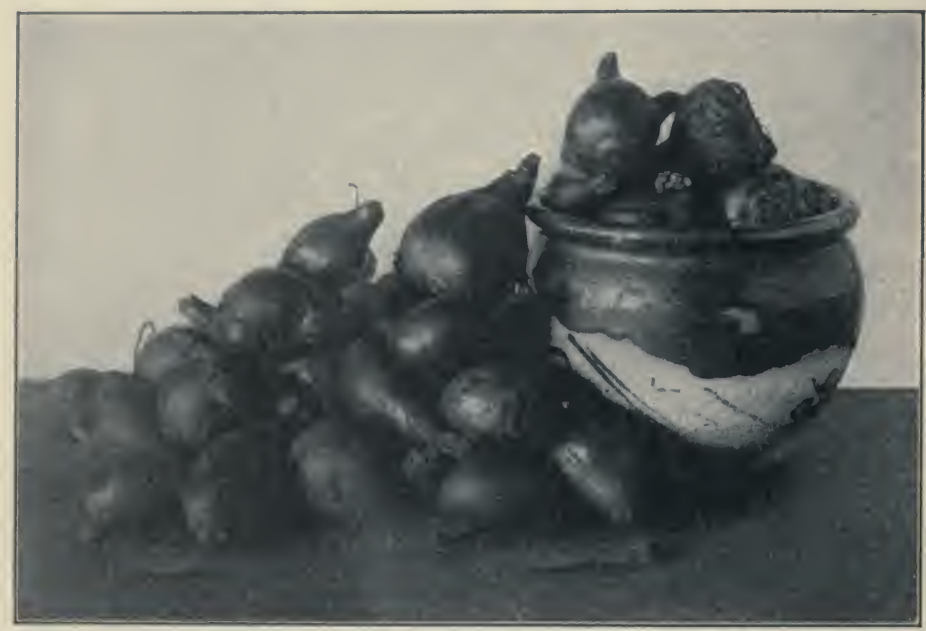

Fifty Bulbs of Campernelle Jonquil.

sirable to be able to put the bulbs in the ground so early that there will be opportunity for a good development of roots before freezing weather. Some of the bulbs, notably the crocuses and daffodils, should be planted in September if possible, while most of the others will do very well if planted in October.

In reply to the question as to what to plant, one should choose at first those sorts of spring flowering bulbs in which one most delights. If you are very fond of crocuses or snow- 
drops or daffodils or tulips, plant these in abundance and at the same time plant also a few bulbs of some of the flowers you are not so familiar with, and perhaps you will thus be able to extend your range of enjoyment. For a liking for flowers depends very often upon our knowledge of or our experience with them, and it is always worth while to increase one's garden experience. The carliest of the spring flowering bulbs are the crocuses, snowdrops, and scillas, all of them low-growing plants which are desirable to put along the borders of hardy perennial gardens or the more formal beds of tulips or hyacinths. The crocuses are very desirable for planting in the lawn, especially in a sunny situation near a building or fence where they will come into blossom long before the snow disappears, thus greatly extending the period of the out-door flower gardens. All that is necessary is to make a hole with a pointed stick in the sod about three inches deep, and to push the crocus bulb right side up down into the bottom of this hole, firming the soil over it when it is thus planted. The snowdrops and scillas may well be planted in small groups to a depth of about two inches.

For starting an annually recurring display of flowers no bulbs are so satisfactory as the daffodils. Of these the single Trumpet Daffodils are the best, although the Poet's Narcissus is also well worth very general planting. These daffodils are very desirable to grow beneath shrubbery, where they will become naturalized and produce beautiful flowers. They will do better, however, if the groups of these bulbs are dug up and replanted late in summer or early in autumn about once in three years. In this way crowding is prevented and the soil may be again thoroughly fertilized.

For a striking display in early spring the early single 


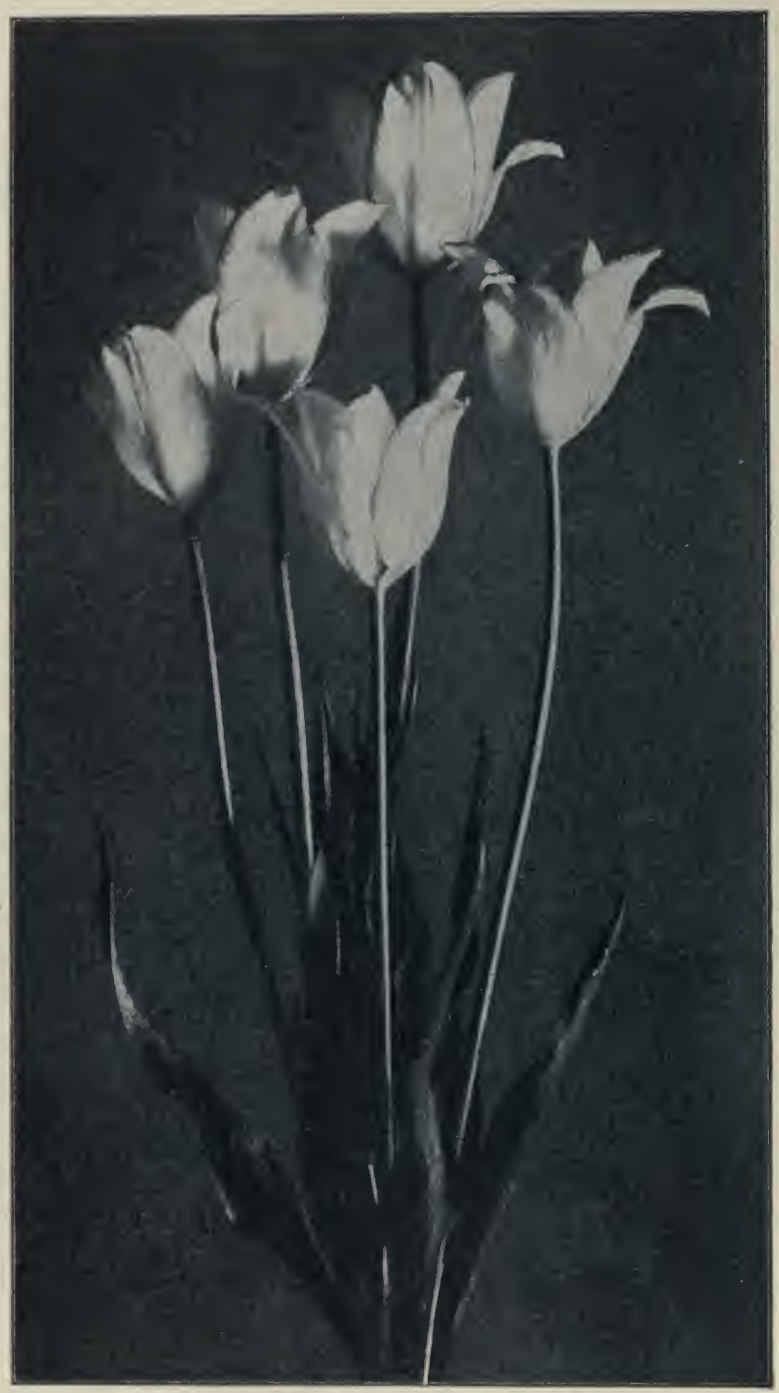

Long-stemmed Tulips. 
tulips are very useful. Named varieties should be selected and planted at a uniform depth of about three inches, so that all may flower at the same time. The long-stemmed late tulips are even more beautiful. These are better adapted to the border garden, where they may be left permanently. When placed in the formal flower beds the bulbs must be

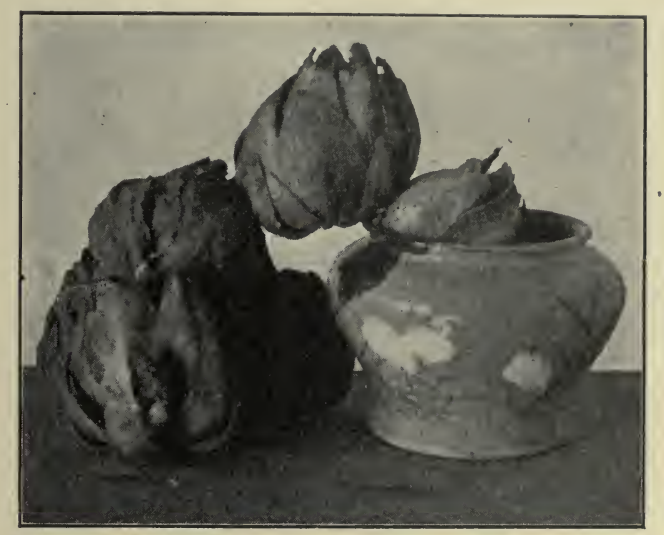

Bulbs of Madonna Lilies.

renewed yearly, for they remain in blossom so long that there is no opportunity for them to ripen off before it is time to plant bedding plants for the summer display.

The beautiful sweet-scented hyacinths are more tender than most bulbs. Named single varieties should be planted in October at a uniform depth of four inches, and in spring as the foliage has ripened off the bulbs should be taken up and stored in a cool, dry cellar until the time for planting again. As they are planted in formal beds, great care should be taken to have the rows uniform and to plant the bulbs at a uniform depth. 
There is no question that nearly all of the lilies do better when planted in autumn than in spring. The Madonna Lily needs to make a leaf growth in autumn, so that its bulbs should be set out in August if possible, but most of the lilies may be planted in October very well.

Nearly all of the bulbs are benefited by a winter protection which prevents the alternate freezing and thawing of the ground and keeps them from starting to blossom so early in spring. This covering, however, had better not be put on until the surface of the soil has frozen; otherwise there is danger that mice will injure the bulbs. It is also advantageous in that the frozen surface soil will check the development of the bud toward leaf growth, while the layer of mulch will retard deep freezing and favor the growth of strong vigorous roots that will lead to splendid flowers the following spring.

\section{THE SEPTEMBER CALENDAR}

\section{In-doors}

START during latter part of month cuttings of geraniums and other plants desired for window gardens. Take cuttings from plants out-of-doors.

Start bulbs for early winter blooming, especially Paper-white Narcissus and Roman Hyacinths.

\section{Out-doors}

Plant lily bulbs, especially thos of the Madonna Lily, as early as possible.

Plant crocuses, daffodils, and other early spring flowering bulbs this month. Tulips and hyacinths may wait until October.

Transplant into three-inch pots seedlings of French Marigolds and Drummond Phlox started in August, and bury pots in the garden soil until there is danger of frost. 
HARvest vegetable crops as fast as they mature. Clean the ground after harvesting.

IF YOU HAVE a cold-frame sow cabbage seed in drills in the garden to start plants to winter over in the frame.

PREPARE a store of soil for use in potting, gathering the necessary garden soil, leaf mould, manure from compost heap, etc.

GATHER seeds of annuals and perennials before they are lost from ripe szed-pods; clean them and store in labelled envelopes.

Hot. a public exhibition of the products of school and home gardens.

SEND cut flowers from the school garden and arrange them attractively in vases as a gift to the School Board at its first meeting of the school year.

PRICK OUT the seedlings of pansies, English Daisies, primrosés, and other half-hardy plants in the cold-frames.

LIFT long-established clumps of hardy lilies which have multiplied; divide and reset the bulbs, adding manure to the soil, but keeping from contact with bulbs.

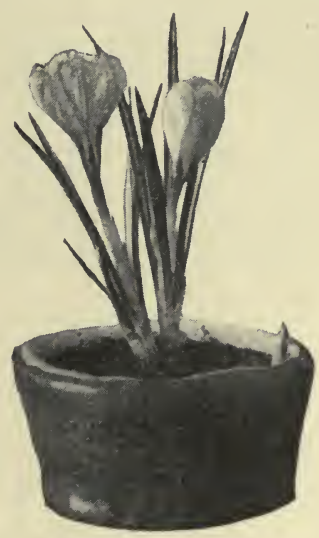





\section{OCTOBER}

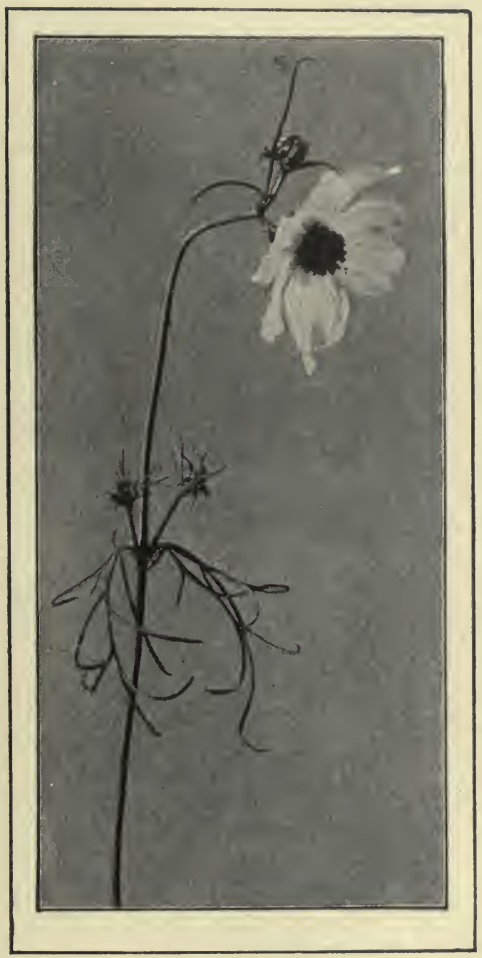

White Cosmos.

"So from the root

Springs lighter thy green stalk, from thence thy leaves More airy, last thy bright consummate flower Spirits odorous breathes." 


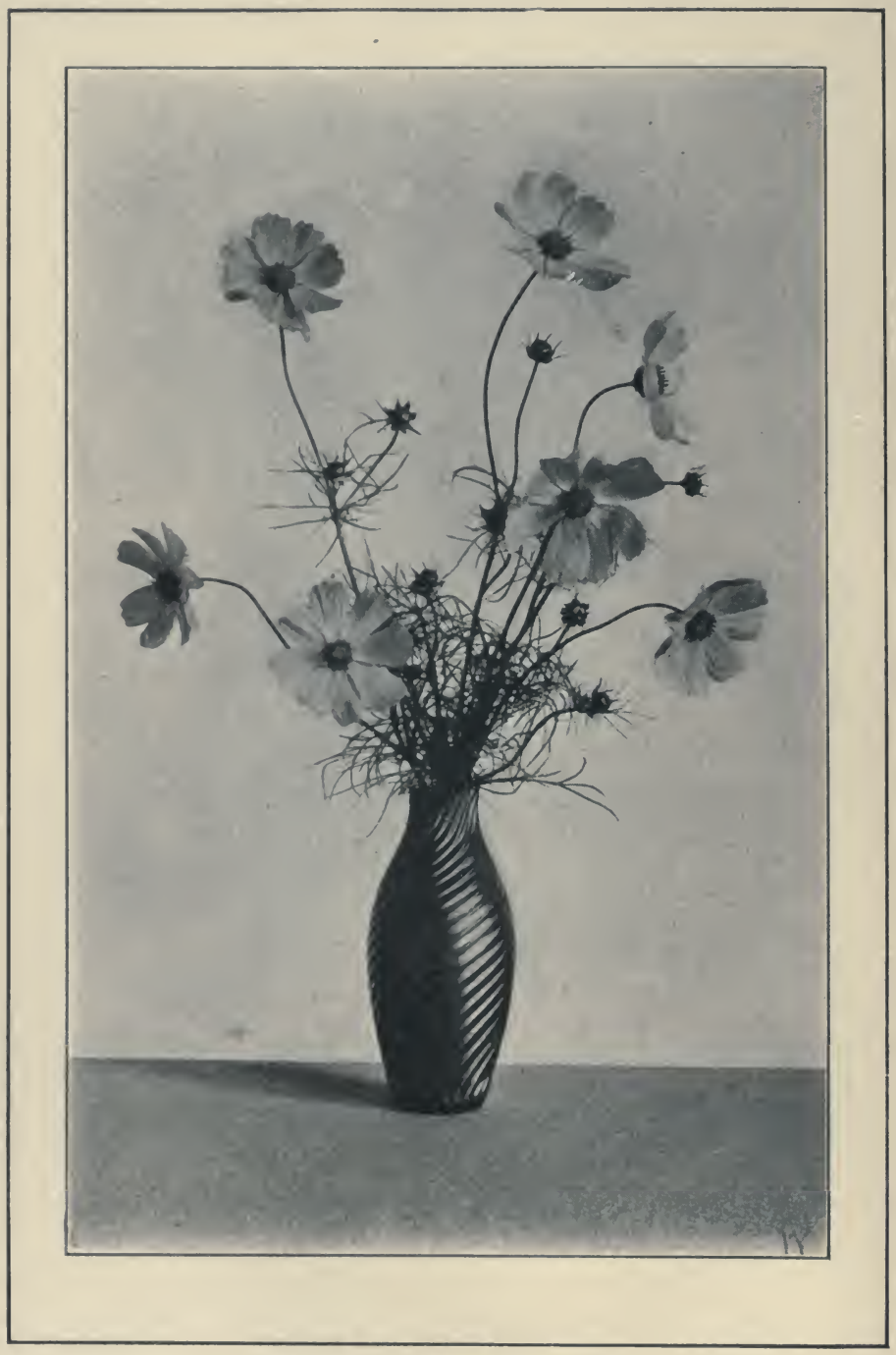

Pink Cosmos in Austrian Glass Vase. 


\section{OCTOBER}

\section{COSMOS: A BEAUTIFUL ANNUAL}

The cosmos is one of the most satisfactory annuals for the border garden, both on account of the grace of its foliage and the beauty of its blossoms. It may be grown as easily as any of the garden vegetables, and may be used to great advantage along fences, walls, and the sides of buildings. By choosing the tall varieties to plant next to the wall or fence, and the dwarf varieties to plant in front, one may get most beautiful effects during the latter part of the season, the flowers of the dwarf forms beginning practically at the ground and extending upward for many feet with a background of attractive foliage that helps in the display.

The seed of the cosmos may be started in a hot-bed, greenhouse, or window garden early in the season and transplanted out of doors when danger of frost is past; or the seeds may be planted in a drill out of doors in May and the young seedlings transplanted, when they are two or three inches high, to the place where they are to grow. These seedlings are vigorous little plants with a compact root system, so that they are very easy to transplant. In a rich soil and with plenty of moisture they grow with great rapidity, sending up fine, fernlike foliage which gives an attractive effect long before the flowers appear. Even the buds have a decidedly decorative value, being rounded in general outline, though flattened on the outer end and more or less enclosed by a 
double row of long, pointed, greenish, leaf-like growths called bracts.

When the flowers appear the plant becomes very conspicuous and attractive. Three colors are commonly grown. In one the flowers are a beautiful glistening white, in another they are an exquisite pink, and in the third they are a deep red, the last-named variety being the least attractive of the three.

While the ordinary varieties do not come into bloom until the autumn is well advanced, strains of the dwarfer sorts flower continuously from midsummer. These are more desirable for children's gardens, although their flowers are not so rich and large as the typical sorts. They may be grown in-doors. The late varieties are well adapted to the school garden, since they bloom when schools are in session, and when the flowers of many plants are disappearing.

The structure of the flower of the cosmos shows at once that it belongs to the great group of composite plants. Around the base of the blossom there is a double row of long, pointed, deep-green bracts, with a more definite lighter-colored series above them. The chief attractiveness of the blossom is given by the petal-like ray florets, of which there are usually eight, and which are sent out in a plane at right angles to the axis of the flower. These petals are grooved in a most interesting fashion and are scalloped on the outer ends in a way that adds greatly to their decorative effect. In the petals of the pink variety, the color of which is really a light violet red, there is at the base a spot of rose color which forms a delightful bit of what the artists call a dominant harmony. The disk florets which form the "eye" of the flower have a general yellow color, due to the yellow petals 
united into tiny tubes and the yellow pollen which is pushed out through the stamen tubes, the latter being brownish black.

The cosmos has so great a spread of branches for the size of the stalk that the plants are easily blown down by the wind, and, in consequence, when growing in exposed situations, each stalk should be tied to a stake to hold it in position. This is not so necessary when they are growing in the shelter of a wall or fence, but even then it is generally desirable.

For use in-doors, where they are extremely effective for ornament, these flowers require a spreading arrangement which shall simulate their manner of growth outside. Two or three sprays projecting from a slender vase and showing stems, leaves, buds, and flowers are exceedingly effective, especially if placed against a plain background, gray or graygreen in tone. A larger display in a broader flower jar may also easily be made one of the most beautiful flower arrangements imaginable.

\section{SWEET HERBS}

In the early history of America, herbs for use in flavoring food grew in every thrifty kitchen garden. Many a man can remember helping his mother gather the ripe caraway seeds in the little old-fashioned garden. How good they tasted in the cookies! Perhaps he also helped cut the fresh shoots of sage, and can recall the bunches of dried sage that hung from garret rafters beside those of wild medicinal herbs. In memory he can taste again, even now, the sage in the savory stuffing for the Thanksgiving turkey. In the corners of the farmyard clumps of catnip and tansy probably grew in abundance, and in earlier years many other herbs had been numerous. 
Even in Bible times herbs were frecly used. Mint, anise, and cumin are mentioned in the pages of this book. Oldtime stories tell of others, such as dill and pennyroyal, which children nibbled at to while away the long hours of the church service. But to-day such herbs are little known. Some large city markets sell a few kinds fresh, and occasionally a limited number are grown in home gardens, but these are mainly on estates with gardeners and skilled cooks. Most of us are content with the tropical spices so cheaply supplied by commerce, while in the main the delicate flavors and the delights of the home garden of herbs are past.

The school garden may restore past joys and values to home garders, as well as serve to introduce there the best products of modern horticultural art. In I9o6, one school garden showed twenty sorts of herbs at the fall exhibition of the Massachusetts Horticultural Society. Some of the fine cooks of the neighborhood of this school welcomed the opportunity of purchasing fresh herbs in great variety, if not in large quantities. Some of the children started mint and sage and annual herbs at home. One boy grew sage and catnip in quantity at his summer home in the country, and realized a snug little sum retailing both fresh and dried herbs of his own production to his city neighbors. A bed of herbs is a very desirable and practical feature of a school vegetable garden or of a home garden.

Herbs of the kitchen garden are plants native to Europe, and mainly to Mediterranean countries, whose aroma attracted attention and led to their use for flavoring food in times when the spices of tropical shores in the Far East were unknown or very costly. Since native to Europe they are either hardy annuals or perennials whose seed may be sown 
sarly in the spring. Fully half the list are members of the mint family, whose odd two-lipped blossoms are familiar. They are grown for their leaves and the tender tips of the branches, which are used for flavoring stews and like foods. Sage, spearmint, and catnip are relatively common. Balm, thyme, pennyroyal, rosemary, peppermint, and summer or winter savory are at least familiar names. Hoarhound, hyssop, pot and sweet marjoram, clary and sweet basil belong to this same mint family.

Most other herbs belong to the parsley family having their flowers in umbels. Caraway is a type of those whose seeds are used in flavoring breads and other foods, the others of this class being coriander, anise, and cumin. Parsley and chervil are species grown for their leaves, which have become finely cut and crisply curled in cultivation so that they are used for garnishing dishes as well as for flavoring. Dill is grown both for its tender foliage and for its seeds.

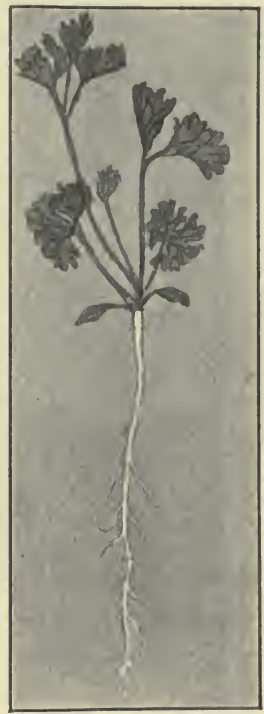

Parsley Seedling.

Of the few remaining herbs which belong to other families of plants, tansy, rue, and lavender are hardy perennials, while borage is a hardy annual which reseeds itself. These hardly deserve cultivation for use in flavoring, although perhaps worth while for their flowers and to complete the herb list in the school garden.

Mint, that is, spearmint, is a good herb to grow first. Its seeds are not catalogued for sale, but it multiplies very 
readily and rapidly from cuttings and root divisions, which every seed house offers cheaply in spring. It thrives in moist soil. If transplanted to a cold-frame in the fall, it may be had fresh until Christmas and again in early spring. Clumps

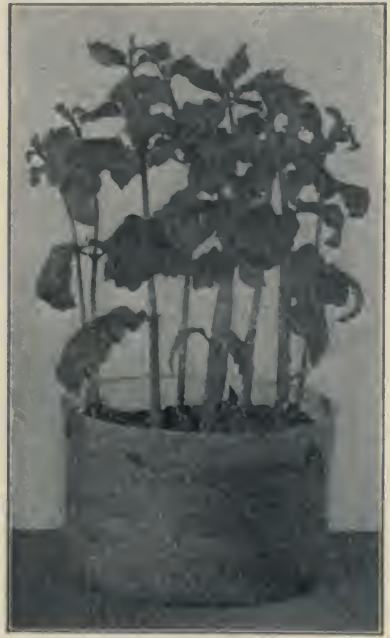

Spearmint Cuttings Rooting in Sand. may be grown in a pot or a box in the house, or even by the cellar windows, also, if potted during the fall.

Tarragon and chives resemble mint in being prized for flavoring and in being hardy perennials propagated by division of clumps, although they are otherwise quite unlike plants. Tarragon is a native of Siberia and hence is very hardy, although, like mint, the stalks should be cut down in November and a cover of litter or mulch provided. Clumps of chives, a diminutive member of the onion family, will produce their hollow leaves if placed in window-boxes or pots in the house or school-room, and the leaves may be cut repeatedly.

Other herbs are grown from seed. Some of the perennial sorts are not very hardy and are usually grown as annuals, although specimen clumps may be protected in a cold-frame. Now while fresh seeds of annual varieties germinate readily, the fine seeds of perennial sorts are often old when purchased, and develop slowly. If the protection of a cold-frame is not available, it is well to support a board an inch above the drill 
in which the seeds are sown. It gives protection from heavy rains which would wash the seeds out, and it keeps the soil moist in its shade during hot, dry weather. As soon as the young plants of pennyroyal or thyme or the like are up, the board may be removed to allow them sun and free growth.

Several of the herbs may be grown as house plants. Among them is parsley, which is frequently transplanted into pots for the house, and it may be grown in the house even from the first. It needs abundant moisture and a rather cool temperature. Curled chervil may be similarly treated. Both may be kept in cold-frames in autumn for holiday use. Sweet basil is a tender annual, being native to India, and serves well for in-door culture. It should be started in the house in spring for out-door beds, and plants that have been cut back may be lifted and potted in September for growing

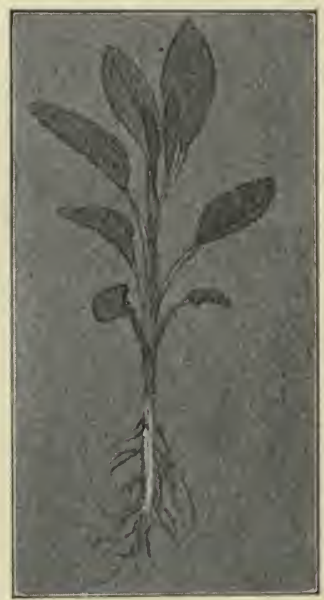

Sage Seedling. in-doors. In southern Europe special dwarf bush varieties are commonly grown as pot plants in cottage homes.

\section{GETTING THE GARDEN READY}

When one wishes to start a garden in spring it is nearly always worth while to begin operations the previous autumn. Very often the ground to be used is covered with sod, in which case it is always best to plough or spade it the fall before in order that the frost may act upon it and enable the gardener to get the soil into good workable condition when he wishes 
to plant the spring crops. The ground also is very often full of the root-stocks of witch-grass or quack-grass, and it is very necessary that these underground stems should be eradicated before the crops are planted. The best time to do this is in autumn when the gardener has comparative leisure. And

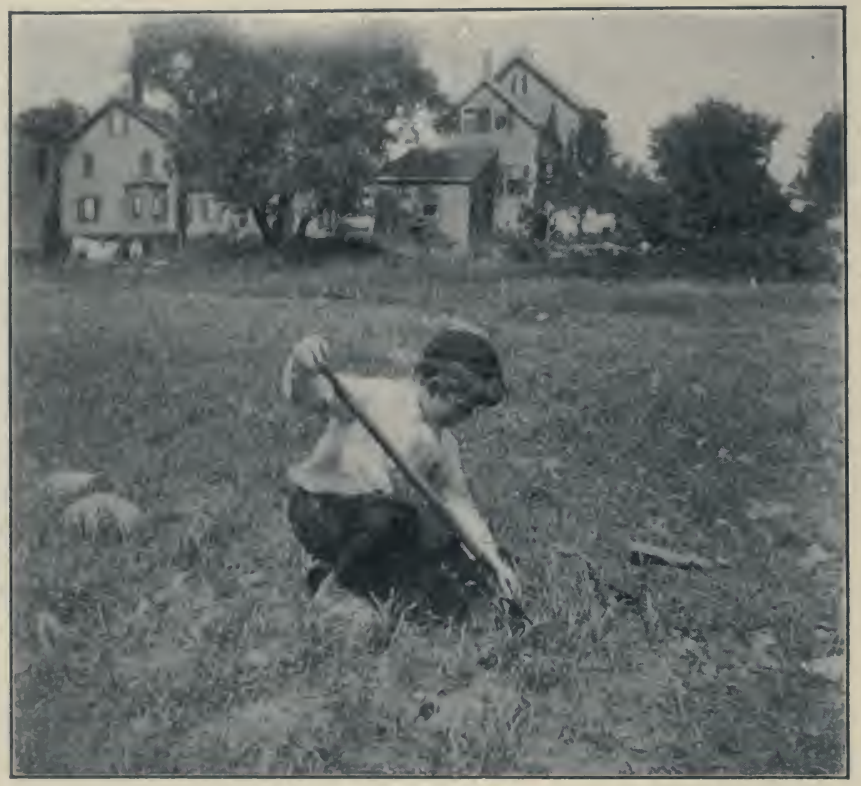

A Young Gardener.

the best way to do it is to dig out the root-stocks with a tined fork, which will not cut them off as does a hoe or spade. It is very desirable also that stones be removed from the soil before crops are planted.

Consequently, if you desire to have a successful garden next season, decide on its location this fall, get the ground as well prepared as possible, and leave it in such good condition 
that the freezing and thawing through the winter will help in giving the soil a finely pulverized condition, in which the roots of the plants grow to much better advantage than in soil where the particles are coarse.

There is much else that may be profitably done for the garden. Well-rotted manures are difficult to obtain in the spring, so gardeners often make compost heaps in the autumn, laying alternate broad layers of manure, ashes or lime; and sods, vines, leaves, or the like. These are forked over once or twice to prevent too rapid or excessive decay, and are ready to be worked into the garden the following season. You will also be able to make plans for your garden during the winter months with more success than if you leave preparation to the few weeks in spring, when there are so many things to take up the time and attention of the gardener.

With plans formed it will be possible to get ready for use the stakes, trellises, and other plant supports which are best prepared in the winter. Many school and children's gardens come to grief from lack of protection against intruders, such as pet animals and younger children of the neighborhood. Before the spring opens, the posts, railings, wire netting, or other means for either temporary or permanent protection should be obtained, ready for erection as soon as the garden is seeded. Plans and preparation betimes mean early vegetables and a long season of bloom in the flower garden.

\section{CALIFORNIA POPPIES}

No other flowers in the garden furnish so rich a display of color in tones of yellow and orange as do the California Poppies or Eschscholtzias. The color tones range from a light creamy white to a deep orange yellow in the varieties 
commonly available. In a single one of the large petals one may see a most beautiful gradation of tones from the comparatively light tint at the outer margin to the much deeper tone at its base. Those varieties in which the changes from yellow to orange are thus shown are particularly fascinating. New varieties in pink and stripes of pink and white have lately been introduced from California, where these flowers grow wild in abundance.

These California Poppies are as attractive through the simplicity of their structure as they are through the beauty of their coloring. The finely cut foliage is of a most delicate glaucous green, which serves as a delightful background for the colors of the petals. The flowers are held erect on the long, slender fluted stalks, each flower when fully opened having four broad petals that give it an expanse of more than two inches. Within these there are a great number of the stamens which have the pollen exposed on very long pollen bags or anthers. These anthers are yellow and much longer than the flattened filaments from which they arise, the latter being blotched with a blackish shade toward their tips. In the centre of the flower is the seed-bearing pistil.

These flowers have a slight odor which would probably be disagreeable to many people. This is not noticeable, however, except when the blossoms are very close at hand, and it does not interfere in the least with their usefulness in the garden or in the home. In the garden they may be planted along the borders in sufficient numbers to give a distinctive color, or in beds by themselves, where the brilliant flowers will stand relieved against the fine green foliage.

For blossoms of such delicate texture these poppies serve admirably as cut flowers. They may be loosely displayed in 
vases or bowls, and are particularly attractive when shown with some of the leaves in clear glass rose bowls, so that the delicate stems are seen through the glass. Very delightful color harmonies may be made by placing the flowers in vases colored in plain tones of yellow, and they are, of course, attractive when placed in jars colored in neutral tones of gray or green. The new crimson and striped varieties are also very pleasing.

These California Poppies are of easiest culture. The fine seeds should be sown where the plants are to blossom. It is said that the best results are obtained when fresh seed is sown in early autumn, a protection of some loose mulch being given through the winter. One can get, however, excellent results by planting the seed in early spring in the open ground.

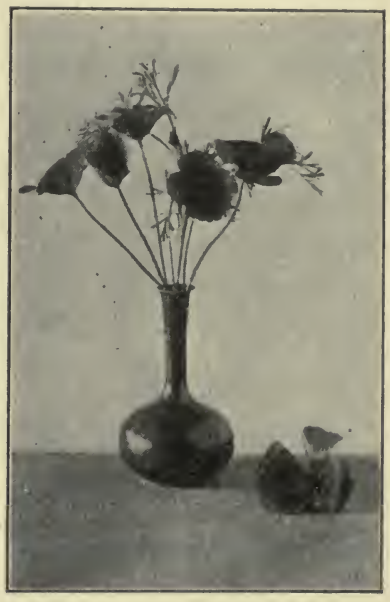

California Poppies in a Slender Vase. The seedlings should be gradually thinned until the plants are about ten inches apart. These flowers, on account of their beauty and simplicity as well as their ease of culture, are especially desirable for school gardens and children's home gardens, a fact, however, that should not prevent the most skilful gardener from enjoying them. 


\section{GROWING HYACINTHS IN-DOORS}

The single hyacinths are perhaps the most generally attractive of the spring flowering bulbs which may be forced into blossom in-doors during the winter months. The flowers are borne in beautiful masses of delightful colors and

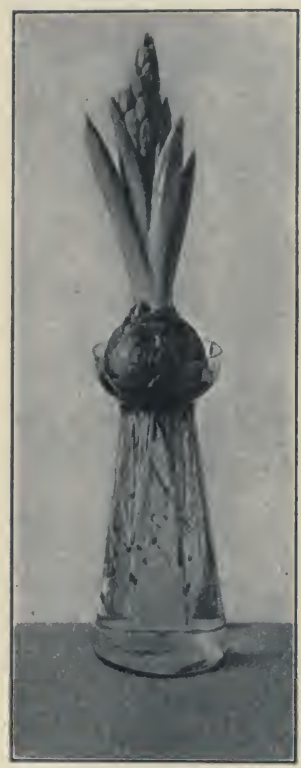

Hyacinth Growing in Water in a Tall Hyacinth Glass. have a perfume which appeals to nearly every one. They are ideal plants to grow in water, and for many years they have been very popular for this purpose.

The water culture of the hyacinth is a very simple process, although some experience is generally necessary before one secures uniformly successful results. The process of growing consists simply of placing a good-sized bulb in some vessel holding water in such a position that the bottom of the bulb is in contact with the water. The vessel and the bulb are put away in a cool, dark closet or basement room for six or eight weeks, in order that the roots may develop in the water. More water is to be added as that present evaporates. At the end of this period the bulbs are to be brought into a moderatcly cool, well-lighted room, where the leaves and flower-stalks will start their growth.

There have long been upon the market various forms of hyacinth glasses especially made for forcing these bulbs. The best shape of these glasses is shown in the accompany- 
ing picture, and the safest color to buy is green, as the blues and reds are not likely to combine so well with variously colored flowers that may be grown in them. It is not necessary, however, to confine yourself to the use of these special hyacinth glasses. Attractive flower jars of almost any sort

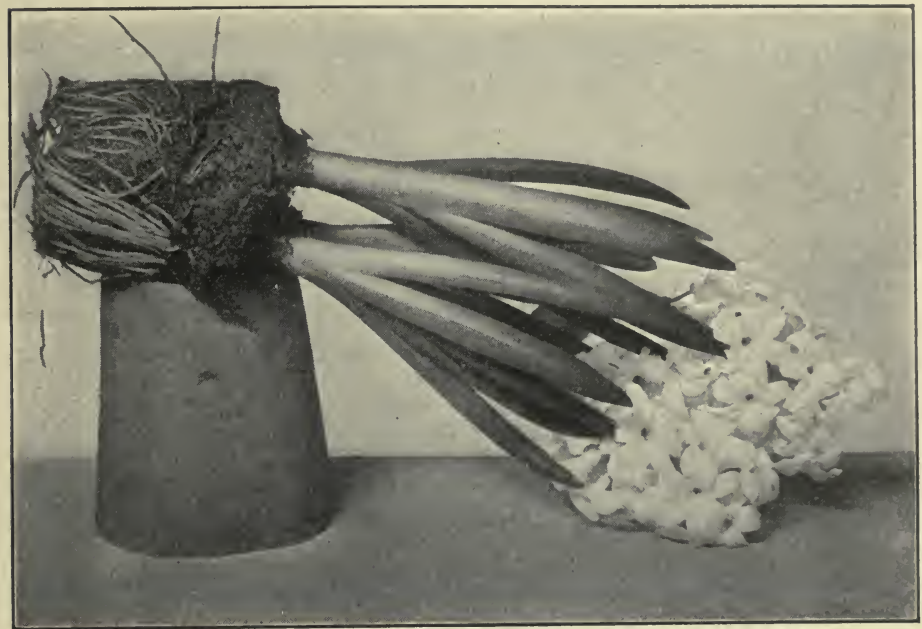

Three Hyacinth Bulbs Grown in a Four-inch Paper Flower-pot.

in which there is room for the development of the roots will serve as well, and will often give more artistic results when the plants are in blossom.

One of the commonest troubles in growing hyacinths in water is that of the development of the blossoms without the lengthening of the flower-stalks. To avoid this it is desirable to leave the bulbs in the cool basement until the crown of the young leaves has broken open.

The single hyacinths may also be grown in-doors in earth, utilizing any good loamy soil held in flower-pots or boxes of 
almost any sort. The cheapest and most satisfactory receptacles, however, are the paper flower-pots, because they occupy so little room and may be set inside of window-boxes or flower jars to such great advantage. An ordinary bulb will develop perfectly in a three-inch paper pot or three bulbs in a four-inch paper pot. In growing these in earth it is only necessary to plant the bulbs in October or November. Firm them down in the soil so that the bulb will not be pushed up as the roots develop, watering thoroughly, and then placing away in a cool, dark basement for about two months. During this time the soil must be kept moist by occasional watering.

As the leaf crowns break apart, the bulbs may be brought into the light and warmth of a moderately heated room, where most of them will develop their beautiful blossoms. One of the most satisfactory ways to utilize them is to set the pots in a narrow window-box, preferably in a window which does not receive a great deal of direct sunshine. The plants may also be readily transferred from the paper pots into artistic jardinières of almost any sort.

\section{THE OCTOBER CALENDAR}

\section{In-doors}

TRANSPLANT to window-boxes the geranium and other cuttings started last month.

StaRT bulbs for winter flowering: "Chinese lily," crocus, daffodil, freesia, hyacinth, jonquil, narcissus.

TranSPLant to window-boxes before frosts kill them the annuals in pots out of doors: China Aster, Drummond Phlox, French Marigold. Remove the pots, planting directly in the soil. 


\section{Out-doors}

LIFT summer flowering bulbs-dahlia, canna, gladiolus, and tuberose-and store them in the cellar.

PLANT before the middle of the month, if possible, all spring flowering bulbs; the earlier the better.

HARvest all vegetable crops except parsnip and salsify.

Clean up the garden, burning all weeds and rubbish.

TRANSPLANT young cabbage plants to cold-frame, also all half-hardy perennials.

MAKE thick straw mats or some other covering for the cold-frames; alsc an outer protective covering of boards.

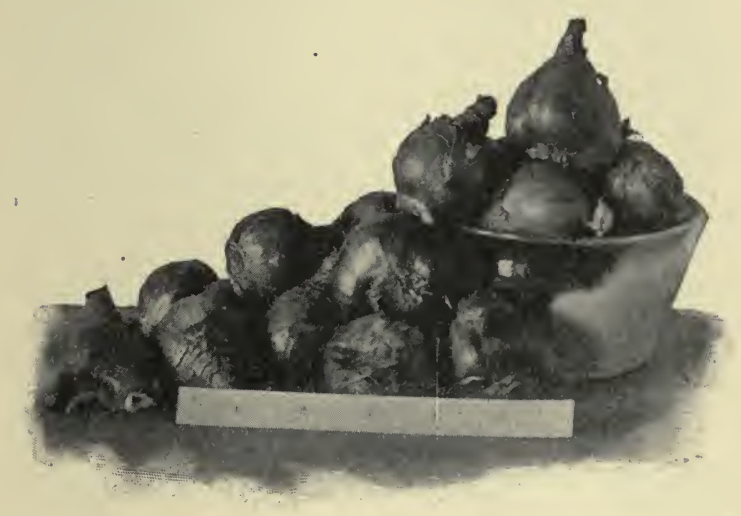





\section{NOVEMBER}

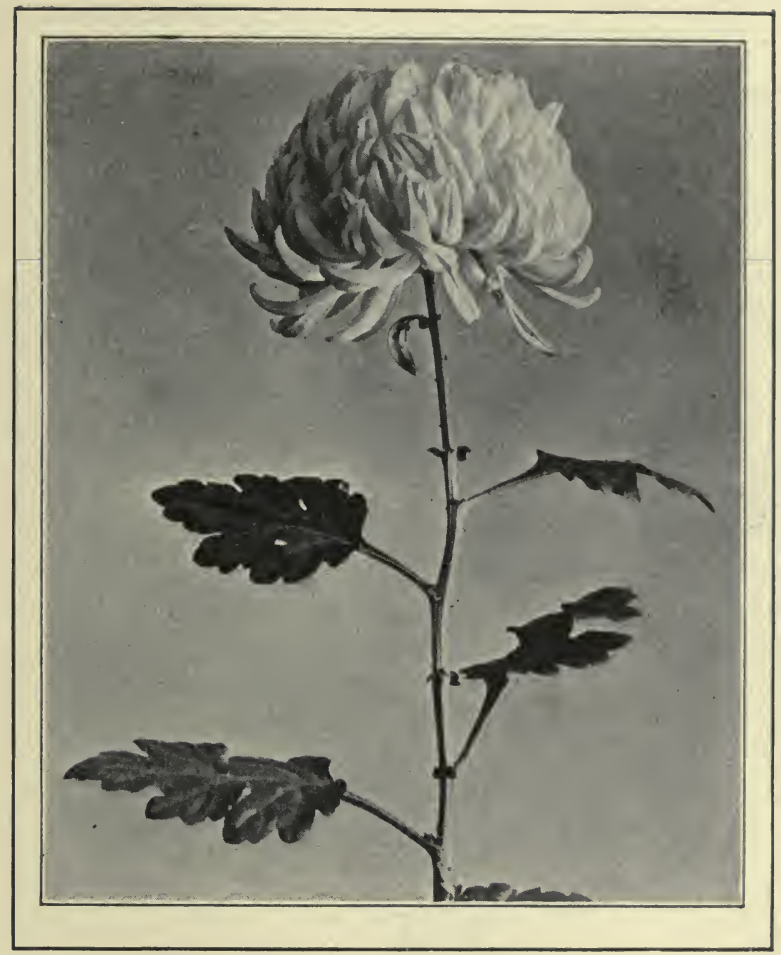

Chrysanthemum Flower

"In the second month the peach tree blooms, but not till the ninth the chrysanthemum. So each must wait till his own turn comes."-JaPANESE PROVERB. 


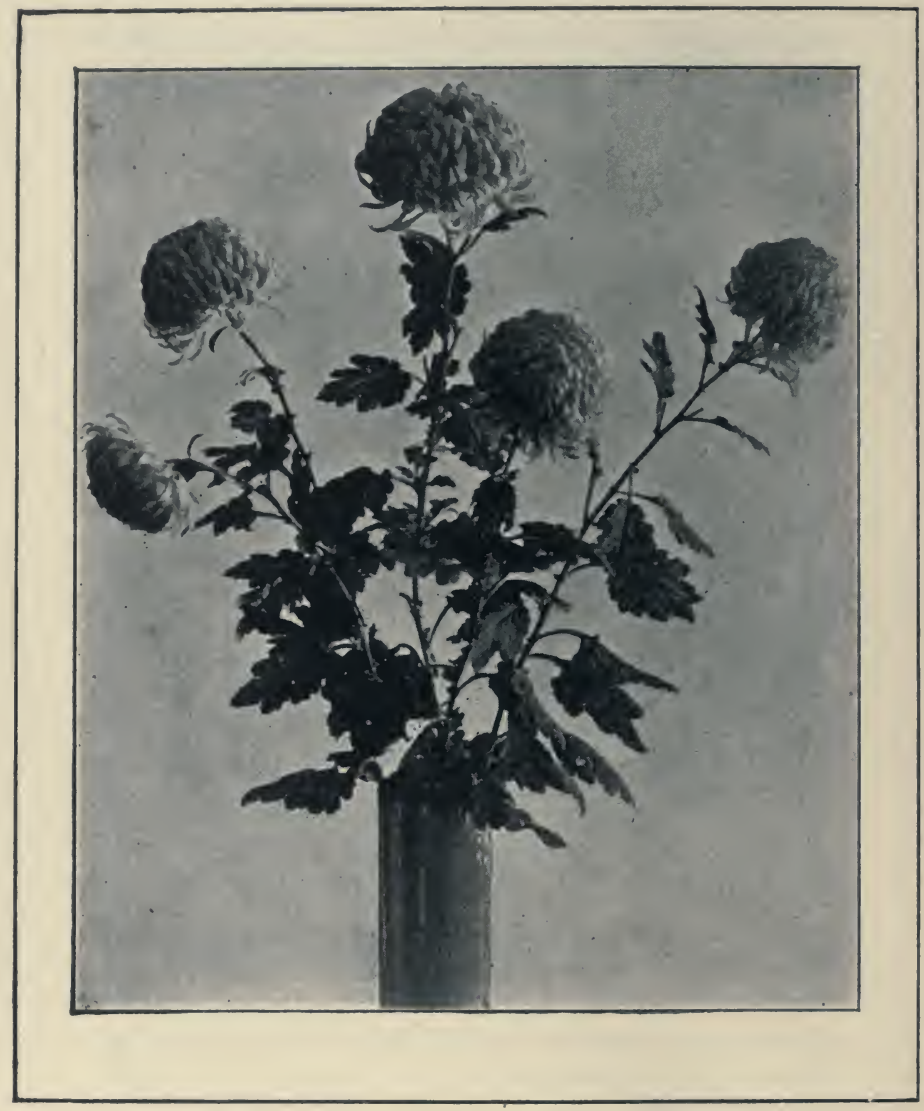

Chrysanthemums in a Japanese Cylinder Jar. 


\section{III}

\section{NOVEMBER}

\section{THE CHRYSANTHEMUM}

The chrysanthemum is the crowning glory of the year. The Japanese rightly regard it as the finest flower of all the wildings that man has developed to perfection. Two thousand years ago Confucius wrote of the flower, and during centuries the Chinese, and later the Japanese, worked to improve by selection the little, yellow, single, daisy-like flower from which the royal race has sprung. Even now some seeds from any of the finest double chrysanthemums will produce plants with flowers similar in form and color to the original wild plant, which still thrives in fields of eastern Asia. It is the chosen flower of Japan, appearing in the national coatof-arms and constantly in decorations. The most popular festival of the year for the Sunrise Kingdom is Chrysanthemum Day.

The plant was introduced into Europe over a century ago, and for eighty years gardeners there have been multiplying varieties from selected seedlings. In America to-day many gardeners count their 'mums, as they affectionately call these flowers, among their chief delights. Florists grow the blossoms by the thousand under glass, usually pruning off all branches and buds'so that each plant may produce one consummate flower for sale in November. The chrysanthemum exhibitions of the large horticultural societies are the closing 
displays of the season, attracting throngs, and showing not only wonderful cut flowers but also magnificent exhibition plants, whose many blossoms are trained into brilliant hemispherical masses of glorious blusm.

The Queen of Autumn is produced in a bewildering variety of forms and shades. As in the case of the dahlia, these are classified under several sections. Incurved chrysanthemums were the popular form years ago, like the Show Dahlia, which they somewhat resemble in their formal character. Their blossoms are regular in structure, the smooth, round-tipped petals curving inward over the flower centre to form a perfect globe. Reflexed chrysanthemums secure the same globular form in just the reverse way, their flatter petals lying smoothly back from the centre and completing their sphere by meeting about the stem.

The Japanese class of chrysanthemums, the modern favorite, departs from all regularity of petal or flower form, and appears in a marvellous variety of transformations. It recalls the Cactus Dahlia in its decorative qualities, but admits a far wider list of flower shapes. The Japanese Incurved section is an intermediate class, with incurved petals, yet loose and free in character. Then there are Pompon Chrysanthemums, just as there are Pompon Dahlias. Many of these are hardy, and some have the merest buttons of flowers arranged in attractive sprays.

Single chrysanthemums are grown, also, even as single dahlias are, and they possess an airy grace and simplicity that give them high value for interior decoration. The Anemone section is an odd intermediate type, with ranks of ray florets surrounding a disk cushioned with short quilled florets. In all these classes there are endless variations of 
tint and shade, both pure and combined, within the range of yellows, reds, and pure white.

The chrysanthemum should be grown at cottage homes as well as in conservatories and greenhouses. Here and there one sees windows bright with the bloom of home-grown chrysanthemums, when November skies are cold and dull. It is quite possible for children to meet success in its culture. Before school gardens were adopted in America, this plant was grown by children at the Eliot School, in Natick, Massachusetts. One June, every child from six to sixteen was given an eight-inch pot, a little chrysanthemum in a three-inch pot, and a sheet of directions for its culture, through the generosity of gardeners on near estates. In November an exhibition was held in the school hall, which not only paid all expenses for pots, prizes, and the like, but yielded a generous balance for decorating the school-rooms. While various accidents had destroyed some plants, there were many that deserved exhibition, and expert gardeners from Boston were delighted by the single blooms and the specimen plants grown by some children. The magnificent plants sent in by the neighboring estates made the exhibition worthy the patronage it received and a real education in horticultural art. While this plan worked successfully for a series of years in this country village, it is evident that it is well adapted to city conditions, where so many children can have no other garden than a potted plant.

Some of the Pompon Chrysanthemums are hardy and should be grown in every garden of perennials. When other flowers are cut down by frost these bloom cheerily on amid the early snows of November. Since the chrysanthemum is readily grown from cuttings, and because it produces many 
underground offshoots with roots in autumn, it is readily propagated. One school secured a division of a little yellow Pompon Chrysanthemum in spring. The following year it yielded a dozen plants. Late that fall the dozen clumps were carefully divided and cut into some three hundred rooted sections. These were closely set in rows within a cold-frame, that the frost might not turn the little divisions out of the soil. The second spring these all touched their glass cover with vigorous foliage by the end of April. They were all slipped, and the sturdy, branching, well-rooted plants were distributed as gifts, prizes, or sales to all the other city schools and to many home gardens. Moreover, the home school had the three hundred plants left in the form of healthyslips.

Since then the plants have multiplied in like manner yearly, while dozens of other varieties-red, pink, yellow, bronze, and white in all gradations, widely different in size and in character of petals-have been added to the collection. This flower should round out the season in every school-yard garden, outlasting even the calendulas and other hardy annuals.

\section{AUTUMN PERENNIAL FLOWERS}

The best perennial flowering plants for young gardencrs should be perfectly hardy, surviving the severest winters without special care. The best hardy plants for school gardens should flower while schools are in session, and should be easy to propagate that they may be distributed freely to home gardens. Most of the tall-growing perennials which flower in the late summer and autumn meet all these conditions. The best include several hardy sunflowers, the heleniums, boltonias, and asters. 
These perennials range in height from three to twelve feet, and are especially adapted to form clumps at the rear of a broad border bed, or for planting among shrubbery. They form banks of green that cover the ground in early May, while from June until autumn they present backgrounds of graceful foliage. From August until October one sort follows another in showing masses of bright bloom, so generously resplendent as to attract attention from all.

One of the earliest of this class is the false dragon's head, or physostegia, whose beautiful spikes of rosy lilac flowers rise to a height of four feet. It blooms in August, but often lasts until school opens. While the square stems are not very stout, its early and attractive flowers make it desirable. The color is unusual among tall perennials. The flowers are delicate in form and color detail, so the spikes have value as cut flowers. It multiplies rapidly, yet not so widely as to be troublesome like golden glow, one of this group of perennials which flowers early.

The Orange Sunflower (Heliopsis Pitcheriana) is neither very graceful nor are the flowers of marked beauty, but it has the merit of free blooming from early summer until late fall. It is very hardy and multiplies readily by self-sown seedlings which flower the first season. A clump in the mid-border gives an early touch of autumn gold; moreover, the long stems to the flowers, their firm resistance to wilting, and the persistent freedom of bloom give a certain value for cut flowers. It is a flower for a beginner to experiment with, and is always worthy of a modest place in a large garden of perennials.

The first hardy helianthus to bloom is the Prairie Sunflower (Helianthus rigidus). It gives a gay bank of color in 
August. It thrives alike in half shade and in full sunshine, persists on dry, barren soils, and gayly welcomes pupils back, even though the school garden has been neglected during the summer. While so vigorous and persistently hardy as to be weedy, its widespread shoots are easily recognized in early spring when appearing near other plants. They can be dug up readily with a trowel, and because roots form just where the underground stem upturns to the light these divisions can be easily distributed to many home gardens. No skill is requisite to insure their survival when transplanted; they will endure the hardest usage. They wilt too easily to be of value as cut flowers, however; their place is in the border.

In September the Graceful Sunflower (Helianthus orgyalis) crowns its spreading clump of lofty foliage with loose panicles of single yellow flowers that possess the finest beauty of the entire family. The tough stems rise to a height of eight or even twelve feet, clothed closely with long, wavy, drooping leaves, and both stalks and leaves bend and sway in the breezes above lawn or garden plot so gracefully as to please every eye. Although the clumps do not divide of themselves through decay of the main stalk, as is the case with most other members of this group, if the separate shoots that rise in the spring are cut several inches below the soil surface, and replanted, they form roots readily, so the plant is easily multiplied. Its height and the grace of all its parts give this sunflower marked merit.

There are other hardy sunflowers of value, second only to these two. The Dahlia Sunflower (Helianthus multiflorus, $f$. pl.) is a fully double form of flower which closely resembles a yellow Show Dahlia. It has a longer season of bloom than most sunflowers, and is used to supply cut flowers. 
Each plant forms a dense mass of new shoots for division, but as it is not surely hardy, one clump should be taken into a greenhouse or the cellar and kept alive with sufficient moisture until spring. The October Sunflower (Helianthus maximiliana) forms a sturdy four-foot clump of pleasing foliage, and has the merit of blooming with the chrysanthemum. A few short-stemmed flowers of rich yellow cluster at every end of its waving stalks, and meet with warm welcome at a time when other plants are yielding to frosts and dying down.

The Tall Sneezewort (Helenium autumnale superbum) gives a great mass of bloom in September. The separate flowers, peculiar in the drooping attitude of their bright yellow rays, are borne in broad-spreading panicles at the top of each stout stalk. A closely related variety of like habit (Helenium grandicephalum striatum) has petals streaked with red. In the spring a ring of eight or a dozen budding tufts of leaves rises closely about every old decayed stalk. Thus the plant is the opposite of weedy in habit, yet is most readily divided, since nature performs this task skilfully herself. It often scatters self-sown seedlings about the garden also, which are easily disposed of with the hoe, or which may readily be transplanted to the home gardens of the children. It is characteristic of several of these plants that after appearing in one home garden of a community, in a few years they may be noted forming strong masses of color in the yards of many neighboring homes.

When school opens the boltonia or false chamomile also spreads its broad masses of daisy-like flowers, surmounting every stalk, Like the heleniums, it gives crowded clumps of new shoots every spring, and is divided and multiplied 
with extreme ease, yet is not weedy. One variety (Boltonia asteroides) bears white flowers, a pleasing change from the yellow hues of other tall perennials. This is the taller, stouter variety, although it needs some support where ex-

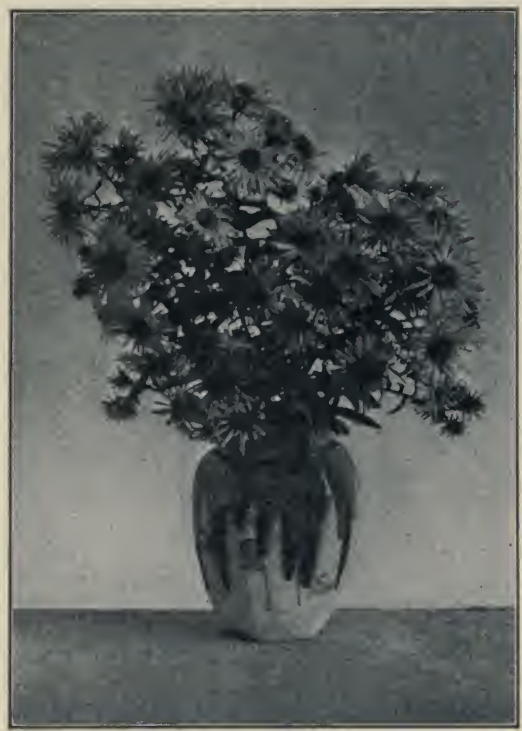

New England Asters in a Japanese Flower-jar. posed to strong winds. The general effect of the growing leafy stalks when newly planted is pleasing a s a back-ground throughout the summer, and the variety is widely and freely used by landscape gardeners for mass effects in the border. The pink variety (Boltonia latisquama), which has a lilac tinge, is of weaker growth, and is only used because the color of the flowers makes it desirable. Neither is valuable as affording cut flowers, for the blossoms are difficult to preserve in form and -freshness when removed from the plants.

The asters round out the season. Few varieties grow to more than medium height, but otherwise they are rightly classed in this group of perennials. . They are in general very hardy, and are easily multiplied by division. One of the best sorts is the Snowflake Aster, which is so clothed with small white flowers in late September as to suggest a bank of feathery snowflakes. Planted in masses or singly it at- 
tracts attention and gives delight. Other varieties, the best native sorts and new hybrids, have larger flowers, varying from white to lilac, violet, and light blue in color. Most are but two or three feet "in height, but the New England Aster, in its variously colored varieties, attains a height of four feet, and well deserves place in the back of the border. It would be interesting to transplant clumps of the various asters native to any school district or its vicinity to the school garden, and there study the effect upon them of a rich soil and regular culture. The first school garden in America, that at the George Putnam School in Boston, was very successful in this work with wild plants.

Most of the tall perennials may be grown from seed without difficulty, with the exception of special varieties of asters. The seed should be started in a cold-frame, or be protected by a board placed on pegs above the furrow until germination has taken place. If started early, several sorts will give bloom the first season. Since these plants multiply so rapidly by division, however, and thrive best when the clumps are divided every year or two, they can readily be obtained for a school or home garden from neighbors who have established them in their own gardens. Thereby the school receives plants from homes already interested in gardening, then distributes their product to other homes of its district.

\section{PLANTING DAFFODILS IN-DOORS}

The spring flowering bulbs are so easy of cultivation, so interesting to handle, require so little window room, and yield such varied types of beauty that one might depend entirely upon them for the winter display of flowers. In the 
great group which is generally included in the genus narcissus there is available a wonderful array of flowers which will easily grow in-doors: the daffodils, the jonquils, the star-flower or chalice-flower, and the Paper-white Narcissus are the more important types of these. The bulbs of good varieties of all these flowers may be obtained of the florists

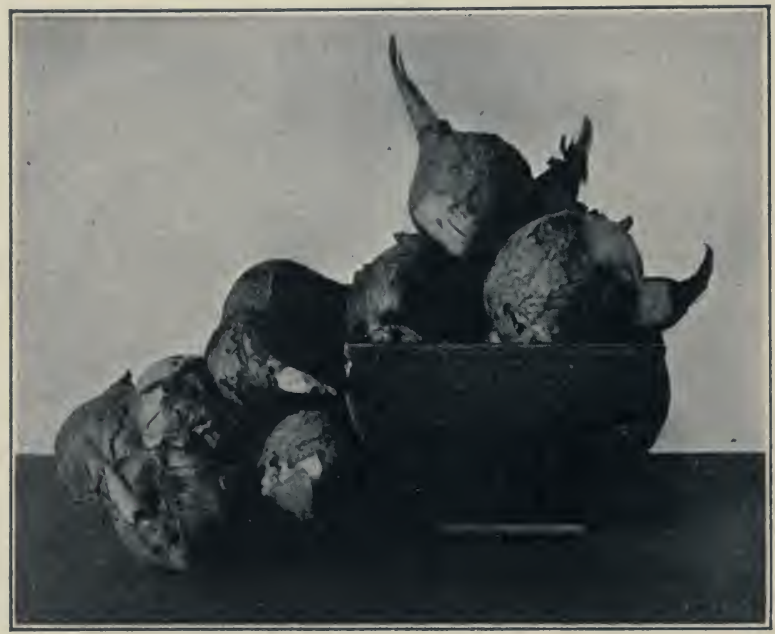

Twelve Bulbs of Chinese Lily Narcissus.

early in the autumn at comparatively little expense. As a rule, they may be bought much more cheaply by the hundred than by the dozen, so it may be worth while to form a club of your friends to take advantage of this fact.

When the bulbs arrive they should either be planted at once or stored in a cool, damp cellar where they will not dry out. They may be planted in almost any kind of receptacle, although for school garden purposes nothing is so satisfactory as the paper flower-pots. In the case of most bulbs, one may 
be planted in a three-inch pot or three or more in a four-inch pot. In planting it is only necessary to use good garden soil, placing a bit of broken pottery over the hole in the bottom of the pot. The bulb should be just buried and the earth around it packed firmly in place that it may not be pressed up as the roots develop. Water thoroughly and set away in a cool basement where the temperature will be low and equable, though not freezing. Sometimes it is desirable to throw over the pots

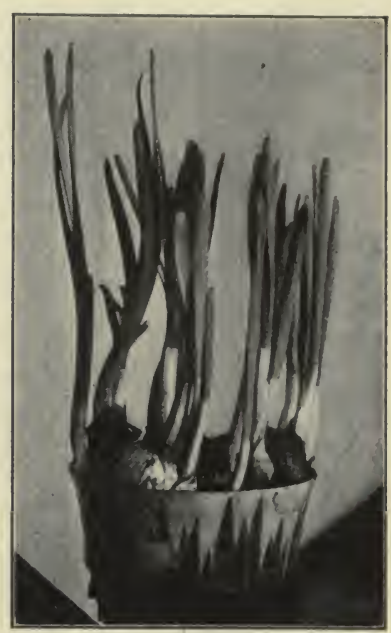

Water Culture of Chincse Liiics.

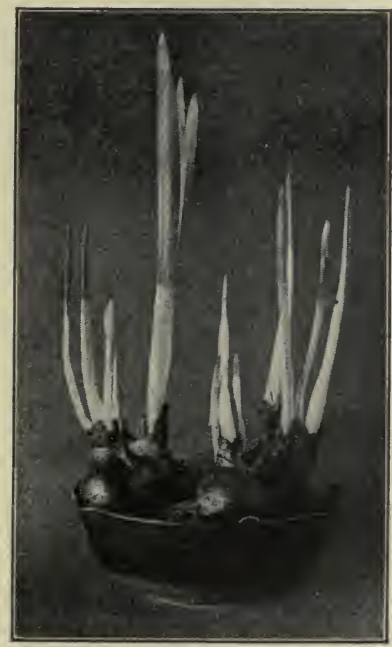

Water Culture of Paper-white Narcissus.

two or three thicknesses of burlap or old carpet to prevent the evaporation of moisture. Water occasionally as may be necessary to keep the soil moist, but otherwise leave undisturbed for six or eight weeks.

The purpose of putting these bulbs away in a dark, cool place is to enable them to develop such a growth of roots as would occur were the bulbs beneath the soil out-doors. Under the latter conditions a large root growth would have taken place in autumn, so that the plant would be 
able to send up its leaves and blossoms in spring very soon after the frost is out of the ground. In the in-door garden we attempt to imitate these conditions just as nearly as possible; consequently the bulbs are to be left in the cellar until such a root growth takes place that it is evident the plant can be forced into blossom successfully. Then is the time to bring the bulbs into the light and heat of the living rooms.

Many of these bulbs may also be brought into blossom successfully in water. Wide shallow jars may be utilized, partially filled with coarse gravel or broken stone and with water added to cover such material. The bulbs of the Paperwhite Narcissus and the so-called Chinese Sacred Lily may be set in such receptacles and placed in a cool, dark room until the roots are well started.

\section{ANNUAL FLOWERS FOR WINDOW-BOXES}

A great deal of satisfaction may be gained by the lover of flowers from growing some of the annual flowering plants in in-door window-boxes. Since one can grow them from seed the cost of starting the plants is very little, and one also has the pleasure of watching them through all the stages of their growth.

It is true, however, that comparatively few annual flowers can be brought into blossom successfully under the conditions of the in-door garden. Of these few the Japanese or Imperial Morning-glory is among the most interesting and beautiful, as well as one of the easiest to grow. As is well known, these are the most attractive of all the morningglories, having been introduced from Japan a few years ago and having become very popular on account of their ease of 
cultivation and their beautiful blossoms. The latter vary greatly in form and color and are among the most gorgeous of garden flowers.

The commonest reason for failure with morning-glories is due to the fact that the outer covering of the seed is very hard. To insure germination a corner of the seed should be notched with a file, that the moisture of the soil may have access to the inside. It is well worth while thus to notch the seed and then to place them between layers of wet blotting-paper. As fast as the seeds become swollen, take them out and plant then.

Another flower which is extremely useful for in-door window-boxes is the Dwarf or French Marigold. These may very easily be grown from seed sown in-doors and may be planted quite thickly in window-boxes, where they will thrive with very little attention and will soon begin to yield an abundant show of attractive blossoms.

In a fairly light room probably no annual will yield more gratifying results in these boxes than sweet peas. For planting in such a situation one should get the earliest varieties, such as are sold by the seedsmen for very early blossoming or for planting in greenhouses. One of the best of these is the Earliest of All, which is a selection of the Extra Early Blanche Ferry. These will come into blossom in about nine weeks, and if the flowers are kept picked will yield an abundance of blossoms for a long period. One can now get from the best seed-houses varieties of sweet peas especially adapted for growing in-doors.

About the only difficulty to contend with in growing annual plants in winter window-gardens is that of the presence of red spiders and aphides, or plant lice-often called 
green flies, which sometimes appear in destructive numbers. A careful watch should be kept for these pests, and as soon as any are seen they should be thoroughly sprayed with some kind of tobacco soap.

\section{THE NOVEMBER CALENDAR}

\section{In-doors}

START more bulbs for winter flowering.

START lily-of-the-valley pips for Christmas flowering.

Sow seeds of French Marigolds and sweet peas for late winter and early spring flowering.

BRING to the light of the school or living room some of the bulbs of Paper-white Narcissus and Roman Hyacinths started in September.

\section{Out-doors}

Clean up yards at home and at school.

Cover spinach sown for spring use with a light mulch.

SPADE up the garden and leave surface rough to let the soil freeze and thaw.

COVER border gardens with coarse litter or leaves held in place by brush or evergreens.

Protect rose bushes and other similar plants by wrapping with straw. 


\section{DECEMBER}

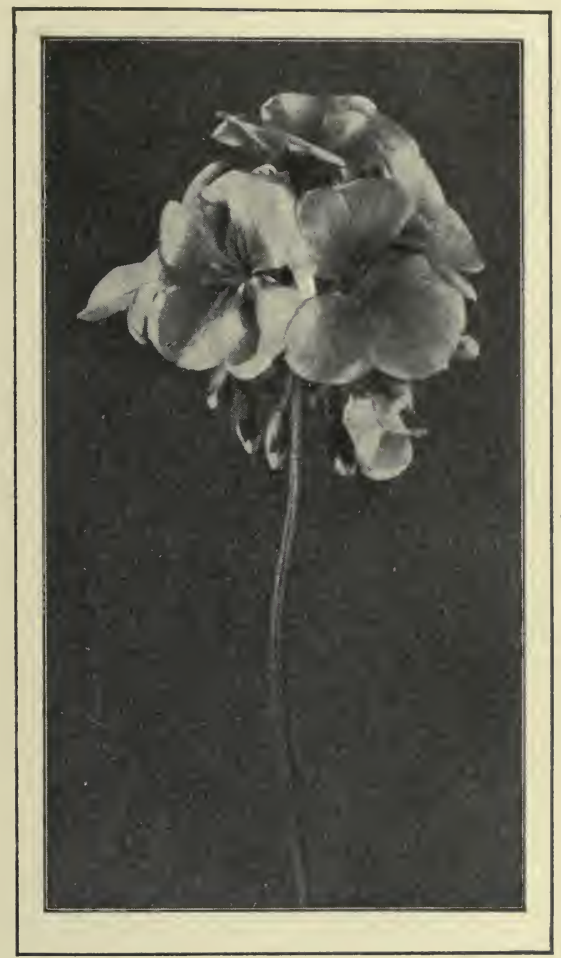

Single Geranium

"Earth's crammed with heaven, And every common bush afire with God; But only he who sees takes off his shoes." 


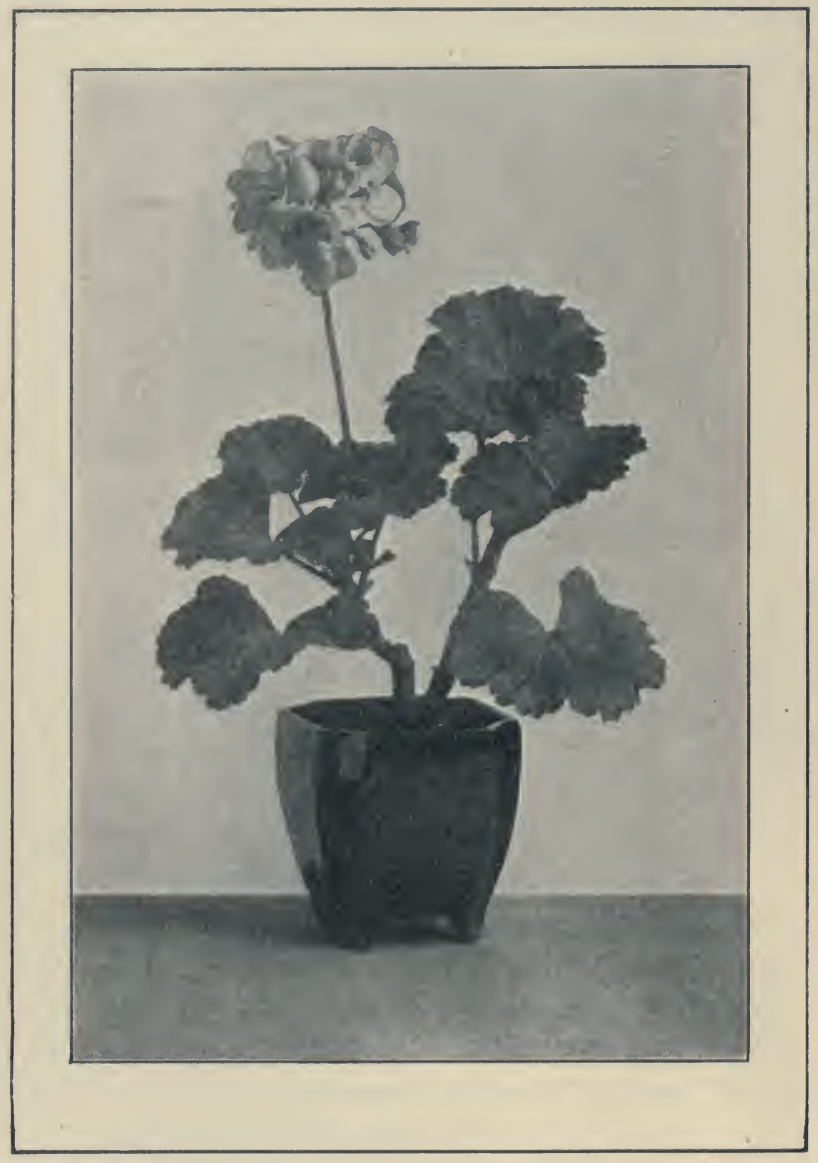

Single Geranium in a Japanese Jardinière. 


\section{DECEMBER}

\section{FLOWERING PLANTS FOR WINDOW GARDENS}

For the beginner at in-door gardening no plant is safer to experiment with than the geranium, the most popular of house plants. Small geraniums recently started from cuttings may be set directly into the soil of the window-box at a distance of about ten inches from one another. Under favorable conditions of heat and light they will grow rapidly, and in order that their growth may be symmetrical the window-box should be turned end for end about once a week. The single or semi-double varieties are really more attractive than the double ones, and it is generally better to include in one box only one color, although if there is a combination of white flowering geraniums with those of another color the result is generally satisfactory. The geraniums will thrive in a window of almost any exposure, although in windows looking south or east they are more likely to blossom freely on account of the abundant sunshine.

One of the most charming and effective groups of plants for in-door use during the winter is that of the primulas or primroses. The forms most generally grown by the florists are varieties of the Chinese Primrose. The plants grow from seeds sown in early spring, the seedling being changed from smaller to larger pots through the summer, so that by autumn they are in five or six inch pots. They come into blossom in early winter and in many cities form a large part 
of the Christmas trade of the florists. They are among the most satisfactory plants for the winter window gardens, especially in northern and eastern exposures where the sunlight is not too intense. They may be transplanted directly

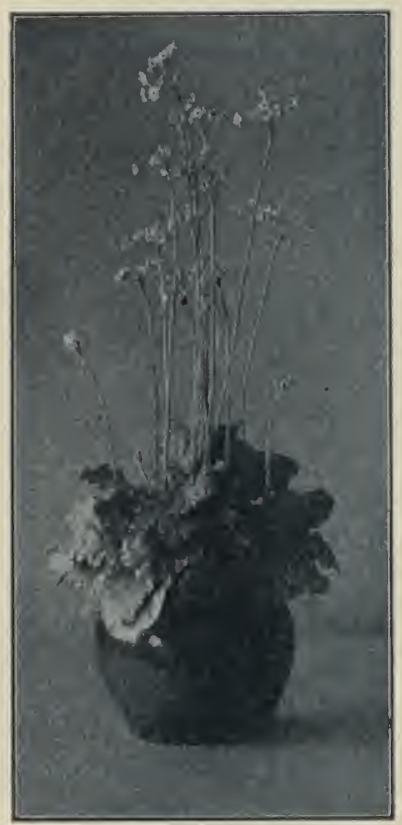

The Baby Primrose. into the soil or they may be left in the pots and the latter set in the soil. In either case each plant should have its crown above the surface of the soil to prevent rotting which happens when water settles around the crown. With good care the plants should blossom through the spring, after which they may as well be thrown away, as old plants generally do not flower as well when used over again as do the new ones.

Some of these Chinese Primroses are single, others double; some are white, others red, and others pink. In general, more attractive results are obtained by not mixing different varieties side by side.

The Baby Primrose is a charming variety which of late has become very popular as a house plant. Its pink flowers are smaller than those of the other primroses, but are much more abundant. They bloom in clusters toward the ends of the long flower-stalks which arise in numbers from the crowns of the plants. The leaves are very attractive, being prettily rounded, with wavy margins and downy whitish hairs over the surface. 
Another primrose which is especially satisfactory as a house plant is the variety called obconica-it seems to have no other common name. It has clusters of good-sized flowers on the ends of long stems and requires less sunlight than many blossoming house plants.

The cyclamens form another group of flowers which are very attractive during the winter on account of their ex-

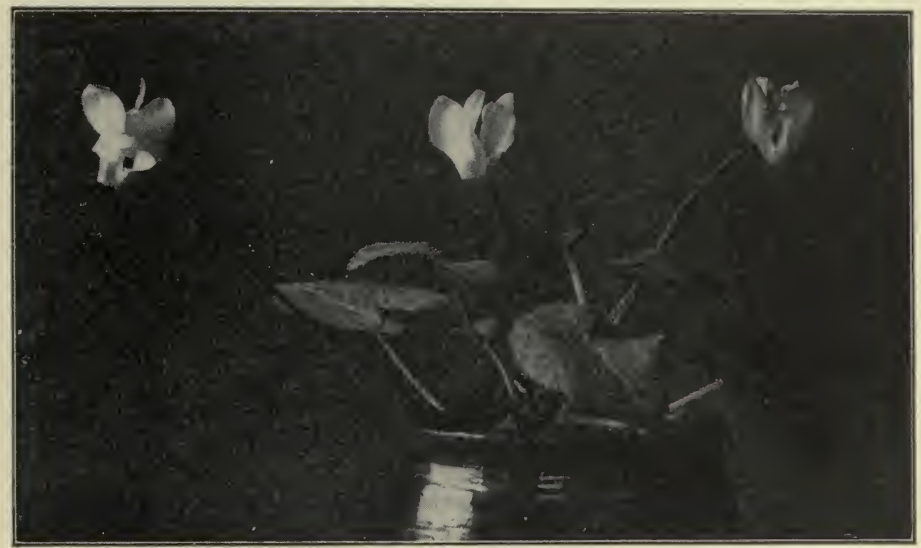

Cyclamen Blossoms.

traordinarily beautiful blossoms. But these plants are much more difficult to keep in a thriving condition in the home or school-room, because they cannot endure a warm temperature. It would be worth while to experiment with one or two plants in the coolest room available.

\section{GROWING LILY-OF-THE-VALLEY IN-DOORS}

One of the most interesting plants that can be grown indoors is the beautiful lily-of-the-valley, which is so attractive out-doors in early summer. Every one knows that these 
flowers are forced into bloom in greenhouses during the winter months, but not every one is aware that it is easy and practicable to get very satisfactory results by forcing them in the school-room or in the home. If there is available a warm closet near a stove, furnace or heated chimney in which a

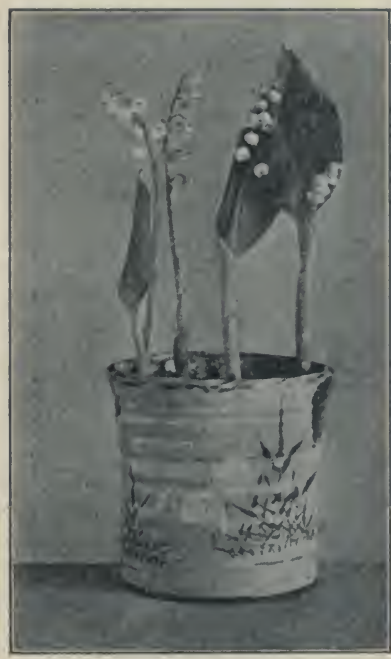

Lilies-of-the-Valley in Japanese Flower-jar. uniform temperature of about $75^{\circ}$ Fahrenheit can be maintained for three or four weeks one can easily bring these plants into blossom.

The pips or roots of the lilyof-the-valley are kept by the great plant-supply houses in cold storage so that they may be purchased at any season of the year. They cost at wholesale about one dollar and a half per hundred. Many of these are retarded plants, that is, crowns in which the normal period of blossoming has long since passed, so that it is possible to force them into blossom in a very short time. As soon as the pips arrive, trim off about one-third of the length of the roots with sharp scissors, then plant them in garden soil or sand, or even sphagnum moss, in a box of some sort, water them thoroughly, and place away in the warm closet where a temperature of $75^{\circ}$ or $80^{\circ}$ will be maintained. In city schoolhouses such a closet can generally be found somewhere in the basement near the boilers. If the room is dark it will be better to bring the plants up during the daytime after they have been in the closet about two weeks, returning them each 
night. Even better results may be expected if the roots can be kept at a temperature of about $75^{\circ}$ and the tops be exposed to a much cooler atmosphere.

In about three weeks the leaves and blossoms will be shooting up, and the plants may be kept in a well-lighted room to complete their development. They may readily be transplanted into flower-jars or window-boxes and will prove of great interest to all who grow them. Every one should remember that the leaves, stems, and flowers of the lily-of-thevalley contain an active poison, so that they should never be put into the mouth.

\section{THE SELECTION OF SEED}

The importance of the careful selection of the seed from which crops are grown is becoming better understood every year. This is true of all plants which man cultivates by sowing seeds. Careful selection of seed has recently almost revolutionized the agriculture of the Central and Western States, where the corn crops have been enormously increased in this way, while special varieties have been produced whose kernels are rich in the oil, the starch, or the other constituents needed for special uses. It has caused great improvements in vegetables, both those grown out-doors and under glass, and it is responsible for a large part of the improvement in the habits of the ornamental flowering plants, and in the size, form, and color of their blossoms.

The improvement of plants is largely a matter of intelligent selection on the part of the gardener. When the plant is given a large food supply it is likely to exhibit variations, the selection of which leads to new varieties. When a plant is brought into new conditions of life, as when seed from one 
locality is introduced into another, variations are also likely to appear. There is an inherent tendency in all plants to vary, and the new varieties which are listed every year in the plant catalogues are chiefly the result of the careful selection, by hosts of gardeners throughout the world, of those variations which seem likely to prove most useful or attractive to mankind.

While plants tend to vary, by repeatedly selecting seed from those that attain a desired standard, they may also be trained to come true to a type from the seed. The varieties thus established are simply mile-stones of progress. The best variety of a given plant this year may be succeeded by a better one next year, and that in turn by one still better the following year. So it is that the novelties of the seed catalogues ought at least to represent the latest progress in horticultural art.

An excellent example of what may be accomplished in the improvement of flowers in a comparatively few years is found in the history of the sweet pea. Thirty or forty years ago the modern, improved varieties of this flower did not exist. In America the principal sort was the Painted Lady, growing here and there in old-fashioned gardens, and perhaps four or five other varieties not well established. In England a similar condition existed. Then there came to the help of the plant a patient gardener, named Henry Eckford, who lived in Shropshire, England. He began the cultivation of the existing varieties with a view to their improvement, and to his long patience we are chiefly indebted for the increased attractiveness of these blossoms.

"When I first took up the sweet pea," he wrote, "there were six or eight distinct varieties in cultivation, and experts 
in the art, as far as I could learn, had come to the conclusion that it could not be further improved, and in the first two or three generations of the work it seemed a fair conclusion. But I had been for many years working on the improvement of various flowers, which work had proved so eminently successful that a first rebuff did not deter me from further attempts."

For more than twenty years Mr. Eckford has been devoting attention to the sweet pea, and a large part of the best varieties to-day originated with him. Thanks to our modern methods of seed distribution, as fast as a new type of flower has become fairly well fixed it has been available for gardeners everywhere, and herein is the advantage derived by the gardener who studies carefully the announcements of novelties in the seed catalogues. It is more or less fashionable to deride these novelties and to say they are not worth the high prices charged for them. Doubtless this is frequently true, but it will not prevent an intelligent gardener from taking advantage of such of them as seem most desirable for his conditions. The improvements in gardening come through these very novelties, and we ought to be thankful to pay a few cents more for seed grown for us by Henry Eckford or Luther Burbank-seed which represents not only the labor of growing but also the special care and intelligence exercised during many years in order to create a new type of flower.

Perhaps the most beautiful of all the varying forms of poppies are the Shirley Poppies. The plants are not very large, and have slender, graceful stems and leaves. The flower buds are enclosed in two large sepals that fall off as the petals unfold, revealing the light-colored stamens sur- 
rounding the broad pistil in the middle. It is an interesting fact that all of the Shirley Poppies have descended from a single plant found by a clergyman, Rev. W. Wilks, in his garden in Shirley, England. The story of their origin has been told by Mr. Wilks in these words:

"In 1880 , I noticed in a west corner of my garden, abutting on the fields, a plant of the common wild field poppy, one solitary flower of which had a very narrow edge of white. This one flower I marked and saved the seed of it alone. Next year, out of two hundred plants, I had four or five on which all the flowers were edged. The best of these were marked and the seed saved, and so on for several years; the flowers all the while getting a larger infusion of white to tone down the red until they arrived at pale pink, and one plant absolutely white. I then set myself to change the black centre portions of the flowers from black to yellow or white, and have succeeded at lasst in fixing a strain with petals varying in tint from brightest scarlet to pure white, with all shades of pink between and all varieties of flakes and edged flowers also, but all having yellow or white stamens, anthers and pollen and a white base."

It is also true that a large proportion of the new varieties of plants are obtained by crossing or hybridizing, that is, by transferring the pollen from the stamen of one kind of flower to the stigma of another kind. In these cases, however, this process of hybridizing is designed to induce variation toward some desired type and is simply preliminary to a great deal of selection requisite to attain and then establish the new type. Only a very small proportion of the plants that are produced by such hybridizing prove worthy of cultivation. And the man who practices the art must throw 
out all seedlings until he finds one especially promising to be saved.

It is well worth while for every young gardener to do at least a little of this selection of seed, for it will add greatly to the interest of his garden work, and will enable him to grow better crops of flowers or vegetables. All that is necessary is to keep watch for the finest and largest of the earliest blossoms or fruits. Then mark them in some way, as by tying a string around the stem, and save the seed to sow another season.

\section{GROWING NAMED VARIETIES}

There are many reasons why it is worth while to grow named varieties of the flowering plants. In the first place, our enjoyment of any subject depends very largely upon the knowledge we have of it. The person to whom "a primrose by the river's brim" is but a yellow primrose like thousands of others, cannot appreciate the beauty of the blossom as can the one whose eye has been trained to see the distinctive characteristics of different species, or even of different plants of the same species. In the same way, the florist to whom an aster is but an aster or a sweet pea but a sweet pea, cannot get the enjoyment from growing these flowers that the one gets who knows by name the varieties of each, and can tell at a glance whether a given specimen is typical of its variety or not. When you go into a street-car crowded with strangers whose names you do not know, your sensations are different from those you have when you go into a similar car filled with friends and acquaintances. So when you go into a garden your delight is always greater when you can call by name a large proportion of its occupants. 
On general principles, also, the seed of named varieties of flowers is likely to have been more carefully selected than the cheaper mixed seed. To keep a variety true to name requires eternal-vigilance on the part of the seed grower and the constant elimination of plants that do not approach the grower's ideal of the variety type.

\section{ROMAN HYACINTHS}

Few spring flowering bulbs are so easy to force into blossom in time for the Christmas holidays as are the Roman Hyacinths. They may be planted in almost any sort of receptacle and crowded together more thickly than most other bulbs, and still yield an abundant supply of beautiful blossoms. Several of the bulbs may be placed in a three-inch or four-inch paper flower-pot, or a great many may be grown in a large shallow box or dish. They need be left in the cool basement only three or four weeks before bringing them to a warmer lighted room.

The beautiful flowers are borne on pedicels along a central stalk. They have a sweet and pleasant perfume and they serve admirably as models for drawing with a lead-pencil. The bulbs are so inexpensive that every school which attempts to do anything with winter flowers should grow an abundance of them.

\section{THE DECEMBER CALENDAR}

BRING from the basement more of the spring flowering bulbs that show a good root development.

BRING to the light of the room the lilies-of-the-valley after they have been in a warm closet about two weeks. 
START a window-box with flowering plants from the florist's. Try primroses, getting enough to make a good showing. Sink the pots in the soil without removing the plants, if so desired. Do not cover the crowns.

KEEP WATCH of all plants for aphides or green-flies. As soon as any are seen, spray with sulpho-tobacco soap solution.

PLANT a root of beet, carrot, radish, salsify, or other root-crop in a window-box to develop into flower and seed. Try a cabbage stock also, having cut the head from around it.

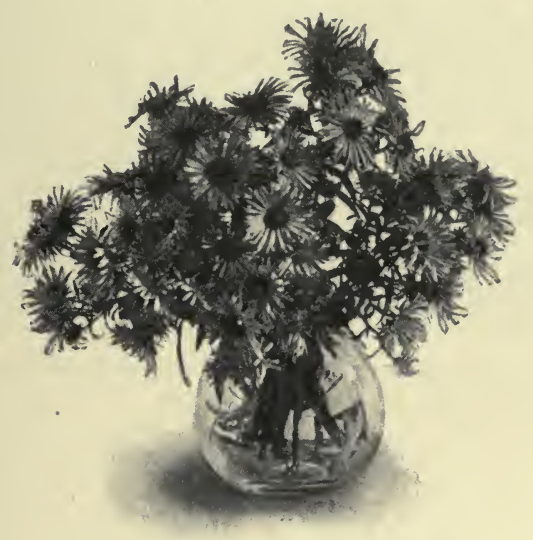





\section{JANUARY}

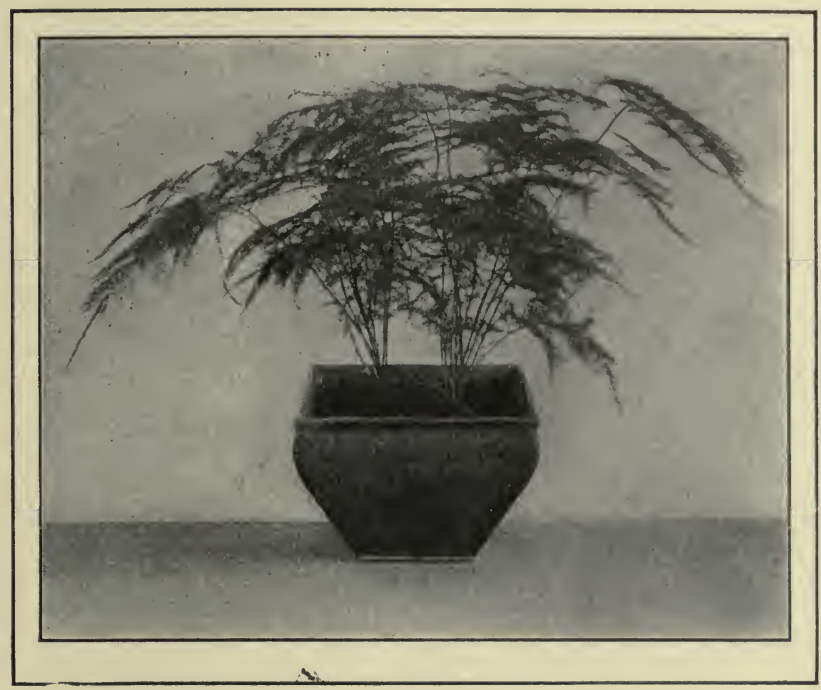

Plumose Asparagus.

Hours fly,

Flowers die,

New days,

New ways,

Pass by;

Love stays.

-Inscription on a Sundial. 


\section{V \\ JANUARY}

\section{ATTRACTIVE FOLIAGE PLANTS}

One who inten ‘s to get the most satisfaction from growing plants in-doors cannot afford to neglect the many foliage plants which are now available. In their beauty and grace some of these appeal to us with as much force as the more striking flowering plants, while on account of their ease of culture and the fact that they need but little direct sunlight, they fill a place that cannot be filled so well by any other group of plants.

Most of the desirable foliage plants may be purchased when small for a few cents. Some of the commoner sorts will be found at the local florist's and can be best purchased there, but many of the varieties must be ordered from the catalogues of the great seed houses, and it is well worth while to try a few of these in order to develop the interest that is always found in growing new things. Study the plant catalogues and the illustrations and select a few of the things which seem most likely to please you and to be best adapted to your conditions.

Some of the best foliage plants may be grown from seed, and wherever possible this is much the most satisfactory way. For the interest in a plant which one has grown from the seed is greater than in one bought from the florist. You remember how Hawthorne described his garden in "Mosses from an Old Manse," and adds: "I used to visit and revisit 
it a dozen times a day, and stand in deep contemplation over my vegetable progeny with a love that nobody could share or conceive of who had never taken part in the process of creation."

To the real gardener the chief delight comes from watching things grow rather than from the results. Like the tourist in Stevenson's song, it is the journey and not the end of the journey that is worth the while. If one is looking always for a certain result one might use the artificial paper flowers and palms and ferns, which require no care whatever, but which are, of all the false things in the world, perhaps the most intolerable.

"The natural course," wrote Forbes Watson many years ago in his classic book on "Flowers and Gardens," "is for people to delight in loving and cherishing plants from earliest youth and to trace their slow progress into age. Nothing can be more pleasurable than this. At the beginning of the season we see the green tips of the snowdrop and crocuses, then those of the daffodils appear, then some fine morning unexpectedly as we enter the garden a golden aconite has lifted its face from a cluster of buds, still downward, and given us cheerful greeting; coming, perhaps, just where we had least expected it, from some bed where we had forgotten that it grew."

For starting the seeds of the foliage plants one may use the ordinary window-boxes, and very often one can utilize a part of a box in which other things are growing. Perhaps no plant is better worth trying than the beautiful fine-leaved asparagus, called by the rather formidable name Asparagus plumosus namus. This is one of the most beautiful of all foliage plants as well as one of the easiest to grow. It starts 
readily from seeds, which are very similar to those of the asparagus in our gardens. The seeds may be planted about a quarter of an inch deep and one inch apart, and, after they are well started, the seedlings may be transplanted into small pots or directly into window-boxes. This plant is often called the asparagus fern, but it is not a fern at all, but a true asparagus and is closely related to the common garden vegetable.

The plant called Asparagus sprengeri is much less attractive than the plumosus form. Its leaves are larger and its general effect coarser. But it gives an attractive mass of greenery and is easy to grow. It may be raised from seed, and is particularly desirable for use in hanging baskets.

Another plant which may be grown from seed is the silk oak, often called grevillea, and known technically as Grevillea robusta. This is an extremely attractive foliage plant. The

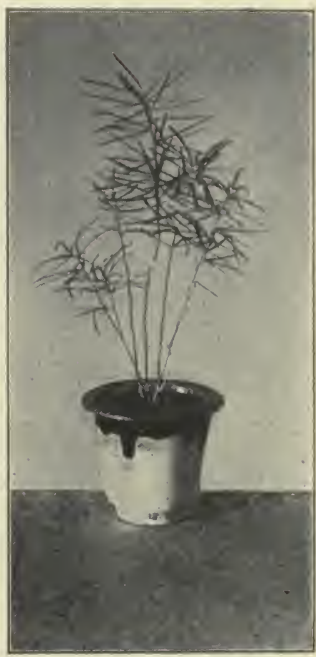

Seedling Asparagus Sprengeri. seed should be sown in February or March, and the young seedlings transplanted into small pots when they have attained a height of about three inches. With the most ordinary care the seedlings will grow rapidly and should be shifted into larger pots as their increase of roots necessitates. By the following autumn they will be of good size and form very attractive foliage plants.

A group of plants which during recent years have come to be very largely grown as specimen plants for halls and living 
rooms is that of the Araucarias. These are really small, coniferous trees, having the general effect of an out-door evergreen with richly colored, spiny foliage that gives them a decided attractiveness. The species most commonly grown is Araucaria excelsa, which the English gardeners call the Norfolk island pine. The foliage of this is a dark, rich,

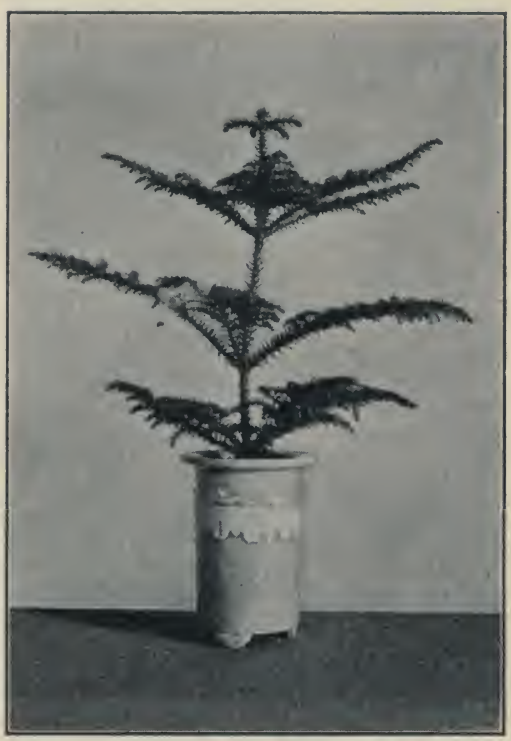

Norfolk Island Pine in a Japanese Jardinière. yellow green color, and the manner of growth is very symmetrical. Another variety, even more attractive, is the Araucaria bidwelli, while several other sorts are offered in the catalogues. All of these are rather easy to grow, and the commoner kinds, if purchased when small, are inexpensive. Care should be taken not to transfer them too rapidly to larger pots, nor to water them too much.

No discussion of foliage plants would be at all adequate which did not include some mention of the Rex Begonias. These are probably, next to the geraniums, the most universally grown of house plants. They have been developed through many years of culture into an extraordinary variety of forms and colorings. Many of them show color combinations of wonderful beauty. Begonias in general are divided into three great groups, namely, the Tuber- 
ous-rooted Begonias, the Fibrous-rooted Begonias, and the Rex Begonias. The Tuberous-rooted Begonias have recently become very popular as bedding plants for out-door gardens, their waxy flowers showing extreme brilliance in coloring. They are most commonly propagated from seed. The Fibrous-rooted Begonias are the flowering kinds generally grown for winter blossoming as well as for the summer garden out-doors.

The Rex Begonias may be propagated either from seed or from leaf cuttings. The seed is sown on the soil surface in shallow boxes in February or March, de-

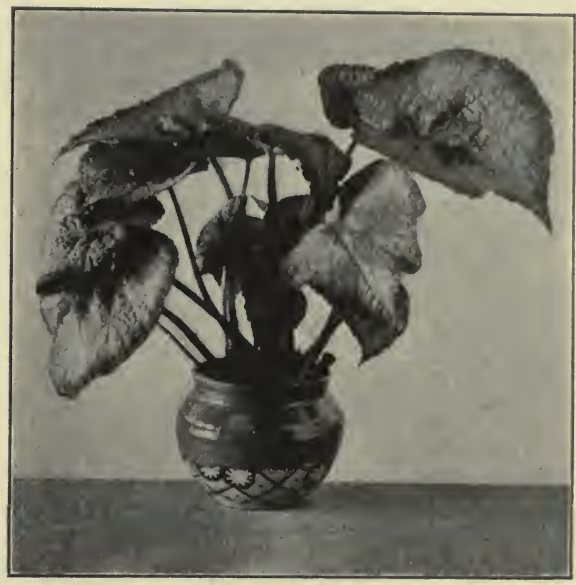

Rex Begonia in a Japanese Flower-jar.

veloping in about ten days into tiny green seedlings, difficult to see without a reading-glass. After some weeks of growth they become large enough to transplant into other boxes, and when an inch high may be transferred to two-inch pots. For leaf cuttings, mature leaves of good size are so cut that two of the principal veins meet at the bottom. These are planted in sand or in a cutting garden like other slips, and will develop into good-sized plants after some months, being transferred, of course, to soil when the root system is sufficiently developed.

A good peaty soil or a soil composed largely of leaf mold 
and sand answers very well for begonias. They all require good drainage, and care should be taken not to give them too much water. It is also desirable to keep the Rex Be-

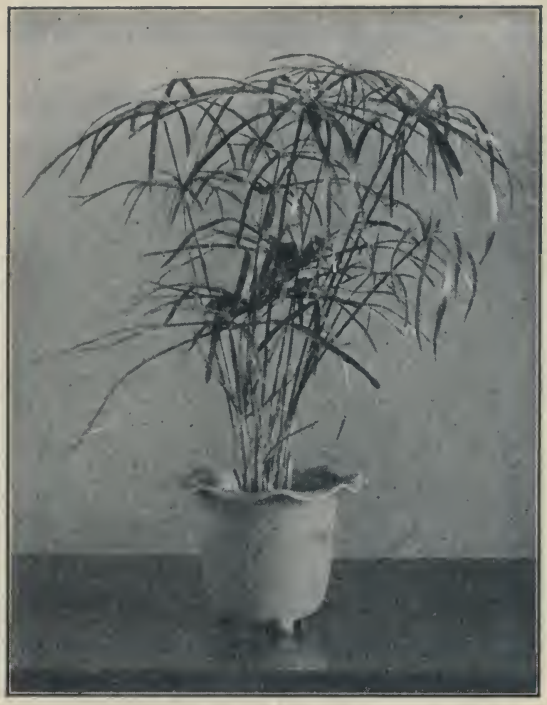

The Umbrella Plant. gonias in rather small pots for the first year of their development. They thrive best where they do not get direct sunshine.

The seeds of the different types of begonias are listed in the catalogues at from ten to twenty-five cents per package. Any one who will try growing them for the first time will find it a most interesting experience.

Some of the sedges are also excellent foliage plants. The one commonly called the umbrella plant is one of the best of these.

\section{CLAY FLOWER-JARS}

It is always worth while to have an appropriate and attractive receptacle for a growing plant. One advantage of the paper flower-pots is that they are so thin that they are easily set into attractive flower-jars. One can get at small cost suitable jars at the shops in the larger cities. One can also make in school or at home flower-jars of great beauty 
and surprising durability by a very simple process. The ordinary modelling clay so largely used in schools is a practicable material which, when dry and coated with enamel paint, makes good durable jars.

The process of making is simple. Having on hand some of the clay, break it up and moisten it to a condition to be workable; then mold it to the desired form and set it aside to dry for a week or more. When dry, coat it inside and out with enamel paint, and set aside again for the paint to harden thoroughly. You then have a flower-jar into which you can easily place a flowering bulb just coming into blossom, and the whole will serve admirably for adorning your own living rooms or as a present to a friend.

Before beginning to mold the jar you should have in mind the form you wish to make. Draw a series of pencil sketches of forms of flower-jars and choose the ones you like best, or

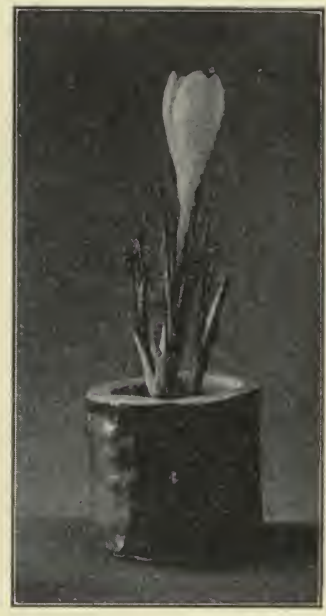

Crocus in a Clay Flower-jar. copy some simple form in vase or picture. For the most part these hand-modelled jars must be not very high in proportion to their breadth and not complicated in design. They are all the better for being of the simplest forms. Different bulbs require different sized jars; the jonquils and smaller varieties of narcissi may be transplanted into smaller jars than the larger daffodils. It is better not to attempt to make a drainage hole in the bottom; the hole is not necessary for the bulbs and the painting becomes more uncertain and 
difficult when it is present. In modelling the clay you must learn to use wet fingers to keep the surface smooth.

The result, so far as beauty is concerned, depends almost as much upon the painting of the surface as it does upon the modelling. The enamel paints which one may get from any dealer are likely to be too brilliant in color for use without toning down. You may easily accomplish this by mixing black or white or gray with the various colors you wish to modify. The inside of the jar may be painted with plain white, or, better, with gray, while the outside may be toned to suit your fancy. Very attractive results may be secured by painting the outer surface in gray green or brown or some other subdued color and then running around the top another harmonizing color, letting the latter run down over the former here and there around the jar.

If you have had no opportunity to study the laws of color harmony, it will be well worth while to get some book upon the subject and learn the principal harmonies. Some color tones combine much more attractively than others, as you will soon find by a little experimenting in the painting of the jars. It will be safer in beginning to keep to gray-greens and subdued browns rather than to try the reds and yellows. After the painting is finished the jars are to be set aside again to harden. This will require several days, the time depending somewhat upon the kind of paint used. When dry there should be no cracks in the surface and the jar should be so firm as to be handled without danger of breaking.

\section{SEED TESTING}

It is often well worth while for a gardener to know before he plants his seeds what percentage of them will be likely to 
germinate. He can determine this very easily by making some tests in-doors. In the making of these tests two methods are commonly employed. In one, the seeds are simply given favorable conditions for sprouting, and as soon as they have sprouted they are counted and then thrown away. In the other, the seeds are planted in soil and allowed to develop into seedlings long enough to show the percentage of plants that would be likely to grow in the garden. In general, the latter method will give more accurate results than the former, for many seeds have sufficient vitality to germinate, but not to develop into growing plants.

The determination of the percentage of seeds which will sprout under favorable conditions is a very simple matter. If you stop to think a moment of the conditions under which seeds sprout in the garden out-doors you will see that in the place just below the soil surface where they rest while they are sprouting they have these three essentials - air, warmth, and moisture. Consequently, if you supply these requirements to any seed, they should be able to start their growth and thus show you what percentage has sufficient vitality to germinate.

One of the simplest ways of conducting a germinating test is to place the seeds between layers of cotton batting, keeping the cotton moist and in a warm room. The cotton batting may be simply rolled up and placed inside a paper flower-pot which should be covered with a piece of cardboard, or it may be laid upon a saucer or plate and another saucer or plate inverted over it. Instead of cotton batting one may use blotting-paper or even flannel cloth.

It is desirable to select for germinating tests either fifty or one hundred seeds in order that the percentage may be 
readily computed. A few days after the seeds are placed in the germinator they will begin to sprout, and as fast as they do this they should be removed and an accurate record kept. By the end of a week or so from the time the sprouting begins all that would be likely to grow out-doors will have germinated, and those which remain will represent the per-

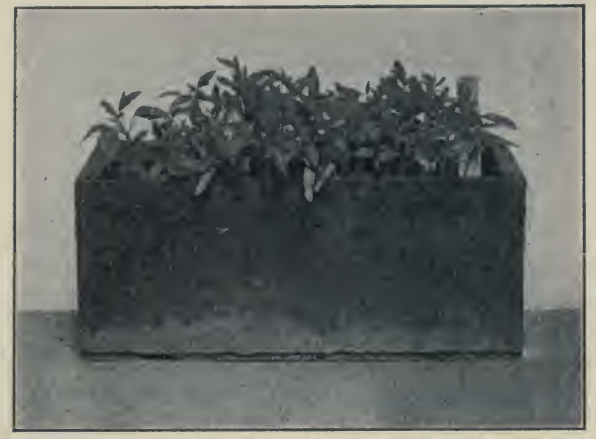

Tomato Seedlings in a Window-box. centage of seeds that do not germinate.

By sowing fifty or a hundred seeds in a tiny drill or furrow in the window-box, one can readily make a test of the growing powers of any seed. In doing this it is necessary that they all be covered with about the same amount of soil. To insure such uniform planting, make a furrow by pushing the square edge of a ruler into the soil one-half inch, thus leaving a small furrow of that depth. Along the bottom of this place the seeds, one at a time, and cover them uniformly with fine soil. Be very careful in watering-simply keep the soil moist, but not wet, and as the plants come up let them grow for a week or two to see what difference there is in the vigor of the different seedlings. When each has shown sufficient vitality so that you are satisfied that it would make a good plant, pull it up, keeping a careful record of the number thus pulled. At the end of the testing, this number, as compared with the total number of seeds planted, will give you the percentage that will be likely to grow. 
Instead of the window-box, paper flower-pots may be used to great advantage for this seed testing. Fill a pot with good loamy soil to within an inch of the top, then scatter evenly over the surface twenty-five or fifty or one hundred of the seeds to be tested, cover these with a half inch of sifted garden soil, water carefully, and watch the seedlings in the way described above.

In general, the highest percentage of good seeds will be found from the sprouting test, the next highest will be found from the seedling test, and both of these will be likely to be higher than the actual results that can be obtained in the garden out-doors. In the latter the conditions are generally less favorable to the development of the seedling than are the conditions of the in-door tests.

It is much more important to make tests of some seeds than it is of others. Two sorts of seeds in which it is well worth while to make such tests are tomatoes and onions. In case of the tomatoes, cheap seeds will often give a comparatively small percentage of good plants, and it is most important that the tests should be made so early that if the results are not favorable other seeds may be obtained in time for planting. For example, a great many poor onion seeds are sold, and it is very important that the percentage of germination of a given lot be determined before the main sowing is made. In case the seeds should prove to have a low percentage of germination, it will be desirable, of course, to sow the seed more thickly, or very often it wilb be desirable to discard it altogether and substitute a better quality of seed.

In case of a few plants, however, older seed is preferred. For example, when cucumber seed is ten years or more old, 
only the strongest seeds, surest to produce plants true to the type preferred, still preserve good vitality; so large growers of cucumbers prefer such seed where the percentage of germination is low. Similarly, seed of double balsam gives a larger percentage of double flowers if aged until the weaker seed has lost power of germination.

\section{THE CLASSIFICATION OF VEGETABLES}

The crops that are commonly grown as garden vegetables may be classified in various ways. One of the most satisfactory arrangements is that adopted by Professor L. H. Bailey in his book, "The Principles of Vegetable Gardening," which is reproduced with slight modifications in the diagram on the following page. According to this system, which is based on methods of culture, garden crops are first arranged into those which are grown as annuals and those which are grown as perennials. Of the latter, the asparagus and rhubarb are much the most important, while the former includes nearly all the crops which we commonly think of as vegetables.

As will be seen by the diagram, these annuals are arranged under three main groups. The first includes those crops in which the underground part of the plant is utilized, these underground parts consisting sometimes of roots, sometimes of tubers, and sometimes of bulbs. The next group includes those crops in which the leaves and leaf stems are eaten, and the third in which the seeds and fruits are eaten.

The six most important Root Crops are the beet, carrot, parsnip, radish, salsify, and turnip. In all of these the edible portion for which the crops are grown consists of a thickened 


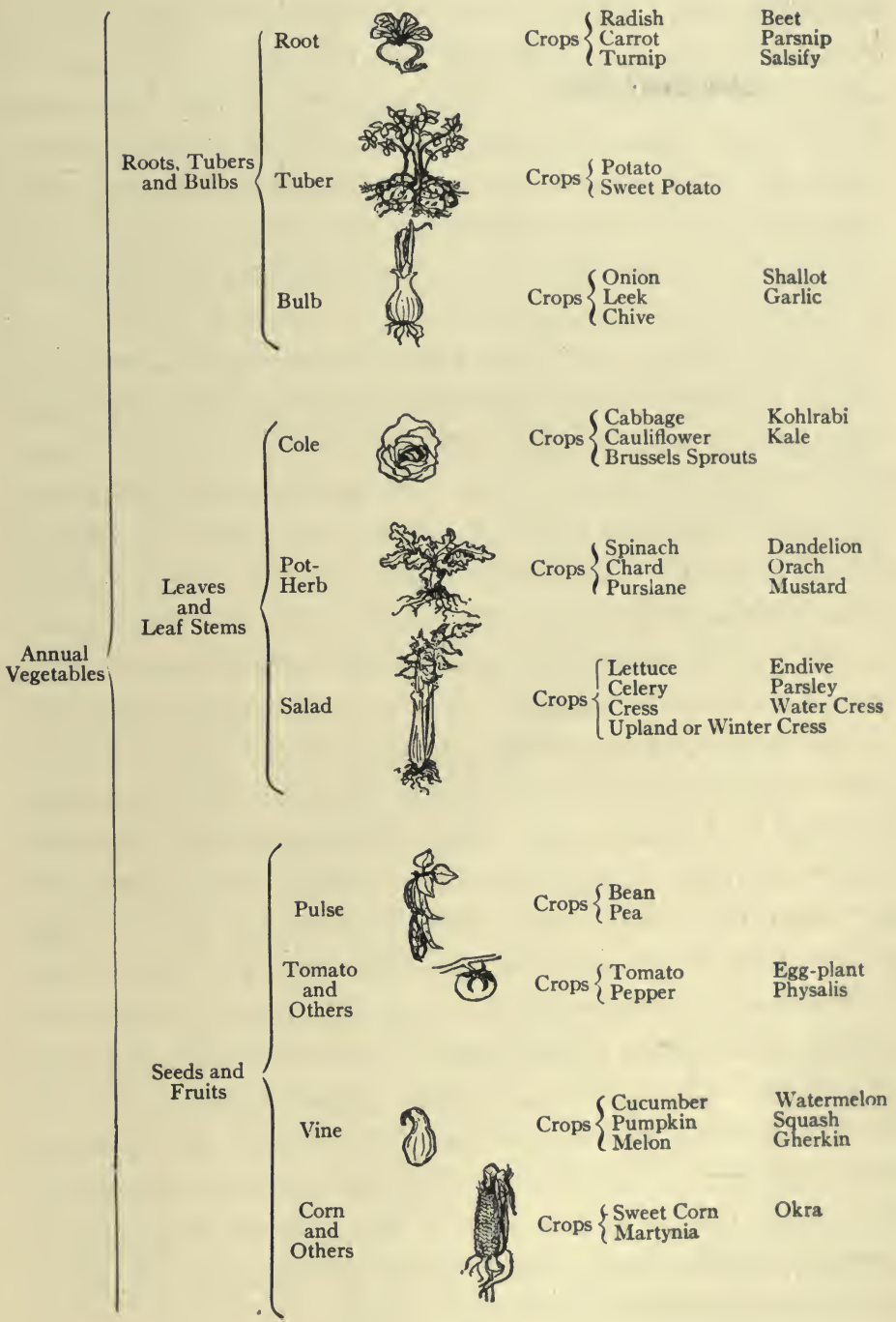


fleshy tap-root. They are biennials in their origin, storing up food the first year underground and using this the second year when flowering and producing seed, so they are hardy enough to be sown early and harvested late or even after a winter in the ground. While varieties of some have been obtained which will produce edible roots within a few weeks, most need a long season to reach maturity, and are still grown as biennials to secure seed.

The only important Tuber Crops are the potato and sweet potato. Potato tubers differ from roots in that each is developed as a store of food at the end of a root-stock, each thickened tuber having buds or eyes from which new branches with leaves may develop. A sweet potato, like a dahlia, is more a thickened root than a root-stock, for the eyes are on the end toward the main plant stem, while the other end is rooted. A potato has no roots on the tuber, and the eyes are clustered on the free end, like any branch above ground.

The most important Bulb Crops are the onions, chives, garlic, and leek. In these bulbs the root-stock is greatly modified into a series of scales, one lapping upon the other in a way familiar to every one who ever saw the structure of an onion. The true roots develop from the base of these scales while the leaves are sent out from the upper ends. These vegetables are grouped together more because they belong to the same plant family rather than because alike in culture. Chives, for example, are grown as perennials for their leaves, which are used like herbs in seasoning, and they are reproduced more by division of the clumps than from seed. And in case of the leek, no large bulb is formed, but the long, thick, blanched bases of the leaves are used, being stored green like celery. 
There are three groups of vegetables arranged under the heading of Leaves and Leaf Stems. The Cole Crops are supposed to be cultivated varieties of one and the same wild plant native to the coasts of western Europe, so they are alike in their hardy nature and preference for cool, moist soil. Since the parent plant is a perennial and the cultivated varieties are biennials, most of them require a long season for full development, and young plants are started early in seed beds. Kale and collards are very hardy, and have large free leaves, thus resembling more closely the wild plant. In cabbage the leaves form a dense head of blanched leaves, while Brussels sprouts produces small heads, as buds in the axils of the leaf stems. Kohlrabi produces a turniplike swelling or tuber on the stem, from which the leaves grow; while cauliflower is grown for the short, thick, white, tender flower parts which form dense heads within the surrounding leaves.

The important Pot Herb Crops are excellent for the school garden. Since in their origin they are hardy weeds, and now in cultivation need to be grown quickly in spring to afford crisp, tender leaves when pot herbs are in demand, they may be grown during the school year, and harvested before school closes. Spinach and mustard are best for this purpose. The dandelion must be planted in spring or summer, and harvested the following April. Swiss chard affords fine greens for the home table, and crisp, white stems, as a substitute for asparagus, throughout the summer heats. It is little known only because it wilts too quickly for sale through the markets.

The Salad Crops are closely akin to the Pot Herb Crops in nature and culture; indeed some, like endive, are used in 
either of the two ways. Lettuce, cress, and corn salad are adapted to the spring school garden, while endive should be sown in late summer for the autumn term of school. Celery and parsley are long season crops.

By a reference to the diagram it will be seen that those vegetables whose seeds and fruits are eaten are of great importance in furnishing food to mankind. The Pulse Crops include peas and beans of all kinds. The tomato, egg-plant, pepper, and physalis or husk tomato, are frequently included under the name Solanaceous Crops, because they all belong to the family Solanacee, to which also the potato belongs. Were the little potato balls which develop from the flowers of the potato the edible part, this crop would be included along with the tomato under the present heading.

The Vine Crops form a very distinctive group, all belonging to a single family of plants, Cucurbitacex, on which account these are often called Cucurbit Crops. Here we find the cucumber, melon, pumpkin, and squash.

The last group includes the sweet corn, okra or gumbo, and the martynia. The two last named are plants which are grown for their pods, althoug't they are not very generally known throughout the Northern States; while the former is the only member of the great family of grains and grasses which is grown as a vegetable. 


\section{THE JANUARY CALENDAR}

SEND for seed catalogues.

START cuttings of carnations.

BRING to light some of the bulbs placed in the basement in November. Sow seed of French Marigolds to have plants for outside windowboxes.

Plant an onion in a window-box to let it develop into seed.

ORDER flower and vegetable seeds, at least of flowers to be sown early, and of onion, tomato, pepper, and egg-plant.

TEST seeds on hand and those purchased to determine percentage of germination.

DECIDE in general the flowers and vegetables you wish to grow. Then write your State Experiment Station for a list of the best varieties of each.

MAKE clay flower-pots and transplant crocuses, jonquils, or other bulbs into them.

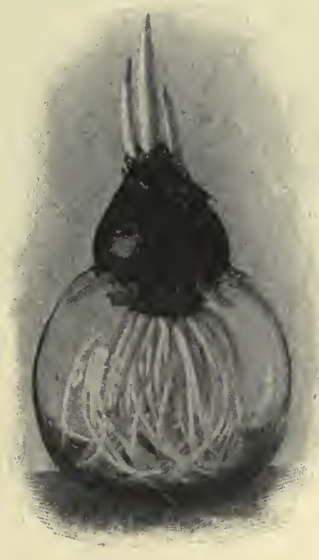





\section{FEBRUARY}

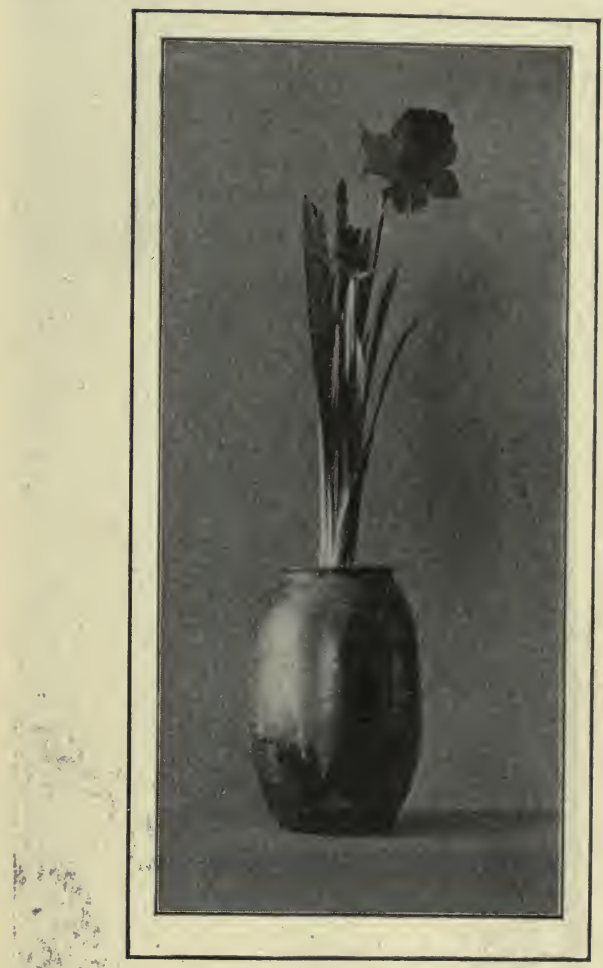

Trumpet Daffodil.

is

We all thave flower favorites, and some of us have flower antipathies, or at least we are indifferent to certain flowers; but I never knew any one but loved the daffodil. Not only have poets and dramatists șung it, but it is a common favorite, as shown by its homely names in our every-day speech.

-Ailice Moŕse Earle. 


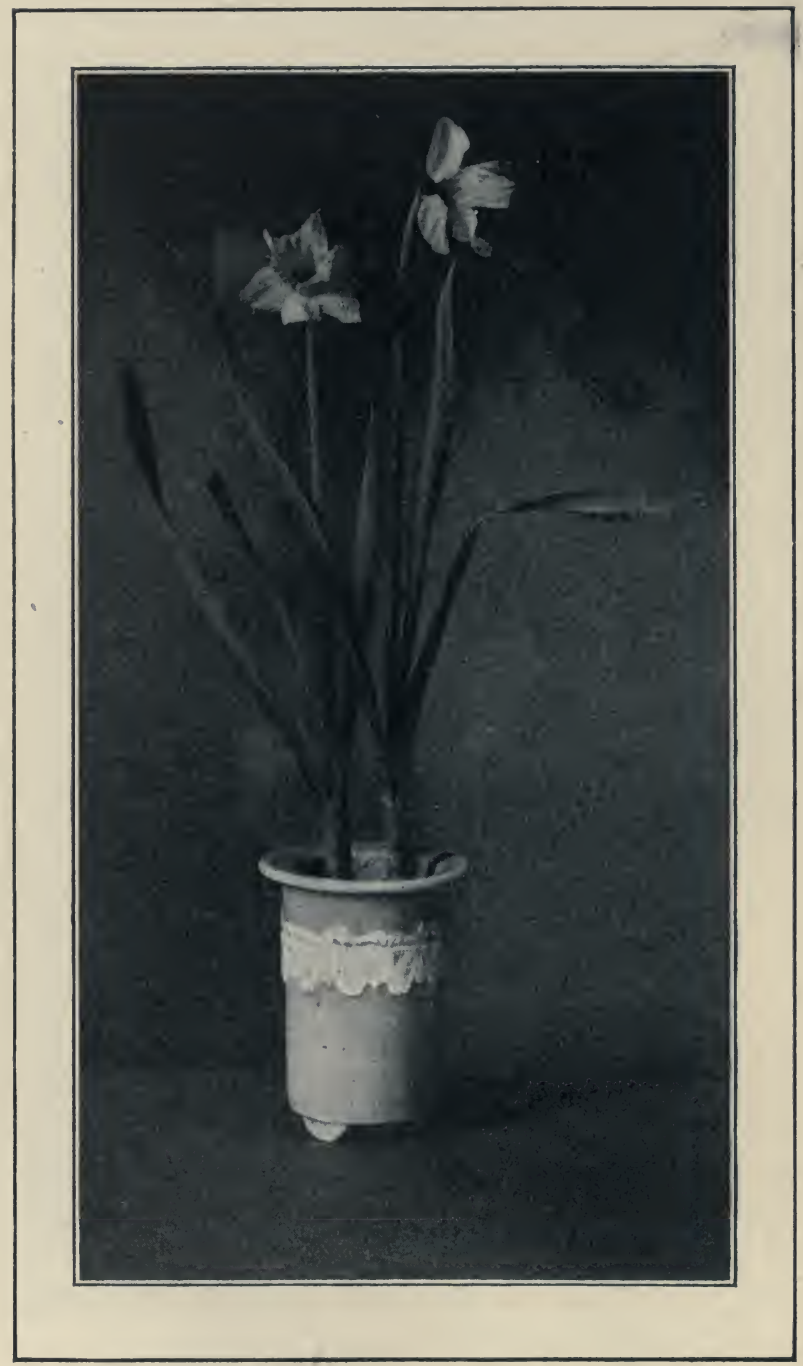

Single Trumpet Daffodils in a Japanese Jardinière. 


\section{VI \\ FEBRUARY}

\section{DAFFODILS}

The time is ripe for a renewed interest in the narcissus, a flower which from time immemorial has been held in especial esteem by many peoples. There are hundreds of beautiful varieties now available, of greatly varying types, and for the most part they can be grown with very little trouble. It seems strange that we should be able to say that there appear to be-fewer varieties cultivated in the average American garden to-day than were grown in many English gardens three or four centuries ago. And even in our own land, the narcissus seems to be less generally grown in our gardens than in those of our forefathers a century ago. In England there are daffodil societies, especially organized to study and improve the flower, and it is very desirable that similar societies should be formed in America.

There are few blossoms better adapted to intensify the delight of spring in the home, in city or country, than this. Whether the grounds be large or small, there is room for these bulbs, which only need to be placed in the soil in autumn to yield their meed of beauty in spring. Once established, they will reappear season after season, delighting the eyes of all beholders. With less care than is required by almost any other plant, they will also bloom in-doors in constant succession from Christmas until Easter. 


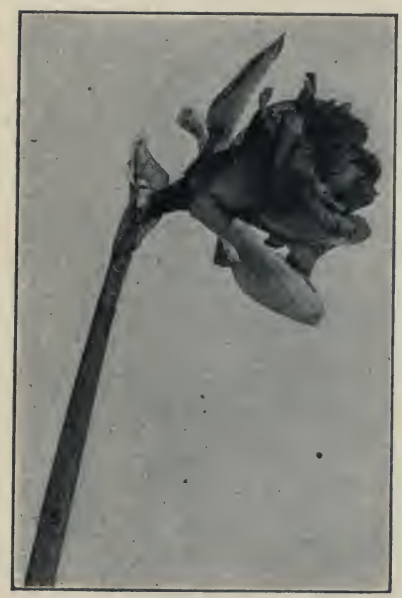

A Double Daffodil.

He who is satisfied with two or three sorts of daffodils misses the best part of the pleasure of growing them. One should not be content without at least one variety, to represent eech of the half-dozen important forms assumed by the hundreds of sorts in cultivation. In a general way they are divided into the Tazetta or Polyanthus group, in which there are several blossoms clustered on a single stem, of which the familiar Paper-white Narcissus is an example, and those in which there is but one flower on a stem. The latter are in turn divided into three principal groups, according to the size of the crown or trumpet in the middle of the flower; namely, the smallcrowned, the medium-crowned, and the large-crowned narcissi. The smallcrowned sorts, of which the Poet's narcissus is an example, are the true narcissi; the medium-crowned, of which the Barrii Narcissus and the variety Stella are ex-

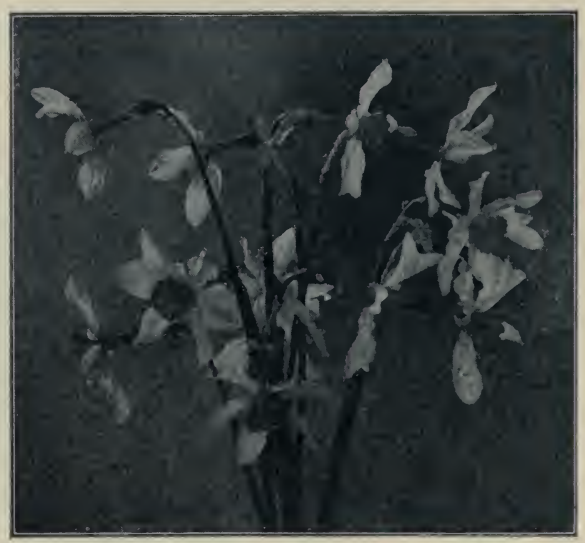

The Stella Narcissus. 
amples, are often called chalice-flowers or Star Narcissi; the large-crowned, of which the Emperor and the Trumpet Major varieties are examples, are the true daffodils. Of the latter there are various double sorts, which, however, are less beautiful than the more simple single varieties.

In the latitude of New York City, the daffodils blossom out of doors in April, and continue well through May. There is much variation in the earliness of different varieties, so that by judicious planting one can greatly lengthen the blossoming period. When protected by a coldframe from wind and rain, the flowers develop in finer condition, a result which may also be obtained by cutting the stalks just before they come into bloom and placing them in flower-jars in-doors. The stalks absorb the water and derelop splendid flowers, which are very welcome in the home at this early season. For holding such blossoms, a few rather small, more or less cylindrical jars are especially desirable, the coloring being in neutral tones of green, gray, or blue, and there being no elaborate decoration. For in these, as in all receptacles for flowers, we should bear in mind that they are to serve to hold objects of beauty rather than to be in themselves the centre of attraction.

\section{Trumpet Daffodils}

In many respects the true daffodils, by which, as already indicated, is meant the large-crowned or trumpet varieties of narcissus, are the most satisfactory ones to grow. The blossoms are large, beautiful in form and color, and easily grown either out of doors or in the house. Many of the larger forms are as easily forced in water as the hyacinths, and they are particularly attractive when so grown. 
There are a great many varieties of these Trumpet Daffodils, the differences between them being shown in the varying colors of trumpet and perianth, as well as in the shape and size of the blossom as a whole.
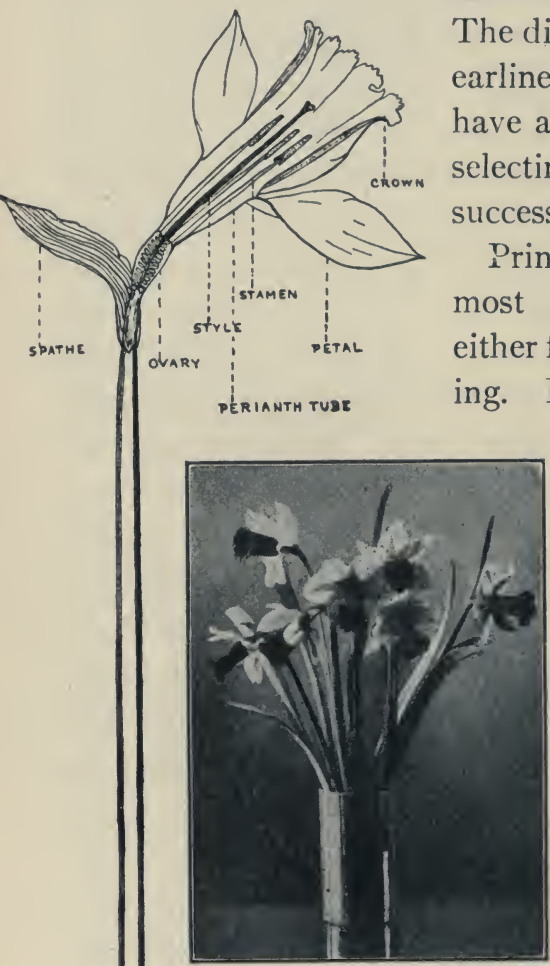

Trumpet Daffodils. The different sorts vary greatly as to earliness, so that one may easily have a long season of flowering by selecting varieties which bloom in succession.

Princeps is one of the earliest and most satisfactory of these sorts, either for in-door or out-door planting. It is a beautiful flower, with a light sulphur yellow perianth expanding about three inches, and a clear yellow trumpet reaching a height of more than one inch and of good length. The bulbs are inexpensive. Spurius, or single Von Sion, is an all-yellow variety somewhat less attractive than Princeps, partly because the flower stalks are likely to be rather short, although this doubtless depends a good deal upon the size of the bulbs and the treatment they receive. Trumpet Major is a golden-yellow variety, which has been very largely grown, but now seems to be generally replaced by 
other sorts. The Trumpet Maximus is a deep golden-yellow flower, which was said by Mr. Eugene Bourne, an English daffodil specialist, to be "the most elegant in form and richest in color of all the daffodils."

Of the varieties which are commonly grown in America, the Emperor is certainly one of the largest and finest. The splendid flowers have the perianth primrose color, and the trumpet golden yellow. The Empress is rather smaller in size, having a yellow trumpet and a white perianth. In this respect it resembles the Horsefieldii, the latter being somewhat smaller than the former.

There are various forms of double daffodils, in which, however, the grace and spirit of the single flower have been sacrificed for a display of color. The only variety which seems at all worth growing is the double Von Sion, which is the variety most commonly grown by the florists. Goodsized bulbs will yield large flowers measuring three or four inches in the spread of the perianth, and about two inches in length. At a little distance there is a decided attractiveness in the color mass, especially when the flowers first open and still retain a suggestion of the daffodil form. As they grow older, however, they spread out in a way that is much less attractive.

\section{STARTING EARLY VEGETABLES}

The success of out-door gardens depends very largely upon getting an early start, especially with those plants that require a long period for their best development. Fortunately, these are comparatively few; but these few are among the most important garden crops.

For growing seedlings of the early vegetables it is desirable 
to have some shallow boxes in which the seeds may be sown quite thickly, to be transplanted as soon as they get one or two true leaves. It is also very desirable to have thesa boxes very near the window in order that the young seedlings may be thrifty and stocky, on account of the abundance of air and sunshine.

One of the most important crops to 'start early in-doors is the tomato. The see⿳亠丷厂 may be sown to advantage even as early as the middle of February, and the young seedlings, when one or two true leaves have developed, may be transferred to three-inch paper flower-pots, where they will continue to develop for many weeks. If they become so large that the roots crowd in the pots before it is time to plant them out-doors, they may be transferred to larger pots to advantage. Whenever they are shifted from the seed-bed to the paper pots, or from a smaller pot to a larger one, it is desirable to set them deeper, in order that the earth may surround the stem higher up, and thus lead to the development of new roots from the portion of the stalk thus covered.

When the danger from frost is past out-doors, the tomato plants may be placed in the open ground, being set so deep that a considerable portion of the main stalk below the leaves is covered with soil: this will lead to a greater root development and, consequently, a more vigorous growth.

"Another crop that is well worth while to plant in-doors is the pepper. The seedlings of these may be grown in much the same way as those of the tomato, although it may not be so desirable to set the plant deeper in the soil at each transplanting, nor need the seeds be sown so early.

One of the best crops for early planting is the onion. It 
has been found that onion seedlings may be very successfully transplanted, and that the crops so grown yield better results than when the seed is sown in the open ground. The onion seed may be sown sparsely in drills in the seed-boxes as early as the first of February, and the young plants allowed to grow until about the first of May, when they may be transplanted out-doors. It is desirable to cut the tops off about one inch from the ground with a pair of scissors once or twice during this period of growth. This will cause a better development of root to take place and will lead to a thriftier, stockier plant. At the time of transplanting the tops should be trimmed so that they are about one inch high, and the plants should be set but very little deeper than they were in the seed-bed.

Many people make a practice of starting seedlings of lettuce in-doors for transplanting out-doors. It is somewhat questionable, however, whether under ordinary school conditions anything is thus

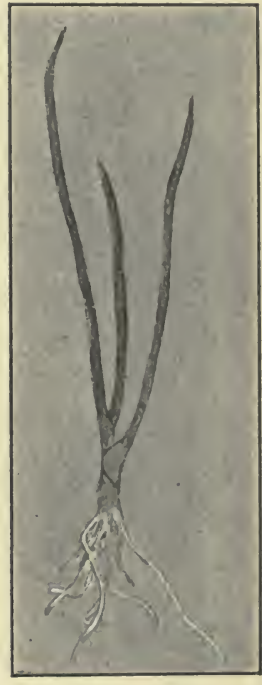

Onion Seedling. gained in the case of this crop. But it is generally worth. while to get such a start with the slow-growing parsley, especially as the parsley in a dry spring will sometimes be a total failure.

One of the most satisfactory crops with which one can get an early start is that of potatoes. It has lately been found that the season of growth of potatoes can be shortened very. considerably by allowing the tubers to sprout in a well-lighted 
cellar or room. They are simply placed upon tables or shelves or benches exposed to the light and air, and the sprouts allowed to develop for two or three weeks. They are then planted very carefully out-doors, special precautions being taken not to break the sprouts off the tubers. With the start thus given the plants come up very quickly and grow rapidly, producing eatable tubers earlier than other potatoes planted at the same time in the usual way. This is one of the simplest and easiest experiments which school gardeners can undertake.

\section{SEED-LEAVES OR COTYLEDONS}

The pictures on the next page tell a story whicn you can easily read in the life of any tomato plant that you grow from the seed. You plant the seed in a warm room in moist soil and it soon comes up as a little seedling with two erect leaves folded flat against each other, and of ten bearing on their tips the tiny seed coat. Almost as soon as they come up these seed-leaves spread out horizontally and continue to increase in size for several days. Then, if you look closely at the plant, you will see one or two tiny leaves appearing from between the bases of these seed-leaves, or cotyledons as they are sometimes called. As these later appearing leaves increase in size you will soon see that they are very different from the seed-leaves in form, and you will find that the seed-leaves no longer grow larger. The other leaves, however, grow rapidly and soon take on an appearance similar to that of an ordinary well developed tomato leaf, and are followed by other leaves that appear from the top of the plant. The seed-leaves, however, are gradually becoming of a paler color and will finally droop downward, 
wither, and fall away, and your plant will be in the condition of the right-hand picture on the plate.

This rise and fall of the cotyledons is characteristic of many seedling plants, for these cotyledons are the storehouses of food materials by means of which the tiny seedling is enabled to get a start in the world, and when they have served this purpose, and the plant is able to shift for itself,

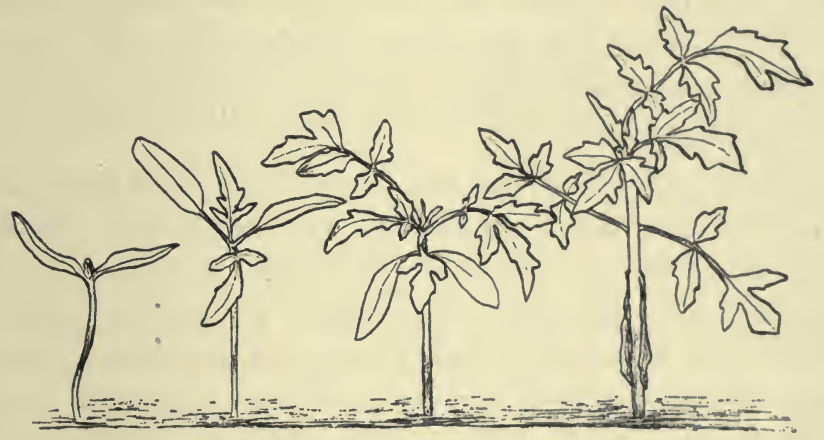

Tomato Seedlings-The Rise and Fall of the Cotyledons.

they drop away. The seed-leaves are green, like true leaves with most plants, and they serve the purposes of true leaves until these have been developed.

If you will sow some seeds of squash or pumpkins you can see the same story told in an even more striking fashion. You doubtless are familiar with the large, deep-green seedleaves of young squash plants, so smooth and shiny and so different in form and structure from the ordinary leaves of the squash. Or you can get the story told in a somewhat different fashion if you will plant some beans in a paper flower-pot and watch the seedlings as they develop. The cotyledons do not appear to be such definite leaves as are 
those of the tomato and the squash, but, nevertheless, they serve their purpose to enable the young bean plant to get a start in the world.

If at the same time as you plant the beans you will also plant some peas in another flower-pot, and when they come up compare the seedlings with those of the beans, you perhaps will wonder where the cotyledons are. Dig up one of the young pea seedlings and also one of the young bean seedlings; wash the soil out of the roots, lay them side by side, and see if you can discover where the cotyledons of the pea seedlings are.

If now you will plant a few kernels of corn in still another flower-pot and watch for the development of these seedlings, you will find that the first leaves which appear are very similar to the later ones. In order to see what is happening in this case, dig up one of the young corn plants, wash out the roots, and compare it with the seedlings of the peas.

In the case of the tomato, the squash, the bean, and the pea there were two cotyledons for each seed, but in the case of the corn there is but one. Consequently the four plants first named are examples of a great group of plants which are called the two-cotyledon plants, or the Dicotyledonous plants, a word of Latin origin which means having two cotyledons. The corn plant, however, is an example of another great group of plants in which there is but one cotyledon, and so these are called the Monocotyledonous plants. See if you can find among the garden crops you grow, or among the wild plants you see out-doors, other examples of each of these two groups. And see also if you can find any "difference in the formation of the leaves of the plants belonging to each. 
One of the best ways to get a good idea of the fact that these seed-leaves enable the plants to get a start in the world is to sprout the seeds in damp cotton or sphagnum moss, or even clean sand. Of course the young seedling will get very little material for growth from such substances, and doubtless you will be surprised to see how large they will become before they die from lack of foot.

\section{THE FEBRUARY CALENDAR}

MAKE definite complete planting plans for all home and school garden plots.

MAKE an estimate of seeds needed and order them from reliable seedsmen.

BRING out more bulbs from the basement.

Don'T throw away your daffodil plants after blossoming. Watch the passing of the flower. Let the leaves ripen off and in spring set the bulbs in the border garden.

Sow sæed of some of these flowers: French Marigold, Tufted Pansy, dahlia, Ten Weeks Stock, salvia, verbena.

Sow in window-boxes, seedling boxes, or paper flower-- ots, seeds of onion, beet, carrot, tomato, egg-plant.

Examine your store of summer flowering bulbs and t'ibers. Cannas may be too dry. If fungus is attacking any, s?porate all diseased stock, improve storage conditions, and examine again soon. 



\section{MARCH}

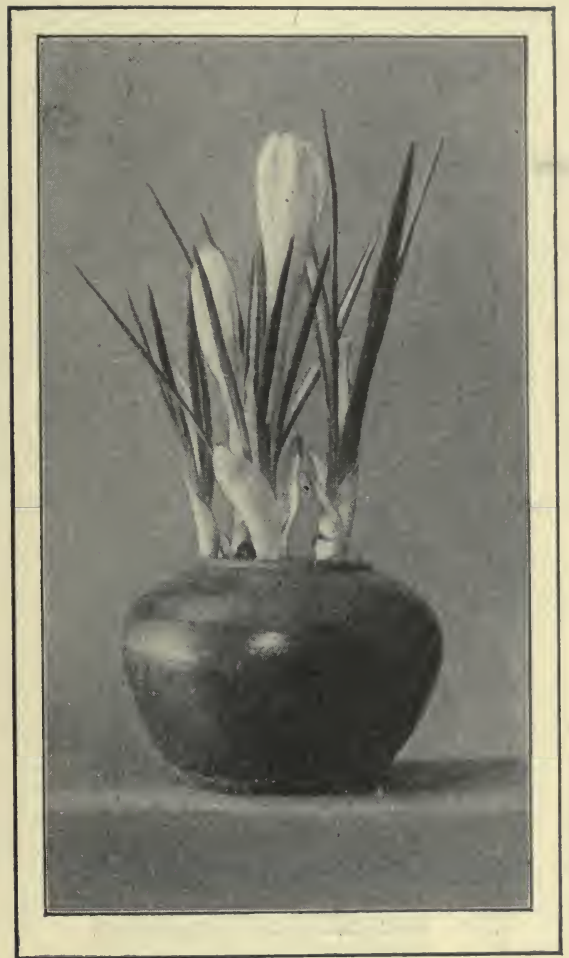

Crocus Blossoms

The buried bulb doth know

The signals of the year

And hails far summer with his lifted spear.

- Coventry Patmore. 


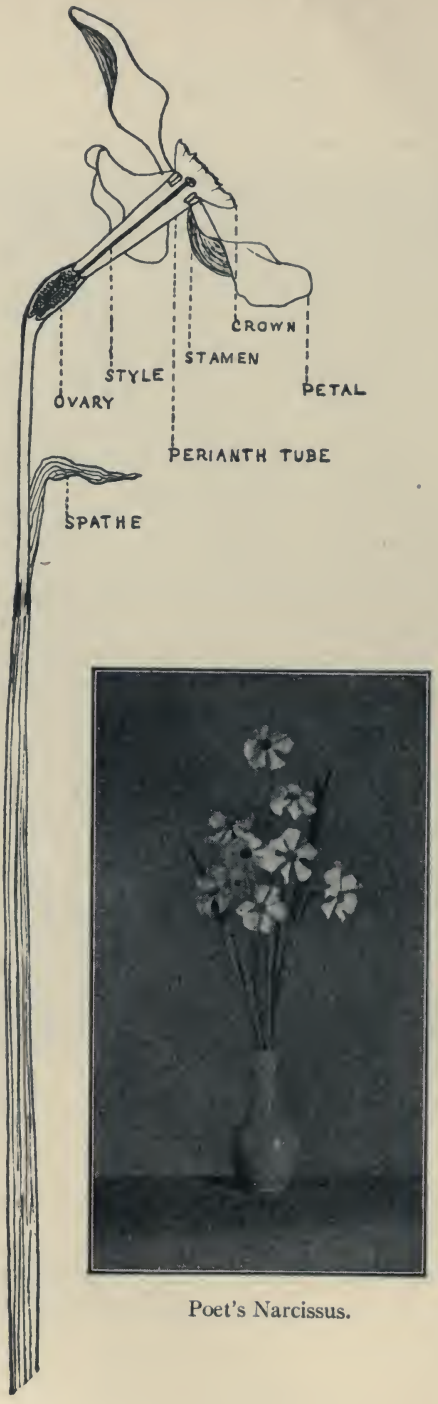




\section{VII}

\section{MARCH}

\section{A NEIGHBORHOOD GARDEN CLUB}

It is not exactly a club, for it has no written constitution and no president. But the children of the neighborhood have worked together as well as though elaborately organized; and all members have gardens. One of their teachers is responsible for the Club; indeed, she has been the cause of many happy times and helpful movements in the community. Several leaders among the children of this neighborhood were her pupils, and, inspired by her encouraging enthusiasm, they determined to make the gardens of their street as successful as their school garden.

Their home street was discouraging in its looks and reputation. The houses were small and weather-beaten. The fences were rickety. The outbuildings were disreputable. The yards were uncared for wastes of weeds. It was small wonder that moving day came often, that property there was unprofitable, and that none was proud of a home on River Street.

Miss Alden-let us call her-had commenced in midwinter to arouse interest in home garden plans. Books and catalogues were at hand, and every now and then some pupil put his garden plan on the board that it might be discussed with the class. But the River Street children seemed hopeless. "What was the use?" they thought. So Miss Alden talked it over with them one night when they had stopped to 


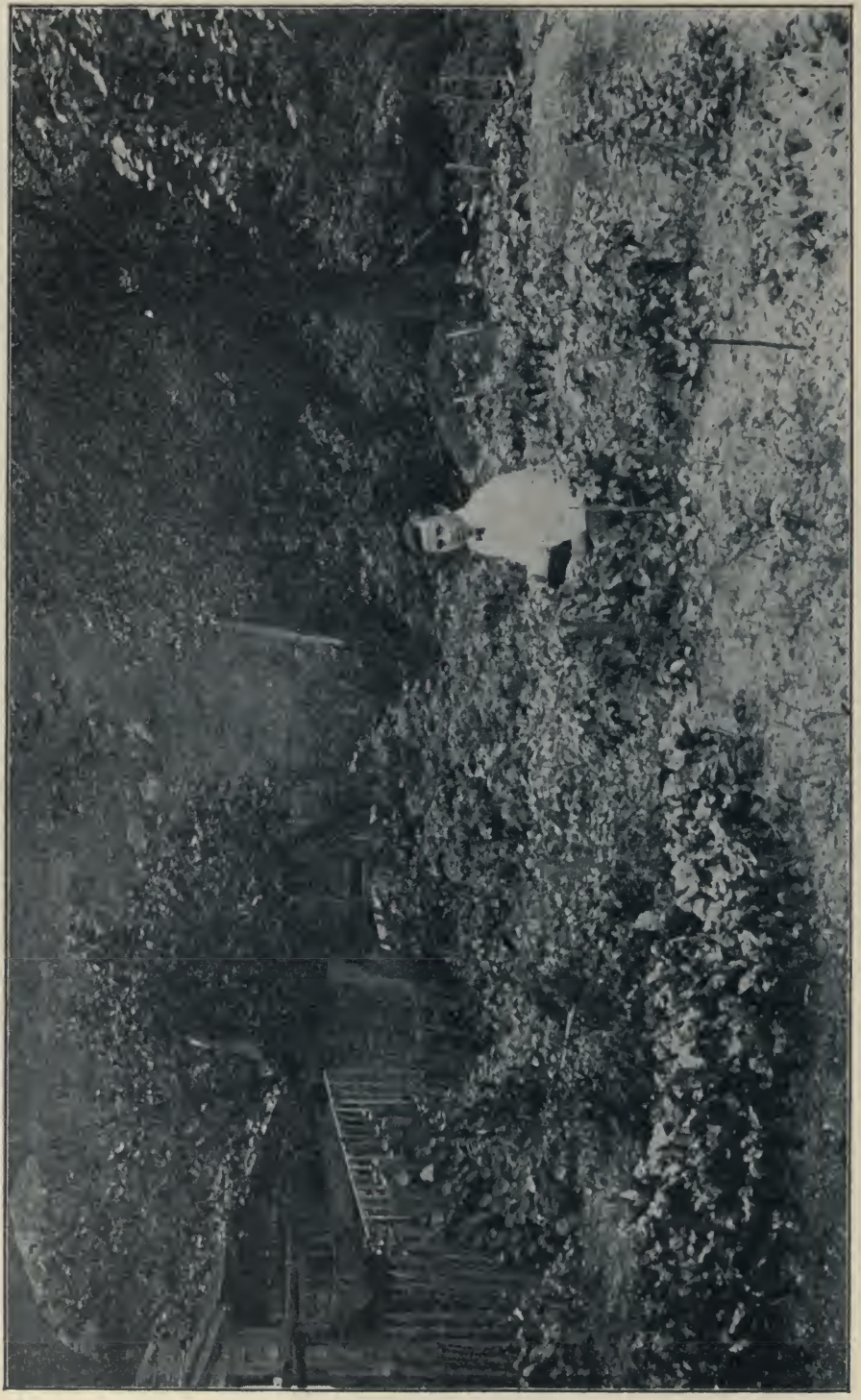

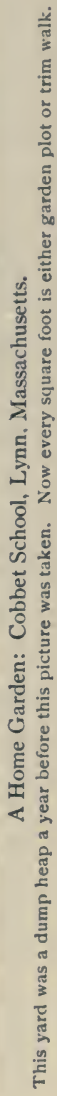


help her. Encouraged by her faith in them, they were aroused to share her evidently sincere belief that they might make their neighborhood one they need not wish to disown, but might claim with pride.

Interest spread. The pennies and nickels that ordinarily went for candy or moving-picture shows were saved for seeds. The River Street children of other rooms and grades occasionally gathered in Miss Alden's room. Real work commenced also. Even if the ground proved frozen beneath the layer of mud when early thaws stirred the blood and impelled one to dig in the soil, there was rubbish that could be cleared away, fences and sheds to be repaired. The boyish attempts at betterment aroused a few fathers to help and secured approval of places for vegetable and flower gardens. Once started in the good work, several boys would not stop for returning snow-storms; they drew on one of their sleds boxfuls of fertilizer

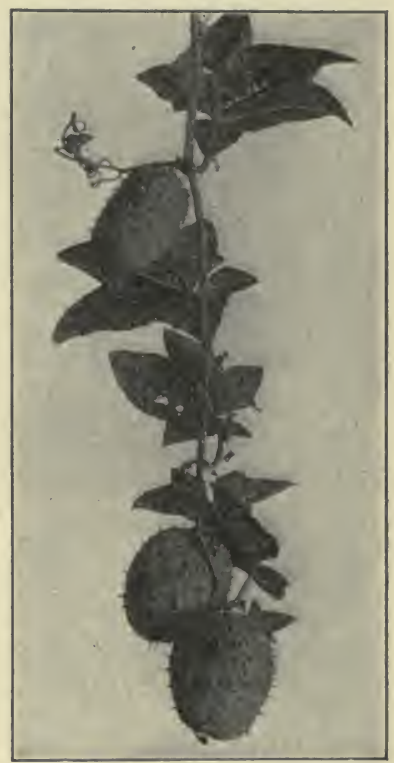

Wild Cucumber. from near-by stables, and piled it under old sheds or covered. it with boards in the centre of their future garden plot.

The people living on River Street were ready to make their neighborhood as good as any other, now that they had set about it. Others had little parks. They must have them. There was the triangle where the street from up-town met 
the river road. Why not trees, greensward, and flowers there for all? The Superintendent of Streets promised Miss Alden and her delegation of children that he would approve and aid. An agent for a firm dealing in young trees agreed to sell them three fine elms and some shrubs at half price, and the money was raised in a few days. Two carpenters of the street helped the boys make tree guards in advance. When the street department ploughed up the triangle and brought in more soil, the boys were ready to place the trees, shrubbery, and the sod borders, under the direction of a workman. River Street had a park.

The home gardens had been advanced meanwhile. Enthusiasm is contagious; the children caught it from Miss Alden, their parents from them. Fathers recalled boyhoot days in other countries, or work years before on New England farms. They took hold and showed how to spade up the soil and how to work the fertilizer in; and when the boys got tired their fathers oftes kept their courage up by working with them after supper. Indeed, if any one thought the work more than he had bargained for, he still could not give up and let John next door do better than he. Mothers remembered the flowers they used to love, and showed just how to plant the seeds when the soil was ready. Every one had a share in the work.

Before enthusiasm thought of waning the judges came. When these three gardeners from other neighborhoods visited River Street with Miss Alden in early May they found twenty-seven garden plots so far advanced as to deserve awards. In ranking them, yard improvements were valued as well as gardens, and whenever a boy or girl was shown to have enlisted younger children of the family or neighborhood 
in the work, he was given additional credit for such help and instruction. Six workers were given first rank, nine second rank, and twelve third rank. The prizes were plants solicited by Miss Alden or grown at the school garden. There were cabbage, cauliflower, kohlrabi, tomato and pepper seedlings, and rhubarb roots. There were Marshall strawberry plants grown at school in pots sunk in the soil beneath runners of the preceding year. There were divisions and young plants of many sorts of hardy perennials-bleedingheart, columbine, larkspur, and globe flower which would soon be in bloom; phlox, helenium, boltonia, heliopsis, and other summer and autumn flowering hardy plants. Then there were some flats of annual seedlings-salvia, asters, and Drummond Phlox, given by a florist, and a good assortment of dahlias from amateurs on other streets, who were glad to assist in the improvements on River Street. They counted it a good insurance investment, for owners of gardens do not invade gardens elsewhere, which was once the habit of those dwelling on River Street.

An automobile trip to famous market gardens and fine estates in a town ten miles distant was planned as a prize for those who earned first rank. The inhabitants of River Street often dodged automobiles up-town, and dreamed of a time when they might own or at least ride in one. But every first-rank gardener seemed disappointed at this award, and begged for plants instead. Pressed for a reason, they said that while the ride would be delightful it would soon be but a memory, while the plants would grow on and the hardy flowers would increase as years went by. They had the gardener's true spirit: they received their plants, and also the promise of the ride and plants as well if they should 
gain first rank when the gardens were judged in the middle of June.

The full story of River Street would be unduly long, and indeed it has yet to be lived in large part. The success of

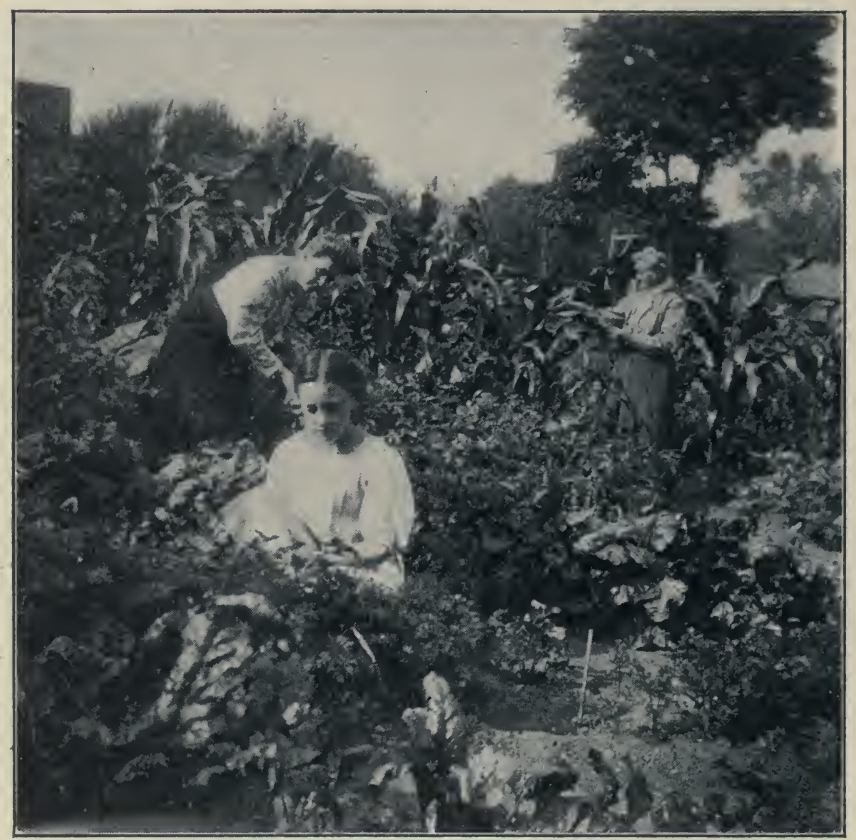

Three Generations in the Home Garden.

the first season has been surpassed at many homes, even though some have been at times discouraged. The park is gay with a central bed of hardy flowers, phlox, iris, and columbine surrounding an inner ring of larkspur and foxglove, and a centre of tall perennials. The city has commenced to reclaim and beautify the river bank. Landlords 
have ventured to invest in repairs and improvements. A few tenants have arranged to purchase their homes. The corner saloon at the end of the street is not gaining business, however. Some of its formerly constant patrons often spend spring evenings with, their children in the home garden; and the benches on the grassy bank under the willows by the river, across the road from the little park, are a pleasant place for good fellowship after the toil of a hot summer day.

There are garden clubs on other streets of the town now. Three years ago Maple Street became the home of a little old cobbler and gardener who very quietly worked a transformation in his neighborhood. The children began coming in to see him at work in his garden, and were delighted to be allowed to help him in the planting and weeding. When dividing hardy plants and resetting them in freshly fertilized soil in early spring, he gave divisions to some of his volunteer helpers. Having seen how he arranged his plants, and how he prepared the soil and established them in it, they were ready to grow successfully the plants given them. Later, these children and other boys and girls were given the extra seedlings of various annuals from the seed-bed of the old gardener, with the understanding that future gifts depended upon the care given those first received.

When this public benefactor planted seeds of some biennials and hardy perennials in his cold-frame, and a little later planted pansies and daisies there for use the following spring, the children were so interested that several got their fathers to allow them to establish cold-frames at home. So the interest grew until several homes became centres for the spread of garden skill and for the distribution of dahlia tubers, 
plants, and seedlings. Whereas the flower gardens on Maple Street had been formal plots of bedding plants, they now acquired individuality and presented a most pleasing variety. Neighborhood and home life on the street gained a new interest, and largely because one little old man who loved flowers loved children also, and shared both his knowledge and his surplus plants with them.

There are many little neighborhood garden clubs of this informal type in town to-day. Some of the wealthy citizens, public-spirited men, heard of the work on these two streets, appreciated its possibilities, and organized to stimulate neighborhood co-operation in other quarters. Under their leadership several hundred dollars have been subscribed by industrial corporations, merchants, and citizens, and a secretary has been secured, who not only knows both gardens and children, but also has faculty for securing the co-operation of others in public effort. Prizes have been offered not only for individual gardens, yard improvements, windowboxes, and the like; but also for the streets and neighborhoods making the most improvement, having the largest percentage of well-kept lawns with attractive gardens.

Mindful of the fact that in the crowded sections where garden space was lacking and families were poor, substantial help would be needed, the association arranged to supply window and piazza boxes, soil, seeds, and plants at their wholesale cost. Quite naturally, in such a community, the School Committee have judged the time ripe to secure a supervisor of gardening and industrial work, and have provided both time in the schedule of weekly studies and space in or near the schoolyards for systematic instruction in gardening, that the enthusiasm of the children for home gardens and improvements 
may be placed on a sound basis in every school district and neighborhood. The full results are yet to be achieved, but, judging by experience in many places, they will be worth far more than all the money and effort invested.

\section{STARTING EARLY FLOWERS}

Several of the annual flowers may be started to advantage in-doors. Under the conditions of the ordinary school-room or home it is not practicable thus to start some of the kinds of plants, seedlings of which may be grown in the hot-bed or greenhouse early, for many plants with the comparative lack of an abundance of sunlight and air commonly found in-doors will grow so spindly that nothing is gained by starting them there. Consequently it is desirable to choose for the in-door plants those flowers which experience has shown can thrive under such comparatively unfavorable conditions.

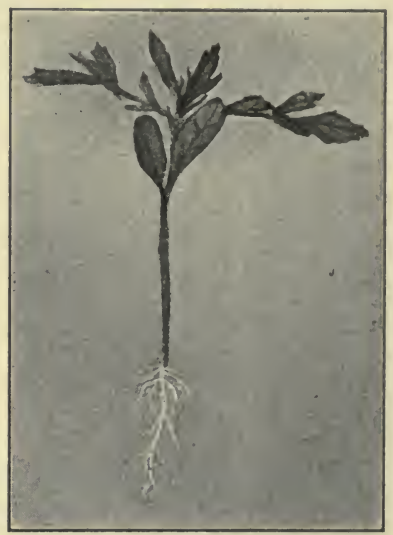

French Marigold.

One of the crops with which something may be gained by starting early inside is that of the sweet peas. By planting several three-inch paper flower-pots with four or five sweet pea seeds each in February or early March one can get several weeks' root development which will bring the flowers out-doors very much earlier than usual. As soon in spring as the ground is in good working condition, the young seedlings may be planted directly from the pots into the soil 
where they are to grow, and they will continue to develop without interruption. If one desires very early flowers one should, of course, select for these plants the earliest varieties.

The Dwarf or French Marigolds may also be started to advantage in-doors. The seed germinates readily and the young seedlings are thrifty and vigorous even where they receive little direct sunshine. They develop very nicely in two-and-one-half-inch paper flower-pots, and sometimes will

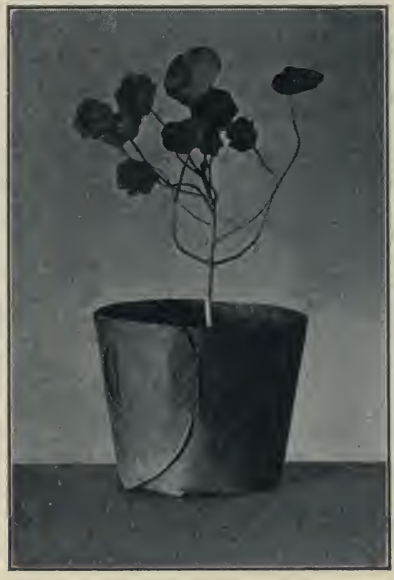

Nasturtium Seedling in Paper Flowerpot. even come into blossom before they are planted out of doors.

It is also worth while to try in the window-box the early flowering varieties of cosmos. In this case, give the seedling plants from the first as much direct sunshine as possible. Something may be gained also in the case of the nasturtium by early planting if the seedlings can be in a window where they get much direct sunshine.

The bachelor buttons and calendula or Pot Marigolds are also easy to start in the window-box, and will yield much earlier blossoms when so treated. This is true also of the annual larkspurs, a number of attractive varieties of which are now offered by seedsmen. The Drummond Phlox is well worthy an early start, as its season of bloom will thus begin out of doors some time before it can under ordinary conditions. 


\section{RADISHES}

The early radishes are perhaps the easiest of all crops to grow in an out-door garden. They mature so quickly, require so little care, and furnish so large a crop on a very small plot of ground, that they are especially desirable for school and home gardens. They may be grown successfully where the soil is only four inches deep, so that, if nothing but a box can be found for the garden, these vegetables may be grown in it.

Radishes are commonly divided into three great classes, based upon the shape of the roots. These are, first, the Round or Turnip-shaped Radishes; second, the Oval or Oliveshaped Radishes; and, third, the Conical-cylindrical or Long Radishes. The first two kinds are now much more commonly grown than the third, as they mature more quickly and are more satisfactory for table use.

Radishes also are sometimes classified as to color, there being white, red, yellow, purple, and black varieties. The red or the red and white forms are much more commonly grown than the others and generally are more desirable. There is one exception, however. The Icicle Radish, long in form and white in color, is one of the best for the table, and is easily grown. The flavor is mild and agreeable, the flesh crisp, while the roots remain tender for a considerable period.

The small brown seeds of the radish vary much in size. Many careful tests have shown that the larger seeds give larger, better, and quicker maturing roots. Consequently, it is worth while for a careful gardener to sort out these larger seeds for planting and throw away the smaller ones. The 
easiest way to do this is to sift the seeds through a wire screen with a mesh of two-twenty-fifths of an inch. This will allow the smaller seeds to pass through while the larger seeds remain above.

Radishes grow most quickly in a cool, moist soil of sandy loam. The seed may be planted in drills one-half inch deep, and in two or three days the two seed-leaves or cotyledons of the young seedlings will push upward through the ground. They will grow rapidly and will need only to be weeded and thinned to about an inch apart. If desired, they will readily bear transplanting at about the time that the fourth leaf appears. They should be kept well watered, and should be pulled as soon as they attain a good size for table use. The more quickly they grow, the better they are, and the less likely they are to be stringy and tough. If left in the ground long, they become hard and unfit for use. Before many weeks they will send up blossom stalks on which the white flowers will appear.

Radishes are pre-eminently a spring crop. The seed should be planted as soon as the ground is in good condition to work, and a succession of sowings should be made every ten days until early in June. It is hardly worth while to attempt to grow them through the summer, unless you have a partially shaded place where you can give them plenty of water during dry times. Another crop, however, may be grown in the fall, sowing the seed about the first of September. Good strains of the quickest growing varieties will readily mature in a month.

There is a special class of radishes that may be grown in summer. They grow to large size without becoming tough or going quickly to seed. A variety recently introduced from 
Japan attains really enormous size, yet is fit for the table. While seldom grown, they are worth trial.

For marketing, radishes are commonly pulled, washed, and tied in small bunches, when they make very attractive objects to sell. Sometimes the tops are cut off and the roots placed in strawberry boxes and thus sold by the quart. Among the best varieties of the round radishes are the Scarlet Short-top, of which each seedsman usually has some special strain, Scarlet Globe, and White Turnip. Of the oval sorts, French Breakfast and Olive-shaped Scarlet are the two leading varieties. Of the long kinds, various strains of the Long Scarlet are the most popular.

The winter radishes are much more popular in Europe than in America. The seed is sown early in summer and the roots are harvested during the latter part of the season. They are then stored away for winter use in the same way that turnips and similar crops are stored. The Rose China Winter and the Black Spanish are leading varieties of this type.

The most troublesome enemy of the radish is the root maggot which attacks the roots in much the same way the onion maggot attacks onions. This is a difficult pest to contend against. It is much more likely to attack the later radishes than the earlier ones, the first crops usually getting through without injury. These maggots hatch from eggs laid about the roots of the plants by small two-winged flies, which naturally increase as the season advances. In the case of a home or school garden, it may be worth while to keep the flies away by bending fine wire screening above the rows. 


\section{THE MARCH CALENDAR}

START more lily-of-the-valley pips about four weeks before Easter to get them in bloom then.

BRING more bulbs from the basement room. The Poet's Narcissus should blossom this month.

EXPERIMENT in sowing seed of annual flowers in-doors to see what sorts it is worth while to start in this way.

Sow, if not already done in February, in window-boxes, flats, or paper pots, seeds of beet, carrot, onion, tomato, egg-plant, and pepper.

THIN seedlings of beet, carrot, and onion so that each plant shall have a little room.

TransPlant to flats or flower-pots seedlings of tomato, egg-plant, pepper, and other crops, except onion and beet.

REMOVE litter from border gardens soon after the last snow has gone.

SPADE or fork the garden soil as soon as the frost is out and the soil is dry enough to work.

Sow, as soon as ground can be worked, a good supply of sweet peas.

Sow, if season permits, seeds of radish, lettuce, spinach, parsley, and the smooth hardy peas.

Plant, if season permits, onion sets and a few early potatoes.

TILL and FERTILIZE the rhubarb and the asparagus beds. 


\section{APRIL}

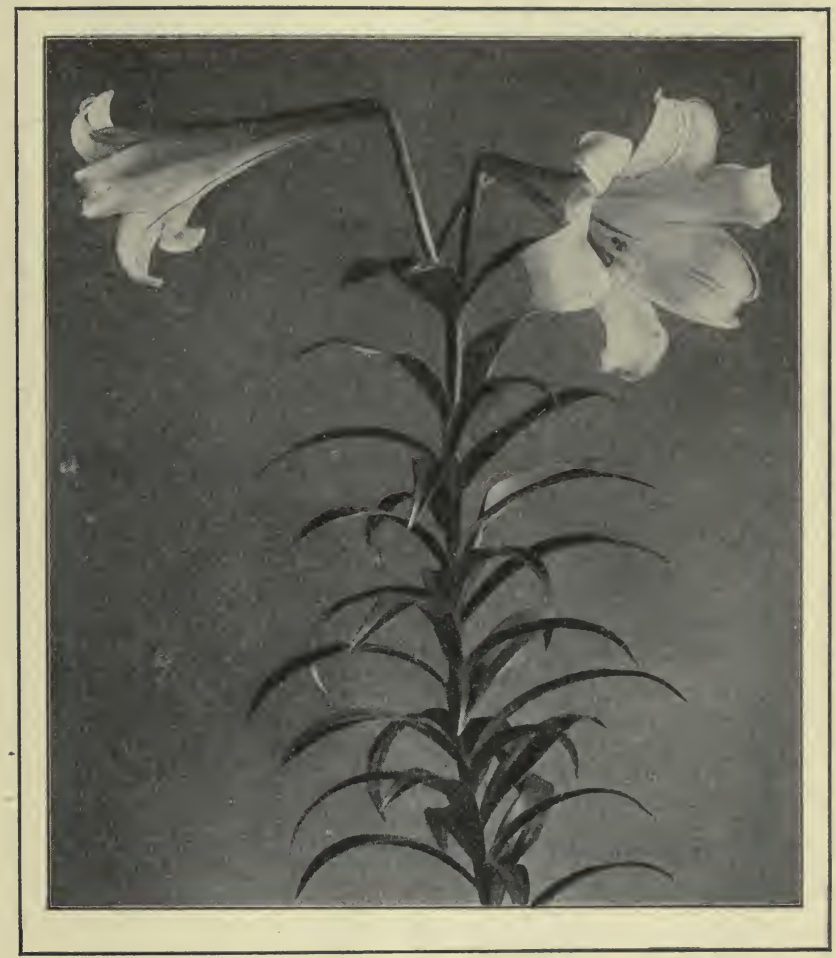

Easter Lily.

"Bear a lily in thy hand,

Gates of brass may not withstand The touch of that same magic wand." 


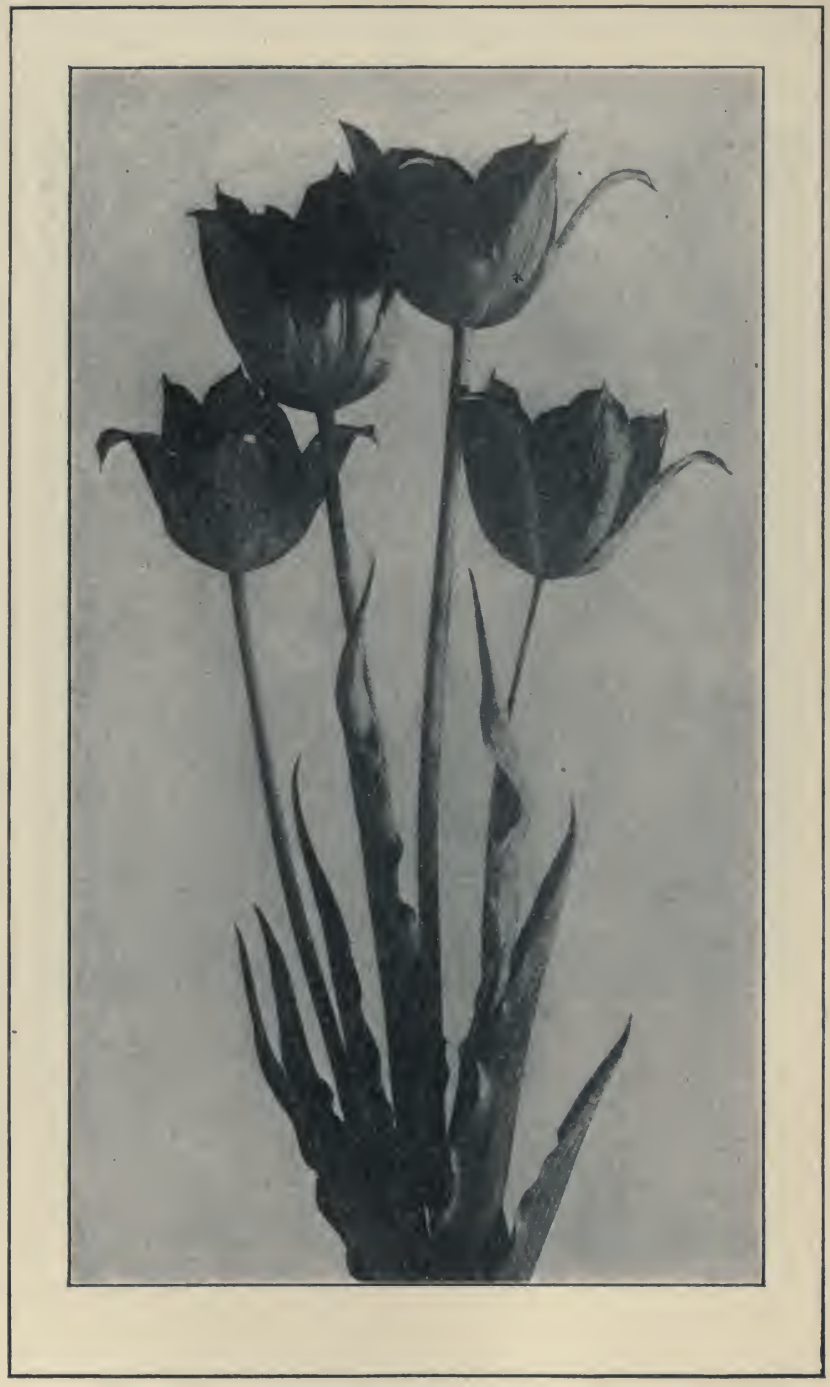

Tulips for the Home Garden 


\section{VIII}

\section{APRIL}

\section{CHILDREN'S HOME GARDENS}

The best way to learn how to plan and to make a good garden, for either a child or a "grown-up," is to see the fine gardens others have made and to talk with their owners as one watches them at work. Come, then, and visit some of last year's gardens in a Massachusetts city. First, Abraham's garden. Never mind his last name, for he's a real boy and rather bashful.

Little Abe was a worker in the school garden, first of all. His class was one of several that had separate plots. Competition was keen. Each class was determined to have the best plot. Spading was not thorough enough for them; they sifted the soil, removing all stones before manuring and planting. Abe's home was in a tenement, with one small back yard for several families. Even weeds found it almost impossible to strike root in the hard-trodden ground of the back yard, amid bricks, tin cans, and other rubbish. But Abe had some of the dogged persistence that enabled his ancestors to live in the cities of Russian Poland, and this combined with the enterprise of the New World. He could dream dreams like his ancient Jewish ancestors, too, and where others saw an ash heap against a dreary fence, he beheld a clump of waving corn, rambling vines, and bright flowers. 
In September the belated judges called. Abe was selling papers, but his parents were at home. They greeted the judges with suspicion, but when at last they understood their visitors' errand they were all smiles. They told how good the sweet corn tasted, told, in their broken English, all the story of the garden and how proud they were of their boy. It was evident that this little garden, the brave enterprise of an immigrant boy, had been a power for good in the home and neighborhood.

Alessandro wanted a garden also. But in the crowded block of tenement homes where he lived there was really no room for a flower bed. The narrow court hardly afforded space for its swarm of children to attempt play. So Aleck worked among the vegetables and flowers of the school garden with his principal. When it was suggested that Aleck might have an old nail keg for flowers, as a reward, he was delighted. The coat of green paint he applied made the keg quite attractive. Then a half-dozen plants were chosen by the boy and carefully set therein, mostly tender perennials and pendant vines. Aleck was a proud little gardener that summer evening as he bore the prize home on the school wheelbarrow.

When the home gardens were judged again in late September, the teacher who accompanied the board of child judges on their rounds found Aleck's tiny keg garden flourishing. Up the tenement stairs they mounted, until, welcomed by Aleck's mother, they were ushered into the close little home room. There was the keg green with foliage, gay with a few flowers, placed for the time just below the crucifix. For the leaves and blossoms recalled to the parents the sunny, flowery slopes of Italy and their terraced gardens, and this 


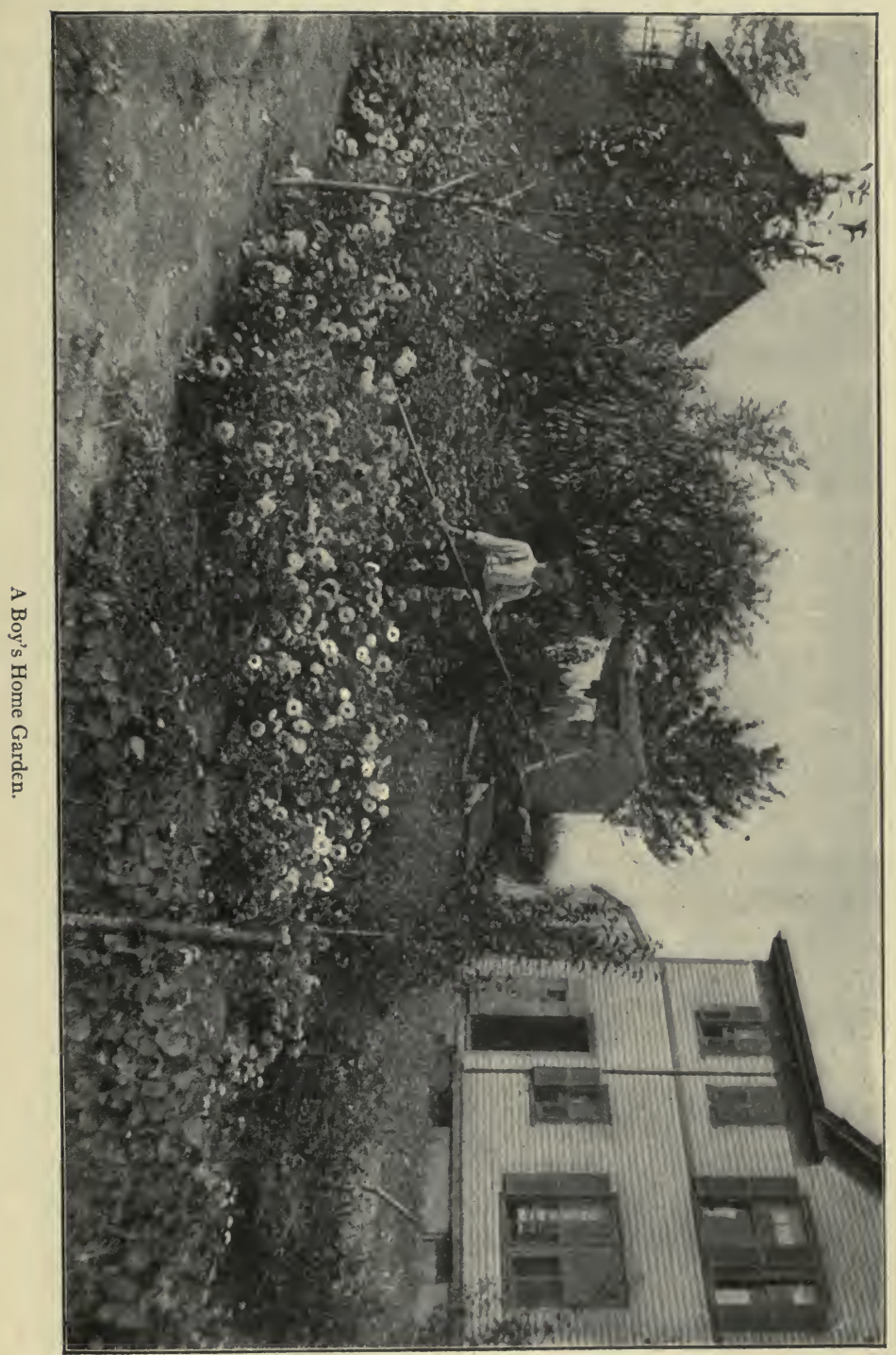


bit of nature seemed appropriately piaced beneath the carving that signified the goodness of nature's God. The following spring Alessandro's father was one of several who rented the only back yard of the street and turned it into a group of thrifty kitchen gardens. Thus a little garden, if merely a keg, may produce a bountiful crop of vigorous self-sown seedlings.

Herman was better situated. His father had been skilled in gardening in Germany, and was thrifty enough to rent a cottage with an ample back yard. Herman and his sister took great pride in their home, and under their father's instruction spent many hours in work about it, so that they well deserved to win the first prize of ten dollars for home ground improvement. The shrubs were pruned and fertilized. The lawn was renewed and kept trim. The walks were edged and raked. Flowers were placed in border beds and beside the porch. In the rear there was row after row of vegetables within the border of small fruit. Not only were there peas, beans, corn, and the like, but celeriac, salsify, winter radishes, cauliflower, Brussels sprouts, kale, endive-familiar enough in Germany, but most interesting to the neighbors here in America, who came to see and inquire, and at times to imitate.

Arthur's large back yard garden is a wonderful surprise to one who knew this same yard last year-a waste of dump heaps overgrown by a tangle of burdock and jimson weed. Arthur was the leading spirit in transforming this forbidding tract of street sweepings into an orderly array of plots for flowers and vegetables, with trim walks sloping down to the brook in the rear. This large family of French-Canadian boys and girls had put the same energy into clearing away a 
long-established forest of weeds that their ancestors had used in replacing the primeval forests of spruce and pine in Canada with thrifty habitant homes and fields.

One might thus call the roll of races that have lately come to our lands and its cities. The descendants of the earlier comers are often in the lead in garden work, however. Their opportunities are usually the best. There is Albert, for example. He lives close to the boulevard that runs along the sea-wall. His parents have ample means and spacious home grounds-lawns and shrubbery. Albert caught the love for flowers at school, even as Abe and Alessandro did. His father granted him generous garden space. His uncle, fortunately, could give him the advice he needed. He himself gave the unflagging zeal to the accomplishment of ambitious plans that was the chief essential to their success.

A plot fifty feet by ten was ploughed, then spaded, fertilized, and worked into shape by Albert himself. In the early spring mornings he was at work; in the evenings he enlisted his uncle to help plan the next day's advance. Having abundance of pocket money, he purchased such large clumps of hardy perennials as the school garden could spare for sale-bleeding-heart, larkspur and iris, phlox and calliopsis. He had to enlist his comrades in carting the heavy clumps home. There he carefully set them out, and, though in full foliage, without wilting, for he had eased them up and down the curb stones. so gently that the masses of earth and roots remained unbroken. Then he studied the seed catalogues evenings and planned to grow several dozen sorts of annual flowers, with dahlias and gladioli at the back of the bed. Everything prospered because he added his own devotion and pluck to every dime and dollar he spent. 
When the city horticultural society gave its September exhibition, Albert's display took first prize for flowers from a child's garden, just as Herman's ranked the highest for vegetables. Albert's flowers were carefully selected, and

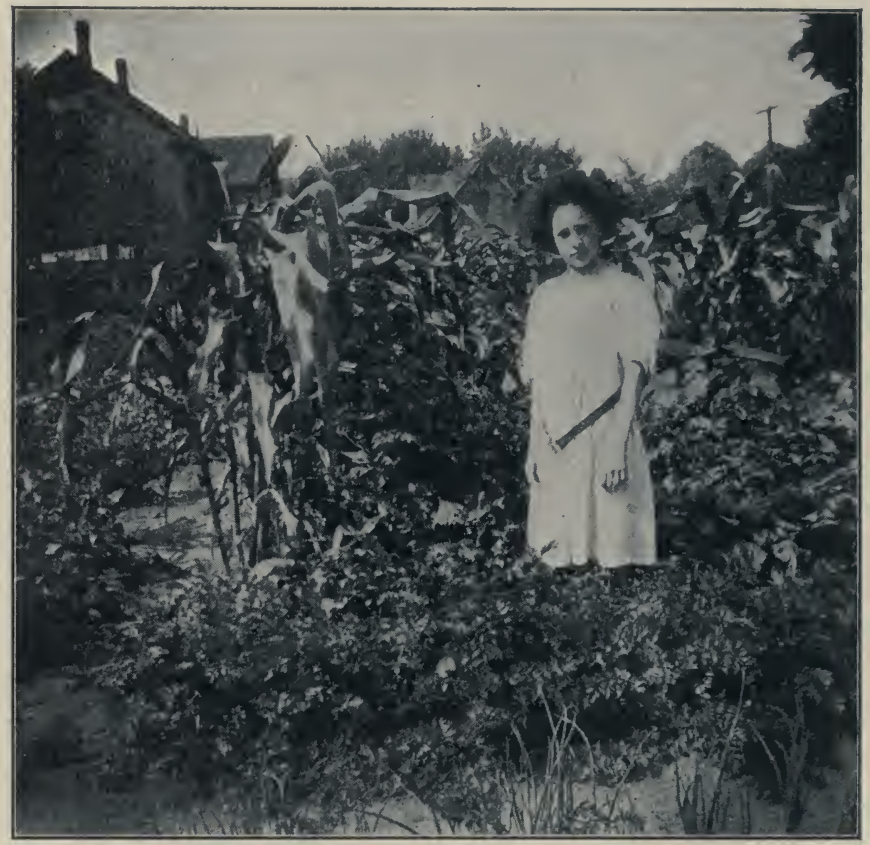

A Good Home Garden.

reached the hall fresh and perfect. Each sort was in its separate bottle, and marked by labels prepared neatly in advance. Many visitors could hardly believe that a boy had grown so varied a collection of flowers in his first year of garden work. Many another boy resolved to have a garden the following year. 
If time permitted, we might visit such gardens as these day after day; some pathetic, some humorous, most inspiring, all worth the while. There are gardens of girls as well as of boys; girls in the slums who can hardly afford a couple of penny packets of seeds, and girls who are free to delight in lilies and other bulbs of high cost in their own home plots. Enough have been seen here, however, to impress the general conclusion that in home gardening, as in all life, where there's a will there's a way. Every youth must study his own home conditions and resources, and after choosing the plan of work most practicable for him, then persist with this plan until it is realized.

\section{THE SPRING AWAKENING}

No season is so welcome to the owner of a garden as is the spring. The disappearance of the snow, the coming of the birds, the tasselling of the alders are doubly precious, because they foretell that thawing of the ground which shall enable us once more to delve in it for happiness and profit. It is like a perpetual renewing of youth, for the garden promises are always fair to think upon, and in the seed we plant we always see a finer harvest than in the crop we gather. Yet, herein lies much of the delight of gardening; it gives us opportunity to hope for the fruition of things unseen. For hope is life, and when we can no longer hope, life is no longer worth the living.

The wise gardener studies his conditions to learn what crops may be planted to advantage as soon as the soil can be worked, thus prolonging his season of out-door activity, and perhaps his season of crop gathering. It is a time-honored saying that when the bluebirds come one should begin to 
think of planting sweet peas; and the smooth "sour peas," as some one called the garden peas to distinguish them from the flowering sorts, may be planted at the same time. Not many, however, for a little later one may plant the new variety called Gradus or Prosperity Pea, which is nearly as early as the smooth sorts, and of very much better quality. The chief value of Alaska and similar smooth varieties is to enable you to get a mess of home-grown peas for dinner a few days earlier than your neighbor, and thus be able to acquire a local reputation as a skilful gardener.

There are other things also to plant early. One of the most delicious vegetables, when home-grown and gathered fresh, is spinach, but it is often sadly neglected. Plant the seed as early as the ground can be worked, in rows a foot apart, sowing the seed fairly thickly in the row. It will

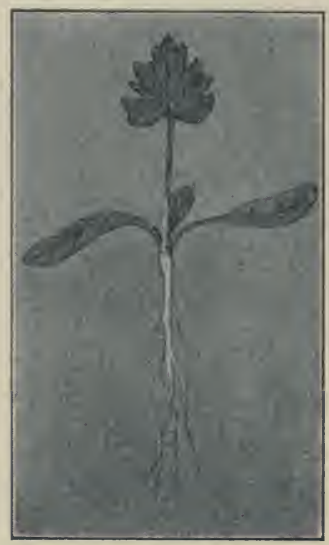

Parsnip Seedling. come up early, and may be gathered in plenty of time for some other crop to be planted. This first crop also will escape the attack of the leaf-miner, a vexatious pest that is very likely to spoil later crops. We have had best success with Victoria Spinach for spring planting. Buy the seed, not by the packet, but by the ounce or pound.

Carrots also may be planted early to give a supply for kitchen use in summer. Such varieties as Early Chantenay or Earliest Short Horn are best for the first sowing. Parsnip seed may also be sown very early, choosing Early Round for the summer crop. Salsify, or vegetable oyster, needs 
to get an early start, and Sandwich Island mammoth is the best variety to plant.

Lettuce and radishes are likely to be the first-gathered "fruits" of the spring sowings. They may be planted when the ground is in good working condition, choosing of each the quickest maturing varieties. The early strains of French Breakfast Radishes are excellent, as are also the Olive-shaped Scarlet, the White Icicle Radish, and other similar sorts. The onion sets for table onions may be planted at the same time as the lettuce and radish, and these will yield quick returns. Onion seed for the later crop should also be planted early; and beet seed should get an early start to make rapid growth and be ready for the table early.

\section{PLANTING HARDY ANNUALS}

As soon as the frost is out of the ground it is time to begin work in the out-door garden. Some of the annual flowers and many of the perennials do best when they are planted very early; consequently, it is desirable that the ground should be thoroughly prepared for their reception as early in the season as possible. In such preparation three things are necessary: the eradication of witch-grass or other perennial weeds that are likely to take possession of the soil; the enrichment of the soil with some fertilizer that will enable it to furnish plant food in abundance and in easily available form; and such tillage as shall render the soil mellow and easily worked, so that it will take in rainfall readily and will be in good condition for penetration by the delicate roots of the growing plants.

The modern gardener is no longer content with a bit of ground in a geometrical design in the midst of a lawn, for 
growing flowers. He realizes that generally such a flower garden is ineffective and is likely to spoil the beauty of the lawn as well. He chooses instead the borders of his grounds, where he can plant to advantage a variety of hardy perennials, as well as many annuals. And for such of the annuals as he desires especially for cut flowers, he chooses some part of the vegetable garden, or else a bit of ground behind the house where such plants can be grown in rows, so that they are easily tilled and supply the greatest number of flowers for the smallest amount of care.

In the preparation of the soil for the annual flowers it is extremely desirable that all traces of witch-grass should be dug out with greatest thoroughness. The fact that a bit of ground is completely infested with this plant need not deter one from utilizing it for growing flowers, for it is easily possible to eradicate the stems and roots by a thoroughgoing treatment with a digging fork, and especially with the implement commonly called a potato-digger, which serves admirably for pulling out the stems. Such infested ground should not be dug up with a hoe, or even with a spade. It is better to dig it up first with a tined digging fork and then to go over it thoroughly either with the fork or a potatodigger, pulling out all traces of underground stems, placing them in loose piles to dry, and then burning them, being very careful also, as a New England farmer once said, where you put the ashes.

In the way of fertilizers there is nothing so generally useful as thoroughly decomposed barn-yard manure, as this not only adds all the elements of fertility, but helps in the mechanical composition of the soil, and probably also in supplying and furnishing the desired conditions for development 
of the bacteria which of late have been found to play so important a part in the growth of plants. The commercial fertilizers, however, are also very useful, especially those

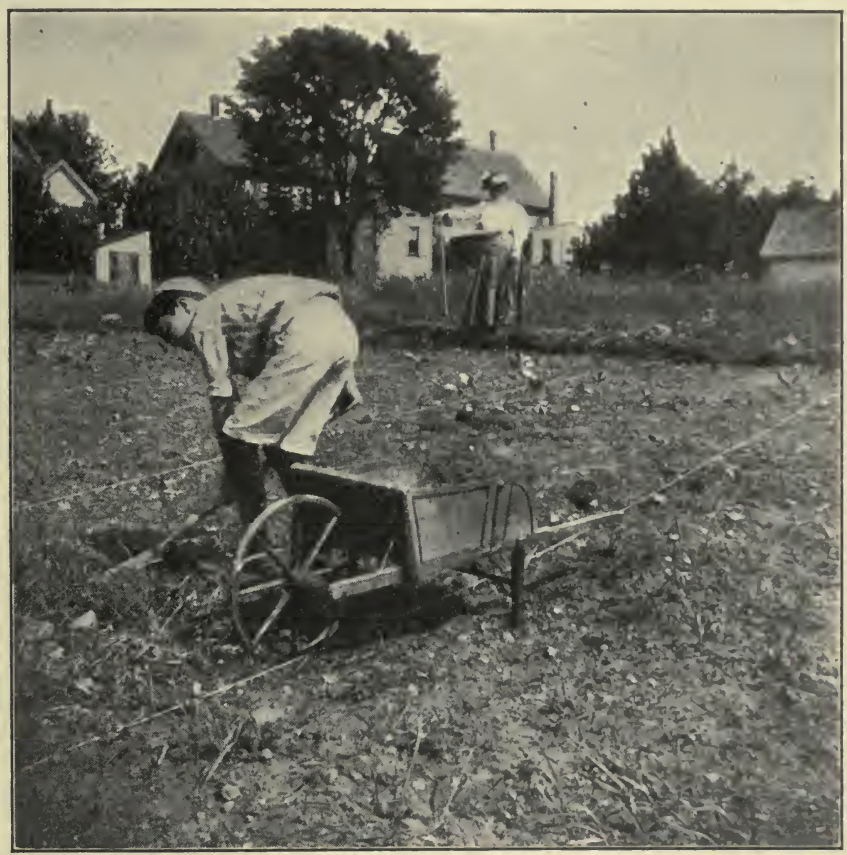

Getting the Gardin Ready.

which have a large quantity of fertilizing material available over a considerable period of time.

In the matter of tillage the amateur gardener should see that the ground is in the best possible mechanical condition before it is planted. The soil which has been dug over to get out the witch-grass will be pretty certain to be fine enough. Other soils should be worked over with a digging- 
fork and raked until they are free from stones and lumps of earth.

In the cases of the hardy annuals much better results are obtained by planting early, as soon as the ground is in good workable condition. One of the plants in which this precaution is of special importance is the poppy. A very common reason for failure in poppy culture is that of planting too late in the season. This is especially likely to be true in gardens where one must depend upon nature for rainfall to keep the soil moist. The seeds are so small that the tiny plants quickly wither under adverse conditions. The remedy for this is to sow the seed early when there is an abundance of rain and when the sun's rays are not so parching on the surface of the soil. In the case of a later planting it will often be necessary to water the soil artificially.

Poppy seeds are so tiny that they require some care in planting. One is sure to sow them more thickly than is desirable unless the seed is first mixed with dry sand or corn-meal, and it must be covered very lightly. Make a tiny furrow and scatter the seed in it, then sprinkle it with a watering-pot. This will generally cover the seeds to a sufficient depth. When the plants are up, thin them from time to time until there is room for each one to develop normally.

The garden portulaca, or sun plant, is a beautiful flower of various colors, which is of special value as a bedding plant in hot, dry situations where few flowering plants can be induced to grow. It is very easy to cultivate, and it has lately been found that the seeds may be sown in the poppy bed and the young seedlings allowed to develop in the shade of the poppies until after the latter have gone by. After the poppies 
are pulled up the portulaca will then occupy the bed for the remainder of the season.

One of the best hardy annuals for use along the border of the flower garden is the candytuft. This plant has been in cultivation for a long while, and is considered indispensable by every florist and gardener. While the varieties most commonly grown are white, there are other sorts having carmine, crimson, and lavender flowers. The easiest way to grow the candytuft is to sow the seed where the flowers are to.blossom, thinning as the plants develop. This is one of the best flowers to use in home or school gardens. Sweet alyssum is another low border plant of easy culture.

One of the most satisfactory hardy annuals for flower beds is the Drummond Phlox. This plant has the advantage of being

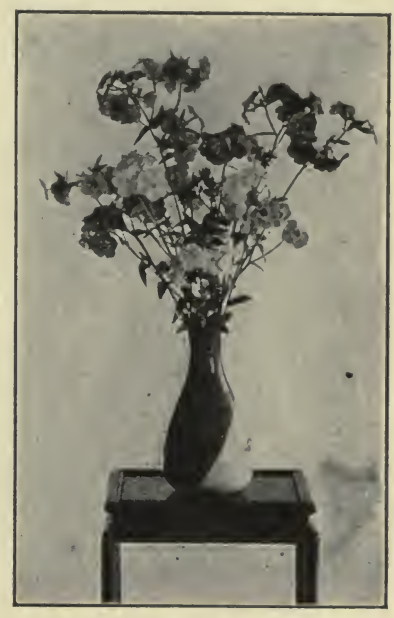

Drummond Phlox. very easy to grow and of showing a great variety of beautiful colors. The so-called dwarf varieties which reach a height of eight or ten inches are generally to be preferred to the taller sorts. They bloom for a long period when the seeds are sown out-doors early in May. They should be thinned or transplanted to about eight inches apart.

The California Poppy is another very desirable hardy annual, which may be sown as soon in spring as the ground can be worked. The gray-green foliage is very attractive in itself and serves as a background for the beautiful blos- 
soms, commonly yellow in color, although recently there have been placed upon the market attractive varieties of red and striped flowers.

There are many other hardy annuals with which the young gardener should become familiar as rapidly as possible.

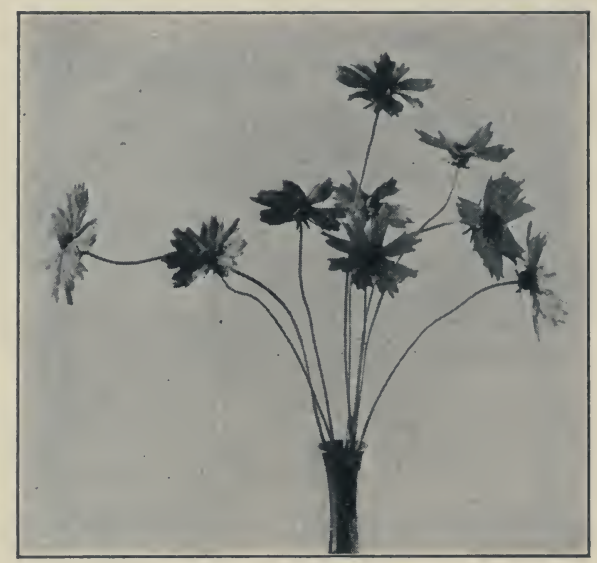

Blossoms of Coreopsis.

Among the more important are the French and the African Marigolds, the calliopsis or coreopsis, the annual chrysanthemums, the nemophila, the pansy, and the zinnia.

\section{THE APRIL CALENDAR}

\section{Out-doors}

Sow in a sheltered seed-bed in the garden the seed of such hardy annuals as are to be transplanted.

Sow seed of hardy annuals that are not to be transplanted, in the position where they are to grow: California Poppy, poppies, sweet peas. Sow the hardy root-crops-beet, carrot, parsnip, radish, salsify, turnip; 
the hardy bulb crops-leek, onion; the hardy cole crops-Brussels sprouts, cabbage, cauliflower, kohlrabi, kale; the hardy pot herb and salad crops-dandelion, spinach, celery, chard, lettuce, parsley; the smooth hardy peas of the pulse crop group and the early hardy varieties of sweet corn.

Plant early varities of potatoes, and onion sets for bunch onions.

TRANSPLANT early cabbage plants from cold-frames and young onion seedlings from seed boxes.

HARDEN OFF toward the end of the month early tomato plants by placing them on a sheltered porch or some place where they can be protected at night.

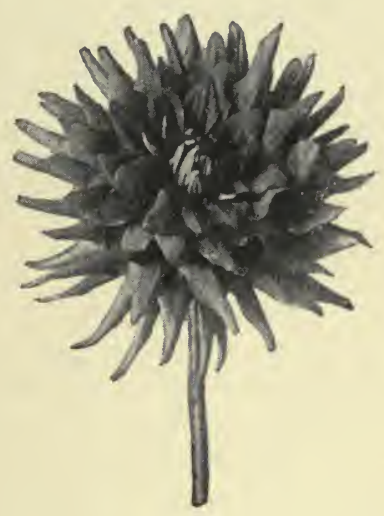





\section{MAY}

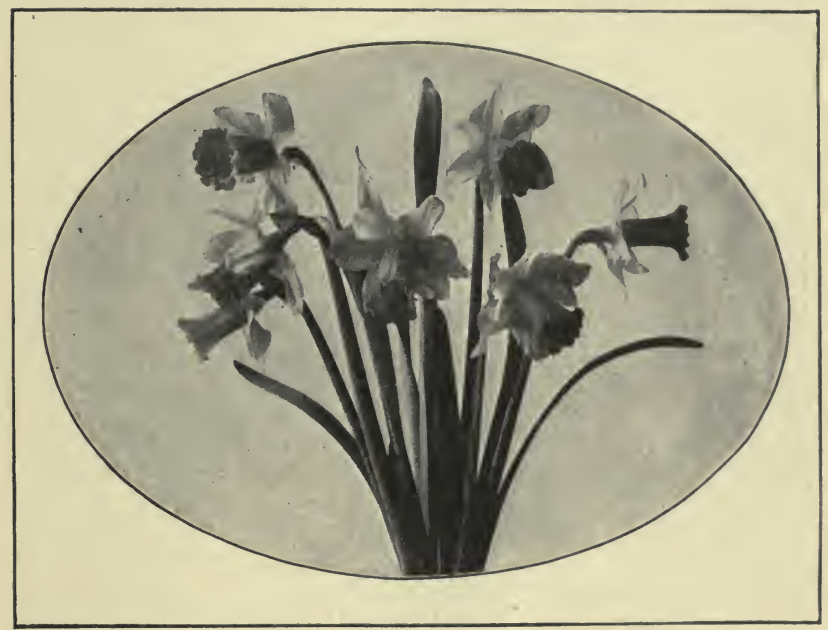

Trumpet Daffodils.

I wandered lonely as a cloud

That floats on high o'er vales and hills,

When all at once I saw a crowd,

A host of golden daffodils,

Beside the lake, beneath the trees,

Fluttering and dancing in the breeze.

-William WordsWorth. 


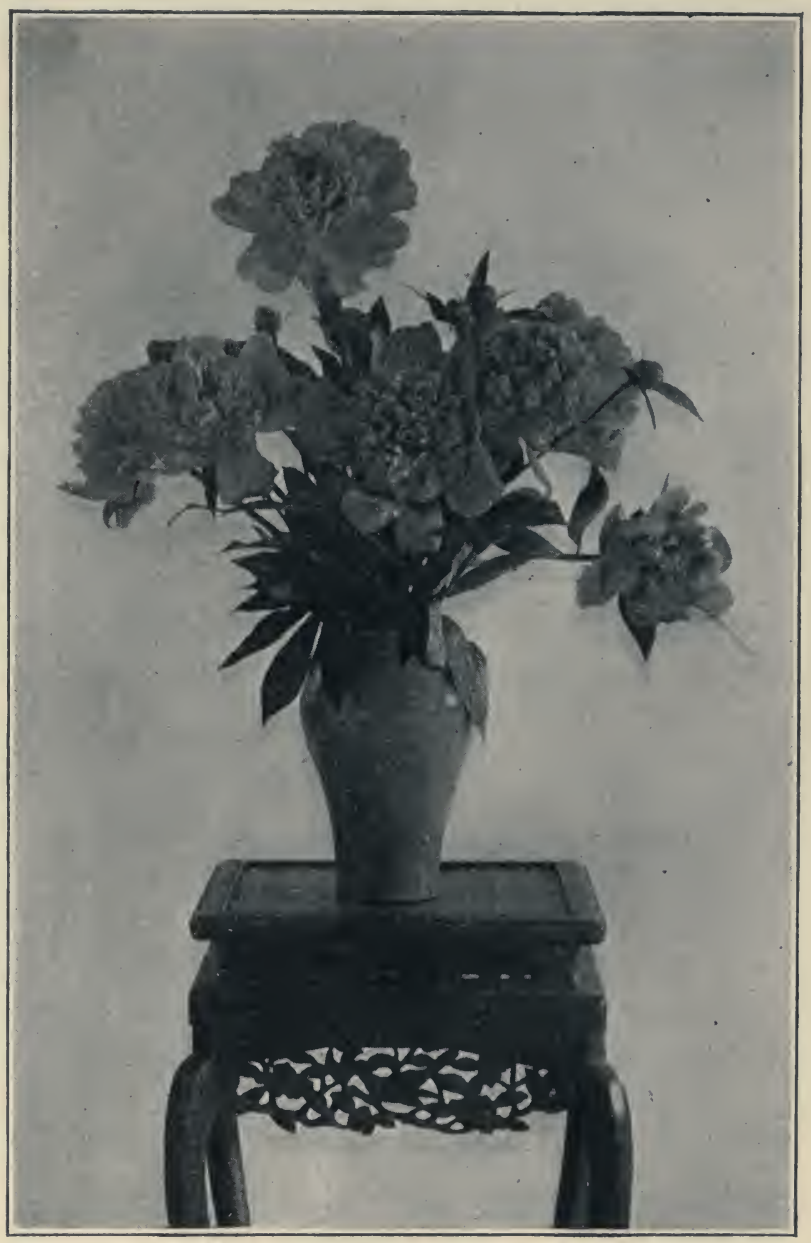

Peonies in a Japanese Flower-iar. 


\section{IX}

\section{MAY}

\section{HARDY PERENNIALS}

The wise gardener will set aside a part of his border garden for a bed for the hardy perennials - those beautiful flowering plants which once established will remain from year to year. In the preparation of the bed it is well worth while to go to considerable trouble in order to get the best conditions for the raising of flowers through many seasons. If the soil can be taken out to a depth of eighteen inches to two feet and the bottom filled in with a well mixed combination of thoroughly decomposed barn-yard fertilizer and soil, it will prove a lasting benefit to the plants. If this cannot be done, a large amount of such fertilizer should be spaded into the soil.

There are so many beautiful flowers on the list of hardy perennials that the average gardener cannot hope to grow them all. It is better to choose those types of flowers that will go well together. Of course, the tallest growing sorts will be planted in the background and the lower in the foreground, and some wise selections will be worth while in order that the garden may have some type of flower in blossom throughout the season. It is more desirable to plant generous clumps of every sort chosen than to dot the garden with single plants of many different kinds.

In the case of the hardy perennials, as in the case of the annuals and most other flowers, there is a very marked 
educational value in making, for a time at least, a specialty of certain favorite flowers grown in named varieties of the principal types of each, thereby becoming familiar with their appearance and habits of growth. One who would thus

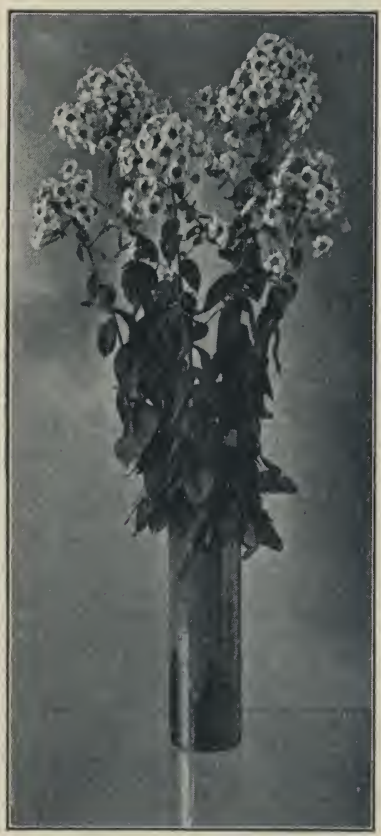

Perennial Phlox. make a specialty of the Perennial Phlox, the columbine, the iris, the larkspurs, the campanulas, or the peony would soon acquire a special knowledge which would add greatly to his interest in gardening.

Most of the hardy perennials start their growth early in the season, and consequently it is desirable to plant them as soon in spring as the ground can be put thoroughly in order. Those which bloom early, like peonies, however, are best divided and transplanted in September, for this allows them to become well established before winter, while abundant new roots are thus developed to support large blossoms the following spring.

The Perennial Phloxes are among the most indispensable of the hardy border plants for a home garden. Coming into bloom rather early in summer, they continue to make a beautiful display until autumn, and may be had in a great variety of colors, so that one can suit almost any taste in their selection. They are easy to grow and the plants are in- 
expensive. Their period of bloom may be lengthened by cutting off the terminal buds of some of the stalks early in the season. This will cause numerous side branches to be thrown up, and these will bear a profusion of blossoms throughout the later weeks of summer. The slips removed in topping the plants should be rooted in sand, then established as new plants.

The irises are exceedingly attractive as border plants. The splendid Japanese Iris is perhaps the most decorative of all our cultivated flowers, while the German Iris - bears blossoms of exceeding beauty. The Siberian Iris is very effective when out-doors or in the house, on account of the long leaves and flower stalks and the attractive blue or

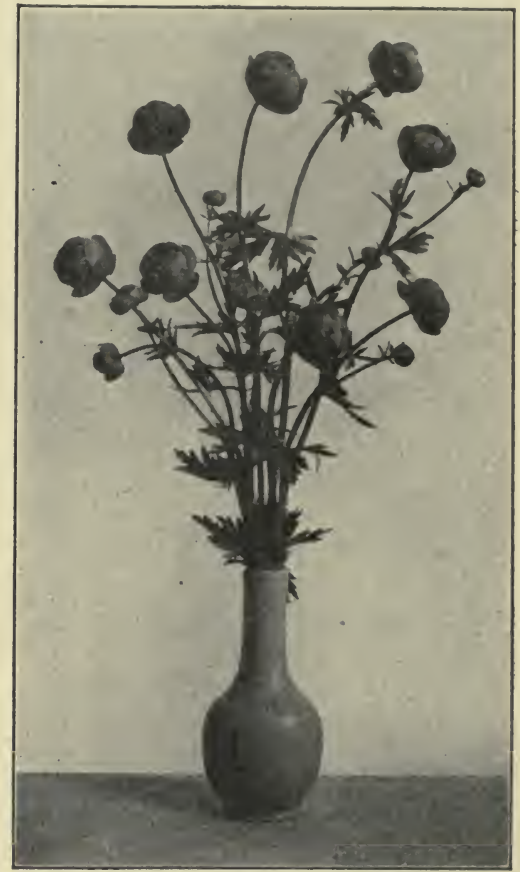

The Trollius or Globe Flower. white blossoms. There are also a number of kinds of iris suitable for the front of the border, on account of their shorter leaves and flower stalks.

The trollius, or globe flower, is a spring flowering, hardy perennial which is not nearly so much grown as its beauty deserves. The blossoms look like great double buttercups 
and exhibit some of the most brilliant tones of yellow to be found in the plant world. The foliage is finely cut and of a beautiful yellow green. The plant is attractive either in the hardy border or for use in in-door decoration, and in May adds a great deal to the attractiveness of the flower border.

The columbines form another group of attractive border plants which are well worth growing. The native wild columbine is one of the best forms, but there are many other single sorts of equal beauty. These plants are easily raised from seed.

No border garden is complete during early summer which does not show a few varieties of the beautiful peonies with their wonderful rose-like blossoms. These display some of the most charming and delightful flower tints to be found in the world of flowers. One should be sure to plant some at least of the light-colored single peonies and learn to discriminate between the simple beauty which they display and the more fulsome beauty shown by the ordinary double peonies.

The golden glow is a hardy perennial which is becoming so generally grown that it is scarcely advisable to make room for it in an ordinary border garden. It is a particularly desirable plant with which to fill in waste spaces or to be grown by people who are not willing to give any special care to the flower garden. It spreads rapidly and soon overruns the other flowers; consequently, it had better be given a corner by itself where it will not have anything to interfere with its development. While it makes a good showing of color and is effective at a distance, it has not the elements of beauty that will bear careful analysis, and it is one of the least desirable for cut flowers of all the hardy perennials. 
Many of the hardy perennials may be grown from seed, although, as a rule, they do not blossom until the second season. This commonly is the cheapest way, however, to get a supply of plants, and it is worth while to raise them in this manner, especially where money is not available to buy well developed plants for starting the border garden. The plants themselves should be purchased in the case of phlox, iris, and any sorts which, while multiplied easily by division, cannot be obtained in choice varieties from seed.

\section{CLIMBING VINES}

The climbing vines serve a particularly useful purpose in covering with a beautiful mass of leaves and flowers, fences, porches, arbors, and the sides of buildings. Nearly all require some support which will enable them to get up in the world by means of tendrils or leaf-stalks or twining stems. Many of the best climbing plants are annual vines. And these are particularly useful on account of their cheapness and their rapidity of growth. The seeds may be planted in the spring with the expectation that by the middle of summer a growth of many feet will have been made, and that the plants will retain their beauty through the remainder of the season.

The typical morning-glories belong to the great genus I pomoea, which includes also the moon-flower and cypress vine. In some seed catalogues various sorts of bind weeds of the genus Convolvulus are also called morning-glories. Some of the typical morning-glories of the former group are annuals, while others are perennials. The largest and most beautiful sorts are the Japanese or Imperial Morningglories which were introduced from Japan a few years ago, 
and have become very popular on account of their ease of culture and the size and beauty of the blossoms. These vary greatly in color and form and are among the most gorgeous of all garden flowers.

The morning-glories are of easiest culture, thriving even under adverse conditions and growing luxuriantly in favorable situations. The outer covering of the seed is very hard, and the most common reason for failure with these flowers is due to this fact. In order to insure the germination of the seed a corner of the seed-coat should be notched with a file, so that the moisture from the soil may have access to the interior and enable the miniature seedling to break through. The seed may be sown where the plants are to blossom, or, perhaps better, on account of the uncertainty in germination, they may be planted two or three inches apart in a drill and the seedlings transplanted to the permanent situation when the seed-leaves are well developed. They will bear this transplanting readily, and one is thus more likely to get an even stand of plants.

These morning-glories, especially the Japanese sorts, may very well be started early in-doors in small paper pots, and transplanted out of doors when danger from frost is past. The Japanese varieties will come into blossom in six or eight weeks after the seed is planted.

The moon-flower is deservedly popular as a climbing plant, giving a luxuriant growth of foliage and large beautiful flowers that open toward evening. Otherwise it is very similar to the better sorts of morning-glories, and requires much the same treatment. It is especially essential that the seeds be notched before planting, in order that they may germinate successfully. 
The cypress vine is a well-known plant of the morningglory group, which is sometimes called the Indian Pink. Its original home was in tropical America, and it has been quite generally naturalized in the Southern States, where the wild plants blossom from July to October. On account of its rapid growth and attractive color it is useful as a climbing plant in many sorts of situations. The common form has scarlet flowers, but there is also a white-flowered variety.

The wild cucumber is one of the most popular annual vines, being extremely useful on account of the rapidity with which it grows and the beautiful effect produced by its leaves, stems, and blossoms. When once established, it will re-seed itself each year, a large number of plants coming up from the seed produced in great abundance in the curiøus fruit pods that mature during the summer and autumn. It is better to lea:e the seeds out of doors on the ground where they are scattered than to bring them in-doors through the winter, as they thus seem to produce stronger and healthier plants. If seeds are purchased, they should be soaked in water for several hours before planting; and it is better to plant with the eye of the seed downward.

As the wild cucumber climbs by means of numerous tendrils which reach out in all directions, it will take advantage of almost any support that may be provided. It makes a particularly effective growth when it is planted beside unsightly dirt piles or rubbish heaps, which it covers and transforms into beauty. It also grows effectively upon wire netting and is a desirable plant to use along wire backstops for tennis courts and similar purposes. The leaves, tendrils, and fruits are particularly desirable as objects for drawing. The plant is also called the wild balsam apple. 
The plant from tropical America which is known in the catalogues as Cobea scandens is one of the best climbing vines available to American gardeners. In its native home it is a perennial, but it is so tender that with us it is to be treated as an annual. The compound leaves have commonly fourstalked leaflets, with the terminal leaflet transformed into a tendril by means of which the plant supports itself as it climbs. The bell-shaped flowers often have a diameter of one and one-half inches, and are either white or purplish in color. The projecting saucer-like calyx around the base of the flower serves to give the plant its common name.

This cobœa is easily grown from seed, which should be planted edge downward that it may come up more easily, and the seed should be covered very slightly. The young plant grows rapidly and in a single season will reach a height of ten to twenty feet, with a varied profusion of handsome flowers. Sometimes other leaflets besides the terminal one will show an interesting tendency to develop tendrils.

There are many hardy vines that are distinctly desirable, and which may be purchased reasonably from dealers in plants at prices given in all the large seed catalogues. Some may be easily raised from seed in the school garden, for example, the Japanese Clematis-Paniculata-whose glossy foliage is hidden in late summer by its profusion of starry white flowers. The Japanese, or Boston Ivy is used to cover the glaring brick walls of many city schools with a curtain of waving green. Such a transformation is as desirable as the change from a yard of gravel and weeds to a well-equipped playground bordered with shrubbery and flowers. The blue berries of this vine persist through the winter, and they may be gathered, their seeds separated and planted at any time of 
spring or summer. Planted thus freshly they germinate readily. The only difficulty is that in most cases they are not hardy the first winter, and so must be protected with a coldframe while seedlings, or grown in the house until of sturdy growth. While annual vines will be used freely at first, it is desirable gradually to introduce the perennial sorts as a mainstay.

\section{WINDOW-BOXES AND PORCH-BOXES}

The outside window garden serves two important purposes. On the one hand it renders the building more attractive to the eyes of passers-by, lighting up the bare walls with patches of beautiful color, while on the other hand it serves to bring to the occupants of the room a continually. renewed suggestion of the beauties of the outer world, giving to those who are confined to the town through the summer months, a suggestion at least of the natural beauties which are enjoyed by those more fortunate ones who are able to escape to the country. The window garden should always please the sense of sight, making the room inside more attractive, and, in the experience of many people, making it appear larger and more spacious. Such a garden may also be made to minister to the sense of smell, that "poet of the senses" which receives so much delight from the delicate fragrance of beautiful flowers.

It is very desirable that the window-boxes be at least ten inches wide and six or eight deep, as this gives an opportunity to fill them with a considerable amount of rich, loamy garden soil, and of course the larger the amount of soil in proportion to the evaporating surface, the easier it is to keep the plants from suffering from drouth. The boxes may very well be 
made of inch boards nailed tightly together and painted both inside and out. It is, of course, desirable that the paint used should be the same color as the house, but if this is not practicable a dark green color will generally harmonize with the plants.

Two methods may be employed in attaching the windowboxes to the house. The first is by the use of the metal brackets to be bought in a great variety of sizes at the hardware stores. These should, of course, be held in place by long screws that run directly into the upright joists of the house, and it will be desirable to paint the brackets the same color as the house. The other method is to fasten the box upon horizontal pieces which run out from a board nailed to the house far enough down so that the window-box fits directly underneath the projecting window ledge. Each of these horizontal crosspieces is held in position by a long bracket piece running from the end to the sillboard of the house. Any one at all skilful with hammer and saw could attach a window-box in this way in a very short time.

Inasmuch as the window-boxes have the direct shelter of the house, one can generally start them considerably earlier than it is safe to plant tender flowers in the larger garden in the ground. The late frosts are not likely to be sufficiently severe to injure the window-boxes, rendered safer both by the house and by the fact that they are several feet from the ground.

If one can get the plants for stocking the window garden from a florist near at hand, it is desirable to do so, as such plants will be well established in pots and may be transferred to the window-box with little or no checking of their growth. In cașe plants are received by mail it will generally be neces- 
sary to pot them and care for them carefully until they are fairly established, when they may be transferred to the window garden.

Two methods of planting the window-box are open to one. The first is to set the plants directly into the soil, allowing the roots to ramify in all directions and to intermingle as they will. This has the advantage of giving a greater opportunity for root development, and, on the whole, for most plants is likely to give surer and better results. It has the disadvantage, however, that the plants once started cannot be changed in position or removed without serious interference with their growth. The other method is to leave the plants in good-sized pots, which are sunk into the soil so that the roots of the plants are practically confined to the pots, although after a considerable period some of them may escape through the hole in the bottom or over the surface of the top. This method has the obvious advantage of enabling one to take out a plant at any time and replace it by another without serious disturbance to the box as a whole. It also has the advantage of enabling one to turn a plant around occasionally, so that if it starts to have a one-sided development, on account of the greater exposure to sunlight of that side, this may be avoided. The method chosen may well vary with the differing conditions. Not infrequently it may be desirable to adopt both in the same box, placing the vines along the margins of the box directly in the soil and setting the plants along the middle in pots. The pots, of course, should be completely submerged, in order that there may not be unnecessary drying of the roots. 
It is entirely practicable to have a successful window garden on a northern exposure. In order to obtain the best results here, as in other situations, it is desirable, of course, to choose plants which thrive in the shade. There are a number of flowers which may be utilized for this purpose, and in most northern exposures one can depend upon a certain amount of sunshine either in the morning or the afternoon.

\section{The Plants to Use}

The caladiums belong to one of the most beautiful groups of plants which may be used in such boxes for they are among the most decorative of all our foliage plants. These caladiums may usually be purchased from the florist. Two or three such plants will make a very satisfactory show throughout the season.

Asparagus sprengeri is another excellent plant for the north window-box. It grows luxuriantly in partial shade, and if a good-sized specimen be planted it will rapidly increase in leafage during the weeks of early summer. The Boston Fern, or some of the recent varieties of it, may also be used to advantage in such a box. An excellent combination may be made by putting a good-sized Boston Fern in the middle of the box and a plant of asparagus sprengeri on each end, utilizing some vine to plant along the front margin of the box. Among the other plants that may be utilized for the north box may be mentioned some of the hardier begonias like the Rubra Begonia, some of the more beautiful fuchsias, of which the variety called Phenomenal is a good example, while for the vines one may use some of the ornamental vincas, the manettia vine or the Japanese Morning-glories, as well as the maurandia vine and the Trailing Fuchsias. 
It would be difficult to imagine a more graceful and attractive window-garden plant than the so-called Asparagus Fern. The delicate foliage of this is exceedingly popular, both as an ornamental house-plant and for greenery to use with cut flowers. It certainly would be well worth while to try either one good-sized plant in the middle of the box or two smaller ones near the ends, especially in situations where the broad masses of delicate spray would not be too severely exposed to strong winds and beating rains.

An eastern exposure is ideal for many kinds of plants in an outside window garden. The box receives the morning sun, so that all the plants get a considerable amount of direct sunshine, but they are not subject to the overpowering heat of the afternoon sun. One can grow successfully in an eastern exposure almost any plants which are available for window-garden culture, although a few shade-loving sorts are likely to thrive better in a northern exposure.

One of the most attractive of the upright plants for the east window-box is the white antirrhinum or snapdragon. Probably there will be more satisfaction in growing the Dwarf or Tom Thumb varieties of these than the very tall varieties. The Queen of the North is one of the most satisfactory of the white sorts. It grows to a height of one foot, and several plants may be set rather close together in the window-box. Another plant which may be used with great satisfaction in such a box is the heliotrope, the delicious perfume of which will come through the open window and scent the room in a most delightful way. Boston Ferns may also be utilized for an eastern exposure, while the Tom Thumb Nasturtiums are here particularly satisfactory. For vines in this situation, one can utilize almost any of the climbers and trailers. The 
wild cucumbers are particularly satisfactory, running up trellises at the ends of the boxes and trailing down over the sides in a way to give an astonishing amount of foliage and blossoms.

Some of the tuberous begonias may well be utilized here, the window-box being a particularly desirable place for growing these plants with their wonderful richness of coloring. It is better not to try to grow more than two colors of these begonias in the same box, and of these two colors one should be white. The double petunias are also admirable flowers for this exposure, the light or pink varieties lighting up the box in a most delightful way. These plants when well grown cover a considerable surface, so that one should be careful not to crowd too many into a box. A box containing two wellgrown plants near each end, with some upright plants like the antirrhinum between them and some vines along the front margin, will make a very attractive effect through the summer.

An excellent vine for use in the east boxes is the interesting plant called solanum jasminoides. As will be noted, this plant belongs to the same genus as the potato, and the white flowers which are borne in beautiful jasmine-like clusters show by their structure their family relationship. The vine is not very generally known, and it would be worth while to try at least one in the middle of the box for the sake of its novelty. The climbing or trailing nasturtiums may, of course, be utilized in these boxes. By choosing colors that harmonize with the colors of the other fluwers in the box one can get very attractive results. 


\section{Special Plants Required for West or South Exposures}

An exposure to the south or west is a trying one for a window garden, as the great heat of the afternoon sun is reflected upon the plants with almost terrific effect. It is, of course, desirable to choose for such exposures hardy plants from more or less tropical climates, which will thrive under these conditions. Perhaps no plants are better adapted to this exposure than the nasturtiums. One can easily obtain beautiful boxes from nasturtiums alone, planting the tall-growing sorts along the margins, to hang over the sides or be trained up beside the windows, and in the middle the Dwarf or Tom Thumb varieties, to yield an attractive upright foliage and a vast abundance of beautiful flowers. No plants are more satisfactory and more easily grown in a window-box, and one can easily choose from the great number of varieties now available a. wide range of colors in flowers. Most people have decided preferences.with regard to these, and one should choose named varieties, the colors of which are individually attractive. If one has already started some nasturtium seedlings in pots, it will be desirable to transfer them directly to the window-box, and thus have them reach the blossoming period earlier.

No plants are more satisfactory for use in these boxes, that get the full glare of the sun, than the various geraniums, those hardy flowers which seem so well adapted to all conditions of existence. One can get a great range of color in the blossoms of these geraniums, one of the most popular being the brilliant hues of the variety called Eugene Sue. Another favorite is the variety called Bruant, which has blossoms of a 
vivid scarlet color. Almost any florist can furnish these as well as the plants of some good white geranium. A good pink variety is the one called Granvilie. For combining with boxes in which these upright geraniums are growing, one may utilize the maurandia, a graceful climbing or trailing plant, which will thrive in a sunny exposure, or the familiar little trailing plant commonly called gill-over-theground or Ground Ivy, often referred to in the books as Nepeta Glechoma. This is much more attractive trailing down from a window-box than it is as it grows on the ground.

\section{Porch-Boxes}

During recent years plant boxes upon the railing or sides of the porch have become almost as popular as have windowboxes, and in general what has been said regarding the former also holds true of the latter. The porch-boxes, however, commonly have the advantage of not being directly against the reflecting surface of house or window, so that the plants do not have to endure so fierce a heat. They generally get, also, considerably more shading on account of projecting roofs.

In addition to their use for beauty, the porch-boxes are often very effective as screens, giving to the occupants of the verandas a privacy to secure which screens or awnings might otherwise be necessary.

In stocking these porch-boxes the same general principles hold as in the case of the window-boxes. The exposure will not be quite so important, for the reasons already indicated, and if the boxes are larger more plants may readily be inserted. Wild cucumber is likely to prove very serviceable in good-sized boxes which are not too directly exposed to the 
southern or western sun. It can be run up upon wire netting and allowed to trail down, forming during the latter part of the season a very beautiful screen. Various other vines can be utilized in the same way.

Many city homes have no other door yard than the flat roof of the building or of some shed or projection from a lower story. Sometimes these little areas in the air, where clothes are hung to dry, are made very beautiful hanging gardens by surrounding them with boxes and half-barrels of soil where a variety of vines and flowers are grown. Not only annuals, but the hardier perennials may be made at home in these seemingly unfavorable conditions.

\section{PLANTING TENDER ANNUALS}

When the mild weather of spring has had time to warm up the soil somewhat, so that danger from frost is past, it is time to sow out-doors the seed of such tender annuals as one may desire to grow. The results from such planting will be much more satisfactory if one has prepared beforehand a careful garden plan in which the flowers to be grown are arranged with reference to harmony of color and form as well as to the time of blossoming.

Most of these annual flowering plants may very well be sown in the position in which they are to grow, the seed being scattered rather sparsely in the rows and the seedlings thinned out when they are two or three inches high, so that each one left will have plenty of room to develop. It is often desirable, however, to sow in some seed-bed such of the annuals as may readily be transplanted and then transfer them to their permanent situation. This is the case when 


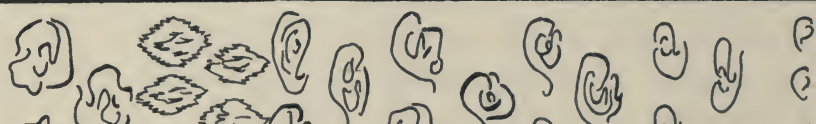

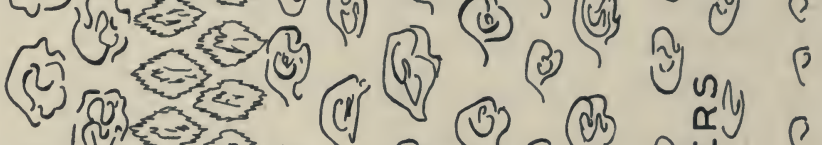
(ल)

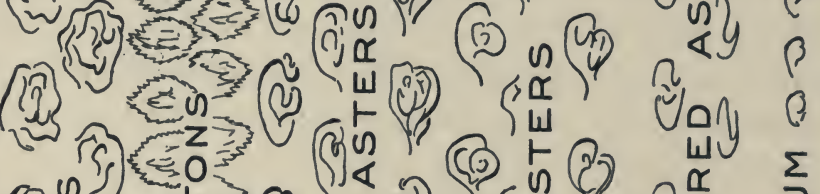

$\begin{cases}y, 0 \\ y\end{cases}$

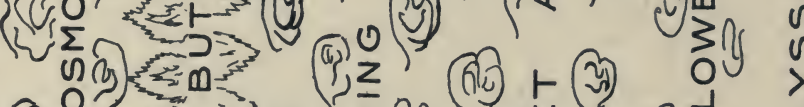
S

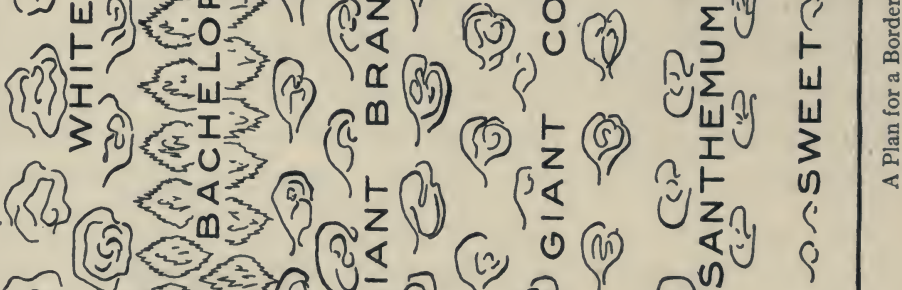

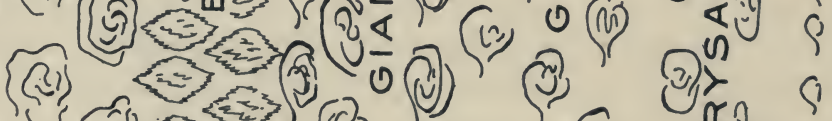

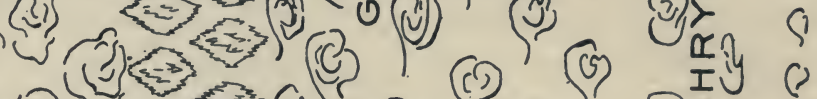

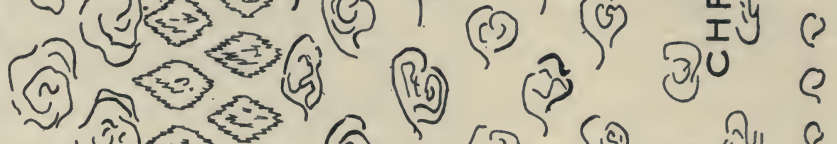

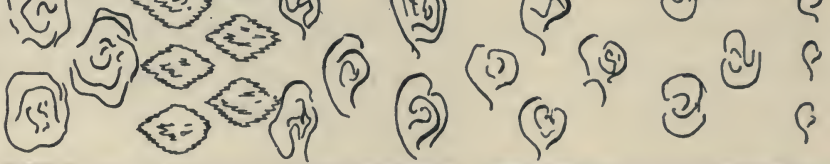


one wishes to fill in with summer flowers the ground occupied in spring by the spring flowering bulbs.

Among the flowers that may be transplanted in this way to great advantage are the cosmos and the China Asters. Both of these are likely to do as well when thus started out-doors as they will do if the seed is started in-doors under the ordinary conditions of the house or school-room. While you desire to get the cosmos started as early as one can obtain a good growth, it is neither necessary nor desirable in the case of most kinds of China Asters; for these will blossom freely in August and September, if the seed is sown out-doors about the middle of May, and the blossoms are not so likely to go by before the end of the open season. The young aster plants are really hardy, sometimes coming up in early spring from self-sown seed of the previous autumn, so that they can, if so desired, be planted out-doors as early as the other hardy annuals. In the case of the large branching varieties, it seems probable that you will get longer stems and larger flowers from seed sown early. Try it and learn for yourself.

\section{THE MAY CALENDAR}

\section{Flowers}

Sow in a sheltered spot near a building, or in a cold-frame, seeds of all flowers that are to be transplanted.

Sow in places where they are to remain seeds of other flowers.

Plant the outside window-boxes and porch-boxes. Make each a picture that shall have unity.

PLANT late in the month the summer flowering bulbs-dahlia, gladiolus, tuberose.

FURNISH support of brush or wire to sweet peas as soon as they are five inches high. 
Vegetables

Sow for succession: beet, turnip, cabbage, spinach, lettuce, wrinkled peas.

Plant main crop of potatoes.

Sow during last half of month the pulse crops-beans and peas; the vine crops-cucumber, melon, pumpkin, squash; also sweet corn and okra.

TRANSPLANT to permanent position during last half of month, if danger of frost is past, tomatoes, peppers, and egg-plants.

HoE or rake the soil surface about all crops.

THIN and weed all crops sown in drills.

HARVEST earliest crops-radishes, onions from sets, lettuce, spinach. 


\section{JUNE}

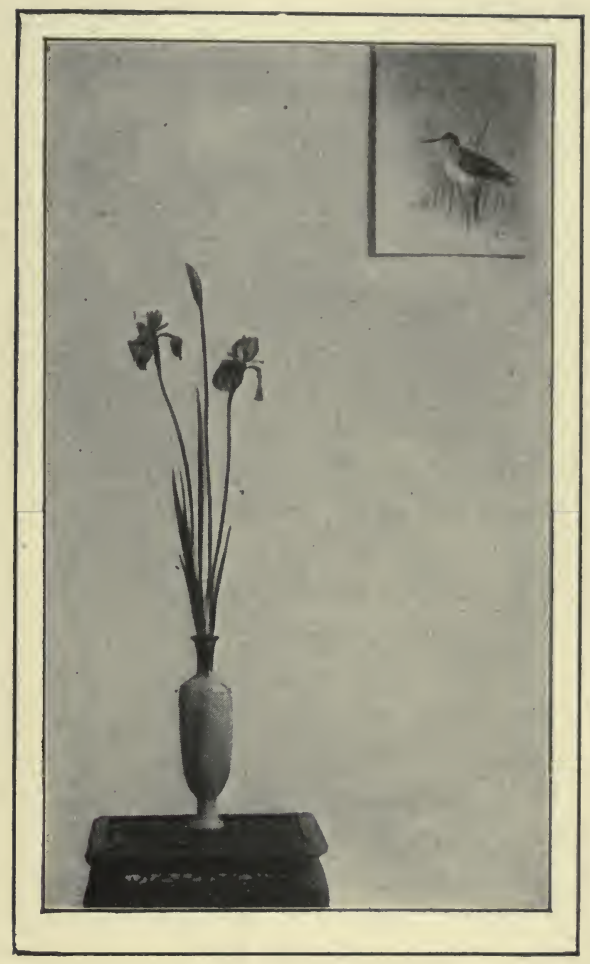

Orıental Iris.

"If so the sweetness of the wheat Into my soul might pass, And the clear courage of the grass." 


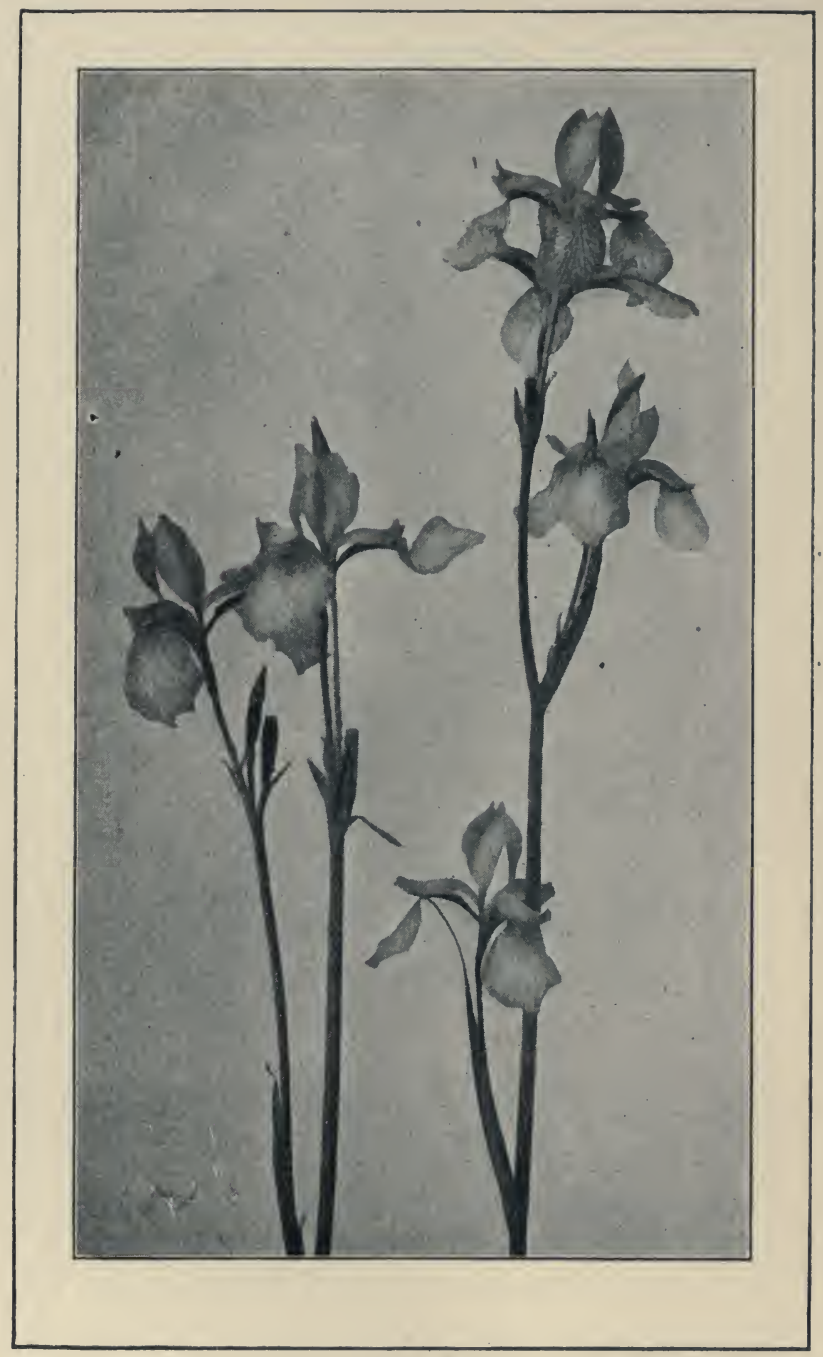

Siberian Iris. 


\section{$\mathrm{X}$ \\ JUNE}

\section{IRIS BORDER GARDENS}

Some one has well said that the greatest trouble with our planting of flowers is the stinginess of it. It is largely on this account that the average border garden falls far short of its possible attractiveness: it usually contains a very few plants of many different sorts which fail to harmonize and so fail to give a suggestion of unity. Now the out-door garden should have in it the elements of a picture, and in a picture the first requirement is that of unity.

A great improvement may easily be brought about in the decorative value of our border gardens by making more special plantings of certain types of flowers. A bed of peonies, of phlox, of Japanese Anemones, of iris, or of almost any of the hardy perennial plants may readily become a feature of extraordinary attraction.

Perhaps no type of plant is better adapted for use in such hardy border gardens than the iris. These exist in a great variety of special blossoms which differ in the time of blooming and vary greatly in height of plant and in size of flowers. They all, however, have a uniformity of growth that enables one to combine them in the same bed with excellent results. In the following diagram is indicated the planting plan for a simple and inexpensive iris bed which would certainly prove a most attractive feature in the border of any grounds. The back row against the fence or wall or the side 
of the building consists of the beautiful Japanese Iris planted two feet apart. Breaking ranks with these, and one foot toward the front of the bed, is a row of the stately Siberian Iris, and in front of these again is a row of the similar German Iris. It would be possible to put in front of the German Iris a row of our attractive native blue flag, and these will thrive

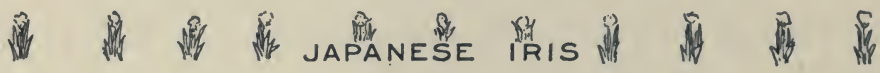
总 泣

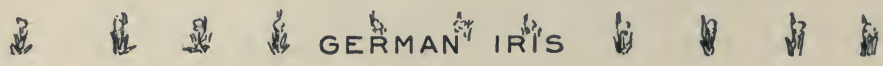

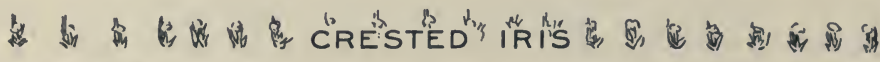

\section{Plan for Iris Border Garden.}

vigorously provided an abundance of water is furnished through the summer season. This is omitted in the plan, however, there being indicated along the front border only a double row of the beautiful Crested Iris which comes into blossom in May shortly before the German Iris. This should be planted even if the native blue flag is also planted, since its dwarf habit renders it desirable for the front of the border.

An iris bed should prove of fascinating interest to any lover of flowers. It would furnish a display from May until August and would give throughout the season an attractive show of the decorative leaves. The low-growing Crested Iris will blossom by the middle of May, to be followed at once by the stately German Iris, and in June by the flowers of the still taller Siberian Iris, and these again in July will be succeeded by the magnificent blcssoms of the Japanese Iris. 
These iris plants are not expensive. One should be able to buy good clumps for setting out at from fifteen to twentyfive cents each. The German and Siberian Irises increase so rapidly that they should be divided and replanted every third or fourth year. It is therefore easy for a school to obtain a good variety of colors of German Iris by means of clumps and divisions received as gifts from home gardens. If neighbors possess or purchase different varieties, they can secure good collections in every home yard by means of exchanges. The plants should be divided in August or September: the blossoming period is then over, the roots are well developed, and time remains for the divisions

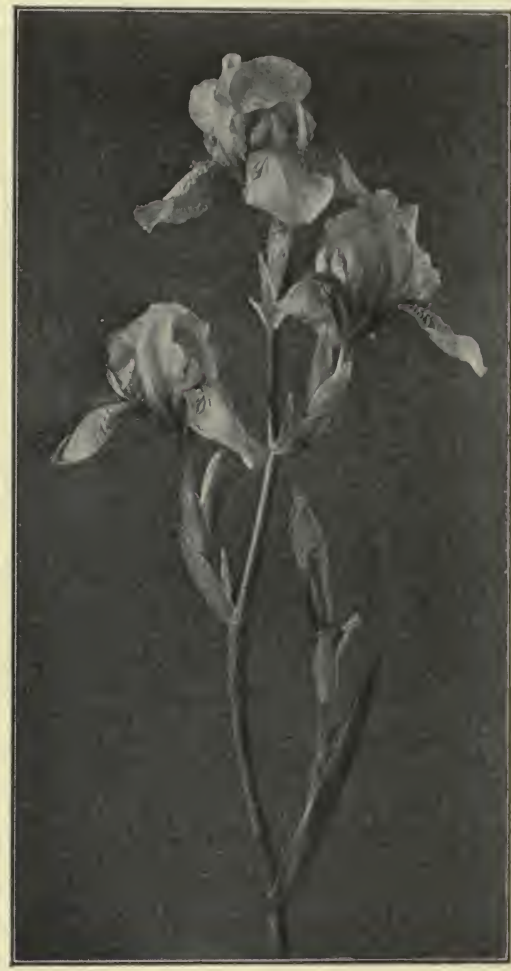

German Iris. to become established before winter. The iris may be transplanted, or even divided, in early spring, however.

The beauty of the German Iris is particularly satisfying. While the structure of the flower is similar to that of the other. 
members of the iris group, the individual parts are so large that they are readily seen and comprehended by any one. At the base of the blossom there are two clasping parts which form the spathe. They cover the undeveloped buds and generally enclose the ovary or fruit pod at the base of the flower. This ovary, which is easily seen by pulling one of the valves of the spathe to one side, is more or less longitudinally ribbed and furrowed.

Arising from the top of the ovary, as we see it from the outside, is the perianth tube, which is a little less than an inch long, and gives rise at its upper end to the showy parts of the flower. These consist of three large sepals, having enlarged outer ends curving downward. Each of these downward parts is called a "fall." Arising from between the bases of these sepals are very slender petals which curve upward and inward, rather than outward and downward. These are commonly called the "standards."

The combination of the downward-curving falls and the upward-curving standards offers opportunity for an infinite variation in the display of colors, and in the scores of varieties of the German Iris some of the most beautiful and delicate colors conceivable are displayed on these surfaces. The space above the sepals and between the petals is occupied by a curious modification of the central pistil of the flower, which covers and protects the stamens, and which projects upward at the end to form what the florists call the "crest." Just below the crest is a stigmatic surface upon which pollen must be left if the ovules in the seed pod are to develop into seeds.

In the conditions of nature, this whole curious device of the structure of the iris serves to bring about the cross- 
pollination of the blossoms by means of bees and other insects that alight upon the fall and crawl down beneath the crest, to get the nectar secreted in the base of the blossom. As they thus go downward their backs are rubbed first against the curious flap of the stigma, leaving upon it any pollen that may have been placed there during a previous visit to another flower. This supply of pollen is immediately replenished from the stamen with which the back of the bee next comes in contact.

Every important flowering plant has certain characteristics upon which its claim to human regard is based. Its beauty may lie in the grace of its foliage, the

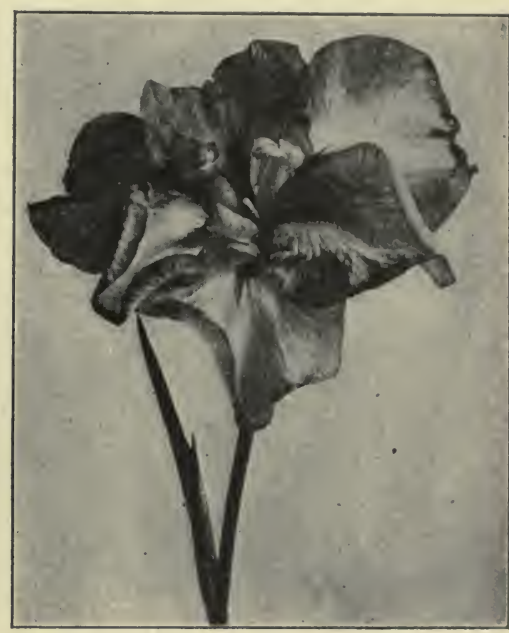

Japanese Iris.

form and color of its flowers, the attractiveness of its ripened fruit, or in a combination of all these features. In the Japanese Iris the lance-like lines of leaf and stem are very decorative, but the blossom is the thing that catches and holds the eye. In the horizontal platform of the expanded petals nature has given us some of the most beautiful color tints to be found in all the world. Cerulean blues, royal purples, brilliant yellows, and glowing whites are the favorite colors in these displays, colors which in one variety may stand alone, while in another they may exist in wonderful com- 
binations that compel admiration from the most indifferent beholder.

The Japanese Iris multiplies less readily than the other sorts, is not quite so surely hardy, and is somewhat more expensive. But the blossoms are the best of all the family.

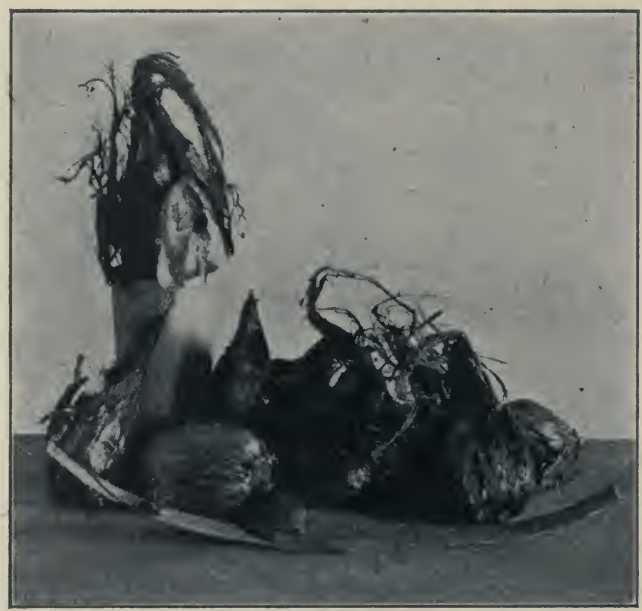

Bulbs of English Iris.

Good results can be obtained by growing this from seed. In two or three years the plants will come into flower.

There are two other sorts of iris, the English and Spanish, which are bulbous. The bulbs are very cheap when bought by the hundred, and as they come into bloom after the German and Siberian Irises are past flowering, it is well worth while planting clumps of them in fall in front of the Iris border. They need to be renewed at least every second year, and require winter protection.

While it is not necessary that the iris bed should be in an absolutely wet place, it is very desirable that it should not be 
in one that is too dry. A northern exposure which is shaded part of the day will serve very well, and a situation in which a thorough soaking may be given through the growing season will be advantageous. In the preparation of the bed it is desirable that the soil be taken out to a depth of eighteen inches and the bottom be filled with a thoroughly mixed compost on top of which good garden loam is to be placed. If the bed is in a low situation, where water will stand to soak in without running off, it will be a very simple matter to apply the water. If it is not in such a situation it will be worth while to arrange for subirrigation by a series of two-

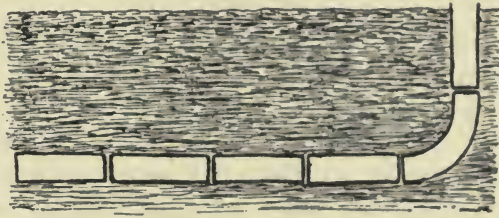

Plan for Subirrigation. or three-inch drain tile placed in a trench in the way shown in the diagram. With this arrangement it is only necessary to run water from a hose into the upright tile and let the stream pour slowly in until the bed is thoroughly saturated. This arrangement will tend to draw the roots downward, where they are least likely to suffer during dry weather.

The irises are commonly planted both in late summer and in early spring. In the former case they should be protected by a mulch of loose litter through the winter, although the German Iris is so hardy that it will survive with no cover.

\section{BEETS, TURNIPS, AND CARROTS}

The beet is one of the most satisfactory of garden vegetables, provided one has a deep, rich, moist, loamy soil to grow it in. In poor, sandy soils it dries out quickly. Beets are likely to disappoint the expectations of the gardener 
in such a soil. They may be grown, however, by adding a nitrogenous fertilizer and furnishing plenty of water during the growing period.

Beets are commonly classified into two principal groups, based upon the size of the roots. These are, first, the flat or turnip-shaped varieties, and the oblong or long-rooted varieties. The former, however, are much more popular because they mature more quickly and are more tender and better for table use. For the home or school garden, the turnip-shaped varieties are certainly much more desirable than the others.

Every seedsman offers many varieties of beet seeds, and the same is true of most vegetables. An inexperienced gardener hardly knows which to choose. For thorough knowledge of a vegetable it is well to grow several typical varieties the same season, that by comparison one may decide which is best for his conditions and which he prefers for his table. Every school garden may wisely present a few vegetables in such representative variety every year. In the case of the beet, one should grow not only varieties of turnip-shaped beets praised by the different seed growers, and several varieties of the long beet, but also one or more varieties of sugar beet.

The growth of the beet is very simple. The seed may be sown as early in the spring as the ground can be got into finely pulverized condition, planting sparsely in drills, the rows being at least a foot apart. The seedlings will soon come up, and should be thinned early so that the plants stand about half an inch apart. Two weeks or more later, they should be thinned again, leaving the most vigorous plants to stand about five inches apart, and utilizing the young plants pulled 
up for greens. The rows should, of course, be kept free from weeds, and the surface of the soil between them should be frequently stirred.

If the seed is planted early in the spring and grows rapidly under favorable conditions, the beets will be large enough for table use early in summer. If they are to be sold they may then be pulled and tied in bunches of five to seven each, when they make a very attractive appearance for market.

Beets may be secured a little earlier if started in a deep flat or cold-frame and transplanted. In some sections this practice is followed on a large scale, and the plants are sold by the thousand for planting out. When transplanting, care should be used not to injure the fine feeding roots, for otherwise the growth will be checked materially.

A fall crop of beets may readily be grown for autumn and winter use. Sow the seed in August and treat in the same way as indicated for the early crop. Beets so grown are much more tender and desirable for the table than those which were sown earlier and stored away for autumn and winter use.

Every amateur gardener should have at least one row of carrots in his garden. These are interesting plants to grow. They require little care after the young seedlings are well started, and furnish a decorative touch to the garden on account of the finely cut, beautiful green foliage. The roots are utilized for soups and stews, and when young and fresh are delicious served as a vegetable alone.

Two general types of carrots are commonly grown: in one, the lower end of the root is distinctly pointed; in the other, the lower end of the root is rounded. In both of these types there are different varieties in which the length varies greatly. 
There are also variations in the color. The common forms are orange, red, or yellow, but there are also varieties which are white and others which are purple. For school and home gardens, the early varieties are generally the most desirable to plant. Of these, the half-long sorts are the more satisfactory. If one has a cold-frame, however, the little round early forcing variety will be particularly pleasing; for it comes to maturity in a few weeks, and has the finest flavor as a table vegetable. Its quick growth commends it for use in the school garden, since it may be harvested before school closes in June.

Like many of the seeds of the great parsley family, to which this plant belongs, the seeds of carrots are generally rather slow in starting. Consequently, it is desirable to scatter in the same row with them a few radish seeds, in order that the latter may come up quickly and mark the rows so that the ground may be hoed before the weeds have a chance to start. The carrot seed should be sowed rather thinly in rows about a foot apart, and the young seedlings thinned to about four inches apart when they are well up. The plants do best in a moist, loamy soil, the surface of which should, of course, be kept well tilled and free from weeds. Care must be taken in hoeing that the plants are not covered up by too much soil on the one hand, and that the soil is not drawn too much away from them on the other. They are not a quick-growing crop and require, even under favorable conditions, eight to ten weeks before they reach a size large enough for use.

About the only insect that is likely to be troublesome to the carrot is the caterpillar of the black swallowtail butterfly. These caterpillars are green and black in color, and on 
account of the injury to the foliage are easily seen when at work. It is a simple matter to shake them off and thus stop their damage, while it is well worth while to place a few of them in breeding-cages and rear them to butterflies. They will feed freely upon the leaves of the carrot, parsley, or related plants, and will soon change into chrysalides, to change again a little later into the beautiful butterflies.

Provided one has a moist, loamy soil, the turnip is a very easy crop to grow. It thrives especially in cool weather, and consequently should be grown in spring or early autumn rather than in midsummer. The seed germinates about as quickly as does radish seed, and the tops are hardy, enduring early frosts without injury. Turnips are commonly divided into four great classes, according to the shape of the roots. These are, first, those varieties in which the root is distinctly flattened; second, those in which the root is round or topshape; third, in which the root is oval; and fourth, in which the root is conical or subcylindrical. The varieties most commonly grown belong to the first two groups, and for ordinary garden purposes it is scarcely worth while to grow the others.

The seeds of turnips are very small and' it is difficult to avoid sowing them altogether too thickly. As germination tests have shown that a large proportion of the seeds will germinate, it will be worth while for the young gardener to mix the seed thoroughly with fine sand before sowing it. In this way he can sow it more sparsely and save himself much trouble in the subsequent thinning of the plants. The seeds should be sown in drills and covered with about one-half inch of fine soil. In a few days the seedlings will appear and should be thinned rather early. It is well to plan for two 
thinnings: the first when the plants are very small, leaving them about one-half an inch apart in the row; the second when they are larger, leaving them about three inches apart in the row. After this, pull the young roots as fast as they get large enough to eat, and this will give room for those that mature later to spread out to a larger size.

Summer grown turnips are very likely to be badly injured by root maggots, a pest that is difficult to contend against. The earliest crop is not so likely to be injured. In localities where these insects are very abundant, it is scarcely worth while to attempt to grow turnips unless one has a considerable area, so that the crop may be rotated from place to place in succeeding years.

\section{POPPIES}

Few flowers are more exquisitely beautiful than poppies, although the very quality of the beauty necessitates that it be ephemeral. Poppies may be grown in any garden and the glorious blossoms are yielded in great abundance, while the variations of type are so numerous that one may gratify almost any artistic taste with them. The simple whiteness of the single Shirley Poppy is very different from the gorgeous splendor of the bright-balled Fairy Blush, while between the two are all gradations of form and color. No flowers, perhaps, are better adapted to the school garden than these; to give each child a row of one variety to care for would be a means of liberal culture.

Poppy blossoms are creatures of a day, but this transitoriness enables their lovers to handle them afresh each morning with new delight. To Celia Thaxter, whose passion for poppies has been revealed so delightfully in the pages of 
"An Island Garden," we are indebted for the knowledge that the blossoms will last through the day if picked very early, while the dew is on them. And the gathering of them at this time brings its own reward, for if there are visions of greater loveliness in the outer world than that of a poppy garden, dew-bediamonded in the rays of the rising sun, they are rarely seen.

In the use of these flowers in-doors it should be remembered that both the leaves and the pods are essentially decorative, so they must not be left out of the scheme of display. Tall jars or vases are needed for this purpose; glass will do, but the warm tones of the Japanese jars are better.

Of all the varieties of poppies the Shirley Poppies are favorites with many lovers of flowers. The leaves are slender and full of grace, and the flowers consist simply of four great petals, inside of which is a circle composed of many stamens, while in the centre is the broad, ribbed, and rounded pistil. Within the pistil are the ovules which are to develop into the tiny seed when the decorative pod ripens.

On the delicate surface of these translucent petals nature paints the most exquisite colors. In some cases the whole flower is of a single hue, while in others there are beautiful combinations. One variety is of a glorious poppy-red with a broad white cross at the base; the stamens have white filaments and yellow anthers. Another is a wonderful tint of orange vermilion, varying slightly in color tone from the base outward. Another flower is a combination of pink and white, the petals being a charming geranium-pink color with a narrow margin of white; the ring of light yellow anthers in the middle of the blossom forms a pretty combination with the light pink. 
The pure white Shirley Poppies are certainly among the most divine of garden blossoms. They are types of that serene and simple beauty which is its own excuse for being, before

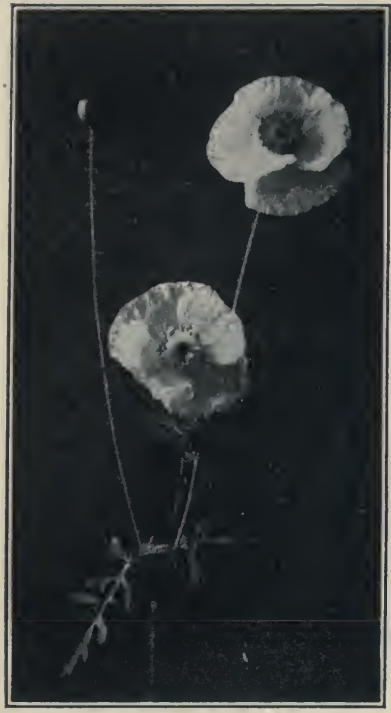

White Shirley Poppies.

From "The Flower Beautiful." which the pen hesitates in token of the hopelessness of adequate portrayal. "If I wished to paint a gloriously simple flower," writes Schuyler Mathews, "I should choose one of these simple white poppies." To attempt to describe a sunset, a beautiful woman, or a white Shirley Poppy to one who had never seen any of them would be a hopeless "escalade of heaven," but, fortunately, every one has seen each of these, and words may serve to bring to remembrance the beauty of the vision. "What is a poet? Why a poet is as much as one should say-a poet." So with this poppy: it is a Shirley Whitesurely that is enough.

\section{SUMMER FLOWERING BULBS}

There are three important bulbous flowering plants which may be planted to advantage in spring in order to get the development of the flowers in summer. These are the gladiolus, the tuberose, and the dahlia. The flowers of each are very different from those of either of the others, yet each in its way is well worthy of cultivation. 
The gladiolus is one of the best summer flowering bulbs for planting in the border garden or in unoccupied corners along a fence or hedge row. The bulbs, which in their structure are like those of the crocus, and so are called corms, are inexpensive, and the plants thrive with the simplest treatment. The bulbs can be planted as early in spring as the ground is in good condition to work. They should be set three or four inches deep and will do better in loamy rather than clayey soil. There should be a succession of plantings every two weeks until the first of July; this will give a long period of flowering and will enable one to have a splendid display of blossoms from early in summer until late in autumn.

The large attractive blossoms of the gladiolus are borne closely crowded in long spikes and the lowest flowers develop first. If the spikes are cut when they are just coming into blossom and placed in water in-doors, the flowers will continue

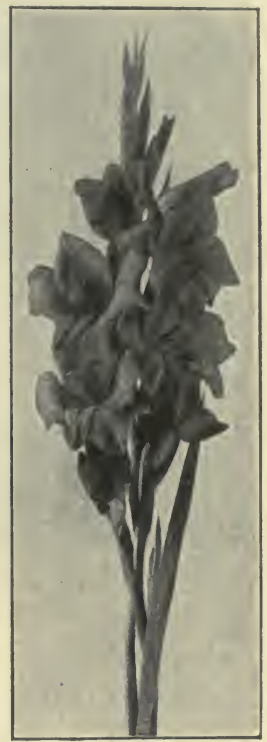

Gladiolus. to come out for many days, yielding a lasting and very interesting display.

The tuberose is one of those plants which were formerly much more popular than they are to-day; but it is well worth while to grow a few specimens in order to become familiar with the attractive blossoms. The bulbs require a rather warm temperature for their development, so that it is not worth while to plant them until the ground is warm and the 
weather is well settled. In the more northern localities they may be planted to advantage about the first of June. Good bulbs may be bought from the florists at small cost and should be set in rich loamy soil, covering about one inch deep. The

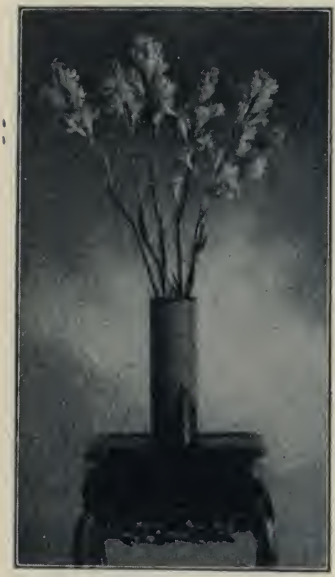

A Jar of Tuberoses plants will develop rather slowly and should blossom in September, producing long spikes of white flowers with a heavy sweetish perfume.

There are few flowers that will give so great a decorative show the same season that they are planted as the dahlia. On this account these plants are particularly desirable for use in new places where the shrubbery has not become fully developed, or where one wishes an attractive display along the wall or fence or in the border garden. For these are the situations where the dahlias may be used to greatest advantage.

One advantage of the dahlia to the average gardener is the ease with which the plants may be grown. If started early from seed in the house, the plants will bloom the same season. It is so easy to multiply the fine named varieties, both by division of the clumps of tubers and by rooting the separate sprouts that spring from them, that these methods are usually followed both in the home garden and by commercial growers.

In April or May the tubers should be taken from storage and divided with a sharp knife. With skill, a clump may be so divided as to give every tuber a portion of the base of the 
plant stem with one or more buds or sprouts. Some sprouts are long and must be handled with great care to avoid breaking them, while other buds are so small as to be hardly noticeable. The best tubers are held to be the smaller ones, which will serve to start the new plant, but which will not check the development of vigorous roots by too large a supply of food. If one has lost his tubers during the winter through some fungous disease, either single tubers or wellrooted plants from flower-pots may be bought of florists or wholesale dealers in plants, then placed directly in the soil.

Too much moisture and enrichment of the soil during the early stages of growth, however, tend to produce more foliage than flowers. It is perhaps better to give the plants top dressing as a mulch when the buds form in midsummer, and follow this with frequent watering during the time of flowering. Unless in a sheltered situation, the plants will be blown over during high winds, the stem is so succulent and the spread of foliage so large. Therefore, all save the shorter Pompon Dahlias should be tied to stout stakes driven into the ground beside the tuber.

\section{THE JUNE CALENDAR}

\section{Flowers}

Go over the surface of the hardy border gardens carefully for chance seedlings of Perennial Phlox, columbine, hardy coreopsis, wild aster, and other plants. Transplant these to some place where they may develop until they flower and show whether or not they are worth saving.

Transplant early in the month, China Aster or other seedlings among the daffodils in the border garden. These will be starting as the daffodil leaves ripen.

WaTcH for greenflies or aphides on allants. When seen, see if there 
are enough ladybird beetles present to kill the aphides; if not, spray with sulpho-tobacco soap or other insecticide.

LIFT bulbs of hyacinths and tulips as soon as the leaves have ripened and store in the cellar till fall.

REMOve the yellowed leaves of the daffodils as soon as they ripen.

Mow the grass where the crocuses are as soon as the crocus leaves turn yellow.

\section{Vegetables}

Sow, for succession, beet, turnip, cabbage, lettuce (black-seeded Simpson variety), beans, wrinkled peas, cucumber (main crop for pickles), sweet corn.

Plant potatoes for main or late crop, if not already done in May. TRANSPLANT to permanent place, cabbage, cauliflower, celery, tomato, pepper, egg-plant, unless this has already been done late in May.

RAKE the soil surface frequently to keep it finely pulverized, and thus prevent growth of weeds and loss of soil moisture.

THIN and weed root, bulb, and salad crops planted in drills-beets, carrots, turnips, salsify, onions, lettuce, celery, parsley; also sweet corn and vine crops planted in hills.

HARvest early crops-Radish, onion from sets, spinach, lettuce, peas. Replant the ground at once. 


\section{JULY}

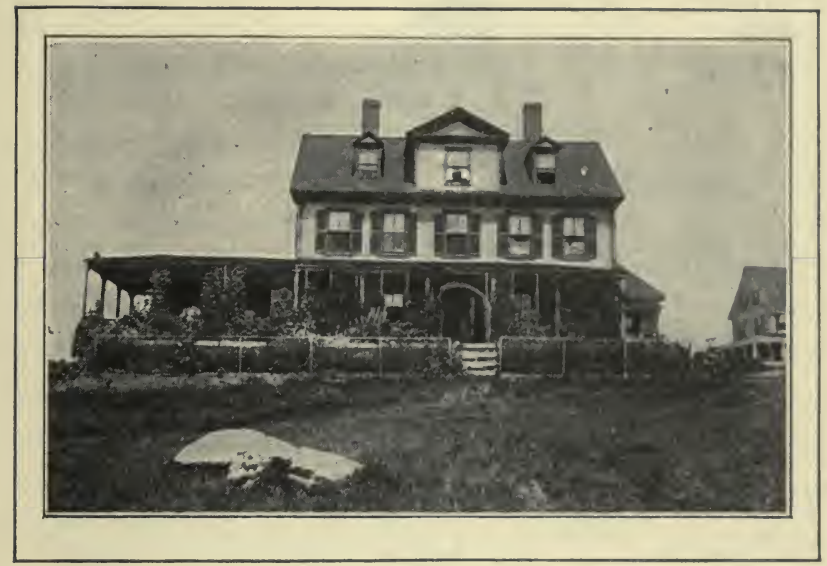

Celia Thaxter's Garden.

"Why is a garden made?" Primarily, it would seem to gratify man's craving for beauty. Behind fine gardening is fine desire. It is a plain fact that men do not make beautiful things merely for the sake of something to do, but rather because their souls compel them. Any beautiful work of art is a feat, an essay, of human soul. Someone has said that "noble dreams are great realities"this in praise of unrealized dreams; but here, in the fine garden, is the noble dream and the great reality.

- John D. Sedding. 


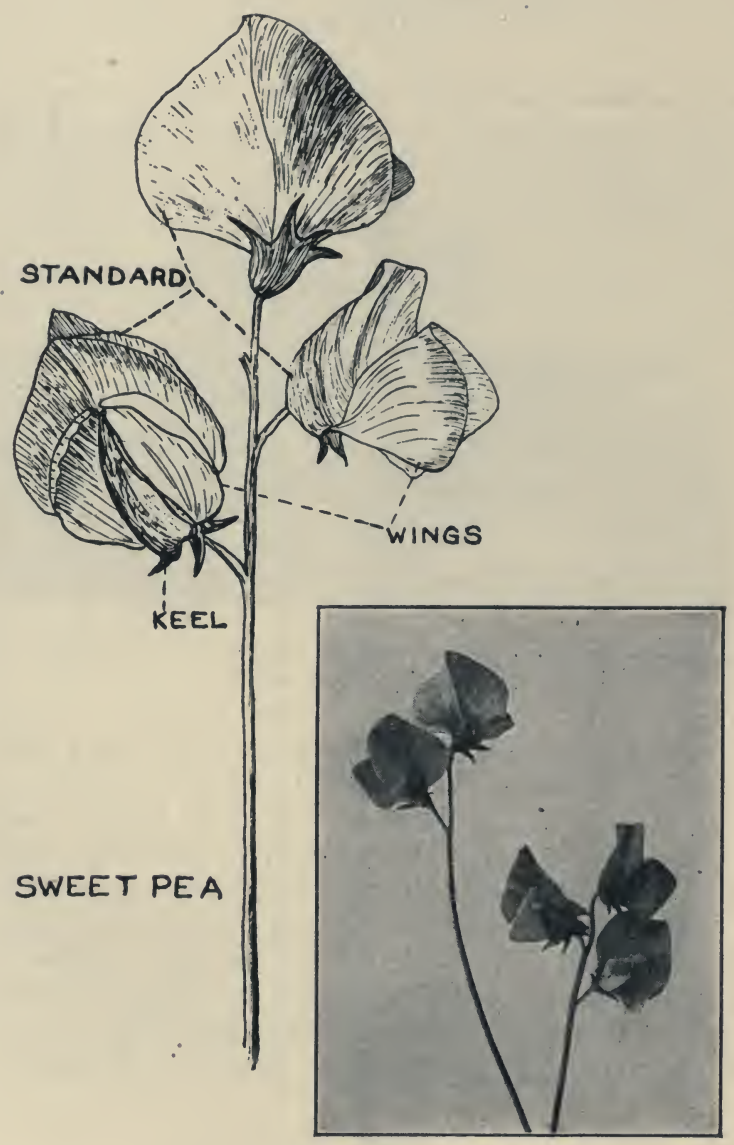

Hooded Sweet Peas. 


\section{$\mathrm{XI}$ \\ JULY \\ SWEET PEAS}

The sweet pea has long been recognized as a necessity in every well-ordered garden. It has been grown in America for at least a hundred years, but only during the last three decades has it become the universal favorite that we now acknowledge. This is largely due to the great improvement in varieties that has taken place since the time Mr. Henry Eckford of England began to cultivate the older sorts with a view to their improvement. To his painstaking and long continued labors we are indebted for most of our beautiful modern sorts. The result of these attempts may be seen in any catalogue, where the Eckford varieties form so large a part of all which are considered worthy of planting.

The different types of sweet pea blossoms are due chiefly to the variations in the shape and positions of the petals which form the showy parts of the flower. Like all complete blossoms, the sweet pea has four sets of organs. The sepals, which taken together form the calyx, are the small green pointed bodies at the base of the flowerr on the outside; they are grown together below. The petals, which as a whole form the corolla, constitute, as just stated, the showy part of the flower. The peculiar form of the sweet pea blossom is due to the irregularity of the petals. The large upright one at the top of the flower is called the standard, the two recurved ones in the middle of the flower are called the wings, 
and the small lower one is the keel. Within the keel are found the stamens, which develop the yellow pollen, and the pistil which matures later into the seed pod.

In the small-flowered wild sweet pea from which our modern

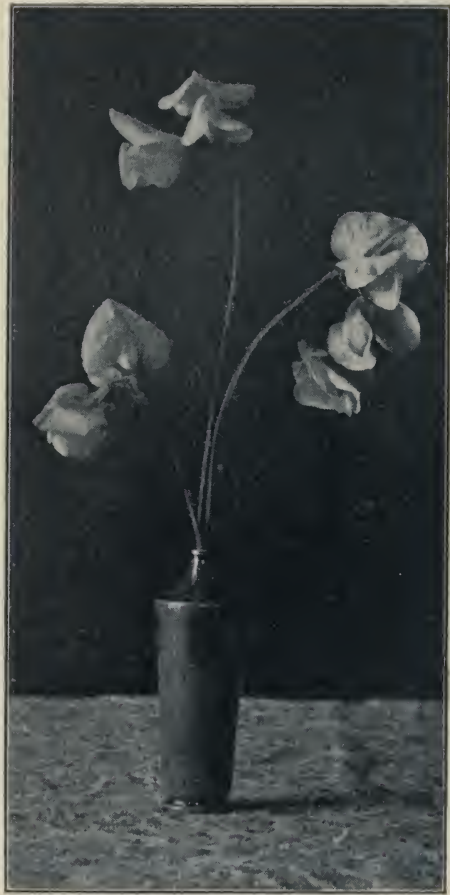

Typical Forms of Hocdcd Sweet Peas. varieties have been developed, this whole complicated structure of the flower has reference to the attraction of insects for carrying the pollen from blossom to blossom. The bright petals, especially the upright standard, attract the bee, which alights astride the wings, thus depressing both wings and keel until the end of the pistil comes in contact with the under surface of the bee. In the meantime, the tongue of the bee has been inserted into the base of the flower, from which it sucks the nectar, and then flies to another blossom, carrying pollen with it.

If you will watch your sweet pea flowers a short time on a bright day, you will see, however, that the bees seldom alight astride the keel of our modern varieties when they visit the flowers. The blossoms are so large that the bees can alight on one of the wings and get the nectar without coming in contact with the pollen at all. Consequently, it 
is probable that most of the sweet pea seed nowadays is selfpollenized.

The fact of self-pollination probably accounts for the ease with which the numberless varieties of modern sweet peas have been developed to come true to the type. These vary greatly both in color and shape, there being several distinct types as to form. The most pleasing of these is the largeflowered hooded type, in which the standard is symmetrical, but full of graceful curves; commonly it curves outward on the lower margins, and inward above to form a hood over the wings. The wings vary greatly in the flowers with this type of standard; in some varieties they are nearly vertical; in others nearly horizontal, curving on the margins to a greater or less degree. The Blanche Burpee and the Lottie Eckford are good examples of the hooded sweet peas.

In another common type of flower the standard is flattened, and in yêt

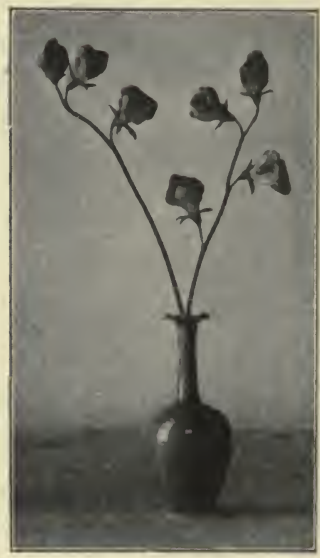

Snapdragon Sweet Peas. another it is rolled backward vertically on the outer margins. The Blanche Ferry sweet pea is an illustration of the first and the Primrose of the second. In these forms, which are much less attractive than the hooded flowers, there is generally a greater angle between the standard and the wings than in the hooded type. In addition to these reasonably normal forms there are various abnormal forms, which, fortunately, the seedsmen are not offering to any extent. One of the most peculiar of these is the Red Riding Hood, 
in which the flowers are very much the shape of those of the snapdragon. But they do not appeal to one as do the normal forms, and with the double sweet peas they are passing to a deserved oblivion.

For revealing the beauty of the sweet pea blossoms indoors almost any simple flower-jar which is not too high will serve very well. Clear glass rose bowls are particularly attractive, the stems showing through in a way that adds to the grace of the picture. Japanese or other vases, colored in neutral or broken tones and decorated only by the blending of colors in the glaze, may be used with any of the varieties.

There is one precaution which nearly always needs to be taken in using sweet peas for indoor decorations. The blossoms are so beautiful that one is tempted to pick them indefinitely; and crowd them in a solid mass into the receptacle. But on the vines they are not so crowded; each one stands sufficiently alone to reveal its loveliness. We may well take a hint from this, and place them so loosely in our jars that each blossom will be in view. And we shall also find much more satisfaction using each variety alone, or combining only a few varieties, than in the indiscriminate mingling of many sorts in the same receptacle.

\section{BEANS FOR GARDEN CULTURE}

There are few crops which yield so great and so satisfactory a return for the amount of labor required as the ordinary string beans or snap beans, as they are often called. These well-known plants are grown for the thick edible pod, and are of the very easiest culture. Two common types of the bush beans are grown: in one the pods are yellow-these 
are often called wax beans; in the other the pods are greenthese are often called the green-podded beans.

Bush beans are tender annuals and are sown out of doors as soon in spring as the ground is settled and warm, and danger from frost is past. They are commonly planted in drills, although occasionally in hills. It seems to make comparatively little difference which of these methods is adopted, although on weedy or grassy soil the hill method has the advantage that the rows can be more thoroughly hoed and kept free from weeds. The seeds should be covered to the depth of at least an inch, and the young seedlings will come up under favorable conditions within a week from the time of planting. They require very little care, but should not be hoed or cultivated when the leaves are wet, as this is liable to cause more serious injury, by the fungous disease called the bean rust, than will otherwise occur. The quality of the pods depends, to a large extent, upon the rapidity of growth. When they grow rapidly without any check during their development, they are likely to be of excellent quality, snapping readily, and with few of the objectionable "strings."

In order to have a continuous supply, several sowings of the beans should be made in succession, at intervals of a week or ten days from May until August.

In addition to the string beans, some varieties are commonly grown for use as "shell beans." In these cases, the beans are taken from the pods shortly before they are ripe, and used as food. The most popular "shell beans" are tall, climbing sorts which require poles or other supports during their development.

Still another type of beans which is commonly grown in many gardens is the Lima Bean. The true Limas are mostly 
tall sorts that require a long season for their development, and some poles or other supports to enable them to climb. In the more northern States, the season is so short that the

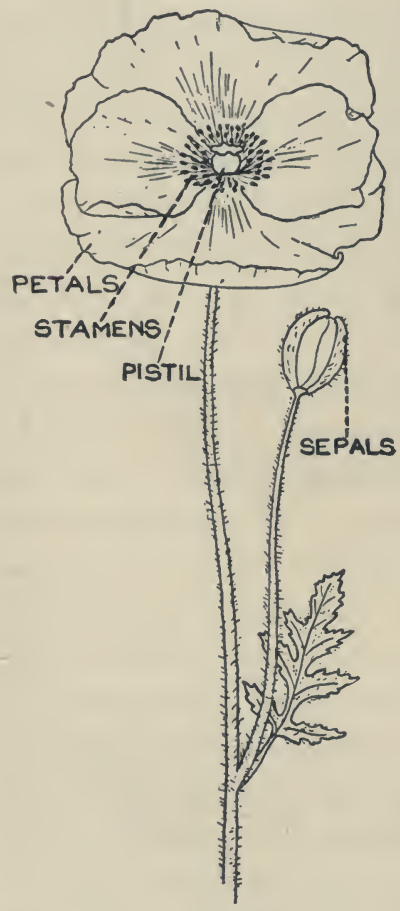

Shirley Poppy.

Lima Beans are not grown so successfully as they are farther south. There are certain low-growing varieties, however, which are commonly called Bush Limas that may be grown in the North successfully; these have not the disadvantage of requiring poles for their support. The Bush Limas are excellent sorts for school and home gardens.

\section{THE STRUCTURE OF THE FLOWER}

The beautiful Shirley Poppies serve very well to illustrate the structure of a flower. As the bud develops it is covered by two large green sepals that serve to protect the blossom until the delicate petals are ready to unfold. At the base of the petals in the centre of the flower are the many stamens, surrounding the large central pistil. An important function of the sepals is, as already noted, to protect the bud: when the poppy flower opens these sepals commonly fall off. An important function of the petals is to attract the bees to the flower for the pollen which is 
produced by the stamens and to carry it to the pistils of other poppy flowers.

The sepals as a whole form the calyx and the petals as a whole form the corolla. Each stamen consists of a slender thread-like stem called the filament, and a larger bag-like part at the end called the anther.

Each pistil in a typical flower consists of a basal part called the ovary, within which are tiny ovules that develop into seeds; a middle part called the style, and an

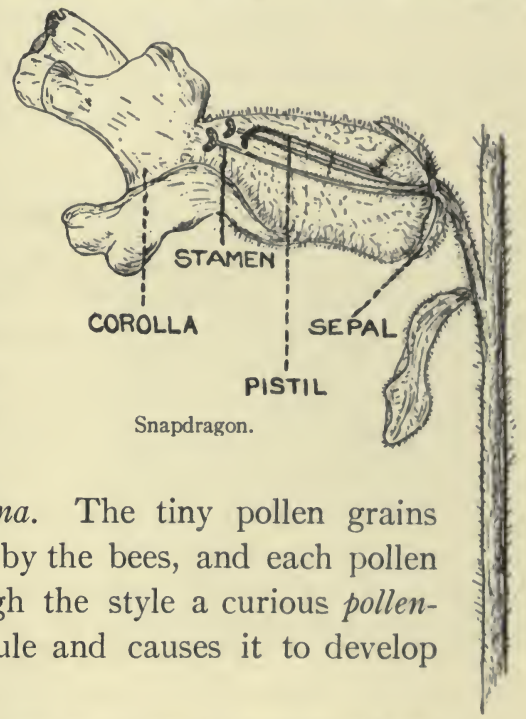
end part called the stigma. The tiny pollen grains are carried to the stigma by the bees, and each pollen grain sends down through the style a curious pollentube that fertilizes the ovule and causes it to develop into a seed.

In the annual flowers there are many modifications of the comparatively simple flower structure of the poppy. One of the commonest of these is the union of the petals into a single corolla, as in the case of the familiar snapdragon. Such combinations of the parts of the flower generally indicate that there are special methods to induce pollination by insects, as you may readily see if you will examine a snapdragon blossom carefully.

The beautiful Madonna Lily may serve as an illustration of a large number of our most popular flowers in which the sepals and the petals closely resemble one another, and are 
commonly said to form the perianth. As a rule, in the lily family there is little distinction between the parts which are commonly called the perianth segments, although for popular garden use it would seem to be justifiable to call them petals. The parts of the flower are. clearly seen in any lily in which two of the segments have been removed to show the stamens and pistil in the centre of the blossom.

\section{NASTURTIUMS}

The nasturtiums are justly favorites with many flower lovers. They are especially notable for the richness and beauty of their colors, and are so easily grown that any one with the smallest bit of ground available can easily have a beautiful display of blossoms. Mr. Schuyler Mathews says there is always some influence of yellow in the nasturtium blossom, but it requires the experienced eye of the artist to see it in many of the wonderful reds the flower displays. Scarlet, salmon, lilac, pink, bronze, brown, gold, orange, yellow-all these and many bewildering modifications of these do the nasturtiums give us in glowing tones which are a delight to the color-loving eye. They give their blossoms with a profusion that can only be realized by one who will patiently count the flowers as they appear. from day to day. A bed six by twenty feet filled with the dwarf varieties will yield a thousand blossoms a day.

The nasturtiums belong to the genus Tropoolum, of which more than a dozen species are known. Only three or four of these, however, are commonly cultivated. The Dwarf, or Tom Thumb Nasturtiums, belong to the species called Tropoolum minus. The Tall, or Climbing Nastur- 
tiums belong to the species called Tropoolum majus. The Lobs Nasturtiums belong to the species Tropoolum Lobbianum. The curious plant called canary bird flower, which is often grown in greenhouses, is a nasturtium which belongs to the species Tropoolum peregrinum.

For use in beds and borders, as well as in window- and porch-boxes, the Dwarf or Tom Thumb Nasturtiums are especially desirable. There are scores of varieties of these, many of them very beautiful. There is also an attractive variation in the colors of the foliage, some sorts having leaves of very light green, while others have leaves of very dark green. The leaves are shield-shaped and the entire plant is smooth.

The Tall or Running Nasturtiums yield much more

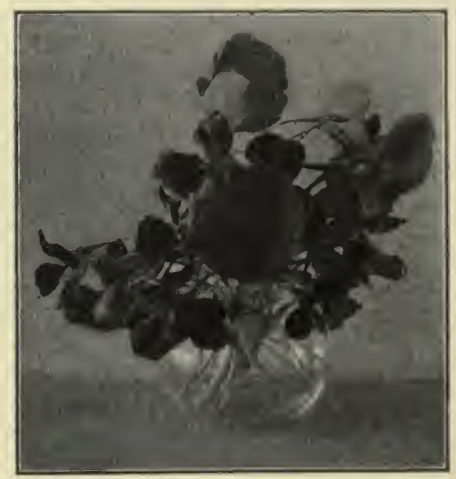

Nasturtiums in a Rose Bowl. foliage than do the dwarf varieties. They are able to climb by means of their leaf stems, which coil around whatever supports are available. The whole plant is more robust than the Tom Thumb forms, although, like the latter, it is smooth in all its parts. These nasturtiums grow luxuriantly under favorable conditions of soil and moisture, and yield blossoms of good size and in many varieties of excellent colors.

The Lobs Nasturtiums are characterized by having all the parts of the plant except the under side of the leaves more or less hairy. This species has been much hybridized with 
the others, so that a large proportion of the nasturtiums now cultivated are of mixed races.

The young seed pods of the common nasturtiums are often used for pickles, and in England the leaves are often used in salads. The ripened seed which we buy really consists of the whole fruit, the wall of the ovary being attached to the contained seeds.

As cut flowers, the nasturtiums are particularly effective when displayed in low glass vases or rose bowls in which the stems show through the sides of the receptacle. They may also be exhibited to advantage in low flower-jars of almost any neutral or subdued colors, but they should not be shown in tall vases, for they will not stand erect above the top for any distance. Consequently, the vase will be too tall, in proportion to the whole display, for a harmonious result.

\section{THE JULY CALENDAR}

\section{Flowers}

KEEP flowers of sweet peas, marigolds, and other annuals picked as fast as they begin to wither. If they go to seed, the plants stop flowering.

KEEP all flower beds free from weeds, and the surface of the soil well stirred.

Sow seed of dwarf China Asters of almost any type in a partially shaded seed-bed where water can be applied. These are for late autumn window-boxes.

PLAN to save the seed of some of your choicest flowers.

\section{Vegetables}

Sow during the first half of the month seed of turnips, bush beans, and of early varieties of beets; during the last half of the month sow seed of spinach. 
Transplant during the first part of the month tomatoes for green fruit and latest crop of ripe fruit, setting on ground from which some early crop has been harvested; also peppers, cabbage, and celery.

KEEP the soil surface finely pulverized by the use of a rake.

WATER frequently, if necessary, but do it thoroughly. One good soaking late in the afternoon is worth a dozen sprinklings.

HARVEST early crops as fast as possible and replant the ground to something else.

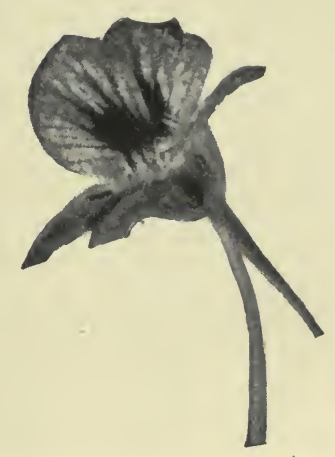



AUGUST

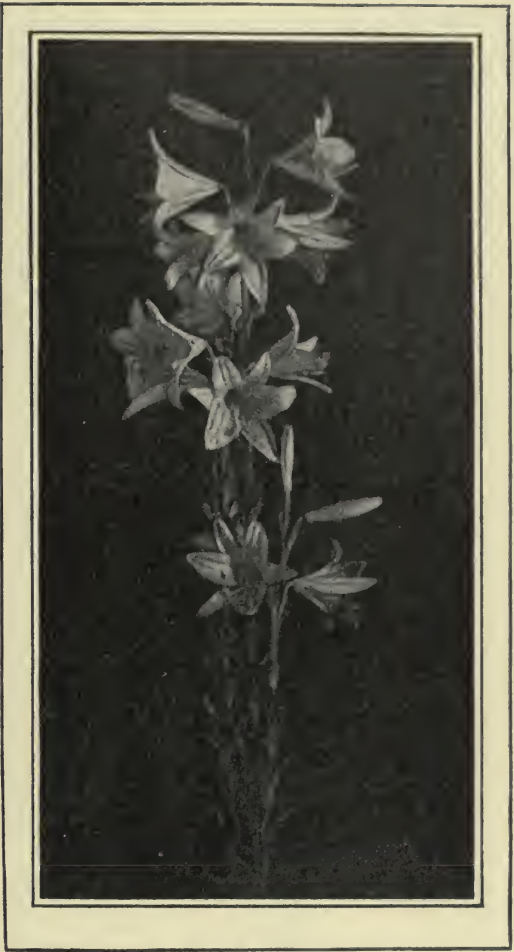

Madonna Lilies.

A Garden is a lovesome thing, God wot!

Rose plot, Fringed pool,

Ferned grot-

The veriest school

Of peace; and yet the fool

Contends that God is not-

Not God! in gardens! when the eve is cool?

Nay, but I have a sign:

'Tis very sure God walks in mine.

-Thomas Edward Brown. 


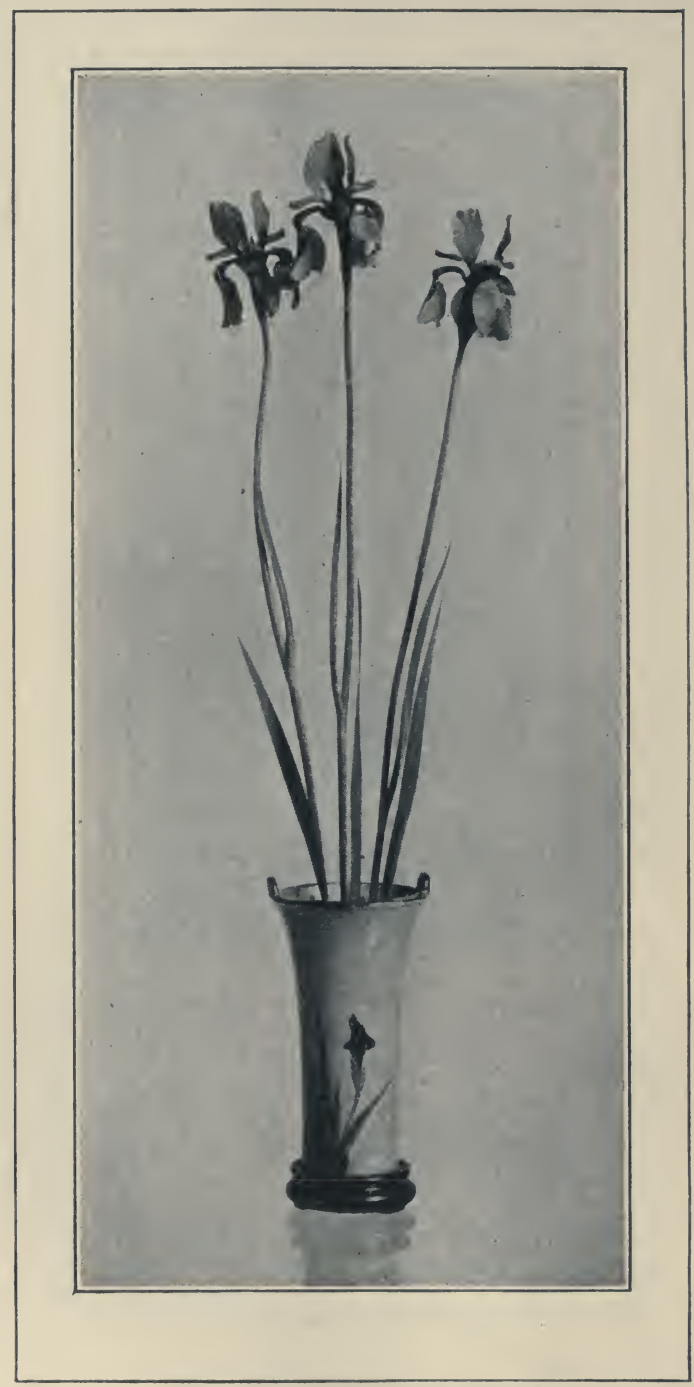

Oriental Iris in a Japanese Flower-jar. 


\section{XII}

\section{AUGUST}

\section{USEFUL FLOWER-JARS}

In few things could the average American home be so greatly benefited by a little careful attention as in the choice of receptacles for displaying cut flowers. When we arrange such blossoms in a jar we are making a picture in which the receptacle, the leaves, and the flowers form the materials of expression. The effectiveness of such a picture is governed by laws of harmony just as much as is the effectiveness of a drawing in black and white or a painting in colors; and, as a rule, the most important requirement is to have a really artistic receptacle to begin with.

The first requirement of a vase or jar for flowers is that it shall be in harmony with its purpose. In form, in color, in decoration it must serve as a fitting receptacle for objects which in themselves are to be the chief centre of attraction. Flowers are infinitely varied in their shapes and colors, and flower-jars which shall be appropriate for holding different kinds must be simple in form and coloring.

During the last few years there has been a wonderful advance in the character of the receptacles for flowers offered for sale in our shops. Several notable pottery establishments have produced wares which serve their purpose admirably, and have put them upon the market at prices which bring them within the reach of people of moderate means. Consequently, there is less and less excuse for buying the 
many ornate, inartistic vases which are still offered for sale by the shopkeepers.

Beauty of line is one of the desirable features in a good flower-jar. It may be simply the straight line of a cylindrical "spill," or the graceful curve of a spherical rose bowl, or any of the innumerable variations between these. But there

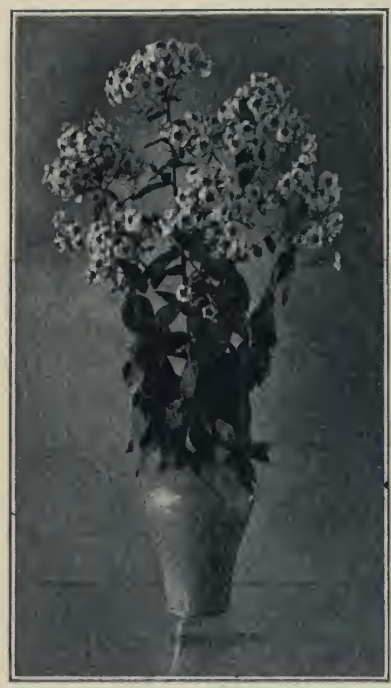

P'erennial Phlox in a Japancse Flower-jar. should be the effect of unbroken lines which will combine rhythmically with the lines of leaf, stem, and blossom of the flowers held by the jar.

Beauty of color is another thing to be desired in such a receptacle - not the brilliancy of standard colors, but the softness of broken and neutral tones. With such, one can make harmonies of many sorts by adapting flower and vase to each other according to the laws of color harmony.

Simplicity of decoration is also desirable in a flower-jar. The blending of harmonious tones in the glaze is the most satisfactory form of decoration, for it permits the use of a wide range of flowers at different times in the same receptacle.

To be able to arrange effectively the great variety of flowers that the seasons furnish in such abundance, one should have jars of several distinct shapes and sizes. If one appreciates the desirability of this, it is really a simple and inexpensive matter to provide them. Get, in the first place, two or three 
cylindrical jars, varying in size. Those of a height of four or five inches and a diameter of about two inches are particularly useful for a great number of the smaller flowers. One or two taller jars, about nine inches high by three inches in diameter, will serve admirably for long-stalked flowers like the various sorts of gladiolus and the Japanese or the Si-

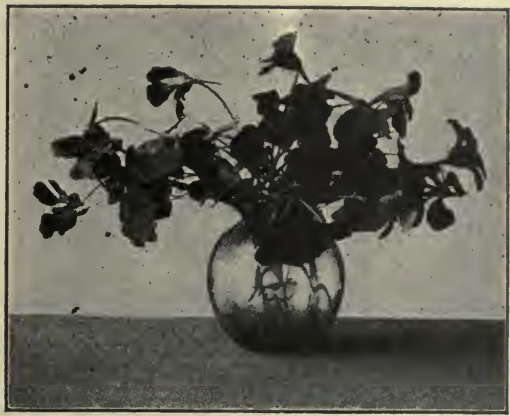

Nasturtiums in Green Glass Flower-jar. berian Irises. In the vertical compositions which will be made by means of these cylindrical receptacles, the best results will be obtained when the jar is about one-third the height of the composition as a whole.

Perhaps the next most desirable form of flowerjar to get is one with more or less rounded outline, but taller than wide, and with the opening at the top somewhat constricted. Such jars are extremely useful for a great variety of plants with large flower-heads, like the asters, peonies, Perennial Phloxes, and chrysanthemums. Useful sizes of jars of this type range in height from six to eight inches, and in diameter at the top from three to four inches.

For masses of small and comparatively short-stemmed blossoms, like nasturtiums, sweet peas, and pansies, small, more or less spherical jars, fashioned on the outlines of the glass rose bowl, are very useful. These are obtainable in a considerable variety of pottery ware of both Japanese and domestic manufacture, and for the most part are inexpensive. 
When we come to consider the infinite variety of vase forms in which the opening at the top is more or less constricted, there is opportunity for a wide range of selection, for these vases are made by potters of all countries, and vary

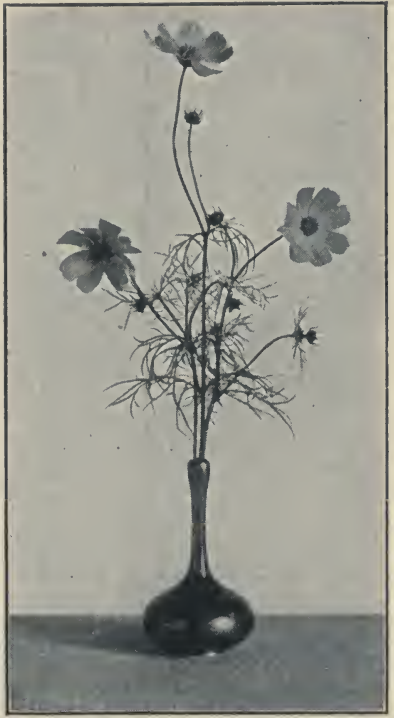

Cosmos in a Slerder Vase. from exquisite forms to those of the crudest design. Some people think that the finer of these vase forms are useful only as mantel bric-à-brac, but many of them are admirably adapted to displaying a few delicate and beautiful flowers on long stems, with more or less foliage attached. This is really the most effective way to utilize many kinds of flowers, as it enables one to appreciate better the exquisite beauty of line in stem and leaf and of color in the petals. One rose or one poppy rising from the slender neck of a beautiful flower-jar is likely to appeal to an appreciative observer with greater force than a mass of roses or poppies huddled together in a larger receptacle.

In the matter of decoration, one who is beginning a collection of artistic and useful flower-jars will do well to avoid almost all of the ordinary designs. There are many jars available in which the ornamentation is that of a mixture of colors in the glaze, and these have the great advantage that they may be used with any flowers without interference with the unity of the result. 
On the other hand, a vase on which there has been painted the picture of some plant form, whether natural or conventionalized, cannot be used to advantage with flowers other than the one in the design. Consequently, such decoration greatly limits the usefulness of the flowerjar, and one would be wise in postponing the purchase of such jars until one had accumulated a sufficient number of those without this special decoration to serve the needs of the home. An exception to this general rule might be made in the case of the beautiful flower-jars so generally offered in the Japanese shops in which the design of the iris is utilized. Throughout a considerable period of spring and early summer one can get various forms of iris to place in such a jar, and the combination is peculiarly effective.

When we leave the plant decorations for those of animals or mountains-to mention two features especially common in Japanese flower-jars - there is opportunity for more extended argument. With

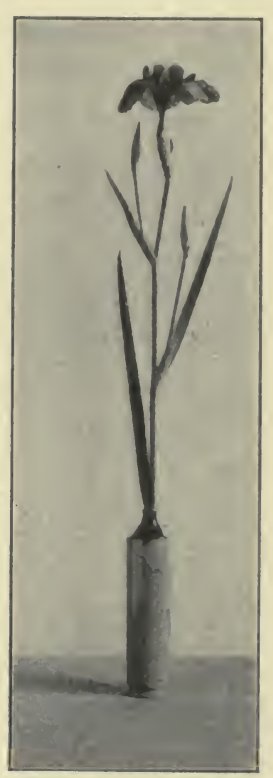

Japanese Iris in Izumo Vase. these it is chiefly a matter of association, and this may well involve the exercise of a wise judgment in which many factors receive due consideration. It is not strange that to the Japanese mind the picture of their incomparable mountain, Fujiyama, which so dominates the landscape of the islands, should always be a welcome addition to their pictures and decorative arrangements, and so we find it upon a large proportion of the better decorated ware that comes to us 
from Japan. In the case of animals, there is always a certain attractiveness in well-executed outlines of birds, rabbits and fishes, and we need not object seriously to jars thus decorated, as they will be found useful for a considerable variety of flower displays.

Next to the possession of a few really simple and artistic flower-jars, the most important point in the utilization of flowers for the enrichment of home life is an appreciation of the beauty of simplicity in their arrangement. A table or shelf should be set aside for the display of the flowers, with a plain background and no massing of bric-à-brac around them. Then into the receptacle do not crowd blossoms indiscriminately, but choose only one kind at a time and, as a rule, only a few of these, giving to each flower an opportunity to speak for itself and to express to the soul of the beholder its special message of beauty.

Do not feel that the flowers need other greenery than that furnished by their own leaves and stems. The universal custom of mixing smilax or the so-called Asparagus Fern with beautiful flowers, is one that cannot be too strongly condemned. This is simply a relic of the old-fashioned bouquet, with its barbarous intermixture of all kinds of form and color into a shapeless mass which might appeal to a Hottentot, but certainly should never appeal to an educated American. It was of these bouquets that Sir Edwin Arnold, after some years of residence in Japan, wrote:

"Your European florist-who masses together his roses and his Maidenhair Ferns and Calla Lilies, surrounding them with a dish of green and an outer overcoat of lace-paperappears to the Japanese lover of flowers lower than a barbarian. He has lost-to the Japanese mind-the chief 
charms of flowers and leaves, which consist in their form of growth, their harmonious asymmetry, and their natural relations. Every school of flower arrangement in Japan would scorn his rural bow-pot or guinea bouquet and teach him far nobler thoughts."

Few American families are so situated that they cannot enrich the home with the beauty of plant life, either wild or cultivated, if they will be content with the simpler things from the outer world and not feel that they must have the expensive hot-house flowers, the only ones in which the world of fashion seems to be able to find any beauty. A twig from the nearest tree is full of the infinite variety of line and color to be found everywhere in nature, and will well repay careful consideration by any observing mind.

\section{MARIGOLDS}

How perfectly some flowers embody the spirit of the season: The dainty mayflower seems to hold

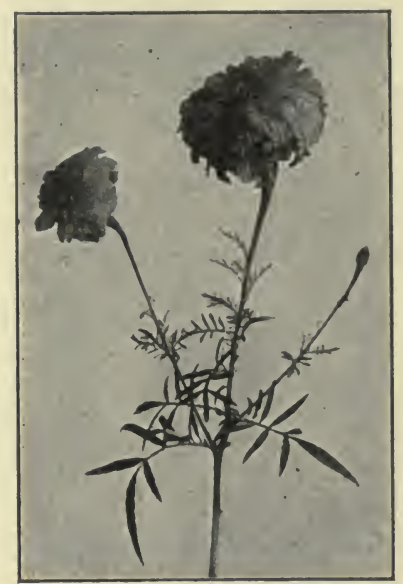

Tall or African Marigolds. within its perfumed cup a suggestion of eternal spring no more surely than the golden marigolds of our gardens seem to carry with them the glorious perfection of midsummer-a fulness of form and richness of color that vividly embody the suggestion of the hazy August noon.

Many people apparently do not care for marigolds. Yet they may be losing something worth while in not cultivating these beautiful blossoms. The perfume may be a trifle 
strong, perhaps, when the flowers are brought in-doors, but surely they may be grown in the garden that the eye may delight in the hemispheres of glowing gold; and the blossoms are yielded in such abundance that it is a pity not to take

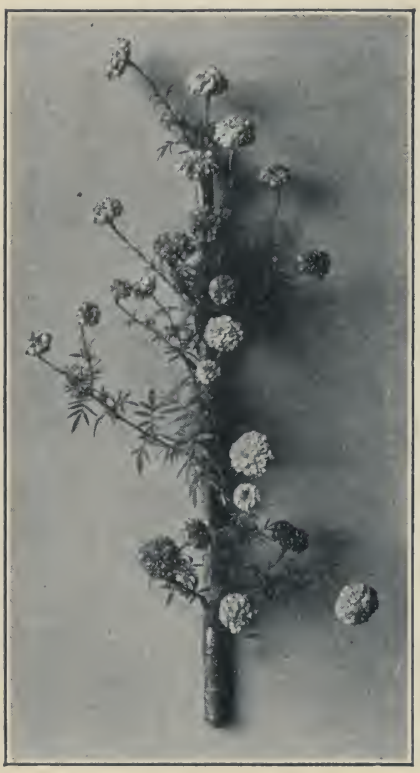

African Marigolds in a Bamboo Wall-holder.

Froin "The Flower Beautiful." advantage of their prodigality.

Two very distinct types of marigolds are commonly grown. The Tall or African Marigolds have spreading plants that reach a height of two or three feet and are admirably suited to the border garden. The Dwarf or French Marigolds are low-growing, bushy plants with small flowers, and are admirably adapted for borders and for bedding purposes. The latter are exceedingly prolific in blossoms. Schuyler Mathews tells of one "of a perfectly symmetrical shape, spreading with luxuriant foliage over a space twenty inches in diameter and bearing seventy-five flowers in various stages of development, which, when fully grown, will measure an inch and a half across."

The marigolds are tender annuals which may be started out of doors in May or in-doors somewhat earlier. The period of blooming of the African sorts may be much lengthened by starting the plants early. The seeds germinate quickly and easily, and the young seedlings grow rapidly in 


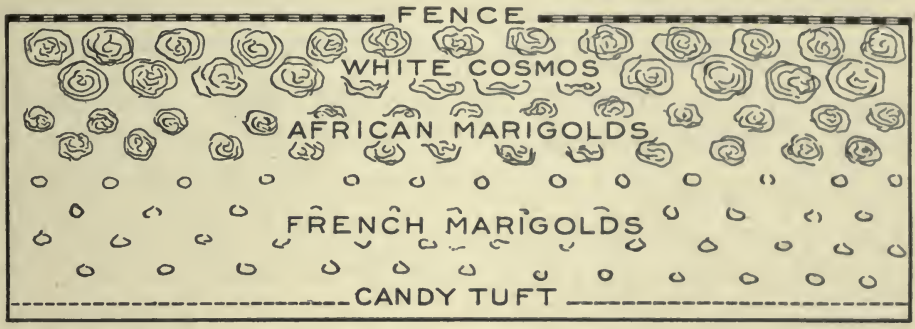

A P

small pots. The French sorts are said to blossom quicker and earlier when their roots are confined to pots, even after setting in the open garden.

\section{POT HERB CROPS}

A number of vegetables which are grown in order that the leaves may be cooked and eaten are called pot herbs. These leaves and plants are also often spoken of as greens. In different regions, different wild plants are commonly used for greens, although those which are grown in gardens for this purpose are comparatively few in number. Of these, spinach, or, as it is often spelled and always pronounced, spinage, is probably the most important.

Spinach is a crop which will not stand hot weather. Consequently, it must be grown in spring or autumn, and, fortunately, it is sufficiently hardy to survive the winter, requiring a protecting mulch, however, in more northern regions. Under favorable conditions the seeds germinate quickly and the seedlings mature rapidly, so that they are large enough for use in from six to eight weeks from the time of sowing. It thrives best in a warm, rich, loamy soil that can be worked early in spring, so that the seedlings may get 
a good start at the beginning of the season. It should be planted in rows about a foot apart, and the soil between be frequently tilled to prevent the growth of weeds. The young seedlings should be thinned to three or four inches apart in the rows, so that each may have room to develop into a goodsized plant. An abundance of moisture will hasten the growth, as will also the application of nitrate of soda or liquid manure.

Spinach is an especially good crop for the school garden, wherever sufficient ground is available, because it can be sown so early in the spring and will be ready for harvest before the close of school. In many localities, the leaves are badly injured by the leaf maggot, which in northern regions usually does not show its injury until about the first of June, consequently the first crop is likely to escape injury by this pest.

Spinach may also be sown late in summer or early in autumn, with the expectation of harvesting the crop before winter sets in. Consequently, it is a good plant to try in the garden when school opens in September. Still later, fall sowings may be made, and the plants covered early in November with a protecting mulch to enable them to survive the winter. This mulch should be removed early in spring and the crop should be ready for harvesting much sooner than the springsown crop. Spinach is also an excellent plant for carrying through the winter in cold-frames.

The varieties of spinach are commonly classed under two headings, according to the character of the seed. The roundseeded varieties are able better to withstand summer heat, and are commonly grown for spring use. Victoria is one of the best sorts in this group. The prickly seeded varieties are 
better able to withstand winter's cold, and are commonly planted in autumn for wintering over. Prickly or Winter Spinach is a good variety of this type.

The so-called New Zealand Spinach is an entirely different plant, which is able to withstand the heat of summer, and consequently is often used for greens in this season. It is sometimes called the New Zealand ice plant. It thrives best in a good, rich, garden soil, and individual plants attain so large a size that they require to be set two feet apart in the row. The seedlings should be started early in-doors and transplanted out of doors when the ground is in condition to work. They may also be sown out of doors in rows and severely thinned as the young plants reach a size large enough to eat.

The mustard is another quick-growing pot herb crop, which is excellent for home and school gardens. The plant thrives best in a rich, moist, loamy soil that can be worked early in the season so that the seeds may be planted as early as possible. They should be sown at a depth of about onehalf inch, in rows a foot apart, and the young seedlings thinned to about four or five inches apart.

The mustard commonly grown for use as a pot herb is Brassica Japonica. The White Mustard and the so-called Chinese Mustard are often used for salad plants as well as for greens. Care should be taken not to allow any of the mustards to go to seed in the garden, because these plants readily become noxious weeds where they escape from cultivation.

Perhaps no plant is more generally used for greens than the dandelion. Almost everywhere, the dandelions that grow wild are cut in early spring for this purpose. The cul- 
tivated dandelions, however, are much more desirable, and where there is sufficient ground they become an excellent crop for school and home gardens.

Dandelion seed should be planted in spring or early summer, in rows a foot apart, and be given careful tillage throughout the season. The plants will then be of a good size for cutting early the following spring. The entire crop should be cut, however, and not allowed to produce blossoms and seeds, because the latter will spread everywhere and cause much trouble in grass lands and cultivated soils.

\section{PLANNING FOR WINTER FLOWERS}

By a little planning during the later weeks of summer and the early weeks of autumn one can very readily have indoors an attractive show of blossoming plants from the time when the killing frosts of October have cut off the display in the out-door garden until the time for blossoming of the winter flowering bulbs. The method by which this may be brought about is to start seedlings out-doors in summer and transplant them into small flower-pots, which are then buried in the ground and kept growing thriftily out-doors until the danger of frost requires that they be transferred to the in-door window-boxes. In thus transferring, they may either be retained in the pots which are to be buried in the soil or the pots may be removed and the plants set directly in the soil. The chief precaution necessary in the out-door treatment is to cover the hole in the bottom of the flower-pot before it is filled with soil, and then, after the plant has got a good start, to lift the pot about once a week in order to break off any roots that may have found their way through the bottom into the soil below. 
There are several annual flowers which may be utilized for this purpose. Among the most satisfactory are the Drummond Phlox, the French Marigold, the China Aster, the Japanese Morning-glories, and the sweet peas. Each of these kinds of plants may thus be started out-doors and transferred to window-boxes with very satisfactory results.

One thus saves a long period of waiting which is necessary when one does not plant the seeds until October. The plants get a better start out-doors than they do inside, and may be brought into the house in a thrifty, vigorous condition so that they will continue to grow ànd blossom for a long period. In a somewhat similar way some of the flowering plants which are grown from cuttings may be started out-doors in submerged pots, and then brought inside just before the frosts of autumn. The various kinds of geraniums are notable illustrations of plants that may be so treated.

In selecting a place to grow these plants for in-door flowering, choose some out-of-the-way corner of the garden, preferably one that is shaded part of the day. The young plants will do better in such a situation during the hot, dry weeks of summer, and the transition to in-door conditions will involve less change than in a fully exposed situation.

\section{PANSIES}

The pansy is universally a favorite with flower lovers. It has been culitivated for many hundreds of years, and in most European countries at least it has been very generally grown by all classes of people. Although the plant is really a perennial, living on from year to year, the best results are obtained by treating it as an annual, and where any attention is given to growing it new plants are started from seed every 
season. By varying the time of sowing the seed, the period of greatest production of blossoms is easily regulated, so that one can very readily have plants in full flower any time during the season.

The pansy is believed to have originated many centuries ago from a wild European violet called the three-colored violet, Viola tricolor. This wild type was somewhat modified by pansy lovers in Great Britain, who paid much attention to the cultivation of the flower, increasing the size of the blossoms and varying the coloration of the petals. Toward the close of the nineteenth century certain French specialists, especially three men by the names of Bugnot, Cassier, and Trimardeau, made a specialty of bringing the pansy flowers to larger size and greater beauty, and they succeeded in a most wonderful way, giving to the world new types of pansies which are commonly named after these three Frenchmen, and which form the prevailing types of these flowers as they are grown to-day.

Pansies do best in regions where there is abundance of moisture and where the summers are not too hot and dry. In most American localities the plants are likely to die during the summer if they are exposed to the full heat of the sun and do not receive artificial watering. In such regions it is best to depend upon seed sown late in summer or early in autumn for an abundant supply of flowers through the spring and early summer, and upon seed sown in spring for a similar supply of flowers through the autumn months. Where the protection of a cold-frame can be given, the blossoming period of the pansies through the late autumn and early spring may be greatly increased. In the selection of a location for the pansy bed it is desirable to choose a place which 
receives the benefit of the morning sunshine but is shaded during the hotter part of the afternoon. A moist clay loam seems to be the soil in which they grow most successfully.

The structure of the pansy flower is very similar to that of the violet. At the base of the blossom are the five long sepals, with the five beautiful petals arising between them, the lower petal having the large nectar spur projecting toward the stem, with a well-marked groove leading to the nectar cavity. The two side petals just above the lower one are generally furnished with a fringe of hairs at their base, these hairs being just above the stigma of the pistil, which occupies the centre or eye of the flower. Surrounding the pistil are the curious stamens with the pollen contained in the large flattened anthers. The whole structure of the flower is well adapted to bringing about cross-pollination through the visits of bees, which are guided to the nectar cavity by numerous colored lines or nectar guides pointing toward it.

\section{THE AUGUST CALENDAR}

\section{Flowers}

Sow seed of pansies in partially shaded seed-bed.

Transplant China Aster seedlings sown in July into three-inch pots in the soil of the garden.

Sow seed of Japanese Morning-glory in three-inch flower-pots sunk in the soil. Keep well watered. These are to transfer to in-door window-boxes.

Sow seed of French Marigold and Drummond Phlox in drills out-doors, for use later in in-door window gardens.

START a window-box of sweet peas on a porch or other sheltered place, so that the plants may get a good start before the box is brought in-doors. 


\section{Vegetables}

Sow seed of radish, lettuce, and spinach for late crop.

RAKE the soil surface frequently. If "pusley" or other weeds get started, hoe and then rake.

PULL up all weeds that appear in the rows. Don't let any go to seed. HARVEST all crops as fast as they mature. Pull up and burn all parts of plants left after harvesting, and thus prevent their serving as breeding grounds for insect and fungus pests. 


\section{PART II}

GARDEN EXERCISES FOR PUPILS 



\section{XIII}

\section{GENERAL EXERCISES}

\section{Filling the Flower-pot}

I. Take the flower-pot in the left hand and put a piece of broken pottery or a small flat stone over the hole in the middle of the bottom.

2. Fill the pot with sifted soil, damp but not sticky, and settle it by dropping the pot upon the bench straight down from a height of an inch or so. If it is desired to have the soil very compact, then press it down with the thumbs.

3. If seed is to be planted, leave a space of about threequarters of an inch from the top. Sow the seed over the surface and cover with one-quarter or one-half inch of fine soil, leaving about one-half inch free space between the top of the soil and the top of the pot.

4. If a seedling is to be planted, fill the pot as before, then make a hole in the middle of the soil and insert the seedling without crowding its roots together. Firm the soil by pressing the thumbs on opposite sides of the plant, repeating this operation two or three times as you turn the pot around by the tips of the fingers.

\section{Starting Geranium Cuttings}

I. Break off a vigorous geranium shoot and cut it off just below where a leaf comes out. Remove all but two or three 
leaves at the top and thrust it into a hole in wet sand in a flower-pot or the cutting bench.

2. Keep the sand rather wet for nearly three or four weeks. By the end of that time a callus should have formed over the cut surface and roots have started out.

3. As soon as the small roots start, put the cutting in a two-and-one-half or three-inch pot in good garden soil, preferably with a little sand thoroughly intermingled. Keep well watered but not too wet.

4. When the small pot is full of roots, re-pot in a larger size pot and keep the plant growing vigorously thereafter.

\section{Carnation Cuttings}

I. Select vigorous young growth for carnation cuttings. Remove part of the lower leaves and trim off just below a node. Thrust about one inch deep into wet sand or the cutting bench, and keep well watered for three or four weeks.

2. About four weeks after planting, the roots should be well started and the cutting may then be planted in a two-andone-half or three-inch pot in fine soil.

3. Carnations are said to start better in winter, especially in January, than at any other season.

\section{Seed Testing Exercises}

I. Make sprouting tests of the seeds of four or five of the following crops: radishes, carrots, parsnips, onions, cabbages, spinach, lettuce, tomatoes, cucumbers, and corn. Determine in each case the precise percentage that germinate.

2. By means of paper flower-pots make seedling tests of the same kinds of seeds as are used in the sprouting tests, 
keeping a careful record, and determine the percentage of good seedlings for each kind of vegetable.

3. Compare the percentage in the sprouting test with those in the seedling test, and then determine the difference in percentage, if any, between the two.

\section{Chrysanthemums in Pots}

I. Soil.-Mix good fresh garden soil with leaf-mold and well-rotted manure, and sift. A little wood ashes, crushed bones, and soot may be mingled with soil. If soil is too clayey, lighten it by admixing sand. Or secure prepared soil from a florist.

2. Plant.-Secure from a florist a well-rooted, vigorous chrysanthemum, in a two- or three-inch pot, of some standard variety he can thoroughly recommend. Or secure cuttings and root them.

3. Potting. - Take a seven-inch earthen pot. Follow directions for filling the pot on page 245. The surface of the soil should be about one and a half inches from the top of the pot to allow for watering and for top-dressing later. In planting, the ball of moist soil on the roots should be placed within one-half inch of the surface of the soil, not at the base of the pot, for there must be room for root growth.

4. Care.-Put the pot in any sheltered, sunny place on the porch or in the house. Or sink it to the rim in the soil of a sunny garden spot. Two bricks, with rough coal ashes between, may be placed just beneath the pot to ensure drainage.

5. Watering.-At first fill the pot each day or so. But test the condition of the soil by looking at it and by rapping the 
pot. If dry, the pot will ring when rapped. Later in the season water should be given two or more times a day, according to the weather and the vigor of the plant. But do not keep the plant too wet.

6. Fertilizing. - If the plant fails to grow thriftily, a topdressing of bone-meal mixed with sifted loam may be added the last of August. Commencing in September, a liquid fertilizer should be given once a week until the buds are formed.

7. Topping and Shaping.-Nip off the end buds now and then in July to secure a bushy growth. In August cease topping and allow the plant to grow. When the flower buds are large enough to handle, remove all but one or two from a branchlet, to ensure large, perfect flowers. Having removed the plant to the house before frosts come, use a few neat sticks to support the branches and secure a well-rounded plant for exhibition.

8. Records.-Keep an illustrated, descriptive record of the plant-its variety, name, its size and growth, details of culture under each head of the directions, notes of insect pests and other troubles, drawings or color sketches of the plant and its blossoms at different stages-and conclusions as to changes in culture advisable the next season. 


\section{XIV \\ SPRING FLOWERING BULBS}

\section{Campernelle Jonquil}

\section{Planting Out-Doors.}

I. Plant the bulbs in loamy soil, setting about four inches deep and five inches apart. Plant them as early in autumn as they are received.

2. When the ground freezes, cover with a few inches of litter or mulch of some sort.

3. As soon as the snow goes in spring, remove the covering and watch for the coming of the leaves and flowers.

\section{Planting In-DOoRs.}

I. Plant one bulb in a three-inch paper pot or three bulbs in a four- or five-inch pot. Cover the bulb with soil, and push the soil down very firmly. Print name and date on a wooden label.

2. Water thoroughly and set away in a cool, dark basement, covering with sacking if the room is light or at all warm.

3. Water two or three times a week, often enough to keep the soil moist clear to the bottom.

4. After the bulbs have thus been developing their roots about nine weeks, bring them to the warmth and 
light of the school- or living-room. Print date on the label. If they can be put in a cool, light room where they will not freeze, they will develop better than in an ordinarily heated room, and the flowers will last longer.

RECORD OF GROWTH.

I. Bulb: shape, size, color. Date of planting.

2. Date of bringing to light; extent of root development; of leaf development.

3. Date when first flower-bud is seen.

4. Date of first open flower; of last flower; length of blossoming period.

5. Height of leaves and flower-stalks; number of flowers; length of perianth tube; shape of ovary as seen from side; expanse of petals; length of crown; number of stamens; appearance of stigma.

6. Conclusions reached as to means of improving culture.

\section{DRAWINGS FOR BOOKLETS.}

I. Bulb.

2. Whole plant and ball of earth as turned out of flowerpot when brought from basement, showing extent of root development and leaf development.

3. Leaves and blossoms; try to express with a sharp pencil point the delicate grace of the long slender leaves with their straight margins, and the beauty of the erect cylindrical flower-stalks, with the blossoms held so charmingly at an angle on the top. Be sure to show the withered spathe. Or use colored crayon pencils on gray or brown paper. 
The STORy.

Write a little story, giving your experience as recorded in the descriptive record. "My Campernelle Jonquil" would be a good title, and some such outline as this may be followed to advantage:

Planting. Period of ioot growth. Period of leafgrowth. Buds and bíossoms. Flower structure.

\section{Crocus}

\section{Planting Out-Doors.}

I. Crocuses may be planted to advantage along the border of the flower garden or in the grass of the lawn, particularly in corners and next to buildings where the grass need not be cut till the crocus leaves have ripened. Plant in September.

2. Set the bulbs three inches deep and in irregular groups, the individual bulbs or corms being rather close to get a mass effect from the flowers.

3. If in the garden, cover the ground after it freezes with a few inches of mulching of some sort.

4. As soon as the snow goes in spring, remove the covering, to give the flowers a chance to shoot up as soon as the frost is out of the ground.

5. Do not cut off the leaves; let them grow and die down late in spring or early in summer. The plants will then form new corms on top of or at the sides of the old ones. This process will bring the new bulbs so near the surface in three or four years that the corms will need to be dug up and planted deeper. 


\section{Planting In-Doors.}

I. Single corms may be planted in two-and-one-half-inch paper pots; three may be planted in a three-inch pot; and six in a four-inch pot. Cover with about half an inch of soil; firm the soil well; water and set in the basement.

2. Water as needed; watch for any plant-lice on the new growth. If found, cover the crown with tobacco powder or wash with tobacco extract solution.

3. After nine or ten weeks, examine the root development; if the lower part of the pot is well filled with roots, bring to a light, cool place and watch the development of leaves and flowers.

4. Keep a sharp watch for plant-lice on the young leaves. If they appear, sponge off with strong soap-suds or some tobacco insecticide solution.

5. When the flowers develop, keep the plant in a cool place at night, and they will last longer. Watch them bud, blossom, and fade. Then keep on watering and tending the plant in order that you may get some new bulbs to grow another season.

6. When the leaves finally wither, they have ripened off. If you dig up the corms now, you will probably find some new ones formed on top of the old ones. Put these away in a dry, cool place, and plant them next fall, or plant them out of doors in spring.

\section{RECORD OF GROWTH.}

I. Corm: shape, size, color, kind of outside covering; internal structure as compared with a hyacinth or daffodil bulb. 
2. Root development when brought from basement; height of leaves.

3. Date of first blossom; number of flowers; length of flowering period.

4. Structure of flower; color.

5. Period of leaf growth after flowers fade.

6. Number of new corms and method of development.

7. Brief statement of advice for another season.

\section{DRAWINGS.}

I. Corm: side view; top view; vertical cross-section.

2. Leaves and flowers. Use colored crayon pencils on drawing paper or colored crayons on the blackboard.

The Story.

Tell or write about "My Crocuses and How They Grew."

The Poem.

Learn or copy into your book the lines on page 135 .

\section{Freesias}

Planting In-Doors.

I. Place one bulb in a three-inch paper pot, or three bulbs in a four-inch pot. Cover to crown of bulb, firm the soil well, and set away in a cool basement.

2. Water as needed to keep the soil moist.

3. After four or five weeks, bring to a light, cool room and watch the development of leaves and flower buds.

RECORD OF GROWTH.

I. Bulbs: size, shape, color. Date of planting.

2. Root development when brought from basement. 
3. Date of first blossom buds.

4. Date of first flower; of opening of last flower on the same flower-stalk as this first one.

5. Structure of the flower.

6. Odor of the flower.

7. Conclusions as to treatment most successful in your conditions.

DraWINGS.

I. Bulb.

2. Leaf and flower-stalk when flower-buds show.

3. Blossom.

The Story.

Tell or write the story of the growth of your freesia blossoms. When written, bind the story up with your drawings in your garden booklet.

\section{Hyacinths}

Planting Out-Doors.

I. Early in October set the bulbs in loamy soil, planting about six inches deep, and being sure that all the bulbs in a row or bed are of the same depth.

2. As soon as the ground freezes, cover the surface with five or six inches of litter or mulch.

3. As soon in spring as the snow goes, remove about half the depth of this covering, and two or three weeks later remove the remainder.

4. Leave a few bulbs in place; take others up when the leaves ripen, but plant again in fall. Plant new bulbs also. Compare results in the three cases. 
Planting In-Doors in Earth.

I. Plant the larger bulbs singly in four- or five-inch paper pots; the smaller ones in three- or three-and-one-halfinch paper pots. Or plant three bulbs in a five-inch pot. Push into the soil until the crown is just covered.

2. Water freely and set away in a dark, cool closet for seven or eight weeks. Water often enough to keep the soil moist throughout.

3. When the crown of leaves breaks apart, bring to a cool, light room. Keep, if possible, in such a room for awhile. The plants grow better in a cool temperature than in too hot a room. Water freely and watch the development of the leaves and blossoms.

4. Sometimes the blossoms will start to open before the stalk elongates. If this happens, try putting a paper cap over the flowers, leaving a hole in the top of the cap.

Planting In-Doors in Water.

I. Select large bulbs of the varieties especially recommended in the catalogues for water culture. Place each in a hyacinth vase or glass, filling the latter so that the lower parts of the bulbs are covered by the water.

2. Set away in a cool, dark basement and fill up with water as often as is necessary to keep it at the original level.

3. Watch the long roots develop; also the leaves. When the crown of leaves breaks apart, bring the plant to the school-room, placing in a cool place, such as a 
window-sill with northern exposure. Here it should soon send up its blossom stalk.

RECORD OF GROWTH.

I. Bulb: shape, size, color; name of variety. Date of planting.

2. Development of crown of leaves when brought from basement. If in water, length of roots.

3. Date of first open flower; length of flowering period. Height of leaves.

4. Color, shape, and structure of single flower; number of lobes; number of stamens; color of pollen; pistil.

5. Note of culture details considered best for another year.

DRAWINGS FOR BOOKLETS.

I. Bulb: whole bulb and one in vertical cross-section, if your teacher can furnish the latter.

2. Leaf crown when brought from basement.

3. If one growing in water is available, root development when brought from basement.

4. Leaves and flowers of plant in bloom.

\section{The Story.}

Write a little story with this title: "My Hyacinth." Tell what the bulb looked like, how you planted it, where you put it, how long you left it there, how much the roots and leaves had grown when you brought it out, when it blossomed, and what you did with the plant in blossom. If you gave it to your mother or some sick friend, tell whether she thought it pretty and the perfume sweet. Adapt your drawings as illustrations for the story. 


\section{Lily-of-the-Valley}

Leaves, blossoms, stalks, and roots of the lily-of-the-valley are very poisonous when eaten. Do not put any part of the plant in the mouth.

Planting In-DOORs.

I. Have "pips" fresh from the cold-storage houses of the seedsmen. Trim off with scissors about one-third the length of the roots. Place three in a four-inch pot, packing solidly in sphagnum moss or sand. Water thoroughly and set several of the pots in a pan or tight box, and place in a warm closet where the temperature keeps pretty uniformly at $75^{\circ}$ or $80^{\circ} \mathrm{Fahr}$.

2. Keep well watered, the sphagnum or sand never being allowed to get at all dry.

3. After two weeks bring out to the ordinary temperature of the school-room, putting back in the warmer closet every night. Watch the leaves and flowers develop.

RECORD OF GROWTH.

I. Roots: characteristics. Size of main "pips"; length of roots. Date of planting.

2. Date of first flower. Length of flowering period. Odor of flowers.

DRAWINGS.

I. Roots before planting.

2. Leaves and flowers. 
The Story.

Tell or write the story of the growth of your lilies-of-thevalley. Why should they require so warm a temperature when the spring flowering bulbs require so cool a place?

\section{Polyanthus Narcissi (Paper-white and Others)}

Planting In-Doors in Earth.

I. Plant one bulb in a three-inch paper pot or three bulbs in a four-inch pot, covering the crown and firming the soil down hard. Water and place in cool basement room.

2. Water two or three times a week for five or six weeks.

3. When roots are well developed, bring out to a light, cool room. Keep well watered and watch the development of the leaves and flowers.

\section{Planting In-Doors in Water.}

I. Select the largest bulbs. Place on small stones in a wide shallow dish; fill with water to cover lower third of bulbs, and set away in a dark, cool basement.

2. Add water as often as necessary to keep it at original level; look at the dish at least twice a week.

3. When roots are well developed, bring to cool, light room. Leaves and flowers will grow rapidly.

RECORD OF GROWTH.

I. Bulb: shape, size, color. Internal structure. Date of planting; name of variety.

2. Rate of root development; how long were the roots when 
the plant was brought from the basement; how high were the leaves; color of leaves when first brought out.

3. Color of leaves twenty-four hours after bringing to light; forty-eight hours after bringing to light. What is the relation between sunlight and the green coloring of plants? This green coloring material is called chlorophyll.

4. Height of leaves one week after coming from basement room. Date of first blossom bud.

5. Date of first blossom; how many to each stalk; shape, structure, and size of flower.

6. Watch the flowers as they go by; how gradually they wither. Do seeds develop in the ovary?

7. Conclusions as to culture.

\section{Drawings.}

I. Bulb: side view, and cross-section if an extra one can be spared to cut open.

2. Crown of leaves when plant is brought to light.

3. Leaves and flowers: try to get the slender grace of the leaves and flower-stalk expressed in your drawing.

4. Sketch or photograph of a group of blossoming bulbs in pots in home window or school-room.

The STORy.

Tell to your schoolmates the story of your plant as you saw it grow; or write the story out for your booklet.

\section{Roman Hyacinth}

\section{Planting In-DOORS.}

I. Plant one bulb in a three-inch paper pot, not quite covering the crown. Or plant three bulbs in a four-. 
or five-inch paper pot. Be sure to place a bit of stone or broken pottery over the drainage hole in the bottom. Leave half an inch space between the top of the soil and the top of the pot.

2. Water thoroughly and place in a cool cellar or basement room where it will not freeze.

3. Water often enough to keep the soil moist, perhaps two or three times a week. If evaporation is rapid, throw a piece of sacking or old carpet over the pots. 4. After about five weeks, when the roots are well developed and perhaps beginning to push through the bottom of the pot, bring to the light of the schoolroom, but not in too warm and sunny a situation. 5. Two or three weeks after bulbs are brought to the light they are likely to push up the flower-stalks with their beautiful bell-shaped flowers. Keep the plant in a cool place, and these will last much longer than in a warm one.

\section{RECORD OF GROWTH.}

1. Bulb: shape, size, color. Date of planting.

2. Root development when brought from basement. (To determine this, turn bulb out of pot.) Date.

3. Leaf development when brought from basement. Is the "crown" open? Date.

4. Flowering period: length of leaves; height of flowerstalk; number of flowers; size and shape of one flower; number of lobes to perianth; number of stamens; pistil. Date of first flower; length of period of flowering.

5. Conclusion as to causes of success and failure. 
Drawings For Booklets.

I. Bulb.

2. Leaf crown when brought from basement.

3. Plant in blossom.

The Story.

From your record write a little story telling of your experience with these bulbs. Select "My Roman Hyacinth," or some similar phrase, for your title. Use your drawings to illustrate your story.

\section{Trumpet Daffodils and Medium-crowned Narcissi}

Planting OUT-Doors.

I. Set the bulbs along the border of the flower garden at least six inches deep and six inches or more apart. Plant as soon as bulbs are received-in September, if ' possible-always before the middle of October.

2. After the ground freezes, cover with a few inches of mulching of some sort.

3. When the snow goes, remove part of the mulching, and late in March or early in April remove what is left.

4. As the flower-buds appear, cut such as you wish to use in-doors, and let them expand in water in vases or flower-jars. They will generally be more perfect than if exposed to wind and sun outside.

Planting In-Doors in EARTH.

I. Plant the bulbs soon after they are received, setting in paper pots or in pottery bulb pans. Adapt the bulbs to the size of the pot; one rather small bulb may be placed in a three-inch paper pot; three bulbs, some- 
what larger, in a three-and-one-half-inch paper pot; three large bulbs in a four-and-one-half- or five-inch pot. Bury the bulbs so that the crown is nearly covered and press the soil down firmly. Water and set away in a dark, cool basement.

2. Water often enough to keep the soil moist throughout.

3. When the roots are well developed, generally in six to eight weeks, bring into a cool, light room. If in the school-room, place in the coolest corner, but do not let them freeze at night. Watch the development of leaves and flowers.

4. After blossoming, let the bulbs continue to grow to ripen off, and as soon in spring as the ground can be worked, transplant them to a sheltered place out of doors.

\section{Planting In-Doors in Water.}

I. Select the largest bulbs of the largest varieties. Place each in a hyacinth glass or some flower-jar that will hold water and has a narrow top. Or fill a wide, rather shallow dish with small stones, place the bulbs on these, and fill with water to cover the lower half of the bulbs.

2. Set away in a dark, cool basement for about six weeks, supplying more water occasionally. When a good root development has taken place, bring to a light, cool room or to the school-room.

3. Watch the leaves and flowers as they develop. Keef the water up to the original level.

RECORD OF GROWTH.

I. Bulb: shape, size, color. Date of planting. Name of varietv. 
2. Root development when brought from basement. Height of leaves.

3. Date when first flower-bud is seen; when first flower opens; when it withers; number of flowers.

4. Conclusion as to causes of success or lack of success.

DRAWINGS.

I. Bulb.

2. Leaf development when brought from basement.

3. Leaves and blossom. Use colored crayons on paper or blackboard.

The STORY.

Title: "My Daffodil." Tell how it grew, and how the flower is composed of the different parts shown in the picture on page 126 .

The Poem.

Copy in your booklet some verses about the daffodil.

\section{Tulips}

Planting Out-Doors.

I. Select loamy, well-drained soil for the tulip bed. Plant the bulbs evenly, about five inches apart and four inches deep.

2. When the ground freezes, cover the bed with coarse litter of some kind. The partially decayed leaves to be raked from the ground in the woodlands are excellent.

3. In spring, when the snow is gone, remove the covering.

4. Leave the bulbs in position till the leaves ripen. Then they may be taken up and stored in a dry place till autumn, 
5. If you wish to get new bulbs started as offshoots, cut off the flower-buds from some of these plants as soon as they appear. Compare the size and number of offshoot bulbs produced by the tulips thus treated with those on the bulbs that are allowed to blossom.

\section{Planting In-Doors in Earth.}

I. Plant one bulb in a three-inch pot; three bulbs in a fourinch pot; five or six in a four-and-one-half- or fiveinch pot. Bury the bulbs firmly in the soil. Water and set away in basement.

2. Water occasionally, but don't keep the soil in the pots too wet.

3. In eight or nine weeks examine the roots; if well developed, filling the bottom of the pot, bring the plants to a light, cool room.

4. Water often enough to keep the soil moist. Watch the development of leaves and flowers.

5. When the flowers are fully opened, pollenize some of them.

6. Watch the flowers fade and the seed pods develop.

7. If you have bulbs enough, cut off the buds of a few of them and keep the plants growing. See if the foliage ripens earlier than those which blossom. After the leaves ripen, dig up the bulbs and compare the size and number of the offshoots with those of the bulbs that produced flowers.

\section{Planting In-Doors in Water.}

I. Select the largest sized bulbs of early varieties; place in hyacinth glasses or other flower-jars. Add rain- 
water to partly cover the bulbs, and set away in basement.

2. Keep water up to the original level. After six or eight weeks there should be a good development of roots. Then bring to a light, cool room, and observe the growth of the leaves and flowers.

RECORD OF GROWTH.

I. Bulb: size, shape, color of outer covering (which is called the bulb tunic). Date of planting.

2. Date when brought from basement; extent of root development; size of flowers.

3. Date of flowering; length of flowering period.

4. Structure of flower; color.

5. Date of pollenizing.

6. Date of ripening of leaves; of seed pod.

7. Notes as to care found best in your experience.

DRAWINGS.

I. Bulb.

2. Flower and leaf.

3. Seed pod.

4. Bulb with offshoots.

The Story.

Tell or write the story of your tulips as recorded in your Record of Growth. 


\section{XV}

\section{FLOWERS FROM SEED}

\section{California Poppy or Eschscholtzia}

\section{Starting OUt-DOORS.}

I. Plant the tiny seeds in a shallow drill, being careful not to get them too thick. Cover with not more than half an inch of fine soil: this may be sprinkled on with a fine sieve-a small flour sieve, for example.

2. When the plants are well up, thin to six or eight inches apart.

3. Keep the soil surface stirred and allow no weeds to grow about the plants.

RECORD OF GROWTH.

I. Seed.

Date of planting. Size. Color.

2. Seedling, first stage.

Date. Height. Character of root. Shape of leaves. Col or of leaves and stems.

3. Seedling, later stage.

Date. Number, height, and shape of leaves.

4. Blossoming stage.

Date of first blossom. Sizo and color of blossoms. Length of flower-stalk. Description of sepals, petals, stamens, and pistils. Length of period of bloom. Use made of cut flowers. 
5. Seed.

Date of ripening. Form of seed vessel and manner of opening to free its seeds. Quantity of seed gathered.

DRAWINGS FOR BOOKLETS.

I. Seedling, first stage.

2. Seedling, later stage.

3. A leaf.

4. A flower and flower bud.

5. A seed vessel.

\section{Castor Bean}

StARTING IN-DOORS.

I. In March or early in April plant the seed of the castor bean in four-inch paper pots, putting but a single seed in each pot, and keeping the soil moist, but not too wet.

2. After the plants come up, disturb them as little as possible, giving them a warm, sunny situation and plenty of water.

3. When danger of frost is past, transplant out of doors in the position where the castor beans are to remain through the season. The mass of earth should be moist and be kept unbroken in transplanting.

Starting OUt-Doors.

I. Plant the beans out of doors, one in a place, where the plants are to remain. Cover with an inch of soil and keep the soil well watered. Do not plant until the ground is fairly warm. 
2. When the seedlings come up, give plenty of water and keep the soil surface well tilled. If more seeds were sown than there is room for the plants to mature vigorously, thin them out as necessary.

RECORD OF GROWTH.

I. Seed.

Date of planting. Size, shape, color.

2. Seedling, first stage.

Date of coming up. Height. Kind of leaves.

3. Seedling, later stage.

Date when seedling has four well-developed leaves. Shape and size of leaves.

4. Blossoming stage.

Date of first blossom. Color and structure of blossoms. Height of plant. Shape and size of leaves. 5. Fruiting stage.

Shape and size of fruit. Appearance of outside of pod. Number, shape, and size of seeds, and their arrangement in the pod.

6. Conclusions as to best time and place for planting the next year.

DRAWINGS FOR BOOKLETS.

I. Seeds.

2. Seedling, first stage.

3. Seedling with four leaves.

4. Drawing of a well-developed leaf.

5. Drawing of a flower.

6. Drawing of a fruit.

7. Sketch or photograph of clump of plants. 


\section{China Asters}

StARTING IN-DOORS.

I. Sow the seeds of the varieties selected in a seed-bed or box, about the middle of March. Cover with half an inch of soil.

2. When the cotyledons are fully developed and there are two leaves additional, transplant into two-and-a-half or three-inch pots and place in a sunny situation. Keep well-watered, and as the weather grows warmer, give all the light and air possible.

3. As soon as danger from frost is past, transplant into the open garden.

StARTING OUT-DOORS.

I. Sow the seeds rather thinly in drills and cover with about half an inch of fine soil. This may be done before danger from frost is past.

2. When the seedlings come up, thin to about an inch apart. Hoe and water as may be necessary.

3. When the young plants have six or seven leaves, transplant to the garden border where they are to bloom. Keep the soil well cultivated and apply water during dry periods.

4. If any plants begin to show disease by their abnormally whitened leaves or spindling growth, pull them up and burn them at once.

5. If black blister beetles appear, to feed upon the buds, shake them two or three times a day into shallow pans, with a little kerosene and water on the bottom. 
RECORD OF GROWTH. .

I. Seed.

Date of planting. Size, shape, color.

2. Seedling, cotyledon stage.

Date of coming up. Shape of cotyledons. Shape of root. Shape of first leaves.

3. Seedling, second stage.

Describe seedling when it has six or seven true leaves.

4. Blossoming stage.

Date of first blossom. Type of blossom structure. Colors. Height and form of plant. Length of flowering period. Use made of flowers. Lasting qualities of cut blooms. Formation and collection of seed.

5. Enemies.

Description of diseased plants. Description of insect enemies. Record success in combating enemies.

6. Insect visitors.

Write a list of the insects that you see visiting the flowers.

7. Changes in treatment planned for another season.

DRAWINGS FOR BOOKLETS.

I. Seeds.

2. Seedling, cotyledon stage.

3. Seedling, transplanting stage.

4. Planting plan of aster bed, showing arrangement of varieties.

5. Leaf drawing or leaf print, showing shape and outline of the leaf.

6. Branch with flower and flower buds. 


\section{Cosmos}

STARTING IN-DOORS.

I. Plant seeds in seed-bed.

2. Transplant seedlings, when first true leaves appear, to three-inch pots. Give plenty of light.

3. When danger of frost is past, transplant fifteen inches apart in garden border.

4. Stake plants when about two feet high.

Starting Out-Doors.

I. Plant seeds in drill half an inch apart, covering with about three-quarters of an inch of fine soil.

2. Transplant to garden border, fifteen inches apart, when seedlings have four true leaves.

3. Stake the plants when about two feet high.

RECORD OF GROWTH.

I. Seed.

Date of planting. Size, shape, color.

2. Seedling, cotyledon stage.

Date. Height. Shape of root. Color of stem. Shape and size of seed-leaves.

3. Seedling, transplanting stage.

Date. Height. Number and shape of true leaves.

4. Seedling, later stage.

Record the growth of the plant about the middle of June.

5. Blossoming stage.

Date of first blossom. Size and color of blossoms. Length of flowering period. Quantity of bloom. Height of plant.

6. Conclusions as to culture another season. 
DRAWINGS FOR BOOKLETS.

I. Seeds.

2. Seedling, cotyledon stage.

3. Seedling with four true leaves.

4. A true leaf.

5. Branch with flower and flower buds.

6. Sketch or photograph of group of plants.

StARTING IN-DOORS.

\section{Marigolds}

I. Sow the seed broadcast in the seed-bed.

2. When the seedlings are from one to two inches high, transplant to small paper pots and place in a sunny situation.

3. When danger from frost is past, transplant out of doors, setting the tall varieties in the border garden and the dwarf sorts in beds or along the front margin of the border garden.

Starting OUt-DOORS.

I. Sow the seeds in drills, covering with about half an inch of fine soil.

2. When the seedlings are up, thin to about an inch apart and leave until four or five true leaves have developed. Then transplant to a permanent situation.

RECORD OF GROWTH.

I. Seed.

Date of planting. Size, shape, color.

2. Seedling, cotyledon stage.

Date. Height. Shape of root. Color of stem. Shape and size of seed-leaves. 
3. Seedling, transplanting stage.

Date. Height. Number and shape of true leaves.

4. Planting plan of bed of marigolds.

5. Seedling, later stage.

Watch for the falling of the seed-leaves and record the height and number of true leaves of the plant at that time.

6. Blossoming stage.

Date of first blossom. Height of plant. Size, color, and odor of the blossoms. Profusion of bloom. Use made of cut flowers.

7. Plans for improvement another season.

\section{DRAWINGS FOR BOOKLETS.}

I. Seeds.

2. Seedling, cotyledon stage.

3. Seedling, with four true leaves.

4. Drawing or leaf print of a true leaf.

5. Branch, with flower and flower buds.

\section{Morning-glories and Moon-flower}

Starting IN-DOORS.

I. Plant the seed about three-quarters of an inch deep, either in a seed-box or in three-inch paper pots, one seed to each pot. Before planting, in the case of the larger seeds, file a notch in one corner of the seedcoat.

2. When the plants are up, watch carefully for the presence of aphides, which are very likely to be troublesome to morning-glory seedlings in-doors. When any of the insects appear, spray the leaves and stems with 
tobacco solution or wash the insects off with a bit of sponge dipped in tobacco solution, or even strong soap-suds.

3. Give the seedlings as much sunshine and air as possible, and when danger from frost is past, transplant out of doors.

\section{Starting OUT-DOORS.}

I. When danger from frost is past, plant the seeds out of doors, preferably where the vines are to grow. Before planting, in the case of the large seeds of the Japanese Morning-glories and the moon-flower, file a notch on one corner of the seed-coat, in order that germination may be more sure. Cover with about an inch of loose soil and see that the ground is kept moist until the seedlings appear.

2. The plants will be likely to come up in about a week. As soon as they are up, or perhaps better, even before the seeds are planted, provide strings or other supports for the vines to climb upon.

3. Keep the surface of the soil well stirred and free from weeds, with plenty of water during dry weather, and the plants will grow rapidly and produce an abundance of bloom in a comparatively short period.

\section{RECORD OF GROWTH.}

I. Seed.

Name of variety. Date of planting. Size, shape. color.

2. Seedling, first stage.

Date of coming up. Size and shape of cotyledons. 
3. Seedling, transplanting stage.

Date. Height of plant. Number of true leaves, their shape and size.

4. Blossoming stage.

Date of first blossom. Structure of blossom. Colors of corolla. Amount of bloom. Hours of full bloom.

5. Enemies and visitors.

What insects attack the leaves and stems?

How were their attacks checked?

What insects can you see visiting the blossoms?

Where is the nectar secreted?

From the structure of the blossom, would selfpollination be possible?

6. Fruiting stage.

Structure of the seed pod. Number and arrangement of the seeds in the pod. Quantity of seed saved.

7. Note of experience gained to govern future culture.

DRAWINGS FOR BOOKLETS.

I. Seeds.

2. Seedling, cotyledon stage, or leaf print of cotyledon.

3. Seedling with four leaves.

4. Drawing or leaf print of a well-developed leaf.

5. Drawing of a stem and blossom.

6. Drawing of a seed pod.

7. Sketch or photograph of vine-covered trellis.

\section{Nasturtium or Tropaolum}

StARTING IN-DOORS.

I. Fill.a three-inch paper pot with soil. Plant in the middle, an inch deep, two nasturtium seeds. Keep moist and in a warm situation. 
2. In a week or so the seedlings should come up. Place the pot in as sunny a situation as possible and watch it grow. When the seedlings have developed three or four feaves, pull the smallest one up carefully and draw a picture of it.

3. When danger of frost is past, remove the plant from the pot, disturbing the roots as little as possible, and transplant into your garden.

Starting OUT-Doors.

I. Select a location along the border of the garden or some other desirable situation, getting the soil into good condition, and plant your seeds, one in a place, at least six inches apart, and about an inch deep. Keep the soil moist and watch for the appearance of the seedlings.

2. After the seedlings come up, give good culture, watering as necessary, and keeping the ground free from weeds.

3. When the blossoming period begins, pick the blossoms before they can go to seed. You will thus increase the number of flowers.

RECORD OF GROWTH.

I. Seed.

Date of planting. Size of seed with covering. Size, shape, and color of seed when covering is removed.

2. Seedling, first stage.

Date of coming up. Height. Kind of leaves. Position of seed upon the young seedling. Shape of root. Size and shape of leaves. Place of attachment of the petiole. 
3. Seedling, later stage.

Date when seedling reaches a height of six inches.

Number of leaves.

4. Blossoming stage.

Date of first blossom. Height of plant. Description of blossom according to this outline:

Flower-stalk.

Sepals.

Petals.

Stamens.

Pistil.

Freedom of bloom. Length of flowering period.

5. Plans for succeeding season as based on experience here recorded.

DRAWINGS FOR BOOKLETS.

I. Seeds before removal of pods.

2. Seeds separated from pods.

3. Seedling, first stage.

4. Seedling, later stage.

5. Drawing or leaf print of a well-developed leaf.

6. Leaf-stalk with bud and flower.

7. Young seed pods attached to stalk.

8. Sketch of growing plants in garden.

STARTING IN-DOORS.

\section{Pansies}

I. Early in March, or even earlier if desired, sow the seed in the in-door seed-bed, covering lightly and keeping the soil moist, but not too wet.

2. Let the plants get a good start in the seed-bed before transplanting. Then transplant to individual pots or 
to boxes, giving plenty of light and air, and not keeping in too warm a place. When the ground outside is in good working condition, transplant to the permanent bed, putting the plants eight or ten inches apart.

\section{Starting OUt-DOoRs.}

I. Select a bit of seed-bed where the soil is in thoroughly good condition and sow the seed sparsely either in drills or broadcast, covering it very lightly and pressing the surface firmly with a hoe or bit of board. If there is danger of drouth, cover the surface also lightly with straw or lawn clippings, or something similar, in order to give it a light mulching. Or sow in a cold-frame and cover with cheese-cloth stretched on a movable frame.

2. When the seedlings come up, gradually remove most of the mulching and see that the bed is kept moist.

3. After the seedlings have reached a fair size, transplant to the permanent bed.

4. Keep the plants watered, if possible, and pick the flowers frequently.

RECORD OF GROWTH.

I. Seed.

Date of planting. Size, shape, color.

2. Seedling.

Date of coming up. Height. Number and kind of leaves.

3. Date of transplanting.

Number, size, and shape of leaves. 
4. Blossoming stage.

Date of first blossom. Color and structure of blossom. Range of color and color combinations. Character of leaves and stems. Use of flowers: description of effective arrangements.

5. Fruiting stage.

Shape and size of seed pod. Manner of breaking open. Number, shape, and size of seeds and their arrangement in the cells of the pod. Method of selection of your seed for sowing next year.

DRAWINGS FOR BOOKLETS.

I. Seeds.

2. Seedling, first stage.

3. Seedling, transplanting stage.

4. Drawing of a well-developed leaf.

5. Drawing of a flower.

6. Cross-section of a flower, side view, showing arrangement of sepals, petals, stamens, and pistil.

7. Drawing of a seed pod, with transverse cross-section of same.

8. Sketches to show arrangement of flowers for display.

Starting OUT-DOORS.

$$
\text { Poppy }
$$

I. Select a bed or border and get the soil into very fine condition, free from grass, stones, and lumps of earth.

2. Mix the seed with sand or corn-meal, and then sow thinly, either broadcast or in a shallow drill, covering either by pouring on water from a watering-pot or raking the soil surface very lightly. Or sift on soil through a fine sieve. 
3. When the seedlings are about two or three inches high, thin to six or eight inches apart in the case of the Shirley and other slender growing forms, and to a foot apart in the case of the more robust forms.

4. Keep the soil surface cultivated, pulling out all weeds.

5. As the blossoms appear, remove the seed pods as fast as the petals drop away, leaving a few of the best - flowers to develop seed for your next season's sowing.

RECORD OF GROWTH.

I. Seed.

Date of planting. Size, shape, color.

2. Seedling, first stage.

Date. Height. Shape of root. Size and shape of leaves.

3. Seedling, later stage.

Date of thinning. Height of plant. Number and shape of leaves.

4. Blossoming stage.

Date of first blossom. Height of flower-stalks. Description of blossom according to this outline:

Stalk.

Sepals.

Petals.

Stamens.

Pistil.

5. Conclusions as to culture details advisable the next year.

DRAWINGS FOR BOOKLETS.

I. Seeds.

2. Seedling, first stage. 
3. Seedling, later stage.

4. Drawing or leaf print of a well-developed leaf.

5. Flower-stalk with bud and flower.

6. Seed pods.

\section{Portulaca}

Starting OUT-DOORS.

I. Choose a hot, dry situation for the portulaca bed. Scatter the seed broadcast, covering rather lightly. When the seedlings appear, weed carefully and thin gradually until they are eight or ten inches apart, stirring the surface between occasionally until it is shaded by the growth of the plants.

RECORD OF GROWTH.

I. Seed.

Date of planting. Size, shape, color.

2. Seedling.

Date of coming up. Height. Number and kind of leaves.

3. Blossoming stage.

Date of first blossom. Habit of plant. Character of stems and leaves. Color. Structure of blossom.

4. Fruiting stage.

Shape and size of seed pod. Manner of breaking open. Shape, size, and approximate number of seeds.

5. Plans for treatment another year.

DRAWINGS FOR BOOKLETS.

r. Seeds.

2. Seedling. 
3. Drawing of stem with flower on end.

4. Drawing of seed pod.

\section{Sweet Pea}

STARTING In-DOORS.

I. A few seeds of the earliest varieties may very well be planted in three-inch paper pots about March first. They will soon germinate, and should be watched and watered carefully.

2. When the frost is out of the ground in April, transplant to the open garden, choosing a warm situation where the plants will be likely to grow rapidly.

3. Very soon after thus transplanting, furnish some kind of support for the vines.

\section{Starting OUt-Doors.}

I. Choose a situation, if practicable, where the row of sweet peas can run north and south, and where the soil is fairly rich and not too light. Hollow out a single or double furrow about four inches deep. In the bottom of this sow the seeds an inch or two apart, as early in the spring as possible. Cover with one inch of soil, leaving the rest of the trench open, to be filled in later.

2. If the weather in spring should be dry, water occasionally, giving an abundance each time, but not watering very often.

3. As the plants grow, fill in the trench gradually, always keeping the surface of the soil in a powdery condition. 
4. Watch for cutworms. Whenever plants are found cut off, hunt in the soil for the worm, or caterpillar, and kill it.

5. When the plants are about four or five inches high, furnish some kind of support for them to grow upon. Birch or other shrubby branches are especially good if they are about five feet high. Wire netting is frequently used, although it may not be desirable in southern localities.

6. Water throughout the season when the weather is dry, keeping the soil surface well stirred, but not digging deep.

7. Pick off the blossoms as they appear, letting no seed pods form, for if the plant is allowed to ripen seed pods, it will stop blossoming.

RECORD OF GROWTH.

I. Seed.

Date of planting. Size, shape, color.

2. Seedling, first stage.

Date of coming up. Comparative height of stem with length of root. Shape of root. Shape and size of first leaves. Position of seed.

3. Seedling, second stage.

Describe seedling when six to ten inches high, telling shape of stem, character of leaves, shape and size of stipules, length and position of tendrils.

4. Blossoming stage.

Date of first blossom. Description of blossom. Height of plant. Use of blossoms. Description of best arrangement. 
5. Insect visitors.

Name the insects you see visiting the flowers.

Do bumblebees light astride the keel or ride upon one of the wings?

Do they come in contact with the anthers and stigma of the flower?

6. Conclusions as to any changes in culture desirable.

DraWINGS FOR BOOKLats.

I. Seeds.

2. Seedling, first stage.

3. Seedling, later stage.

4. Leaf; showing leaflets and tendrils.

5. Branch, with flower and flower buds.

6. Sketches of garden plan; method of supporting vines; vines in bloom.

7. Sketches of most pleasing arrangement of sweet peas in vase.

\section{Zinnia}

StARTING IN-DOORS.

I. Sow the seed in the seed-bed in rows or broadcast, covering half an inch deep.

2. When the seedlings are two or three inches high, transplant to small pots.

3. When the plants are started so early that the roots fill the small pots before it is time to set the plants outdoors, transfer to a larger pot.

4. When the ground is in good condition and the weather well settled, transplant out of doors. 
Starting OUt-DOORS.

I. Sow the seeds sparsely in drills a foot or more apart, covering with about an inch of soil. Keep well watered.

2. When the seedlings come up, thin gradually, so that at the last thinning the plants will stand ten inches apart if they are dwarf varieties, fifteen or twenty inches apart if they are medium-sized varieties, and two feet or more apart if they are the tall varieties. Plan to have the space completely occupied by the flowers and foliage when the plants are fully developed, and record your success or failure in this as a guide for another season.

RECORD OF GROWTH.

I. Seed.

Date of planting. Size, shape, and color of each of the two types of seeds.

2. Seedling, first stage.

Date of coming up. Height when described. Kind, shape, and size of leaves.

3. Seedling, later stage.

Date when seedling has six well-developed leaves. Height of plant.

4. Blossoming stage.

Date of first blossom. Color, structure, and size of blossoms. Height of plant. Shape, size, and arrangement of leaves.

5. Fruiting stage.

Let a few blossoms go to seed. Harvest the seed and notice the number, shape, and size of those in a single head. 
Drawings For Booklets.

I. Seeds: examples of both types.

2. Seedling, first stage.

3. Seedling with six leaves.

4. Drawing or leaf print of a well-developed leaf.

5. Drawing of stem, leaves, and flower.

6. Plan of arrangement of varieties and colors in zinnia bed. 


\section{XVI}

\section{VEGETABLES}

\section{Beet}

Growing OUT-Doors.

I. As soon in the spring as the ground is in good condition to work, sow the seed sparsely in rows twelve or fifteen inches apart, covering about three-quarters of an inch deep. To secure a very early crop, sow early in cold-frame or house, and transplant.

2. When the seedlings appear, stir the soil surface between the rows, and weed the rows as early as practicable.

3. When the young plants have developed two or three seed-leaves, thin to about three inches apart. If taken up without injuring roots, beet plants may be transplanted successfully.

4. During the following weeks keep the plants free from weeds and the surface between the rows frequently tilled.

5. As soon as the young beets are about two and one-half to three inches in diameter pull the larger ones for use. Continue pulling, as the beets become large enough, until the crop is harvested. Remove the cut leaves and all discarded beets to a heap or some place where they will not permit the spores of various fungous diseases to develop. 
RECORD OF GROWTH.

I. Seed : size, shape, and color. Cut one of the "seeds" in two, and you will find that this is really a fruit with two or three tiny seeds inside of it. Date of planting.

2. Date of coming up of seedlings. Size and shape of seedleaves.

3. Date of thinning. Number of true leaves then present.

4. Date of first harvest. Number of beets gathered.

5. Date of last harvest.

6. Comparison of varieties: conclusions.

\section{DraWINGS.}

I. Seeds: cross-section of "seeds."

2. Seedling with seed-leaves well developed.

3. Seedling at time of thinning.

4. Fully developed beet with or without the leaves.

5. Plan of vegetable garden. Plan of plot of beets.

\section{The Story.}

Tell the story of your beets and how they grew. What is the difference between the beet seed that you plant and the radish seed that you plant? When does the beet blossom? Is it an annual or a biennial? Make the story more interesting by telling your schoolmates that the beet originally was a wild plant related to our common pigweed, and that it has been in process of improvement for more than two thousand years. Learn more about this in the encyclopedias or books on horticulture at the library. 


\section{Bush Beans}

Growing OUT-Doors.

I. As soon in spring as danger from frost is past, sow the seed about one inch deep, with the hills about one foot apart in the row, or in a continuous row, with the beans about one inch apart. The rows should be twelve or fifteen inches apart. Three weeks later make another planting for succession.

2. When the plants come up, stir the soil surface and pull up any weeds that may appear in the row. Do not till the soil when the leaves are wet, as this is believed to increase the danger from fungous diseases.

3. The only subsequent treatment is to keep the ground frequently stirred and free from weeds. The plants will blossom and set the pods with very little care.

4. As soon as some pods are of eatable size, gather them, and repeat the picking until the crop is gone. Then pull up the vines and burn or bury them, in order to prevent the development of the spores of fungous diseases. Seed may be saved by allowing pods on best plants, or on part of best row, to ripen their beans.

RECORD OF GROWTH.

I. Seeds: size, shape, and color. Date of planting. Name of variety.

2. Date of coming up. Appearance of seed-leaves.

3. Date of blossoming. Abundance and kind of insect visitors to the flowers. 
4. Date of first picking; of last picking.

5. Comparison of varieties.

Drawings.

I. Seeds showing external and internal structure.

2. Seedling showing seed-leaves and first true leaf.

3. Blossoms.

4. Pods.

5. Garden plans.

The Story.

Tell or write the story of your experience in raising beans. What was the market price of string beans at the time you gathered the first part of your crop? Can you estimate your income from a quarter of an acre of beans grown as you grew yours? Calculate wages per hour of labor by comparing net income with time spent on planting, culture, and harvesting.

\section{Cabbage}

Growing OUT-DOORS.

I. Soon after the ground is in good condition in spring, sow the cabbage seed in a shallow drill, covering only lightly. A cold-frame allows earlier sowing.

2. The young seedlings will soon come up, and should be transplanted when the first true leaf is well developed. They may be transplanted to another part of the same seed-bed or, if the ground where the main crop is to be grown is ready, they may be transplanted. directly there. The soil must be very rich.

3. Plant in rows at least eighteen inches apart in the rows. 
4. For subsequent culture keep the ground well tilled, free from weeds, and, in case of very dry weather, give the plants a liberal supply of water occasionally.

RECORD OF GROWTH.

I. Seeds: shape, size, and color. Date of planting. Name of variety.

2. Date of coming up. Shape and size of seed-leaves.

3. Date of transplanting. Number of true leaves.

4. Date of setting out. Size of plants.

5. Caterpillar enemies: description; injuries caused; means taken to destroy them.

6. Date of gathering first head, and date of clearing ground.

DRAWINGS.

I. Seeds: natural size and magnified.

2. Seedling with seed-leaves.

3. Seedlings at time of first transplanting.

4. Fully developed head.

5. Insect pests: butterfly egg; caterpillar; chrysalis.

The Story.

Tell your experience in growing cabbage. Do you consider it a difficult crop to grow?

\section{Carrots}

Growing OUT-Doors.

I. Sow the seed sparsely, in rows about one-half inch deep. Sow in the same rows a few radish seeds to mark the rows.

2. When the radishes are up, hoe the soil between the rows, and when the carrots come up, weed carefully. 
3. After the carrots are well started, thin to about one inch apart, leaving the more vigorous plants and pulling up those less vigorous.

4. The only later treatment required is that of keeping the soil surface loose and free from weeds by frequent tillage.

RECORD OF GROWTH.

I. Seed: size, shape, and color. Date of planting.

2. Date of coming up.

3. Date of first weeding.

4. Date of first pulling.

5. Date of main harvest.

6. Description of caterpillar pest.

DRAWINGS.

I. Seeds: some of them as seen through a magnifying glass.

2. Seedlings as they appear at the time of thinning.

3. The full-sized carrot, with or without the leaves, at the time it is pulled for use.

4. Caterpillars and their transformations; appearance when touched.

The Story.

Tell your experience in growing carrots. In what ways are carrots utilized? When does the carrot blossom?

\section{Cucumber}

Growing OUT-Doors.

I. Mark off hills four feet apart each way, dig out several shovelfuls of earth, then fill the hole thus made 
with old, well-pulverized barn-yard fertilizer. Cover with a few inches of soil, but do not have the surface of the hill higher than the surrounding soil surface. Plant a dozen or fifteen cucumber seeds, scattering them over a circular surface a foot or more in diameter, so that plants will come up in all parts of the hill. Cover with about one inch of soil.

2 As soon as the young seedlings appear, watch carefully for striped beetles and black squash bugs. If these pests are very thick, apply a shovelful of tobacco powder to each hill or dust with plaster; or, perhaps a better way, protect the hills with mosquito netting held up by supports or frames. In most sections of the country the raising of cucumbers or other related plants involves a constant fight against these insect enemies.

3. Keep the surface of the ground well tilled and stirred, and do not thin the plants until they begin to crowd so that there will be danger of disturbing the roots of those left when you pull up those that are to be taken out. Thin finally to about four plants to a hill, having the plants left well distributed in the hill.

\section{The StoRy.}

Connect your records of culture and accounts of insect pests to make an instructive story. Illustrate it with sketches. In closing, summarize your opinions as to the best means of securing good results another year. 


\section{Lettuce}

Growing OUT-DOORs.

I. As soon in spring as the ground can be worked, sow the lettuce seed sparsely in a shallow drill and cover with about one-half inch of fine soil.

2. As soon as the young plants appear, stir the surface of the soil between the rows and keep the rows free from weeds.

3. When the first true leaf is fairly well developed, thin the plants to six inches apart in the rows; or the plants may be sown in cold-frame and transplanted.

4. The only subsequent treatment needed will be frequent stirring of the soil and pulling of weeds. Gather the heads as soon as they reach full size.

RECORD OF GROWTH.

I. Seeds: shape, size, and color. Date of planting. Name of variety.

2. Date of coming up. Appearance of seed-leaves.

3. Date of thinning. How does the first true leaf differ from the seed-leaves?

4. Date of gathering first heads.

5. Date of gathering last heads.

6. Comparison of varieties, and conclusions.

DraWINGS.

I. Seeds: natural size and magnified.

2. Seedlings with two seed-leaves.

3. The first true leaf.

4. Fully developed head. 
The Story.

Write the story of your lettuce and how it grew. What was the market price of lettuce at the time you gathered the first heads? At this price, how much would you receive for a crop from a quarter of an acre of lettuce in rows fifteen inches apart, estimating the plants as being set ten inches apart?

\section{Okra or Gumbo}

Growing OUT-Doors.

I. Plant three or four seeds in hills a foot or eighteen inches apart, covering one-half or three-quarters of an inch deep.

2. When the plants come up, pull out any weeds that may appear, and thin to one or two plants to a hill.

3. Later treatment consists only of keeping the ground well tilled and free from weeds.

4. Pull the pods before they get too large: they are used chiefly for thickening soups.

\section{Onions from Seed}

StARTING IN-DOORS.

I. Sow the seed in seed-boxes, in drills one-half inch deep and one inch apart. Cover with one-half inch of fine soil and water carefully.

2. When the seedlings come up, give as much air and sunshine as possible and avoid too warm a place. Water carefully.

3. When the little plants are two or three inches high, cut off the tops about one inch above the soil surface. This is to make them grow more stocky. 
4. About two weeks later cut off the tops again.

5. When the outside garden is in good condition for planting, transplant the seedlings from the seed-box into rows, setting the plants only a little deeper than they were in the seed-box, and about one inch apart in the rows. The rows should be twelve or fifteen inches apart.

6. Keep the surface of the soil well tilled and free from weeds.

7. When the onions are matured, pull them during dry weather, and leave them on the surface of the ground to ripen.

Starting Out-DOors.

I. Sow the seeds sparsely in shallow drills and cover with about one-half inch of fine soil. Rows should be twelve or fifteen inches apart.

2. When the seedlings are up, weed the rows carefully and thin the onions to about one-half inch apart.

3. About two weeks later weed again, and thin to one inch apart.

4. For the rest of the season treat as outlined in paragraphs six and seven above.

RECORD OF GROWTH.

I. Seed: size, shape, and color. Date of planting.

2. Date of coming up. Method by which the leaf breaks through the ground.

3. Date of transplanting.

4. Date of harvest. 
DRAWINGS.

I. Seeds: natural size and magnified.

2. Seedling as it first appears.

3. Seedling when leaf straightens out.

4. Seedling at time of transplanting.

5. Mature bulbs.

THE STORY.

Tell or write the story of your experience in raising onions.

\section{Onions from Sets}

\section{Growing OUT-Doors.}

I. Plant the sets, one inch apart, in rows twelve inches apart, just burying each set and pushing the earth firmly down beside it.

2. Keep the surface of the soil stirred frequently, and pull out the weeds between the plants.

3. When the new onions are about one-half inch or more in diameter, pull and tie in bunches of a dozen or fifteen each.

RECORD OF GROWTH.

I. Onion sets. Size, shape, and color. Name of variety. Date of planting.

2. Date of hoeing and weeding.

3. Date of pulling.

\section{DRAWINGS.}

I. Two or three onion sets.

2. A plant at the time it is pulled. 


\section{The Story.}

Tell the story of your experience in growing onions from sets. What advantage do you gain by planting sets instead of seeds?

\section{Parsley}

\section{GROWING OUT-DOORS.}

I. Soak the seed in warm but not hot water a few hours before planting it.

2. As early in spring as the ground can be worked, plant in rows, sowing the seed rather sparsely in the rows. Sow also enough radish seed to mark the rows when the plants appear, and cover with at least one-half inch of fine soil.

3. When the radish plants come up, stir the soil surface beside the rows, but do not disturb the rows themselves. The parsley plants will probably not come up until some time after the appearance of the radishes.

4. When the parsley plants have one or two true leaves well developed, thin to about four inches apart in the row, and pull up the radishes. Parsley may be sown in a seed-bed and transplanted.

5. The only subsequent treatment needed is to keep the plants free from weeds and the surface of the ground frequently tilled. Do not pull the parsley leaves too soon, and do not at any one time take all the leaves from the plant.

6. In late October take up several vigorous plants and transfer to a cold-frame or to a box in the house. 
RECORD OF GROWTH.

I. Seeds: size, shape, and color. Date of planting. Name of variety.

2. Date of coming up. Shape and size of seed-leaves.

3. Date of thinning. How do the first true leaves differ from the seed-leaves?

4. Date when leaves are large enough to pull.

Drawings.

I. Seeds: natural size and magnified.

2. Seedlings showing seed-leaves and one true leaf well developed.

3. Parsley plant when ready to furnish leaves for garnishing.

The STORY.

Tell or write the story of your experience in growing parsley. When does the plant blossom?

\section{Parsnip}

Growing OUT-Doors.

I. Plant the seed in rows fifteen or eighteen inches apart. Sow thickly and cover with at least one-half inch of soil. Be sure to get the seed started early in the spring.

2. When the seedlings appear, stir the soil surface between the rows and pull out any weeds that grow among the plants.

3. As soon as one or two true leaves have developed, thin to four inches apart, of course removing all weeds at the same time. 
4. The subsequent treatment is simply to keep the plants free from weeds and the soil surface well stirred. This must extend all through the summer months and into early autumn.

5. Late in autumn some of the roots may be pulled for use and the others left in the ground until the following spring. In the latter case it is desirable to cover them, as winter sets in, with a few inches of autumn leaves held in place with some coarse rubbish. Then in spring the roots will be found in good condition when dug.

RECORD OF GROWTH.

I. Seeds: size, shape, and color. Date of planting.

2. Date of coming up of seedlings. Shape and size of seed-leaves.

3. Date of thinning.

4. Dates of autumn harvest; of spring harvest.

DraWINGS.

I. Seeds.

2. Seedling with seed-leaves well developed.

3. Seedling at time of transplanting.

4. Parsnip root when pulled to eat.

The Story.

Tell or write of your experience in growing parsnips. When does the plant blossom? Is it an annual or biennial?

\section{Peas}

Growing OUT-Doors.

I. Sow the hard blue peas, of which the variety Alaska is a good example, as early in the spring as the 
ground can be worked. The wrinkled varieties of peas should be planted about two weeks later.

2. Plant in rows about one inch deep, placing the seed quite thickly for the low-growing varieties and more sparsely for the tall-growing sorts. The distance between the rows should also vary with the height of the variety. The low-growing sorts may be planted in rows twelve inches apart, while the taller ones should be eighteen inches to two feet apart.

3. When the plants come up, hoe between the rows to kill weeds and save moisture. Very little other attention is necessary for the low-growing sorts.

4. Tall-growing varieties will need some sort of support. Various forms of bushes may be used, or wire netting may sometimes be substituted. An excellent way is to set in place a row of birch or other brush before the seed is sown, and then plant the peas in rows along each side.

5. After the peas are up, keep the soil between the rows well tilled, and pull out the weeds that may appear among the peas.

6. As soon as the pods are well formed, watch them daily to determine when they are ready to pick. The varieties of the Alaska type should be gathered rather early, as they become hard and of poor quality if left to grow too long.

7. As soon as the pods are all harvested, pull up the vines and burn them, and thus prevent the development of disease that might otherwise take place. Plant bush beans, endive, turnips, or other succession crops. 
RECORD OF GROWTH.

r. Seed: size, shape, and color. Date of planting.

2. Date of coming up.

3. Date of first blossom.

4. Date of first picking; last picking.

Drawings.

I. Seeds.

2. Seed and seedlings with roots attached as the plant breaks through the ground.

3. Young plant as it appears above ground when four inches high.

4. Leaf and tendril.

5. Blossom.

6. Pod.

The Story.

Tell the story of your experience in growing peas. How large a crop did you get? What are your plans for growing peas another year?

\section{Pepper}

Starting In-DOORS.

I. Sow the seed in seed-boxes late in March. Water and keep in a warm place.

2. When the seedlings have one or two true leaves in addition to the seed-leaves, transplant into two-and-onehalf-inch paper pots, and place in a warm, sunny situation; or plunge in soil of cold-frame. Give as much air and light as possible, and water often enough to keep the soil moist, but not wet. 
3. When all danger of frost is past, plant out of doors, placing the plants at least one foot apart.

4. Keep the soil in the garden well tilled and, if practicable, water occasionally during dry weather.

5. Select the best early fruit from a vigorous plant, for seed.

RECORD OF GROWTH.

I. Seed: shape, size, and color. Date of planting.

2. Date of coming up.

3. Date of transplanting, number of leaves, and height of plant.

4. Date of blossoming.

5. Date of first ripe fruit.

DRAWINGS.

I. Seed.

2. Seedling with seed-leaves of full size.

3. Seedling when transplanted.

4. Seedling when planted out of doors.

5. Leaf and blossom.

6. Fruit: appearance as whole; sectional view.

The Story.

Tell or write the story of your experience in growing peppers, and use your drawings for illustrations; or, write a letter to a friend telling him just how to grow peppers from seed, giving him the benefit of your experience as to details of culture, and using plans and other drawings to make your advice clear. 
Growing OUT-DOORS.

\section{Potato}

I. If you wish to get an extra early crop of potatoes, start sprouts on the tubers in-doors in the way described on pages I 29 and I30.

2. Cut the tubers to three or four eyes, and plant in hills fifteen inches apart, in rows eighteen inches or two feet apart. Cover rather deeply. Or plant ten inches apart in a trench four to six inches deep, covering two inches at first.

3. As soon as the plant comes up, stir the soil surface and keep watch for potato beetles. At first pick off all these beetles and kill them by dropping them into a pan containing a little kerosene and water. If planted in a trench, gradually fill it until the soil is level.

4. When the vines are six or eight inches high, spray with a combination of Bordeaux mixture to which has been added Paris green or arsenate of lead.

5. When the blossom buds appear, hill the plants by drawing up the soil toward them from between the rows. Spray again about two weeks after the first spraying. 6. Keep the rows free from weeds, but do not disturb the roots.

7. Harvest the main crop when the plants commence to die down. Thrust a fork under the hill, or loosen from the side with hoe, being careful neither to cut nor overlook any.

RECORD OF GROWTH.

I. Date of planting. Name of variety.

2. Date of coming up. 
3. Date of spraying.

4. Date of blossoming. Date of second spraying.

5. Date of harvest; amount of yield from largest tubers.

\section{DraWINGS.}

r. A piece of tuber like those planted, showing number of eyes.

2. Well-developed potato leaf.

3. Blossoms.

4. An average sized tuber.

5. Dig up the plant deeply and carefully, and make a sketch or diagram, showing the relation of tubers to roots and leaf parts.

The Story.

Write an account of your experience in growing potatoes, telling how to plant and cultivate them, what enemies you found to harm the vines, how often you sprayed them, and how large a yield you obtained. At the rate the potatoes yielded, how many bushels would be obtained from an acre? And at the market price at the time you harvested your crops, how much would the potatoes from such an acre bring in?

\section{Radish}

Growing OUT-Doors.

I. Sow the seed about one-quarter of an inch apart in drills about one-half of an inch deep and twelve inches apart. Cover with half an inch of soil.

2. When the plants are up, weed carefully and thin to one inch or three-quarters of an inch apart. 
3. Keep the soil between the rows hoed freely and, if practicable, water the plants if the weather is dry.

4. Pull the radishes as soon as they are of good size, and do not leave them so long that they become stringy, or hollow and pithy.

RECORD OF GROWTH.

I. Seed: sizes, shape, and color.

2. Date of coming up. Appearance of seed-leaves.

3. Date when the first two true leaves reach the length of one-half inch or more.

4. Date when first radishes are pulled, and date when last radishes are pulled.

5. Date when maggots appeared; amount of damage.

DraWINGS.

I. Seeds.

2. Seedlings when seed-leaves are of full size.

3. Seedlings when first two true leaves are one-half inch long or longer.

4. Radishes when pulled.

The STORY.

Tell or write the story of your experience in growing radishes. If written, bind it in your school garden book with the drawings to illustrate the story. If you sold bunches to your neighbors, include an account of expenses and profits.

\section{Salsify or Vegetable Oyster}

Growing OUT-Doors.

I. Sow the seed in drills at least one-half inch deep early in spring. 
2. When the young plants come up, stir the soil surface, and after the first true leaves appear, weed and thin to three inches apart, being careful to distinguish the seedlings from grass.

3. Give frequent tillage and keep the plants free from weeds throughout the season.

4. Some of the roots may be dug in autumn and others left in the ground until spring, in the latter case being covered with leaves or litter to prevent alternate freezing and thawing at the surface of the ground.

RECORD OF GROWTH.

I. Seed: size, shape, and color. Is the "seed" an achene?

2. Date of coming up. Shape and size of seed-leaves.

3. Date of thinning. Number of true leaves.

4. Dates of harvesting.

\section{DraWINGS.}

I. Seeds.

2. Seedling with seed-leaves well developed.

3. Seedling at time of thinning.

4. Full-grown root.

The STORY.

Write the story of how you grew a crop of salsify. When does it blossom? Is it an annual or biennial? Do you see any relation in root or plant to the common chicory found along the roadside? Why is salsify called "vegetable oyster"? What have you found to be the best ways to cook the roots? 


\section{Spinach}

Growing OUT-Doors.

I. As soon in the spring as the garden ground can be worked, sow the seed sparsely in drills about one foot apart. Cover with one-half or three-quarters of an inch of fine soil.

2. When the plants come up, hoe between the rows, pull out all weeds in the rows, and thin the plants to about one-half inch apart.

3. If the weather should be very dry, water occasionally, if possible. If the ground is not rich, sprinkle a little nitrate of soda between the rows to hasten the growth.

4. As the plants get of good size, cut out about every other one to use as greens, leaving the others to grow to larger size before being cut.

RECORD OF GROWTH.

I. Seed: size, shape, and color. Date of planting. Name of variety.

2. Date of coming up.

3. Date of thinning.

4. Date of first cutting; of last cutting.

5. Conclusions as to culture.

\section{Drawings.}

I. Seeds.

2. Seedling with two seed-leaves.

3. Seedling with two true leaves.

4. A well-developed plant. 
The Storỵ.

Write or tell your experience in growing spinach. What crops may be grown on the same ground the same year when the spinach has been removed?

\section{Sweet Corn}

Growing OUT-DOORS.

I. When danger of hard frost is past, plant the sweet corn out-doors in hills eighteen inches apart, in rows two or three feet apart, placing six or eight kernels in each hill.

2. As soon as the corn is well up, hoe the rows and stir the soil surface between the rows; pull up any weeds that may appear about the plants.

3. When the corn is three or four inches high, thin out the weaker and more crowded plants, so that three plants are left in each hill.

4. The later treatment of the corn consists chiefly in frequent and prompt removal of any swollen ears which show the characteristic growth of corn smut. Such diseased portions should either be buried deeply or burned.

5. Select a large, early ear on a vigorous stalk and let it mature for seed.

RECORD OF GROWTH.

I. Seed: size, shape, and color. Date of planting. Name of varieties.

2. Date of coming up.

3. Date of thinning.

4. Date of appearance of brace roots. 
5. Date of blossoming.

6. Date of pulling first ears. Average number of ears to a stalk.

7. Comparison of early and main crop varieties.

\section{Drawings.}

I. Seeds: natural size and magnified.

2. Seedlings when two inches high.

3. Tassels and ear when silk first develops.

4. Ear of corn at time of picking. Sectional diagram of ear in husk.

\section{The Story.}

Tell or write the story of your corn crop. Was there much variation in the number of ears per stalk? See what you can find out about the methods by which the yield of corn is increased by the careful selection of seed.

\section{Tomato}

StARTING IN-DOORS.

I. Make little drills one-half inch deep and one inch apart in the earth of the seed-box by pressing downward a ruler or other straight-edge. Sow the seed in these, leaving the seeds one-eighth inch apart in the rows. Cover with one-half inch of fine soil. Water carefully.

2. Keep the seed-bed moist for the next ten days. By that time the little seedlings should appear. As soon as they show, put the seed-box where it will have ali the sunlight possible, and arrange for as much air as 
can be given without chilling the plants. Water carefully, preferably when the sun is shining.

3. The greatest danger to the seedlings is the "damping off" fungus. In cloudy weather and when the surface of the soil is kept wet this causes the plants to die through injury to the stems. As soon as any plants are injured, withhold water and give all the air and sunshine possible. Take care also that mice do not nibble the seedlings at night, in the house.

4. When the plants have one or two leaves in addition to the cotyledons, transplant them to shallow boxes, or preferably to two-and-one-half-inch paper pots. Set as deep in the pot as you can that roots may develop along the stem above the place where the roots first came out. Keep in a sunny place.

5. After three or four weeks' growth in the small pots it will probably be desirable to transplant into threeinch paper pots. Set rather deeply down that more roots may come from the additional part of the stalk that will thus be covered with earth.

6. As soon as weather out-doors permits, set the plants on a sunny porch, or in a cold-frame, or in some sheltered place where they can be protected at night, and be gradually "hardened off." By the time they are ready to put in the garden they should have buds or blossoms. If they blossom much before they can be set out, pollenize the flowers. You may thus get some fruits started early.

7. When danger of killing frosts is past, plant in rich soil in the garden. The distance apart will depend upon the method of after treatment. Set the plant so 
deep that the stem is buried in the soil about half-way up to the lower leaves. New roots will come out on the buried part and enable the plant to grow faster.

8. If space is very limited, and the plants are set close, say eighteen inches apart, prune the growing plant to a single stalk and tie this with cloth strips to a stout stake, four feet high. With more space, support vines on a low rack of slats, or within hoops around the plants, raising the fruit above the soil. Cultivate, weed, and water, if necessary, like other crops.

9. As soon as frost touches the vines, gather the green tomatoes, then pull the vines and burn them to prevent the spores of fungus diseases from developing. Or pull up the vines with the unripened fruit attached and hang up in the cellar. Some will ripen nicely.

RECORD OF GROWTH.

I. Seed: shape, size, color. Date of planting.

2. Date of coming up of seedling. Appearance of seedleaves (cotyledons).

3. Date of transplanting; number of true leaves.

4. Date of first blossom; height of plant.

5. Date of setting out. Distance apart; method of after treatment.

6. Date of first ripe fruit. Number of fruits to a vine.

7. Conclusions as to possible improvement in culture another season.

\section{Drawings.}

I. Seeds: natural size and magnified.

2. Seedlings showing cotyledons. 
3. Seedlings with two or three true leaves.

4. Seedlings when cotyledons are withered.

5. A true leaf.

6. A flower.

7. A fruit.

The Story.

Tell or write the story of your experience in growing tomatoes. Calculate your profits, comparing expenditures with value of fruit harvested. What other profits?

\section{Turnips}

Growing OUT-Doors.

I. Sow the seed sparsely in a shallow drill, covering with not more than one-half inch of soil.

2. In a few days the young seedlings will appear; then the soil surface between the rows should be stirred with a rake to keep the ground loose and free from weeds.

3. When the first true leaf is developed, weed the rows and thin the plants to about one inch apart.

4. Subsequent treatment is simply frequent tillage, and perhaps an additional thinning to prevent too great crowding of the roots.

5. Pull the turnips when they are large enough for table use and before they get hard and stringy.

RECORD OF GROWTH.

I. Seed: size, shape, and color. Date of planting.

2. Date of coming up. Appearance of seedling.

3. Date of first hoeing, of first weeding and thinning. 
4. Date of first gathering. Size of turnips.

5. Date of main harvest. Amount of yield. Market price of turnips at this time.

DrAWINGS.

I. Seeds: natural size and magnified.

2. Seedling at time of thinning.

3. Seedling with seed-leaves well developed.

4. Turnip with or without leaves at time of pulling.

THE STORY.

Tell your experience in growing turnips, and estimate whether there would be any profit in them at the rate of yield you obtained and at the market prices at the time of your harvest. Put the story in the form of a letter to some friend. 


\section{BIBLIOGRAPHY}

IT is very desirable to have some of the more attractive garden books and magazines available for use by both teachers and pupils. Many public libraries are likely to have the Cyclopedia of Horticulture, and the splendid series of English garden books in the Country Life Library, as well as other standard works. Among the less expensive books which it is desirable to add to the school library the following may be mentioned:

Bailey: Garden-Making.

Bailey: The Nursery Book.

Bailey: Principles of Vegetable Gardening.

Bennett: The Flower Garden.

Duncan: Mary's Garden and How It Grew.

French: The Book of Vegetables.

Hall: Three Acres and Liberty.

Jekyll: Children's Gardens.

Kirby: Daffodils and How to Grow Them.

Rexford: The Home Garden.

Sedgwick: The Garden Month by Month.

Shelton: The Seasons in a Flower Garden.

St. Maur: The Earth's Bounty.

Thaxter: An Island Garden.

Watson: Flowers and Gardens.

Weed: The Flower Beautiful.

Wright: "The Perfect Garden. 



\section{INDEX}

Annuals, planting, 187; for windowboxes, $84-86$.

Antirrhinum, 183.

Aphides, 85 .

April Calendar, 166.

Araucaria bidwelli, I06; excelsa, 106.

Asparagus fern, 183; plumosus, 104; sprengeri, 105, 182.

Asters, hardy, 80; China, I3, 40-45, 189, 269-270.

August Calendar, 24I.

Bachelor's buttons, 146.

Balsam, I I 4 .

Beans, 131, 216-218 ; bush, 289290.

Beet, 199-201, 287-288.

Begonia rex, 106, 107, 108; tuberous, 107,184 .

Boltonia, 79; asteroides, 8o; latisquama, 80.

Booklets, 8.

Borage, 59.

Brassica japonica, 237.

Bulb crops, i 6.

Bulbs, 45-50; spring flowering, 249; summer flowering, 206-209.

Cabbage, 290-29I.

Caladium, I82.

Calendar, April, 166.

August, 24I.

December, 98.

February, I33.

January, II9.
July, 222.

June, 209.

March, 150.

May, 189.

November, 86.

October, 68.

September, 50.

Calendula, 146.

California poppy, 63, 165 .

Candytuft, 165.

Caraway, 57, 59.

Carnation cuttings, 246.

Carrot, 160, 20I-202, 291-292.

Castor bean, 267-268.

Chervil, 59, 6r.

China aster, 13, 40-45, 189, 269270.

Chinese sacred lily, 84 .

Chives, 60.

Chrysanthemum cuttings, 247 .

Chrysanthemums, 73-76.

Clay flower-jars, I08-I Io.

Clematis, Japanese, 178; paniculata, I 78 .

Climbing vines, 175 .

Cobæa scandens, 178 .

Cold frame, 20.

Cole crops, 117 .

Columbines, 174 .

Corn, 132.

Cosmos, 55-57, 146, 189, 271-272.

Cotyledons, $130-132$.

Crocus, 46, 47, $25 \mathrm{I}-253$.

Cucumber, I1 3, 292-293.

Cucurbit crops, I 8 .

Cuttings, $35^{-40}$. 
Cyclamen, 91.

Cypress vine, 177 .

Daffodils, 47, I23-1 27, 26I-263; indoors, $8 \mathrm{I}-84$.

Dahlia, 29-35, 208.

Dandelion, 237-238.

December Calendar, 98.

Dill, 59.

Eschscholtzia, 63-65, 266-267.

Exhibits, 12-I6.

False chamomile, 79 .

False dragon's-head, 77.

February Calendar, I33.

Fern, Boston, 182.

Flower, structure of, 218-220.

Flower-jars, useful, 227-233.

Flower-pot, filling, 245.

Flowers, starting early, I45-1 46.

Foliage plants, IOI-I08.

Freesias, 253-254.

Garden, getting ready, 6I-63; club, I 37-I 45 .

General exercises, 245-248.

George Putnam School, 8I.

Geranium, 36, 185; cuttings, 245246.

Gill-over-the-ground, 186.

Gladiolus, 207.

Globe-flower, I 73 .

Golden glow, 174 .

Grevillea robusta, 105.

Ground ivy, 186.

Gumbo, 295 .

Hardy annuals, I6r; perennials, I 7 I. Helenium autumnale, 79; grandicephalum, 79 .

Helianthus maximiliana, 79; multiflorus, 78; orgyalis, 78; rigidus,
Heliopsis pitcheriana, 77 .

Heliotrope, 183.

Home gardens, 7, I 53-159.

Horse-radish, 38 .

Hyacinth, 49, 66-68, 254-256; Roman, 98, 259-26r.

Ice-plant, New Zealand, 237.

In-door gardens, 3-6.

Ipomœa, 175 .

Iris, I72; border gardens, I93; English, 198; German, I95, 196; Japanese, 198; Oriental, I91, 226; Siberian, I92; Spanish, 198.

Ivy, Boston, I78; Japanese, I 78 .

Japanese iris, I98; ivy, I78; morning-glory, 84 .

Jonquil, Campernelle, 249-25 I.

July Calendar, 222.

Larkspur, 146.

Lavender, 59.

Leaf-cuttings, 39 .

Lettuce, I 29, I6I, 294-295.

Lily, Madonna, 50, 219.

Lily-of-the-valley, 91-93, 257-258.

March Calendar, I 50.

Marigolds, $\quad 233-235, \quad 272-273$; dwarf, 85, 146; French, 85, 146.

Maurandia, 186.

May Calendar, I89.

Moonflower, I75, 273-275.

Morning-glory, I 75, 273-275; imperial, 84 .

Mustard, 237.

Narcissus, Poet's, polyanthus, 258259.

Nasturtium, I84, 220-222, 229,

275-277; dwarf, 22 I.

Nepeta, glechoma, 186 . 
New England aster, 8r.

Norfolk Island pine, ro6.

November Calendar, 86.

Okra, 295.

Onion, II3, I29, 297-298.

Out-door gardens, 7 .

Pansy, 239-24I, 277-279.

Paper flower-pots, 6.

Paper-white narcissus, 84 .

Parsley, 59, 6r, 298-299.

Parsnip, 160, 299-300.

Peas, I32, 160, 300-301.

Peony, I7 2, I74.

Pepper, I 28, 302-303, 305 .

Perennials, hardy, 76-8I.

Phlox, 39; Drummond, I46, I65; perennial, I 72.

Physostegia, 77.

Plant-lice, 85 .

Poet's narcissus, 47.

Poppy, I64, 204-206, 279-28I; Shirley, 95, 204, 205, 206, 218.

Porch-boxes, I79, 186.

Portulaca, I64, 28I-282.

Pot herb crops, II 7, 235-238.

Pot marigolds, 146.

Potato, 39, I 29, 304-305.

Primrose, baby, 90; Chinese, 89; obconica, 91.

Primula, 89.

Prizes, 15-16.

Pulse crops, II8.

Quack-grass, 62.

Radish, I47-149, I61, 305-306.

Red spider, 85 .

Roman hyacinth, 98, 259-26r.

Root crops, I14, II6.

Root cuttings, 38 .

Rue, 59.

Salad crops, II 7 .
Salsify, 160, 306-307.

Scilla, 47 .

Seed-leaves, I30-133.

Seed, selection of, 93-97; testing, I IO-II4, 246.

September Calendar, 50.

Silk oak, 105 .

Snapdragon, $183,219$.

Sneezewort, 79.

Snow-drop, 47.

Solanaceous crops, iI8.

Solanum jasminoides, 184 .

Spearmint, 59 .

Spinach, 235, 308-309; New Zealand, 237.

Spring awakening, the, ${ }_{59}-161$.

Squash, I3I.

Stem cuttings, 37 .

Subirrigation, I99.

Sunflower, dahlia, 78; October, 79; orange, 77 .

Sun plant, $\mathrm{r} 64$.

Sweet basil, 6r.

Sweet corn, 309-310.

Sweet herbs, 57-6r.

Sweet pea, 85, 94, 95, 145, 213$216,282-284$.

Tansy, 59 .

Tarragon, 6o.

Tomato, I28, 130, I32, 310-3І1.

Tools, 8 .

Trollius, 173 .

Tropoolum, 275-277; lobbianum, 22I; majus, 22I; minus, 220; peregrinum, $22 \mathrm{I}$.

Tuber crops, Ir6.

Tuberose, 207.

Tulips, 49, 263-265.

Turnip, 204, 313-314.

Umbrella plant, 108.

Vegetables, classification of, $\mathrm{II}_{4}{ }^{-}$ I18; starting early, $127^{-1} 30$ 
Vegetable oyster, 160, 306-307.

Vine crops, I 18.

Viola tricolor, 240.

Wild balsam apple, $17 \%$.

Wild cucumber, 177 .
Window-boxes, in-door, 4; outdoor, 179.

Window gardens, in-door, 89-9r.

Winter flowers, 238-239.

Witch-grass, 62 .

Zinnia, 284-286. 


\section{Useful Books for the School Library PVVLLSBSD By}

\section{CHARLES SCRIBNER'S SONS, NEW YORK}

\section{Zoölogy}

\section{BY WILLIAM TEMPLE HORNADAY}

The American Natural History

"A great Natural History."-New York Sun.

Illustrated, $\$ 3.50$ net

Taxidermy and Zoölogical Collecting

"It is replete with all that is necessary to make a thorough workman."

Illustrated, \$2.50 net

- The Ornithologist.

\section{BY ERNIST THOMPSON SETON}

\section{Animal Heroes}

Illustrated, $\$ 2.00$

"They all have that fascinating quality which he manages to throw around all his stories."-Brooklyn Eagle.

Wild Animals I Have Known

Illustrated, \$2.00

"The breadth of his sympathy is the finest part of his work." - A gnes Repplier.

Lives of the Hunted

"It should be put with Kipling and Hans Christian Andersen as a classic."

Illustrated, $\$ 2.00$ -The Athenaum (London).

Monarch, the Big Bear of Tallac

"A fascinating account of a bear family."-Providence Journal.

The Trail of the Sandhill Stag

"I fancied that no one could touch The Jungle Book, but Mr. Setun has done it."

Illustrated, $\$ 1.25$ net Illustrated, \$1.50 -Bliss Carmen.

Lobo, Rag and Vixen

Illustrated, \$0.50 net

"A faithful description of animal life."-A merican School Board Journal.

Krag and Johnny Bear

Illustrated, \$0.50 net

"Nowhere exaggeration, but a true artistic sense of the humorous side of nature."

-Toledo Blade.

\section{BY J. H. PORTER}

Wild Beasts

"He has a sympathetic regard for the animals of which he writes"that fits him well

for the task. His studies of their habits and capacities are exceedingly valuable." -St. Paul Pioneer Press.

\section{BY N. S. SHALER}

Domesticated Animals

"An exceedingly interesting and valuable series of essays, and a valuable addition to the library of the lovers of our dumb friends." - Public Opinion. 


\section{Useful Books for the School Library}

\section{Birds}

\section{BY WILLIAM LOVELL FINLEY}

American Birds-Studied and Photographed from Life Illus., \$1.50 net

"The most delightful bird book that has ever been written."-The Dial.

\section{BY JOHN B. GRANT}

Our Common Birds and How to Know Them

"Very enjoyable and instructive."-The Congregatianalist.

Illus., \$1.50 net

\section{Botany}

\section{BY HARRIET L. KEELER}

Our Native Trees and How to Identify Them Illus., $\$ 2.00$ net "No admirer of trees should be without it." - Brooklyn Eagle.

Our Northern Shrubs and How to Identify Them Illus., \$2.00 net "The photographs are very beautiful, and so clear as to make identification perfectly simple."-The Dial.

\section{BY FRANCES THEODORA PARSONS}

How to Know the Ferns Illustrated, \$r.50 net "A notably thorough little volume . . . the author has mastered her subject."

According to Seasons - Nezw I'ork Tribune.

"The charm of this book is pervading and enduring as is the charm of nature."

Illustrated, \$r.75 net -New York Times.

How to Know the Wild Flowers

Illustrated, \$2.00 net

"It is exactly the kind of work needed for out-door folks."-Theodore Roosevelt.

\section{Bi N. L. BRITTON}

Illustrated Flora

3 volumes. \$12.00 net "Will find an enthusiastic welcome in the private study as well as in the classroom." - Chicago Tribune.

\section{By MRS. SCHUYLER VAN RENSSELAER}

Art Out=of=Doors: Hints on Good Taste in Gardening \$1 50

"The best work in the field we have had in many a day." -Nezo lork Post.

\section{BY H. E. PARKHURST}

Trees, Shrubs and Vines in the Northwestern United States Illustrated, \$1.50 net

"Is so introduced that even the nost unscientific reader can readily recognize all the varieties." -Neze York Times.

\section{BY LOUISE SHELTON}

The Seasons in a Flower Garden Illustrated, \$1.00 net "Admirably adapted to the needs of people who desire to utilize a small garden space to the best possible advantage."-Providence Journal. 


\section{Useful Books for the School Library}

\section{Manual Training and Invention}

\section{BY DAN BEARD}

The Field and Forest Handy Book

"A treasure for all boys and not without its use for men."

Illustrated, $\$ 2.00$ -New York Times Saturday Review.

The Jack of all Trades

Illustrated, $\$ 2.00$

"This book is a capital one to give any boy for a present at Christmas or at any time." -The Outlook.

The Out=Door Handy Book

Illustrated, $\$ 2.00$

"This volume will be an unmixed delight to any boy." -Nerv York Tribune.

The American Boy's Handy Book

Illustrated, $\$ 2.00$

"The bnok has this great advantage over its predecessors, that most of the games, tricks and other amusements described in it are new." -New York Tribune.

\section{BY LINA AND ADELIA BEARD}

Things Worth Doing and How to Do Them Illustrated, \$2.00

"The book will tell you how to do nearly anything that any live girl really wants to do."-The World To-day.

Handicraft and Recreation for Girls

Illustrated, $\$ 2.00$

"The girl who gets this book will not lack for occupation and pleasure." - Chicago Evening Post.

What a Girl Can Make and Do Illustrated, $\$ 2.00$

"A most inspiring book for an active-minded girl."-Chicago Record Herald.

The American Girl's Handy Book

Illustrated, $\$ 2.00$

"It is a treasure which, once possessed, no practical girl would willingly part with."-Grace Greenwwood.

\section{BY PARK BENJAMIN}

The Age of Electricity

Illustrated, $\$ 2.00$

"There is a real fascination about this volume; the public is indebted to $\mathrm{Mr}$.

Benjamin."-Hartford Evening Post.

\section{BY CHARLES STEDMAN HANKS}

\section{Camp Kits and Camp Life}

Illustrated, \$1.50

"With this handy volume a novice can go into the woods and come back well versed in woodcraft." - Los Angeles Express. 


\section{Useful Books for the School Library}

\section{Industry and Geography}

BY FRANK O. CARPENTER

Foods and Their Uses

Illustrated, \$o.6o net

"One of the most attractive supplementary readers we have seen."

-Nezuark Evening Nezus.

\section{BY J.. W. REDWAY}

Commercial Geography Illustrated, \$1.25 net A book for high schools, commercial courses, and business colleges.

\section{BY HUGH R. MILL}

The Realm of Nature

$\$ 1.50$ net

An explanation of the methods by which our knowledge of nature has been acquired and is being daily enlarged.

\section{BY N. S. SHALER}

Nature and Man in America

Designed in part for the use of the general reader and particularly for the use of beginners in the study of geology.

\section{BY J. W. REDWAY}

Elementary Physical Geography Illustrated, \$I.25 net An outline of physiography with numerous illustrations, maps, charts, etc.

\section{BY CHARLES F. KING}

Elementary Geography

Illustrated, \$1.25 net

Profusely illustrated with reproductions of photographs and with attractive colored plates.

\section{BY HENRIETTA C. WRIGHT}

Children's Stories of Great Scientists Illustrated, \$1.25 Written in a simple, straightforward manner, especially useful for children of the lower grades.

\section{BY PHILIP G. HUBERT}

Inventors
"The book is alike interesting and instructive." - New York Observer.

Illustrated, \$1.50

\section{BY JOHN C. VAN DYKE}

Nature for Its Own Sake

"No one can read it without having his knowledge of nature enlarged."

\section{BY WILLIAM T. HORNADAY}

ramp Fires in the Canadian Rockies Illustrated, \$3.00 net "A valuable contribution to the natural history of the region." 



RETURN TO the circulation desk of any University of California Library

or to the

NORTHERN REGIONAL LIBRARY FACILITY

Bldg. 400, Richmond Field Station

University of California

Richmond, CA 94804-4698

\section{ALL BOOKS MAY BE RECALLED AFTER 7 DAYS}

- 2-month loans may be renewed by calling (510) 642-6753

- 1-year loans may be recharged by bringing books to NRLF

- Renewals and recharges may be made 4 days prior to due date

\section{DUE AS STAMPED BELOW}

\section{TJUL 262004}

\section{JAN 152007}

REC'D BIOS

\section{NOV $292006-8 \underline{00}$ AM}


pre m

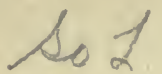

U. C. BERKELEY LIBRARIES

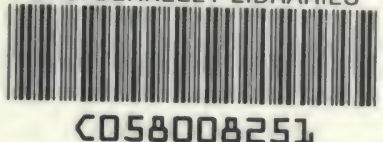

C058008251

\section{8}

$\angle D 3503$

$W_{4}$ 
